\title{
Promoting discovery learning of formulaic language with the aid of online resources: A classroom-based study with intermediate EFL learners
}

\author{
by \\ Thuy Thi Bich Bui
}

\begin{abstract}
A thesis
submitted to the Victoria University of Wellington

in fulfilment of the requirements for the degree of

Doctor of Philosophy
\end{abstract}

Victoria University of Wellington

2019 
To Dad, Mum and Kem, with lots of love and gratitude 


\section{ABSTRACT}

This classroom-based study was motivated by the call for effective pedagogical paths to help learners of English as a Foreign Language (EFL) acquire multiword expressions (MWEs) in the target language. The central question addressed was how training EFL learners to identify MWEs in authentic texts (text-chunking) with the aid of online dictionaries and the online interface of the Corpus of Contemporary American English (COCA) (http://corpus.byu.edu) affected their uptake and awareness of formulaic language. Learners' discovery strategies during text-chunking activities were also investigated.

The participants were 54 Vietnamese intermediate-level university students, randomly assigned to an experimental or comparison group. Over ten weeks, the experimental group ( $n=26)$ was asked to look for MWEs in texts, while the comparison group $(n=28)$ used the same reading materials for content-related activities. Utilizing a mixed methods approach, this project analysed data gathered from a pre-test, an immediate post-test, a five-month delayed post-test, students' classroom notes and audio-recorded discussions, and immediate and delayed questionnaires.

Four main findings emerged from this study. Firstly, the practice of text-chunking benefited the students' retention of the MWEs they identified in the texts. Whereas test results indicated that learning occurred in both groups, the experimental group demonstrated the greater gains in MWE knowledge. Secondly, experimental learners decided to investigate whether given word strings might be MWEs mostly if they were phrases (a) that they had previously seen, (b) that included known words combined in novel ways, and c) that included unknown content words within familiar structures such as verb + preposition, preposition + noun, or binomials (i.e. noun 'and' noun). Also, learners relied mostly on constituent words and language contexts to guess the meaning of newly-found MWEs. Thirdly, text-chunking practice with the aid of online dictionaries and COCA heightened the learners' awareness of the importance of expanding their knowledge of formulaic language. This heightened awareness endured over the fivemonth gap between the end of the classroom experiment and the final questionnaire. The intervention also concentrated experimental learners' MWE learning strategies on those practised during the treatment including underlining new MWEs, taking notes, looking 
them up in dictionaries and COCA, and discussing with peers. Fourthly, while the experimental group reported increased autonomy in strategy use to support their MWE acquisition, the use of online dictionaries and corpora still posed challenges for learners' self-study. Stumbling blocks included how to choose the resources to consult and how to extract the necessary information from not-so-user-friendly interfaces.

This thesis also discusses pedagogical and methodological implications of the findings so that teachers and learners in EFL contexts can make judicious use of text-chunking activities and online resources for the ultimate purpose of promoting learners' autonomous MWE acquisition. 


\section{ACKNOWLEDGEMENTS}

There were moments during the research project that I did not believe I would reach this completion point. Every time I thought I had finished a part, I realized there was something more to be done. Had it not been for the invaluable guidance and amazing patience of my supervisors, Associate Professor Averil Coxhead and Professor Frank Boers (University of Western Ontario, Canada), this thesis would never come into being. Above all, I would like to express my heartfelt gratitude and thanks to them. I have learnt immensely from their insightful feedback and generous support, be it on weekdays or at weekends. Associate Professor Averil Coxhead and Professor Frank Boers will always be my role models in academia.

I would like to thank Dr. Anna Siyanova for her guidance at the early stage of this project. I would also like to thank Dr. Lisa Woods (School of Mathematics and Statistics) for her great support in the statistical part of my work.

I highly appreciate the enthusiastic participation of students and lecturers at Hanoi National University of Education, Vietnam. Working with them as a teacher researcher made me realize how I could continue doing research with my future classes.

Next, my thanks go to Victoria University of Wellington for all the financial support throughout my PhD journey in the form of Victoria Doctoral Scholarship, Faculty Research Grant and Victoria Doctoral Hardship Fund. The timely support has enabled my dream of researching applied linguistics abroad and working closely with scholars whose names I had only seen in papers.

I thank my officemates and friends at LALS, vocabulary group, thesis group and friends from different weekend writing Bootcamps I have attended. Discussions about each other's research issues and those times of working together have helped me tremendously. I thank my close friends in Wellington and Vietnam who have always reminded me of life outside $\mathrm{PhD}$ work. They gave me just the right amount of distraction to get back to research later being more productive.

My biggest thanks go to my parents, my sister and my daughter for being with me always through ups and downs, patiently listening to my complaints in stressful times, and 
constantly encouraging me to move forward and achieve my dreams. I dedicate this work to them. 


\section{TABLE OF CONTENTS}

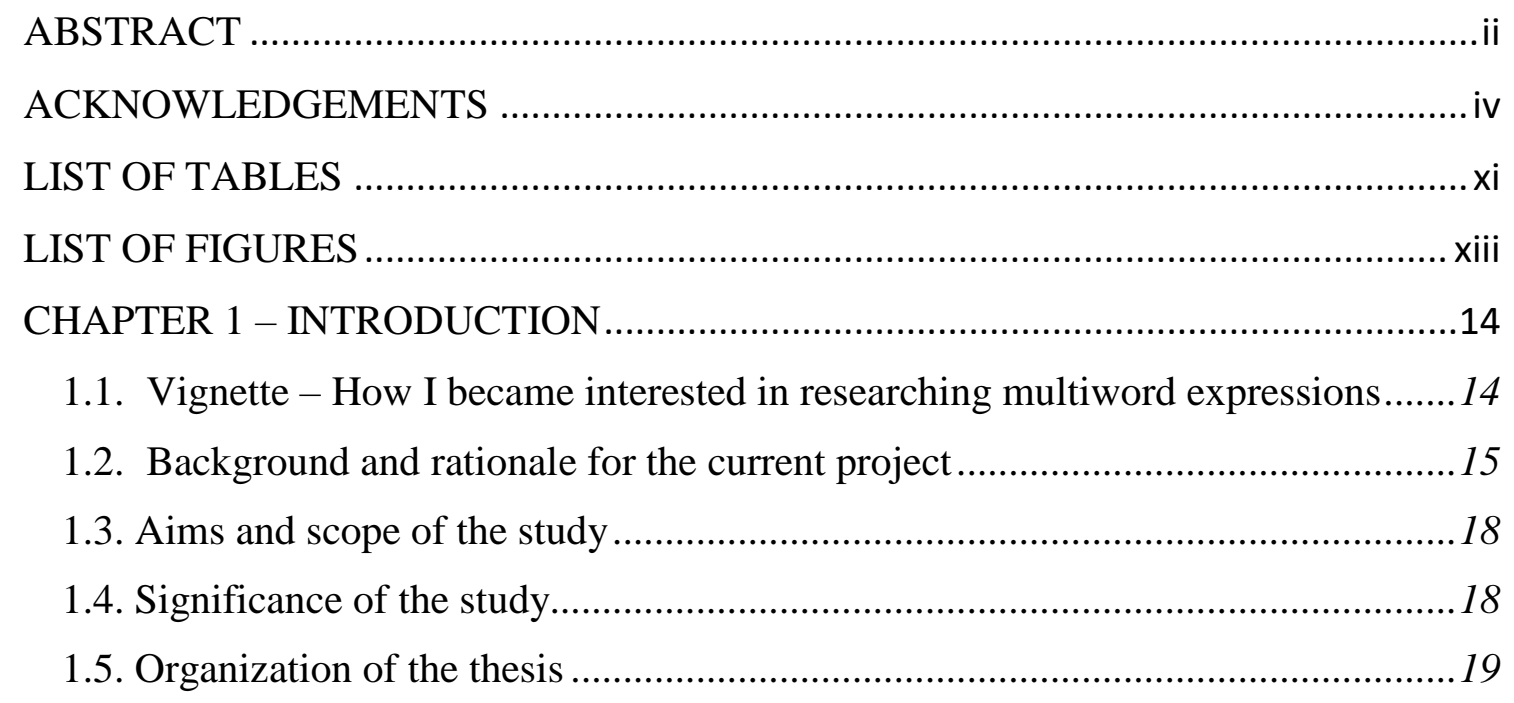

CHAPTER 2 - LITERATURE REVIEW .............................................................21

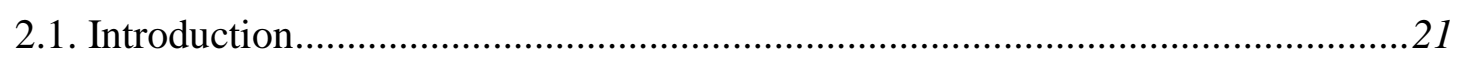

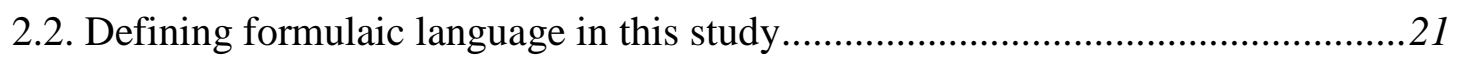

2.3. Why do L2 learners need to acquire multiword expressions? ............................24

2.4. Why is MWE acquisition challenging to L2 learners? .......................................26

2.5. What have intervention studies found about ways to promote L2 MWE

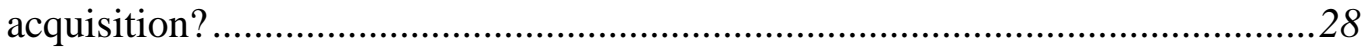

2.5.1. Incidental learning condition is not enough for effective MWE acquisition. 30

2.5.2. Semi-incidental learning condition of MWEs works, with a trade-off............33

2.5.3. Intentional learning condition of MWEs also works, but explicit teaching

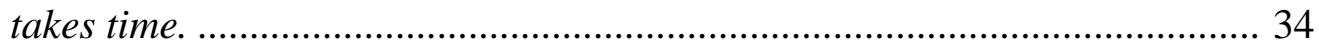

2.6. How has awareness-raising and text-chunking intervention been implemented in

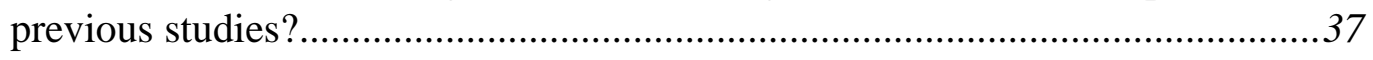

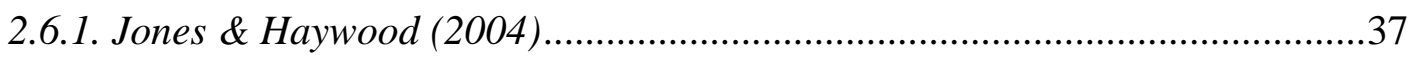

2.6.2. Boers, Eyckmans, Kappel, Stengers, \& Demecheleer (2006) and Stengers,

Boers, Housen, \& Eyckmans (2010) ...............................................................39

2.7. What might be the elements for an optimal pedagogical intervention for the uptake

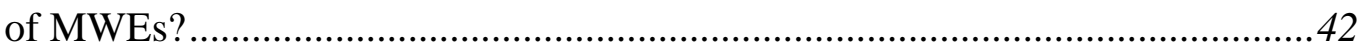

2.7.1. More about the MWE learning scenario in Vietnamese context ....................42

2.7.2. What elements might be effective for the typical EFL context in this study?.43

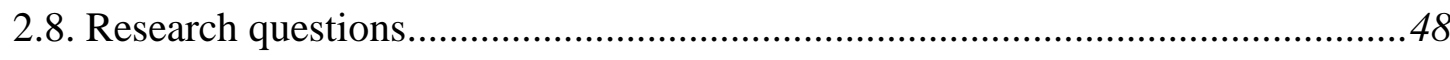




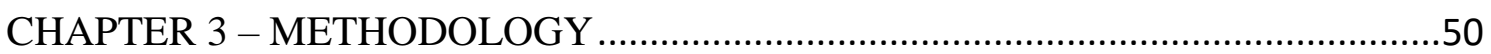

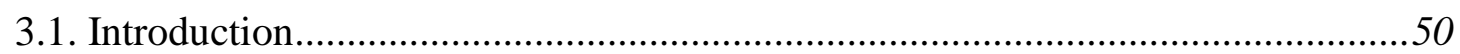

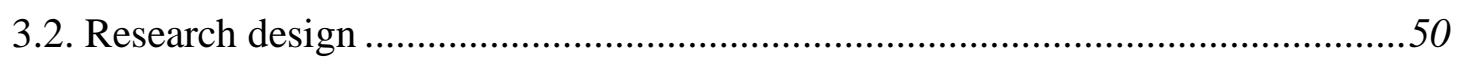

3.2.1. Mixed methods research approach ..........................................................50

3.2.2. A longitudinal classroom-based research project ........................................53

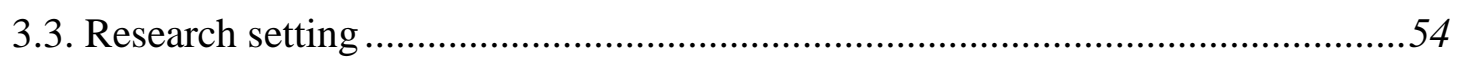

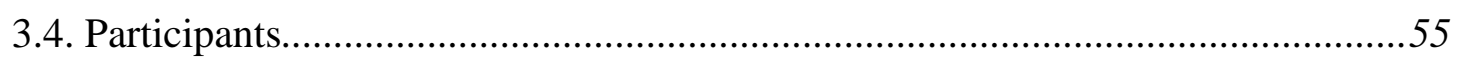

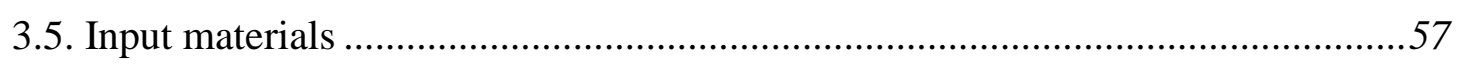

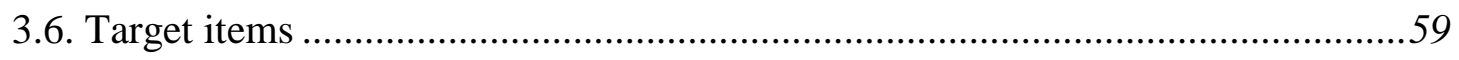

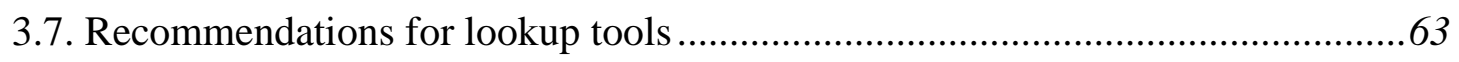

3.7.1. Recommendations of online dictionaries ....................................................64

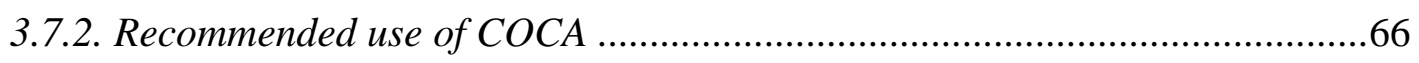

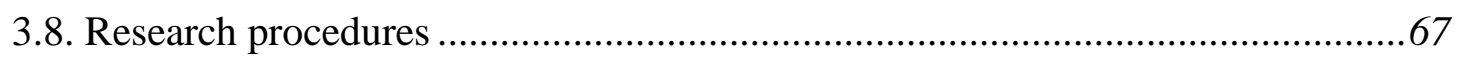

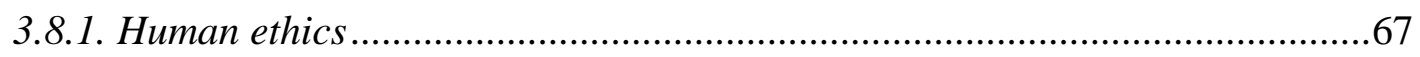

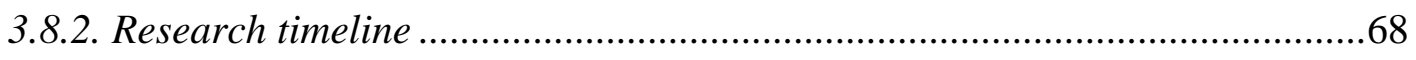

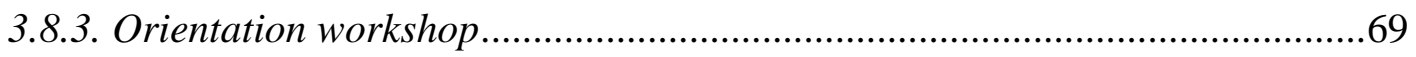

3.8.4. Class procedures - Teacher and Student Roles ..........................................69

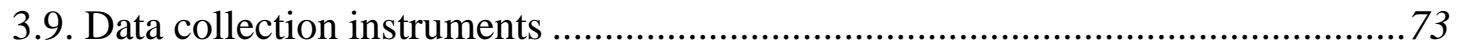

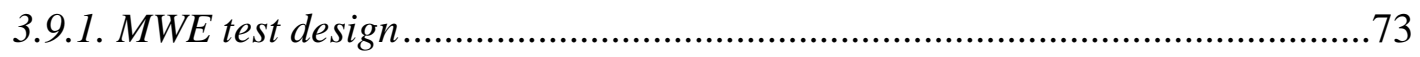

3.9.2. Audio-recordings of students' discussions .................................................75

3.9.3. Students' vocabulary notes - individual and pair work................................76

3.9.4. Intermediate and delayed questionnaires .....................................................77

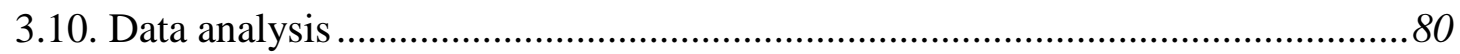

3.10.1. Scoring pre- and post- vocabulary tests ......................................................8

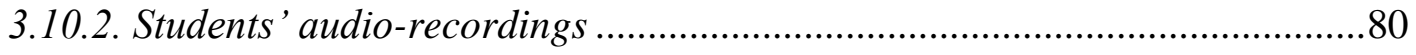

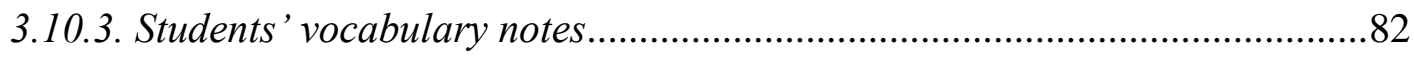

3.10.4. Immediate and delayed questionnaires ....................................................82

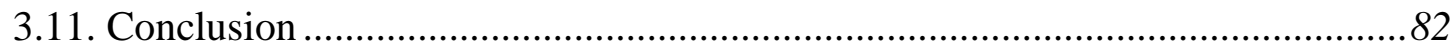

CHAPTER 4 - LEARNERS' PERFORMANCES IN THE MWE RECALL TESTS \&

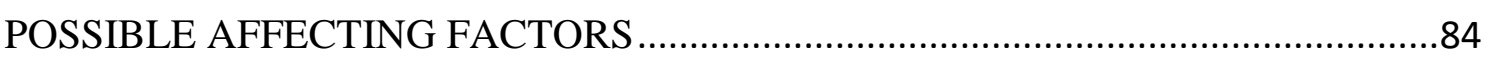

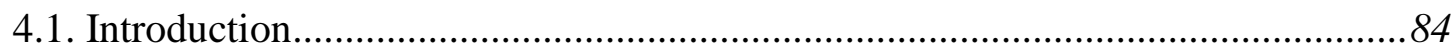


4.2. Did the intervention positively affect learners' MWE acquisition? .84

4.2.1. The learning gains - Learner analyses .84

4.2.2. The learning gains - Item-wise analyses .87

4.3. What factors may affect learners' learning gains of the target MWEs? .91

4.3.1. Learner-related factor - vocabulary sizes . .92

4.3.2. Item-related factors .94

4.4. Conclusion 103

\section{CHAPTER 5 - STUDENTS' DISCOVERY STRATEGIES IN MULTIWORD} EXPRESSION EXTRACTING ACTIVITIES 104

5.1. Introduction 104

5.2. What drove learners' initial hunches in identifying the forms of MWEs? 104

5.2.1. Previously-seen intact combinations. 106

5.2.2. New combinations of familiar constituent words. 109

5.2.3. Combinations of brand-new words within familiar structures .112

5.3. What drove learners' decisions on the MWE status of word strings? .113

5.3.1. What makes learners decide a word string is an MWE? 113

5.3.2. What makes learners decide a word string is not an MWE? .....................117

5.3.3. What makes learners hesitate about the MWE status of a word string? ....120

5.4. How did learners work out the meanings of novel MWEs?

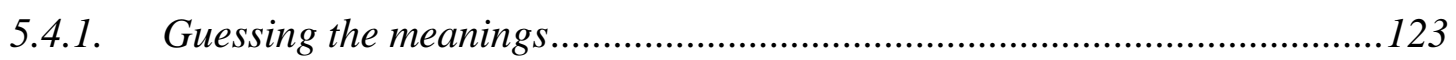

5.4.1.1. Making guesses based on constituent words ....................................123

5.4.1.2. Making guesses based on context .....................................................125

5.4.1.3. Making guesses based on mother tongue congruency ..........................127

5.4.1.4. What is the success rate of learners' meaning guesses? .....................128

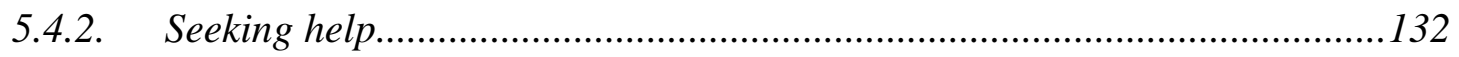

5.4.2.1. Seeking help from pair partners …..................................................132

5.4.2.2. Seeking help from dictionaries .........................................................135

5.4.3. Associating new MWEs with known MWEs .............................................137

5.5. How did learners evaluate the usefulness of an MWE? .......................................138

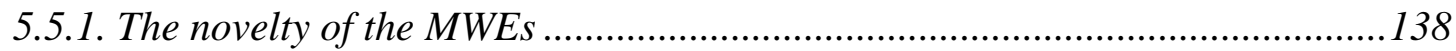

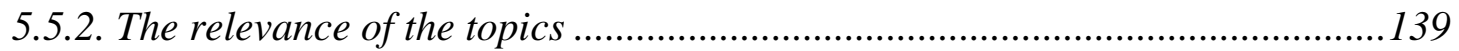

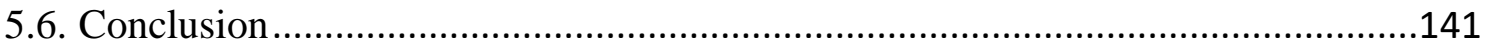


CHAPTER 6 - LEARNERS' AWARENESS OF MULTIWORD EXPRESSIONS AND THEIR LEARNING STRATEGIES

6.1. Introduction.

6.2. Students' MWE awareness and learning strategies - What do statistics say? ....142

6.2.1. Learners' general awareness of multiword expressions

6.2.2. Learners' perceptions of their learning strategies

6.3. Students' MWE awareness and learning strategies - What did the learners say? 160

6.3.1. Did the learners make any progress in the five months? 160

6.3.2. What are the learners' preferred lookup resources for MWEs? 163

6.3.3. What are the learners' mostly-used MWE learning strategies? 165

6.4. Experimental learners' self-evaluation of chunking activities and the use of COCA 168

6.5. Conclusion 172

CHAPTER 7 - HOW DOES THE INTERVENTION PROMOTE THE DISCOVERY LEARNING OF FORMULAIC LANGUAGE AMONG THE LEARNERS AFTER ALL?. .173

7.1. Introduction .173

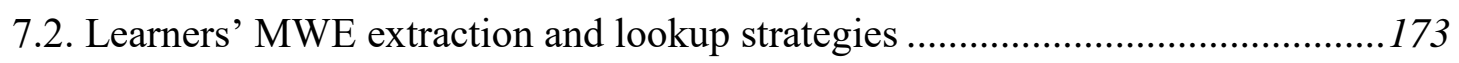

7.2.1. Learners' discovery strategies in MWE extraction .....................................174

7.2.3. Learners' 'MWE dictionary lookup strategies ............................................181

7.2.4. Learners' COCA lookup use .................................................................... 183

7.3. Learning gains of target MWEs from the intervention activities .......................185

7.3.1. Why did the experimental group achieve better gains?..................................185

7.3.2. Why were the learning gains not so spectacular? .......................................... 189

7.3.2.1. The nature of the intervention activities..................................................189

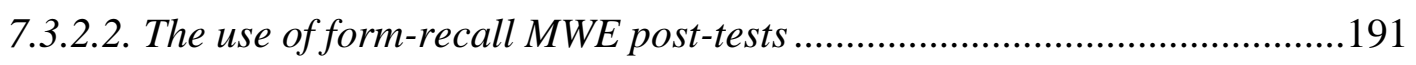

7.3.3. Why did the comparison group achieve learning gains too? ...........................192

7.4. To what extent did the intervention work after all?..........................................193

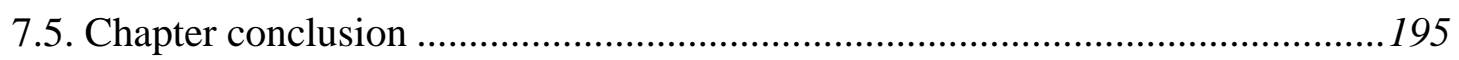

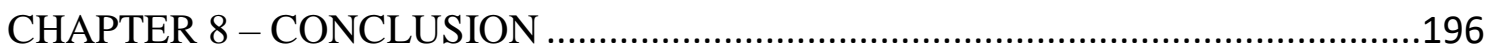

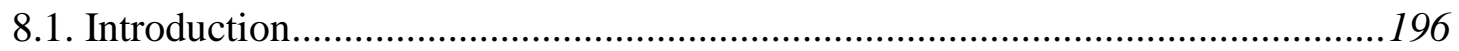




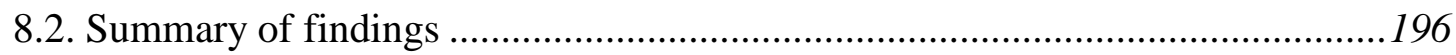

8.2.1. Positive effects on acquisition of target MWEs …………………………....196

8.2.2. Learners demonstrated their use of text-chunking strategies ........................198

8.2.3. Heightened awareness of MWEs and learning strategies.............................199

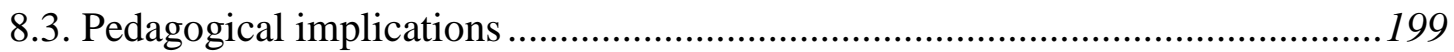

8.3.1. How can teachers set up a conducive learning condition for independent

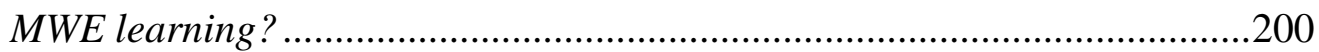

8.3.2. How can teachers choose the input materials to promote MWE-

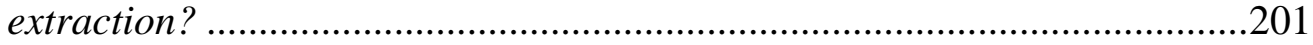

8.3.3. How can the utility of COCA be optimized? ………………………….......202

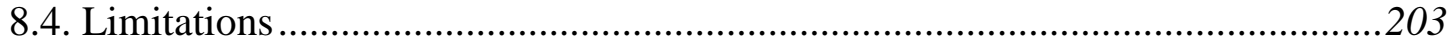

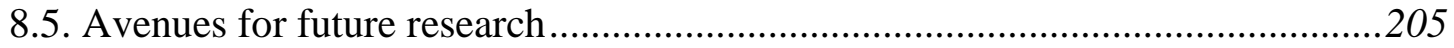

8.6. Concluding remarks ....................................................................................206

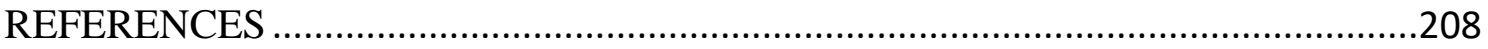

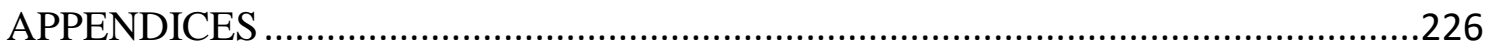

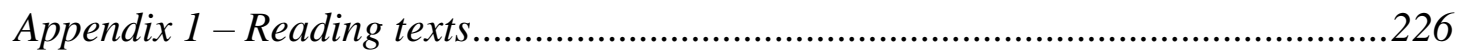

Appendix 2 - COCA guidelines .......................................................................25

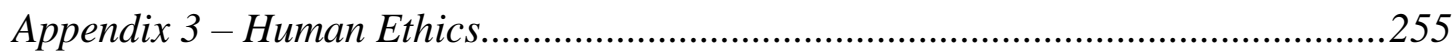

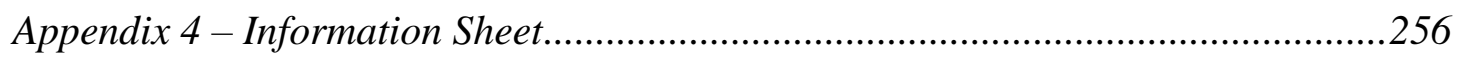

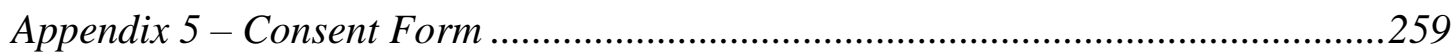

Appendix 6 - Template of pair work MWE lists and samples of students' work.......260

Appendix 7 - Vocabulary test .........................................................................264

Appendix 8 - Sample of students' worksheets ..........................................................269

Appendix 9 - Questionnaires ............................................................................221 


\section{LIST OF TABLES}

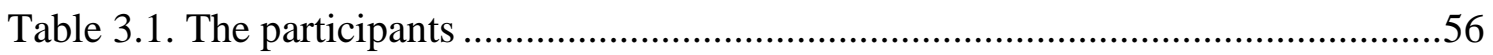

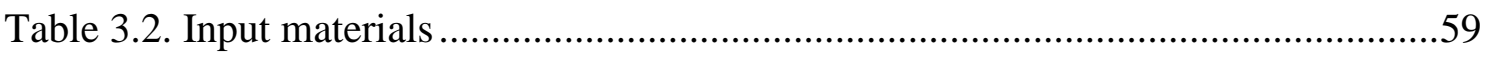

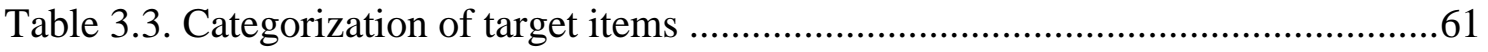

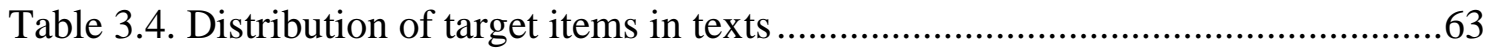

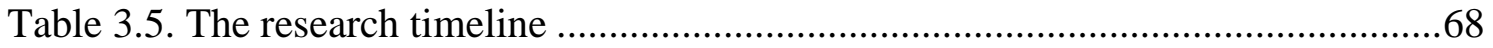

Table 3.6. Post-reading activities in the comparison group ........................................ 72

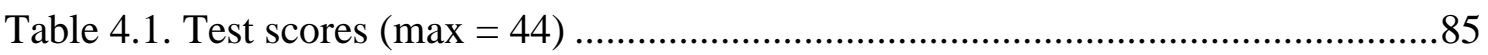

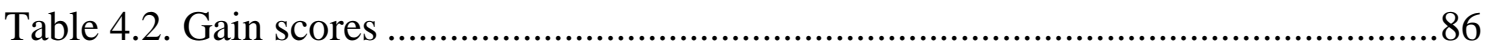

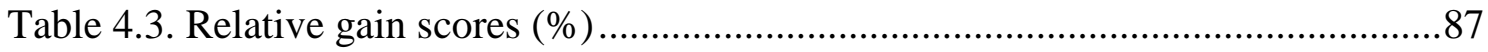

Table 4.4. Item-wise learning gains - the experimental group $(\max =26) \ldots \ldots \ldots \ldots \ldots \ldots \ldots . . . .88$

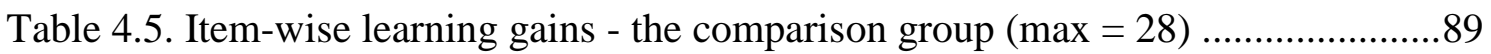

Table 4.6. Item-wise learning gains - Both groups - The 'clean' set..............................91

Table 4.7. Correlations between VST scores and gains ..........................................93

Table 4.8. Correlations between pre-test scores and gains ..........................................93

Table 4.9. Target items most known by the learners vs. the most frequent items in

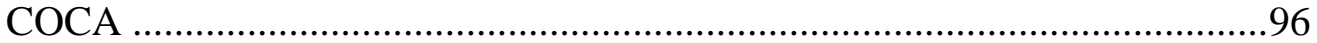

Table 4.10. Target items least known by the learners vs. the least frequent items in COCA

Table 4.11. Frequency levels of some medium- and low-frequency constituent words .97

Table 4.12. Logistic regression outcome for the immediate post-test..........................100

Table 4.13. Logistic regression outcome for the delayed post-test .............................101

Table 4.14. Nature of items in students' end-of-class vocabulary selections................102

Table 5.1. Combinations of new words in familiar structures ....................................112

Table 5.2. Roles of different factors in learners' confirmation of MWE status.............114

Table 5.3. Learners' engagement with the meanings of MWEs ...................................122

Table 5.4. The frequency of use of meaning guessing strategies ................................123

Table 5.5. The success rates of learners' meaning guesses...........................................128

Table 5.6. The frequency of students' help-seeking strategies and the success rates ...132

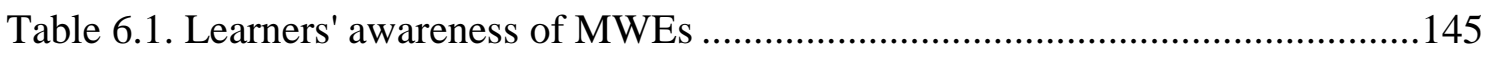

Table 6.2. Changes in learners' perceived attention towards MWEs...........................149

Table 6.3. Which MWEs draw learners' attention the most?......................................150 
Table 6.4. How do learners work out the meanings of MWEs?..................................152

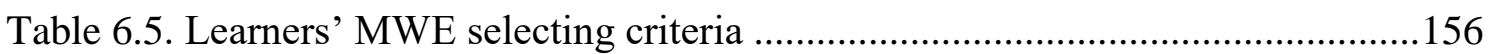

Table 6.6. Learners' intentional efforts to memorize new MWEs ...............................157

Table 6.7. Learners' self-report of their progress in MWE acquisition .........................161

Table 6.8. Students' positive answers on their progress .............................................. 161

Table 6.9. Students' negative answers on their progress ............................................ 162

Table 6.10. MWE learning strategies - The experimental group ................................166

Table 6.11. MWE learning strategies_The comparison group ....................................167

Table 6.12. Experimental students' self-evaluation of chunking activities..................169

Table 6.13. Difficulties when using COCA …......................................................... 171

Table 7.1. Task-induced involvement load of both groups ........................................188 


\section{LIST OF FIGURES}

Figure 2.1. Elements of the current research project ................................................43

Figure 2.2. The proposed setting up of an autonomy-scaffolding learning condition.....45

Figure 3.1. Different components of the research design ..........................................51

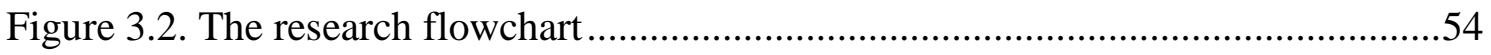

Figure 3.3. A screenshot of Macmillan Dictionary for the search of 'play' ....................64

Figure 3.4. A screenshot of Macmillan Dictionary for the search of 'recommendation'.65

Figure 3.5. A screenshot from Macmillan Dictionary for the search of 'importance' .....66

Figure 3.6. The class procedures in both groups .....................................................69

Figure 3.7. MWE extracting activities in the experimental group ............................... 71

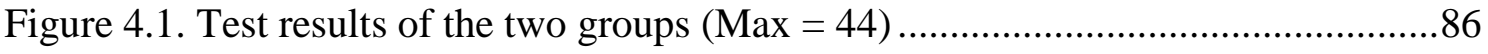

Figure 4.2. Learners' vocabulary size and chunked items vs. immediate post-test results. .99

Figure 4.3. Learners' vocabulary size and chunked items vs. delayed post-test results 100

Figure 5.1. Learners' discovery strategies with new MWEs 105

Figure 5.2. How learners identify the forms of new MWEs of familiar words..... 111

Figure 5.3. Steps of how students worked out the meanings of new MWES 123

Figure 6.1. Changes in students' awareness of MWEs_Between-group comparison....146

Figure 6.2. Changes in students' acquisition strategies of MWEs_Between-group comparison

Figure 7.1. Samples of individual learners' phrase lists 


\section{CHAPTER 1 - INTRODUCTION}

\subsection{Vignette - How I became interested in researching multiword expressions}

My interest in multiword expressions (henceforth MWEs) was first sparked during my growth as a language learner. I have been learning English in Vietnam since I was 12 years old. During the first 6 years of my learning experience, I was taught to memorize lists of new individual words by rote learning and to do hundreds of grammar exercises. The language lessons were also filled with reading comprehension, translation and short writing exercises. As a result, when starting my tertiary studies, I found it difficult to produce English fluently, both in speaking and in writing beyond the sentence or short paragraph levels. Later, when training for different language proficiency tests like the International English Language Testing System (IELTS) or the Test of English as a Foreign Language (TOEFL), I was introduced to some set phrases that we language learners could use in the speaking or writing tests. These phrases were picked out from sample pieces of high achievers in these tests and could be used as templates for our monologues or essays. The use of these templates was purported to save ourselves some of the effort needed to prepare for the contents of the speaking and writing tasks, increase our fluency, impress native examiners and possibly heighten our scores. This is how I first realized the benefits of memorizing word strings as building blocks for my language production.

My interest in researching MWEs evolved during my language teaching career. I had been teaching English in Vietnam for more than ten years before I started this research project. As a language teacher in a context where English was used as a foreign language (EFL), I fully understood the constraints facing EFL learners including the limited exposure to English in this environment. I believed that vocabulary provided fundamental components for learners to communicate in the target language, be it in oral form or written form. What interested me most as a teacher was how to help my students to be proactive in making use of available language materials, either within or outside classrooms, to acquire more useful vocabulary and to develop self-study skills. With experiences of being both a learner and a teacher combined, I thought that a project in search of approaches to promoting formulaic language learning through classroom 
activities would be both fascinating and practical. That was how I started this current project.

\subsection{Background and rationale for the current project}

Second language acquisition research in the last two decades has seen a growing consensus on the pervasiveness of MWEs (Conklin \& Schmitt, 2012; Erman \& Warren, 2000; Foster, 2001; Hill, 2000; Pawley \& Syder, 1983; Shin \& Nation, 2007; Sinclair, 1996) and on the importance of acquiring a sizeable repertoire of MWEs to learners of English as a second language and as a foreign language (addressed henceforth as L2) (e.g. Buckingham, 2006, Granger, 1998; Pawley \& Syder, 1983; Schmitt, 2010; Wray, 2002). However, there is also growing recognition that this is far from a straightforward job for L2 learners to build a sizeable repertoire of MWEs, especially in non-immersion settings such as an EFL context like Vietnam.

Pedagogically-minded researchers have been searching for approaches to help in their MWE acquisition. Attempts have included raising learners' awareness of the utility of MWEs (e.g. Boers, Eyckmans, Kappel, Stengers, \& Demecheleer, 2006; Jiang, 2009; Jones \& Haywood, 2004) and investigating the effects of different factors on the learning process such as the exposure to the target language, the frequency of the target items (e.g. Durrant \& Schmitt, 2010; Pellicer-Sánchez, 2017; Webb, Newton, \& Chang, 2013), and different teaching approaches (e.g. Le-Thi, Rodgers, \& Pellicer-Sánchez, 2017, Lewis, 1993, 1997; Pellicer-Sánchez, 2017). That said, the multi-faceted nature of MWEs still hinders applied linguistics researchers from reaching an optimal way to address this L2 acquisition challenge. In other words, as Meunier (2012, p.123) put it, 'though L2 teaching no longer ignores the formulaic nature of language, the exact paths to follow to better teach it are still insufficiently lit'.

Literature has seen few classroom-based longitudinal studies on approaches to teaching and learning of MWEs, leaving substantive room for more research in this realm. Among the few classroom-based studies so far are the oft-cited Jones \& Haywood (2004) and Boers et al. (2006). These studies highlighted the effectiveness of raising learners' awareness in promoting their use of MWEs in language production. Boers et al. (2006) also put to the test the technique of having the learners extract MWEs from authentic texts proposed by Lewis $(1993,1997)$. This process is called 'text-chunking'. The rationale for 
this approach is that there are far too many MWEs in a language's lexicon for explicit teaching, and that learners will therefore benefit more in the long run if they develop a habit of engaging autonomously with lexis beyond single words. The effectiveness of text chunking ultimately rests on at least two premises. One is the widely accepted notion that, for items to be learned, they first need to be noticed (e.g., Schmidt, 2001), and so, since text chunking promotes noticing of MWEs in texts, it should also promote learning. Another premise is that learners can successfully identify standard MWEs and distinguish these from 'free' word combinations - or, to use Sinclair's (1991) terminology, distinguish between word strings that are the product of the Idiom Principle and those that manifest the Open Choice Principle (see Section 2.2). It was found in Boers et al. (2006) that a group of learners who had regularly done text-chunking activities in their L2 English course used significantly more MWEs from a text that they were asked to talk about in their oral exam than a comparison group did. However, when the intervention was repeated in Stengers, Boers, Housen, \& Eyckmans (2010) but students were in the exam given a text to talk about that was in their first language (L1) rather than English, there were no significantly different quantities of MWEs between the two groups. The mixed results generated from these studies cast some doubt over the effectiveness of textchunking activities, thus inviting further investigation.

A conceptual replication classroom-based intervention in a totally new context and with a few changes to the technique put to the test would therefore be welcome for several reasons. First, it is worth noting that the context in previous studies concerned mostly European countries where learners could enjoy much more abundant exposure to the target language (English) than in the Vietnamese context. Examining the approach in a non-immersion context like Vietnam might shed more light on its effectiveness. Second, having limited exposure means that learners may require some sort of assistance with the proposed MWE identification activity when it comes to verifying the MWE status of considered word strings. In earlier research, it was the teacher who provided this assistance (Boers et al., 2006; Stengers et al., 2010). Yet, if a longer-term aim is to foster autonomy in learners' extraction of MWEs from samples of language, an alternative way may be to familiarize them with available resources. Potential resources are online dictionaries that give due consideration to MWEs and corpora that may help learners gauge whether a given word combination is common enough to be a useful addition to 
their repertoires. Third, the post-test narratives from an input text used in Boers et al. (2006) and Stengers et al. (2010) might not have provided the pressing need for the learners to use the MWEs they learned during the course. This argument was raised by Thomson, Boers and Coxhead (2017) in their call for replication research on pedagogical approaches to spoken fluency and formulaic sequences. Therefore, post-tests focusing on the selected target MWEs occurring in the input texts might allow more learning gains to emerge. Fourth, little is known about what learners actually do when completing a textchunking activity. Key questions that currently remain unanswered include what types of word strings draw learners' attention, how learners identify where a MWE starts and ends, how they deal with the meanings of such MWEs, and how they make decisions on which MWEs to study. The answers to these questions will undoubtedly be relevant to researchers and teachers alike.

The current research project addresses these issues with a view to gaining more insight into the effectiveness of text-chunking as well as the learners' text-chunking processes. Core elements in this study include those inherited from Boers et al. (2006) such as the awareness-raising approach, the exposure to authentic language input and the intentional learning condition with explicit instructions about MWE learning. Newly introduced elements to optimize the effectiveness of the text-chunking activity include lookup training and a pairwork text-chunking activity, as well as MWE recall pre- and post-test and a questionnaire (see below). More specifically, two intact classes of EFL intermediate students were assigned to either a text-chunking condition or a comparison condition. Rather than having them rely on intuition and teacher feedback alone, the students in the text-chunking condition were directed to online dictionaries and were trained to use an online corpus to help them identify MWEs in the reading texts. Students' uptake of MWEs from texts was gauged through a pre-test - post-test comparison. The extent to which they were successful at finding MWEs in the texts was gauged by means of an analysis of the notes the students took during and at the end of the activity. In another departure from previous studies, learners were instructed to do the text-chunking activity in pairs and record their discussions. The data collected from the learners' discussions revealed their online thoughts and strategies when identifying MWEs in texts. The findings of these datasets were triangulated with the data from questionnaires in which the learners reported on their awareness of the importance of MWEs and their learning 
strategies. In short, the results of the study may help to estimate the merits for MWE learning of interventions which try to raise EFL learners' general awareness of the formulaic dimension of language and equip them with tools for learner-autonomous identification of useful MWEs at the same time.

\subsection{Aims and scope of the study}

This research project has three main aims. The first aim is to investigate whether directing learners' attention to MWEs in texts improves their learning of target MWEs better than conducting only meaning-focused post-reading activities. Second, the study investigates how students with intermediate proficiency go about extracting MWEs from reading texts. Third, the study examines the learners' awareness of the importance of MWEs, their learning strategies and the use of online resources for the acquisition of formulaic language.

The scope of this study is restricted to a specific language context and a specific group of participants. The research setting is Vietnam, where English is used as a foreign language (henceforth EFL). The participants, as will be further specified later in the thesis, are at intermediate level of English. The objective is thus to investigate how teachers in this type of educational environment could create conditions to promote their EFL learners' discovery learning of formulaic language.

\subsection{Significance of the study}

The current study is of significance to the existing literature on formulaic language acquisition in several ways. First, the project generates fresh insight into L2 learners' direction of attention when they are instructed to extract MWEs from authentic texts. It provides evidence about what is happening in the learners' minds when they are doing this activity, what interests them, how they manage the boundaries of new MWEs, how they work out the meanings of new phrasal items, and when they decide to look the items up. This insight will inform researchers in the field of the ways L2 learners attend to formulaic language when steps have been taken to raise their awareness of this dimension of language. It may also assist material designers, curriculum developers and teaching practitioners in selecting more fruitful input materials and designing more effective activities both in classrooms and beyond. 
Second, as an extension of previous studies, the project helps to evaluate the affordances of awareness-raising approaches combined with lookup training. The intervention was considered intentional teaching in the sense that the learners' attention was explicitly directed to the phrasal dimension of texts (Nation \& Webb, 2011). Put differently, it belongs to what Nation (2013) calls language-focused learning. That said, the students were given a lot of freedom in making their own learning decisions with the aid of online tools. Hence, the results of the study will inform practitioners in EFL contexts about effective ways to further support the learners in their independent acquisition of formulaic language.

\subsection{Organization of the thesis}

This thesis consists of eight chapters. Following this introductory chapter, Chapter 2 outlines key concepts related to the acquisition of multiword expressions among second language (L2) learners and its significance in second language acquisition in general. This chapter also provides a critical review of previous research on attention-drawing techniques in guiding L2 learners to acquire MWEs autonomously. From this review, research gaps are pointed out, paving the way for the design of the whole project detailed in the subsequent chapters.

Chapter 3 describes the research approaches chosen to achieve the research aims. In this chapter, information about the research design, the participants, the data collection instruments, and the data analysis is provided.

Chapters 4-6 report the results from the analysis of three data sets. More specifically, Chapter 4 provides the findings from the study of the learners' performances on tests of target MWEs. This chapter answers the question of whether the intervention brought about any improvement in the treatment learners' knowledge of the target items. Chapter 5 focuses on the qualitative analysis of the audio-recordings of the learners' in-class discussions. This chapter addresses the question of what was going on in the learners' minds when they were extracting multiword expressions from reading texts. Chapter 6 presents the findings on the learners' awareness of the importance of MWEs in their L2 acquisition, drawing on the immediate post-course questionnaires and the delayed questionnaires. This chapter indicates any changes in the experimental learners' awareness that might be attributed to the awareness-raising intervention. 
Chapter 7 discusses the two most significant themes from the findings chapters. One is the impact of directing learners' attention to MWEs in texts on their retention of target MWEs compared to conducting only meaning-focused activities in class. The other is the strategies the learners used in extracting MWEs compared to their learning strategies with individual words. Most importantly, Chapter 7 addresses the central question of the whole project: To what extent can the regular practice of extracting MWEs from texts with the aid of online resources promote learners' autonomous acquisition of MWEs?

Chapter 8 reiterates the main findings and highlights the main pedagogical contributions of the thesis. This chapter also acknowledges various limitations and outlines avenues for future research. 


\section{CHAPTER 2 - LITERATURE REVIEW}

\subsection{Introduction}

This chapter starts with the challenge of defining formulaic language and the justification for an umbrella term for the phenomenon in this study. Next, the influential role of the mastery of formulaic language in second language acquisition as well as the hindrances for second language (L2) learners in developing their knowledge and use of multiword expressions are highlighted. Given the significance of formulaic language and the difficulties learners have in acquiring it, pedagogical efforts are required to help learners overcome barriers in their learning. Hence, the main parts of the chapter will be devoted to reviewing recent intervention studies in the pursuit of optimal ways to help L2 learners. The consideration of both the findings and limitations of previous studies, especially those directly relevant to the focus of this study, leads to the identification of the research gap which this current project aims to address. The chapter ends with the research questions underpinning this entire thesis.

\subsection{Defining formulaic language in this study}

This section aims to clarify how formulaic language was understood in this current project since this concept can be very diverse and fuzzy at times in literature. Also, judging from a plethora of terms referring to this linguistic phenomenon, it is important to justify what term was chosen in this study. Hence, the section starts with the discussion on a definition of formulaic language that fits the purpose of this project, then continues with choosing a term to be used.

As posited by Sinclair (1991), language may either occur as a result of a large number of complex choices in the open choice principle or in prefabricated phrases that constitute single choices according to the idiom principle. Different types of these prefabricated phrases include compounds (e.g. press conference), binomials (e.g. fish and chips), phrasal verbs (e.g. amount to), idioms (e.g. to have your feet on the ground), standardized similes (e.g., good as gold), proverbs (e.g., When the cat's away...), aphorisms (e.g. No pain, no gain), collocations (e.g. strong tea, mutually exclusive), lexicalized sentence 
stems (e.g. It stands to reason that), lexical bundles (e.g. one of the), conversational formulae (e.g., Have a good day), and other ready-made units.

Wray (2002) proposed the term "formulaic sequence" to refer to these pre-constructed phrases and defined it as:

a sequence, continuous or discontinuous, of words or other elements, which is, or appears to be, prefabricated: that is, stored and retrieved whole from memory at the time of use, rather than being subject to generation or analysis by the language grammar.

While this definition is comprehensive, the job of breaking down its complex components and understanding it might not be straightforward to the participants of this project. For several reasons mentioned below, the definition by Erman and Warren (2000) might be more comprehensible to the target learners:

combinations of at least two words favoured by native speakers in preference to an alternative combination which could have been equivalent had there been no conventionalization.

This definition suits the purpose of dealing with the phenomenon of formulaic language in this thesis quite well. First, it clearly highlights the phrasal level which is above the level of single words. Second, it emphasizes the feature of conventionalization and asserts that without this conventionalization, alternative combinations are readily available. It is of great importance that L2 learners and language teachers in EFL context are aware of this feature of conventionalization in the target language. Without this awareness, L2 learners may resort to alternative but non-standard ways to express their ideas based on their knowledge of single words and grammatical rules, sometimes due to L1 interference. For example, L2 learners may say a quick car instead of a fast car, simply because they think quick and fast are synonyms and the two words can be used interchangeably. Likewise, a Vietnamese learner may say Have you called the food? instead of Have you ordered the food? / Have you placed the order? since in Vietnamese, the phrase translates literally to goi đồ ăn (call the food). Therefore, limited knowledge of conventionalized 
word combinations in the target language potentially inhibits L2 learners from the level of native-like language production. This definition from Erman and Warren (2000) fits the purpose of the current study in raising learners' awareness of larger-than-word units and the use of those conventional units as building blocks for language production instead of single words.

Now that the broad notion of formulaic language or 'formulaicity' has been clarified, the next job is to choose an umbrella term for the diverse kinds of phrases which reflect the phenomenon. A key element of the current project was to raise the learners' awareness of the pervasiveness of different types of conventional expressions in the target language, rather than one or two specific categories such as collocations or phrasal verbs. That said, choosing an inclusive term among numerous existing terms was far from an easy task.

The growing recognition of the formulaic nature of language has brought about a vast array of terms referring to it. In her seminal work on the formulaic nature of language, Wray (2002) listed more than 50 terms in literature to refer to different aspects of formulaic language. Among the plethora of terms available in current literature, the most frequently used umbrella terms are lexical phrases, chunks, ready-made (complex) units, fixed expressions, formulaic sequences, and multiword expressions.

This study opts for multiword expressions as the term to refer to different instances of formulaic language identified and analysed from the introduced input. The term is chosen as it is self-explanatory in highlighting the above-word-level nature of word strings. One important consideration in the choice of an umbrella term in the present study is the comprehensibility and utility of the term to the learners. This study involves L2 learners of English in the Vietnamese context who might need a clear term for the linguistic aspect they would look into. Among the mostly-used terms in literature, multiword expressions (henceforth MWEs) was deemed more understandable and memorisable for the participants than terms such as formulaic sequences or lexical phrases thanks to the transparent meanings of its high-frequency component words. For the central aim of raising the learners' awareness, the term will obviously be introduced to them.

In short, in this project, multiword expressions (MWEs) is used as a blanket term to refer to different categories of formulaic language. That said, for the sake of stylistic diversity, at times chunks and phrases might be used interchangeably with MWEs in this thesis. 


\subsection{Why do L2 learners need to acquire multiword expressions?}

This section underlines the pivotal role of the acquisition of MWEs in learning a second language and, from there, points out why it is well worth the attention and efforts of language learners and teachers as well as researchers. According to Nation (2013, p. 83), 'knowing a word involves knowing what words it typically occurs with'. Cowie (1992) even asserted that, "it is impossible to perform at a level acceptable to native users, in writing or in speech, without controlling an appropriate range of multiword units" (p.10). This paramount importance of the mastery of MWEs to L2 learners has been welldocumented in research that demonstrates their ubiquity in language, their essential functions in communication, and their influence in improving L2 learners' fluency and proficiency.

The first feature making MWEs essential is that they are pervasive in natural discourse. There is a consensus among researchers that a very large proportion of spoken and written native-speaker discourse consists of lexical units larger than single words (Conklin \& Schmitt, 2012; Erman \& Warren, 2000; Foster, 2001; Hill, 2000; Pawley \& Syder, 1983; Shin \& Nation, 2007; Sinclair, 1996). Estimates vary depending on how one defines an MWE, with proportion of MWEs in native discourse ranging from 32\% (Foster, 2001) to more than 50\% (Erman \& Warren, 2000). That MWEs make up such a large proportion of natural discourse implies that MWE acquisition should be placed high on L2 learners' learning agenda.

Second, the knowledge of MWEs can help speakers fulfil basic communicative needs (Schmitt, 2010; Wray, 2002). MWEs are used for various communicative purposes in language use, and grasping a sizeable repertoire of MWEs, especially those with figurative meanings can help non-native speakers better comprehend daily life conversations (Buckingham, 2006). As asserted by Schmitt (2010), MWEs "can be used for most things society requires of communication through language" (p. 10). For example, MWEs appear in most speech acts such as apologizing (e.g. I'm terribly sorry...; My bad!), thanking (e.g. I would like to express my sincere thanks ...), greeting (e.g. How are you doing?), or asking for permission (e.g. May I please...?). This high frequency of MWEs in communication nicely illustrates Widdowson's (1989, p.135) point that, 'communicative competence is not a matter of knowing rules...' 
Third, the acquisition of MWEs has been proposed to facilitate learners' fluency in their language production (e.g. Granger, 1998; Pawley \& Syder, 1983; Wray, 2002). In studies by Boers, Eyckmans, Kappel, Stengers, and Demecheleer (2006) and Stengers, Boers, Housen, and Eyckmans (2010, 2011), learners using more MWEs were rated as more fluent speakers. Similarly, strong correlations between the use of MWEs and fluency indicators were also found in research by $\operatorname{Wood}(2006,2010)$ and Ushigusa (2008). The higher fluency may be attributed to the processing advantage of MWEs in the sense that they seem to be cognitively stored and retrieved holistically (Wray, 2002). As discussed in Boers and Lindstromberg (2012), when MWEs are well entrenched in memory, they help learners to anticipate words that follow the onset of these MWEs. This depth of knowledge can speed up the processing of the formulaic segments of discourse and thus free up attentional resources for the non-formulaic and, therefore, less predictable parts. This then benefits the fluency of language production (and comprehension).

Fourth, knowledge of MWEs helps learners come across as proficient language users (Bartning, Forsberg \& Hancock, 2009; Crossley, Salsbury, \& McNamara, 2015; Dai \& Ding, 2010; Forsberg, 2010; Granger \& Bestgen, 2014; Kremmel, Brunfaut, \& Alderson, 2017; Hyland, 2008; Stengers, Boers, Housen, \& Eyckmans, 2011). Whereas the knowledge of MWEs is considered a promising indicator of very advanced levels of L2 acquisition, the inappropriate use and/or under-use of L2 MWEs is one of the characteristics that distinguish non-native and native (or otherwise 'expert') language use (Siyanova-Chanturia, 2015). When it comes to language production, the lack of MWE knowledge can result in utterances which sound "odd" or "foreign" to native speakers if learners build up those utterances by relying on their knowledge of grammar and singlewords (Cobb, 2018). Also, according to Coxhead (2007, 2011), learners do not necessarily pay close attention to multi-word units in their reading or writing. This lack of awareness and attention may to some extent explain L2 learners' limited phraseological knowledge.

Taken together, it is undeniable that the acquisition of MWEs is vital in second language acquisition. Therefore, as Meunier (2012, p.112) puts it, 'if teaching is meant to help learners improve their proficiency levels, it should then - at least in part - be devoted to improving learners' knowledge and use of formulas', or MWEs. The next section focuses 
on obstacles facing both L2 teachers and learners in promoting the process of MWE acquisition, which makes it a pressing need for pedagogical research efforts.

\subsection{Why is MWE acquisition challenging to $\mathrm{L} 2$ learners?}

While it is clear that L2 learners stand to gain a lot from mastering MWEs, research has suggested that, unfortunately, this mastery does not come easily, especially in nonimmersion settings such as English as a Foreign Language (EFL) contexts (e.g. Granger, 1998; Laufer \& Waldman, 2011; Li \& Schmitt, 2010; Nesselhauf, 2003; Siyanova \& Schmitt, 2008; Siyanova-Chanturia \& Spina, 2015). Research has uncovered different shortcomings in L2 learners' MWE knowledge.

One frequently-mentioned issue is L2 learners' MWE knowledge lags behind their knowledge of single words (e.g. Bahns \& Eldaw, 1993, Forsberg, 2010; Li and Schmitt, 2010; Peters, 2014) and lags behind other aspects of their language acquisition (Nguyen \& Webb, 2017; Schmitt \& Carter, 2004). This has resulted in limitations in learners' communication in the target language. At the receptive level, learners can find it difficult to understand a reading passage with idiomatic formulae even when they know all the words (Martinez \& Murphy, 2011). At the productive level, advanced learners still make abundant errors in their use of MWEs even when the language they produce is free of grammatical errors (Altenberg \& Granger, 2001; Laufer \& Waldman, 2011; Nesselhauf, 2005). For instance, in her investigation of 2000 collocations extracted from the English learner corpus of German learners, Nesselhauf (2005) found that a quarter of these collocations contained errors. In Siyanova \& Schmitt's (2008) study of 810 adjectivenoun collocations extracted from 31 essays written by Russian learners of English, only around $45 \%$ of the collocations were appropriate. L2 learners have also been found to be over reliant on certain collocations that they know very well (e.g. Foster, 2001; Granger, 1998) while showing lack of production of some others commonly used by native speakers (Nesselhauf, 2003, 2005).

Another issue is that the development of MWE knowledge tends to be slow and uneven (Kuiper, Columbus, \& Schmitt, 2009; Qi \& Ding, 2011). Specifically, Qi \& Ding (2011) analysed and compared the use of MWEs in the prepared monologues of 56 Chinese university English majors. These speeches were collected at the beginning and at the end of a three-year period. Although progress was found regarding the frequency, accuracy 
and variation of MWE use, no significant changes were seen in the types of errors that were made. According to some authors, MWEs even constitute the final aspect of language to be mastered by language learners (Bahns \& Eldaw, 1993) or 'the final difficult hurdle' (Wray \& Fitzpatrick, 2008, p.124).

Possible reasons why mastery of MWEs is so daunting for L2 learners, especially in a non-immersion context, include the enormous number of MWEs available, the lack of exposure to the target language (which also means insufficient exposure to low-frequency MWEs), and importantly, the lack of attention learners are believed to pay to this phenomenon. First, as Schmitt (2000, p.81) asserted, 'one of the main pedagogical hurdles is the sheer number of collocational possibilities to deal with.' While there is no need for learners to acquire all the MWEs available in the target language, the more they can acquire, the better they will be able to learn and use the language. Research attempts have been made in developing different MWE lists to draw learners and teachers' attention to the most frequent MWEs worth the priority in the teaching and learning agenda (e.g. Liu, 2012; Martinez \& Schmitt, 2012; Shin \& Nation, 2007; Simpson-Vlach \& Ellis, 2010). However, those lists regard just the top of the phraseological iceberg, so to speak. Clearly, more initiatives are needed to help learners develop an adequate command of formulaic language.

Second, in an EFL context where the exposure to the target language is largely restricted to textbooks and classroom interactions, there is a lack of exposure to a wide variety of MWEs, let alone to multiple instances of the same MWEs. Given that an MWE will probably need to be encountered more than once to leave a somewhat durable memory trace in leaners' minds (which will be discussed below), this limited exposure to the target language in general will also limit the number of re-encounters with MWEs. The time lapse between different encounters with the same MWEs, if too long, may cause the loss of the memory trace (if any was established in the first place). As a result, the learning of those MWEs can never properly get off the ground (Durrant \& Schmitt, 2010; Boers \& Lindstromberg, 2012). Also, as pointed out by Cobb (2018, p.196), 'what linguists discovered is that while formulaicity is pervasive in language, particular formulae sadly are not'. 
The third explanation for the difficulty of MWE acquisition to L2 learners is their lack of awareness of the pervasiveness and significance of MWEs. MWEs are more likely to be ignored in texts as this part of vocabulary has received little attention in textbooks and from language teachers. Vocabulary instruction has put remarkable emphasis on single words (Nguyen, 2014) whereas the acquisition of MWEs demands a richer and deeper attentional level (Fan, 2005). Wood (2015) attributed learners' odd use of MWEs to their poor sensitivity toward formulaicity, while Laufer (2011, p. 44) mentioned the phenomenon of 'deceptive compatibility', i.e. learners simplistically believe that semantically compatible words can co-occur. These issues are both concerned with the lack of MWE awareness. It is this third explanation for the slow rate of MWE acquisition that is particularly relevant for the current study.

Considering both the paramount role of MWEs in second language acquisition and the difficulties that EFL learners face in their learning process, pedagogical interventions would therefore be most welcome. The next section reviews some of the research on such interventions to date.

\subsection{What have intervention studies found about ways to promote L2 MWE acquisition?}

As mentioned in Chapter 1, the current study is an attempt to contribute more insight into the field of pedagogical intervention into the learning and teaching of MWEs. Therefore, a review of the interventions implemented to date can help shape the dimensions of the research problem this project can investigate. Since the learning condition - whether the learning is expected to occur incidentally or intentionally - accommodates all the features included in an intervention, I consider it to be the fundamental factor that can help categorize different interventions. As a result, this section is structured into three subsections corresponding to three categories of learning conditions that have been proposed to facilitate MWE acquisition among L2 learners. Initially, I was tempted to categorize intervention attempts in just two categories: 1) interventions to promote incidental learning of MWEs, and 2) interventions to promote intentional learning. However, for some interventions, it is not always obvious which kind of learning condition is being (more) stimulated and so a simple dichotomy is hard to maintain. 
Bearing this in mind, Pellicer-Sánchez \& Boers (2018) recognized a third category of intervention studies which they called semi-incidental learning conditions.

In the incidental learning condition, the acquisition of MWEs occurs naturally when the learners are interacting with the target language in different activities without focusing their attention on the learning of certain lexical items (Ellis, 1999; Schmitt, 2010). This learning condition can be set up in classrooms as well as outside classrooms when learners are doing meaning-focused activities like reading, listening or speaking (Nation, 2013). In classroom environments, the incidental learning condition may occur as a result of indirect teaching (Nation \& Newton, 1997), in which teachers organize meaning-focused learning activities such as pairwork or groupwork discussions, jigsaw reading activities, or note-taking-while-listening activities. For incidental learning, it is hoped that target vocabulary will be picked up as a by-product of these communicative activities.

The focus of the second category of pedagogical approaches is the promotion of intentional or deliberate learning of MWEs. Unlike the incidental learning condition outlined above, intentional learning involves learners' efforts to memorize new vocabulary items, e.g. through flashcards, translation, and dictionaries (Nation, 2013), and to use them in their language production. This learning condition might be stimulated by direct teaching (Nation \& Newton, 1997) in which teachers explicitly teach new items through vocabulary exercises, vocabulary testing or word lists for rote learning. Alternatively, learners may find some motivation to deliberately learn particular items, perhaps from their own needs for participating in different language interactions in classrooms or as part of extracurricular tasks or in their daily lives. For example, if learners are reading an article and find by chance a useful phrase which can express exactly something they have been struggling with, they may decide to note the phrase down in a vocabulary notebook so that they can review it later and attempt to memorize it. In this case, the learning intention comes from the needs felt by the learners themselves. In other words, the two learning conditions mentioned above are complementary.

The third category, semi-incidental learning, consists of interventions in which reading texts are manipulated so that the visual saliency of the target lexical items is increased, but no explicit instruction is given. For example, target MWEs are italicized, printed in bold type, or highlighted in input texts to draw more of learners' attention to these items. 
According to Nation \& Webb (2011), a learning condition can be considered intentional if the learners are alerted about a vocabulary test and/ or learners' attention is explicitly directed to the target items. Hence, as argued by Pellicer-Sánchez \& Boers (2018), interventions in this category do not qualify as the intentional learning condition since there is no explicit teaching. They do not qualify as purely incidental learning condition either since visual manipulation to draw more attention to certain items has been added to the textual input.

Studies in the three categories have revealed the advantages and disadvantages of each learning condition concerning their efficiency in supporting MWE learning. MWE knowledge can be gained to some extent in every one of these conditions. However, it is clear that the incidental learning condition is not particularly efficient (see Section 2.5.1). The semi-incidental condition may result in a trade-off between the salient MWEs and less salient ones (see Section 2.5.2). Also, explicit teaching may take time (see Section 2.5.3). Different pedagogical factors introduced in each condition are mentioned accordingly. Based on what has been uncovered in earlier empirical studies, a learning condition with relevant pedagogical elements chosen for this classroom-based intervention will be presented later in this chapter.

\subsubsection{Incidental learning condition is not enough for effective MWE acquisition.}

While research on incidental acquisition of L2 vocabulary has repeatedly highlighted the role of the number of encounters with, or the frequency of, the target lexical items in the language input (Horst, Cobb, \& Meara, 1998; Pellicer-Sanchez, 2015; Pellicer-Sanchez \& Schmitt, 2010; Pigada \& Schmitt, 2006; Waring \& Takaki, 2003; Webb, 2005), only recently have researchers started investigating the acquisition of MWEs incidentally from reading. These studies have been based on evidence from single word research and the role of reading in the incidental acquisition of single items. While there is a consensus among researchers that frequency matters, the required number of occurrences that may lead to durable retention of new vocabulary items varies, ranging from six (Rott, 1999), to eight (Horst, Cobb, \& Meara, 1998), to more than 10 (Nation \& Wang, 1999; PellicerSanchez \& Schmitt, 2010).

The question of the extent to which repetition affects learners' uptake of MWEs has only been investigated by a few studies (Durrant \& Schmitt, 2010; Pellicer-Sánchez, 2017; 
Webb, Newton, \& Chang, 2013). In an experimental study, Durrant and Schmitt (2010) examined the acquisition of target adjective-noun collocations in three conditions: 1) learners were exposed to the collocations only once in sentence contexts; 2) learners were exposed to the collocations repeatedly in the same linguistic context (verbatim repetition); and 3) learners were exposed to the target collocations repeatedly in different contexts (varied repetition). All these three conditions were followed by the testing phase in which the adjective part and then the two initial letters of the noun were shown to the learners so that they could recognize the nouns and say them out loud. The results showed that learners demonstrated more retention of target collocations in the two repetition conditions than in the condition with only one exposure.

In the same vein, the study by Webb et al. (2013) underlined the significance of repetition in MWE incidental uptake. In this study, the EFL learners were reading and simultaneously listening to one of four versions of a modified graded reader containing 18 target Verb + noun collocations. In the four versions of input, the target items were embedded with different numbers of encounters: 1, 5, 10, and 15 times. Afterwards, the learners took four tests on the receptive and productive knowledge of the forms and on the receptive and productive knowledge of form and meaning mappings of all the target collocations. They were not informed prior to the study that there would be tests. The results showed the beneficial impact of the repetition of the target items, with the best learning gains when learners were exposed to 15 occurrences of each new collocation.

That said, a conceptual study by Pellicer-Sánchez (2017) did not yield the same results for the usefulness of repetition, even though it also confirmed the possibility that learners can acquire incidental MWEs from reading. In this intervention study, the participants were randomly assigned to two conditions: 1) reading a story containing six target collocations (adjective-pseudoword) with four occurrences of each item; 2) reading the same story with eight occurrences of the target collocations. No significant differences in learning gains were found between the two experimental conditions in the post-tests on the form, the meaning and the collocational behaviour of the six pseudowords. It is worth noting that the inclusion of pseudowords might have affected the learning gains to some extent as novel lexical items might attract more of learners' attention, as acknowledged by Pellicer-Sánchez (2017). It can be seen from these studies that textual input has the 
potential to promote incidental learning of MWEs, especially when the input offers frequent reoccurrences of target items.

However, a couple of counter-arguments have been made in literature about the feasibility and usefulness of manipulating the frequency of target MWEs in reading texts. First, as Cobb (2018, p. 198) stated, 'while this is an interesting result in principle, it is also highly limited as a pedagogy for formula acquisition'. Cobb (2018) argues that the conditions in Webb et al. (2013) are not practical in the sense that it is rare that learners will read and at the same time listen to a piece of language input containing most of words known to them apart from the target items. Also, it is rare that any MWE appears 10 or 15 times in a text, not to mention that an unmanipulated text may have far more than 18 collocations. Put differently, the conditions created in these studies, though useful, involve the use of stilted language input which may cause more work for language teachers while limiting the possibilities of learners to apply what they learn in classrooms to situations beyond.

The question that follows would be, without the frequency manipulation, whether reading alone will suffice for L2 learners to incidentally pick up instances of MWEs from the input they are exposed to. As shown in the abovementioned studies, durable learning may not occur just after a single exposure. Research into single word acquisition has also demonstrated low uptake rate in incidental learning conditions (e.g., Laufer, 2005; Waring \& Takaki, 2003). It seems unreasonable to expect remarkable uptake of multiword units merely from natural exposure (Boers \& Lindstromberg, 2009). As already noted above by Cobb (2018), it is not often that one MWE occurs several times in a text. For example, Byrd \& Coxhead (2010) found out that on the other hand occurred only once every 15,000 words in a corpus of academic written English of 3.5 million words. Moreover, by the time an MWE is re-encountered, the time lapse between the first and second exposure might be too long for the memory trace to remain (Boers \& Lindstromberg, 2012). It might also be hard for learners to autonomously recognize an MWE in the first place if their awareness of MWEs is not raised. The case might be different between single words and MWEs. A learner might easily recognize an unfamiliar word but might not recognize a new MWE consisting of familiar component words. For example, a learner might easily spot the new word Islamophobia in the sentence, 'For starters, we can no longer pretend that Islamophobia doesn't exist in America', but he might overlook the MWE for starters, simply because both the 
component words are not new to him. In other words, in a pure incidental learning condition like this, noticing, the first step in the acquisition process (Schmidt, 1995, 2001), might be missing. In his Noticing Hypothesis, Schmidt (1995, 2001) emphasized the role of noticing, or attention, as a necessary condition for learning. He stated that learning only occurred, i.e. the target items can be acquired from the input, when learners could notice them and build a mental representation of those items in their memory for further processing.

To sum up, the review of several studies promoting the incidental learning condition has shown that this condition might not be optimal for L2 learners' intake of MWEs, especially when opportunities for exposure to L2 and repeated encounters with the same MWEs are rare (as is often the case in EFL contexts). In other words, similar to the acquisition of single words, there is a role for deliberate vocabulary learning (Nation, 2013). Before turning to interventions that are clearly of the intentional learning type, the next subsection looks at research in which learners' attention was 'merely' directed to MWEs in reading texts.

\subsubsection{Semi-incidental learning condition of MWEs works, with a trade-off.}

Several intervention studies have attempted to direct more of learners' attention to instances of MWEs in reading texts through input-enhancement techniques (Ellis, 2015), such as typographical enhancement. This means using italicizing, bolding, underlining, or highlighting the lexical items in written texts to make them stand out. Typographical enhancement stimulates learners to attend to target MWEs, which makes the learning condition no longer purely incidental.

Studies investigating the effects of typographical enhancement so far have yielded positive results of these techniques in raising learners' awareness and retention of enhanced MWEs (Bishop, 2004; Boers, Demecheleer, He, Deconinck, Stengers, and Eyckmans, 2017; Choi, 2017; Peters, 2009, 2012; Sonbul and Schmitt, 2013; Szudarski and Carter, 2016). Among these studies, only Boers et al. (2017) examined typographical enhancement on its own as an awareness-raising technique. The others, however, looked into typographical enhancement in combination with other techniques, such as input flooding, i.e. including multiple instances of certain MWEs in a text (as in Szudarski \& Carter, 2016; Webb et al., 2013), and glossing, i.e. providing meaning explanations of 
certain MWEs on the margin of the text (as in Peters, 2009, 2012). These combinations were found to be beneficial to the learners in their MWE acquisition.

It is encouraging that applying only typographical enhancement to authentic textual input is advantageous to the learners too. In Boers et al. (2017), learners were given one of three versions of two reading texts, including one version with 16 underlined MWEs, one with only eight out of the 16 target MWEs underlined, and one with no typographical enhancement. The findings showed better memory traces of enhanced items among the learners, confirming the hypothesis that input enhancement draws more attention to the target items and, therefore, facilitates retention of such items. Similar results about the effects of typographical enhancement were also found in Choi (2017). In that eye movement study, the group reading the enhanced text version were observed spending more time processing the underlined items. This group also outperformed the control group who read the unenhanced text in the post-reading collocation test regarding those target MWEs.

That said, a trade-off between the attention to and the retention of enhanced and unenhanced MWEs in the reading texts was detected in both studies by Boers et al. (2017) and Choi (2017). More specifically, despite showing better knowledge of the enhanced target items, the learners could recall fewer unenhanced MWEs than their control counterparts. One of the explanations put forward by the authors was the limited attention resources that might have been allocated more to the enhanced MWEs at the cost of the unenhanced items. Also, typographical enhancement might give the impression to students that only the enhanced items are worth learning. Possibly, this trade-off needs to be taken into consideration in the search for an optimal approach to L2 MWE acquisition. The implementation of these techniques should be to raise learners' awareness of the phrasal dimension of the language in general, not only certain items. It is likely that learners' attention needs to be directed more explicitly so that they can recognize target items from textual input on their own. The next subsection will discuss intervention studies following this strand.

\subsubsection{Intentional learning condition of MWEs also works, but explicit teaching takes time.}

One would argue that if noticing can lead to the intake of language knowledge (Schmidt, 1995, 2001), more noticing should be stimulated in language classrooms. Hence, explicit 
teaching of MWEs has been well advocated in literature (e.g. Granger \& Meunier, 2008; Nattinger \& De Carrio, 1992; Pawley \& Syder, 1983; Sinclair, 1991). Recent studies in this line of research have examined the usage of decontextualized exercises on MWEs (e.g. Szudarski, 2012; Webb \& Kagimoto, 2009), the introduction of mnemonic techniques to make MWEs more memorable (e.g. Boers, Demecheleer, \& Eyckmans, 2004; Boers, Eyckmans, \& Stengers, 2007), and the training to raise the learners' awareness of the importance of MWEs so that they would attend to those phrases outside classroom contexts (Boers et al., 2006; Jiang, 2009; Jones \& Haywood, 2004; Stengers et al., 2011).

In the first strand are studies evaluating the use of decontextualized MWE-focused exercises have given rather mixed results. It was found in some studies (e.g. Szudarski, 2012; Webb \& Kagimoto, 2009) that doing language-focused exercises enhances learners' knowledge of MWEs at both the productive and receptive level. The findings of other studies revealed influential factors to the effectiveness of such exercises, including the nature of the items targeted as well as the exercise format. More specifically, the learning gains of target MWEs may depend on the different learning burdens exerted from a variety of MWEs, with verb-noun collocations appearing particularly challenging (Peters, 2016).

Some studies (e.g. Boers, Demecheleer, Coxhead, \& Webb, 2014; Laufer \& Girsai, 2008; Peters \& Pauwels, 2015) have looked into the usefulness of the exercises of the kind featured in many course books, e.g. matching exercises and blank-filling exercises. Results showed that working with exemplars of intact expressions appears more judicious than assembling expressions by matching their constituent parts, e.g. make/ take and effect/ a contribution (Boers, Dang, \& Strong, 2017; Stengers \& Boers, 2015). The failed effort the learners put in such matching or cloze exercises might leave strong memory traces of the wrong word partnerships which later corrective feedback does not necessarily supplant. Collectively, various factors need to be considered when it comes to the use MWE-focused exercises. Among those factors, the vital one is possibly learners' exposure to intact MWEs, which can save them the effort to make blind guesses and avoids the risk of remembering the wrong guesses (Boers et al., 2014). Conversely, it is arguable that this kind of exposure is readily available in authentic texts and that MWE-focused exercises, while requiring teachers' and/ or textbook designers' time and 
effort to design, can only focus on a limited pre-selected number of MWEs. These shortcomings, therefore, restrict the utility of the decontextualized exercises for the longterm MWE learning process.

In the second strand are interventions which have examined ways of harnessing the memorability of particular features of MWEs, such as raising learners' awareness of the etymological associations of figurative idioms (e.g., Boers, Demecheleer, \& Eyckmans, 2004; Boers, Eyckmans, \& Stengers, 2007) and drawing learners' attention to 'catchy' phonological patterns such as rhyme and alliteration exhibited by a considerable number of MWEs (e.g., Boers, Lindstromberg, \& Eyckmans, 2014a; Eyckmans, Boers, \& Lindstromberg, 2016). These studies have shown positive effects of stimulating more insightful learning, rather than rote memorization, of a not-so-arbitrary part of phraseology. However, while promising, the scope of application of these interventions is inevitably confined to a subset of MWEs.

In any case, given the limited classroom time and the sheer number of phrases L2 learners have to master, explicit teaching can never suffice (Nation, 2013). It will be too ambitious to deliberately teach a comprehensive command of MWEs in language classrooms, just 'like someone trying to empty the sea with a teaspoon' (Swan, 2006).

So far, the review of previous intervention studies in this section has pointed out all the three learning conditions have their own pros and cons. That said, it is undeniable that awareness, or noticing, is of paramount importance in the long-term MWE learning process of L2 learners. Possibly it would be optimal to devote the limited classroom time to raising learners' awareness of the pervasiveness and significance of MWE mastery. Ultimately, one would hope learners will begin to autonomously attend to and pick up MWEs from authentic, non-modified texts. Lewis $(1993,1997)$ proposed text-chunking activities with a view to fostering the appreciation of MWEs in the classroom by asking students to screen authentic texts for instances of MWEs, namely text-chunking. The effectiveness of this activity was investigated as part of a classroom study by Jones \& Haywood (2004), and it was the focus of the studies by Boers, et al. (2006) and Stengers, et al. (2010). The next section discusses these three studies in the third strand of studies promoting intentional learning condition. These studies directly motivate and inform the design of the current project. 


\subsection{How has awareness-raising and text-chunking intervention been implemented in previous studies?}

Given that the purpose of the current project is to put the text-chunking activities (Lewis, 1993, 1997) to the test one more time, this section looks into the study design and findings of the three abovementioned studies in detail so that the agenda for the new project can be built. It is hoped that the proposal for added factors and for implementing the approach differently will fill some gaps left in research and therefore contribute to the existing literature of intervention studies on MWEs.

\subsubsection{Jones \& Haywood (2004)}

An early and well-cited attempt in raising learners' awareness to facilitate their MWE acquisition, Jones \& Haywood (2004) carried out an exploratory classroom-based study in an English for Academic Purposes (EAP) context. Participants were 21 L2 learners from two intact classes in their first half of their six-month intensive pre-sessional course. The two classes were assigned as the experimental group $(n=10)$ who received explicit training in MWEs and the control group $(n=11)$ who did not. The study was conducted in ten teaching weeks with a variety of pedagogical techniques to promote the noticing, processing and generation of the target items. Eighty MWEs, such as the study of, on the basis of, or to what extent, were chosen as target items from the research on lexical bundles of Biber, Johansson, Leech, Conrad \& Finegan (1999). The intervention consisted of reading and writing components.

In the reading component, four texts either in problem-solution or cause-effect text type were selected. In each class, the learners started by doing normal meaning-focused reading activities such as reading for the main ideas and reading for specific details. Once the learners were familiar with the text content, the texts were re-presented to them with the target MWEs highlighted in bold italics for attention-drawing purposes. Other activities were designed in a way that the learners could engage with the target MWEs in different contexts and understand how to use those phrases appropriately, both grammatically and semantically. These contexts were taken from concordance lines or corpus extracts.

In the writing component, the learners were given exercises to review the MWEs they had learnt from the reading classes. Subsequently, they were instructed to produce 
concordance texts and investigate aspects of the MWEs, including their frequency and information on collocates. The learners were also asked to write four cause-effect and problem-solution type of essays.

The effects of the intervention were gauged by learners' MWE identification in texts and MWE production in a C-test before and after the treatment and by their use of MWEs in two essays collected with a two-week gap. Also, daily classroom observations and three 30-minute interviews with three experimental students were conducted. The results of the MWE identification test showed that the experimental group were more aware of MWEs because they underlined more word strings than the control group. The heightened awareness was evident in the interviews with learners too. However, progress in the knowledge of the target items did not clearly show both in the C-test and in the learners' essays. Of note, the C-tests used before and after the treatment were on different MWEs, which made it difficult to compare the results, and made it hard for any improvement to show.

The strengths of this study lie first in its comprehensive endeavour to set up an intentional learning condition so that the target items can be acquired, and the learners' awareness can be raised as well. The teacher's step by step guidance started from making the target items more salient in texts to helping the learners understand their usage patterns before asking them to put the new MWEs in their written output. The second plus point is the teacher researcher's principled choices of target items and efforts in designing multiple activities to raise learners' awareness and build up their MWE processing and learning skills.

Conversely, there are some issues which might hinder the measurement of possible learning gains in Jones \& Haywood's (2004) study. First, the experimental group and the control group were working with different teaching materials and different teaching styles, which makes it hard to determine precise cause-effect relations. Since the language input can immensely affect the learning process, it needs to be a tightly controlled variable. Second, the complex design with a wide range of activities can be a doubleedged sword. On the one hand, it serves the purpose of the author to foster learning. On the other hand, it is challenging to attribute the learning effects, be they negative or positive, to any single activity. It is advisable to simplify the research design for easier 
interpretation of the findings, as stated by Coxhead (2015) in her call for conceptual replication of Jones \& Haywood (2004). Third, as already mentioned, the pre-test and post-test should gauge the learning gains of the same set of MWEs. Fourth, it might be too ambitious to expect visible improvement in free production of MWEs from the 10 weeks' time of exposure and practice (Boers \& Lindstromberg, 2012). Fifth, a larger number of participants and more qualitative data collected on how the learners approach the classroom tasks could yield more fruitful findings (Coxhead, 2015).

A conceptual replication Jones and Haywood (2004) was implemented by Peters and Pauwels (2015). In this study, analyses of students' end-of-term assignments showed a good proportion of formulaic language produced. Also in line with Jones \& Haywood (2004) in using awareness-raising techniques is the study by Boers et al. (2006) and its approximate replication - Stengers et al. (2010). Unlike Jones \& Haywood's complex design, Boers et al. (2006) only focused on investigating the effectiveness of learners' MWE extracting from authentic texts. A review of this study and its replication will be in the next subsection.

\subsubsection{Boers, Eyckmans, Kappel, Stengers, \& Demecheleer (2006) and Stengers, Boers, Housen, \& Eyckmans (2010)}

Boers et al. (2006) is another exploratory study in an awareness-raising approach. The study focuses on gauging the effects of the phrase-noticing treatment on learners' oral proficiency. Two intact groups including 32 high-intermediate college learners majoring in English were randomly assigned as the experimental group and the control group. While the experimental group $(n=17)$ were instructed to pay attention to the phraseological dimension of input texts through instances of MWEs, the control group $(n=15)$ were taught with the focus on individual words and grammar patterns. Unlike in Jones \& Haywood (2004), the teaching materials, including reading passages and transcripts of selected recordings, were identical in the two groups. Also, in each lesson, language-related activities were done after the students were familiar with the text contents. The only different variable was the teaching instructions given in each group. The project took place over a whole school year with a total of 22 teaching hours.

At the end of the course, the students' proficiency was gauged by means of text-based speaking tasks and the MWEs they produced in those tasks were tallied. More 
specifically, the participants were interviewed by two 'blind' judges. The first part of the interview involved the learners in a conversation with the judges about the content of a text given to them right before the interview. The second part of the interview was a spontaneous conversation about an unprepared, but familiar topic. Results showed that the counts of the MWEs in the learners' oral production correlated well with the judges' assessment of the oral proficiency of the learners. To put it another way, learners using more MWEs in their speech were perceived to be more proficient. That said, some aspects of the results in the study were inconclusive. On the one hand, there was positive evidence that students in the experimental group recycled more MWEs from new texts they were asked to talk about. This deliberate effort in making their language more formulaic shows learners' heightened awareness of the importance of MWEs. On the other hand, the posttreatment communicative tasks did not show compelling evidence that the experimental students had effectively acquired more MWEs they had met in their course texts.

A replication of Boers et al. (2006), Stengers et al. (2010) re-ran the experiment with 60 Dutch-speaking students included in two groups, one of L2 learners of English and the other of L2 learners of Spanish. In each group, two learning conditions were set up, which were identical to those in Boers et al. (2006). Interestingly, to avoid the learners' strategic recycling of phrases they would encounter in the text given to them before the conversational tasks, the learners were given the text in their first language before they were asked to retell the text content. The results again did not show hard evidence of any superior uptake of MWEs from the course texts by the experimental groups compared to their control counterparts. The researchers concluded that mere teacher-led phrasenoticing activities may not be enough to boost the acquisition of MWEs.

Compared to Jones \& Haywood (2004), Boers et al.'s (2006) and Stengers et al.'s (2010) research design was much less complex in the sense that they focused on the efficiency of a single variable - the teaching instructions. By narrowing the focus, it is easier to attribute the heightened awareness among the learners to the pedagogical intervention. One possible explanation for the inconclusive results about whether or not the experimental students gained more knowledge of the chunks they had encountered in the language input could be that the post-treatment speaking tasks may simply not have created sufficient need or opportunity for the students to produce specifically the MWEs they picked up from the course materials. In other words, the experimental learners' 
superior uptake of the MWEs from the course texts might have been elusive simply because using these particular MWEs was not task-essential, as argued in a recent call for replication by Thomson, Boers and Coxhead (2017). Evidence of a treatment effect is therefore more likely to emerge in a test which directly tests participants' recollection of MWEs encountered in the course of the treatment. Another possible explanation lies in the fact that in these three longitudinal classroom-based studies, all the pre- and post-tests were on the free production of language in longer discourses, either in conversational long turns or in essays. This kind of language generation may give learners the freedom to choose the lexical items they are more comfortable with, and because these are demanding tasks where the students need to allocate a lot of attention to the content of their messages they are thus likely to use lexical items they have fully internalized and added to their active vocabulary. More evidence of learning gains might emerge in receptive knowledge tests or in productive knowledge tests that require less multi-tasking, such as discrete-item tests.

One gap of research that has hardly been touched upon in these awareness-raising studies, and in other intervention studies in literature in general, is the insight into the processes taking place in the learners' minds when they do the text-chunking activity. Such issues as what draws learners' attention when they are identifying possible MWEs in texts, what factors affect their chunking decisions and whether or not learners ponder over the meanings of new chunks are still open to investigation.

Altogether, this review of these classroom-based studies suggests it would be useful to conduct another classroom-based project also in the awareness-raising approach but with necessary additions and changes to its operationalization and with different instruments for measuring learning gains. Such a study might shed more light on how an awarenessraising intervention like text-chunking can facilitate L2 learners' acquisition of the MWEs they are exposed to. The next section will elaborate the motivations for the current study from what has been revealed in previous intervention studies reviewed so far in this chapter, especially from Jones \& Haywood (2004), Boers et al. (2006) and Stengers et al. (2010). 


\subsection{What might be the elements for an optimal pedagogical intervention for the uptake of MWEs?}

The aim of this section is two-fold. First, it reiterates all the elements that have been shown to be effective for the acquisition of MWEs among L2 learners in previous intervention studies. Second, it provides justification for the research design in the present study with a view to filling the gap left in the search for an optimal pedagogical intervention. Obviously, the choice of elements in a pedagogical intervention depends markedly on the context where the project is conducted. Hence, an outline of the EFL context in Vietnam and research into Vietnamese learners' knowledge of MWEs will start the section.

\subsubsection{More about the MWE learning scenario in Vietnamese context}

The non-immersion learning context of Vietnam in this project is different from the contexts in the studies mentioned above. This difference in context provides an additional insight into the investigation of the awareness-raising approach. Jones \& Haywood (2004) carried out their study in the UK where the learners could enjoy ample exposure to the target language. The experiments in Boers et al. (2006) were also conducted in a part of the world (Flanders in Belgium) with abundant out-of-class exposure to English (through the media, the internet, TV, film, etc.). The different amounts of language exposure in different contexts may affect learners' sensitiveness to the MWEs they might have encountered previously. Put differently, in such an EFL context with restricted language exposure as Vietnam, learners are less likely to have developed frequency-based intuitions about which word strings in a text qualify as MWEs. For these learners it must often be difficult to evaluate whether a given word string is a common expression, if they have no latent memories of seeing/hearing it before. This consideration naturally casts doubt on the feasibility of learner-centred MWE identification tasks in such EFL contexts and suggests more scaffolding may be necessary for the learning activities in the current project.

Research conducted so far in Vietnamese context has revealed limited knowledge of MWEs in English. For example, Nguyen and Webb (2016) investigated receptive knowledge of verb-noun and adjective-noun collocations at the first three 1,000-word frequency levels among 100 Vietnamese university students majoring in English. The 
research findings indicated that the participants did not reach the mastery of collocational knowledge at any word frequency level. Tran (2013) examined the knowledge of 50 frequently used idioms among 74 Year 1 and Year 2 English-major students and found that the learners' competence of figurative language was very limited. The author then called for more attention in the language teaching curricula to improve the learners' knowledge and production of MWEs in Vietnam. The limited knowledge of the phraseological behaviour of words among Vietnamese learners might be attributed to the limited language exposure as well as the limited awareness of the learners, and possibly the teachers, about the ubiquity of MWEs and the importance of their acquisition. It follows, then, that pedagogical interventions to stimulate the acquisition of MWEs in Vietnam would be welcome. Now that the context has been detailed, the next subsection will justify the learning condition selected for the present project.

\subsubsection{What elements might be effective for the typical EFL context in this study?}

Bearing in mind the language context with the participants' possible limited command of MWEs, the research design of the current study entails several core elements that combine into a conducive learning condition for the target learners of this study (see Figure 2.1).

Figure 2.1. Elements of the current research project

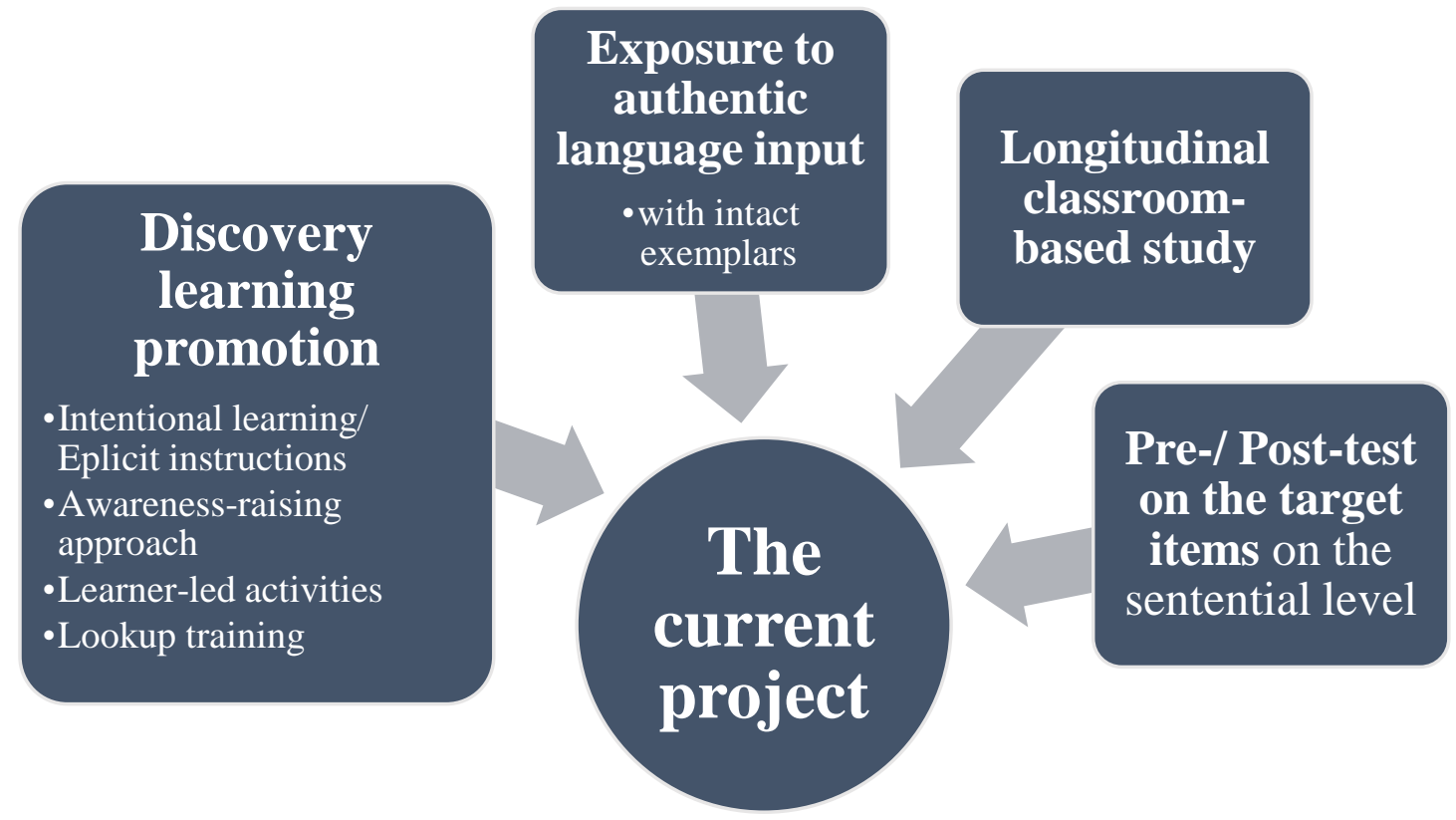

Figure 2.1 shows that the present study shares some common grounds with Jones \& Haywood (2004), Boers et al. (2006) and Stengers et al. (2010). Also, several elements 
were added in an attempt to optimize the practice of text-chunking (Lewis, 1993, 1997) in classrooms. More specifically, this study shares the appreciation of authentic input that accommodates more exposure to intact exemplars. Further, it shares the design of a longitudinal study instead of being a one-off experiment, taking into account the consideration that raising awareness takes time. The departure from the earlier studies involves the setup of a discovery learning condition that supports independent acquisition of MWEs and the utility of pre- and post-tests that focus directly on the target items occurring in the texts used in the course.

The discovery learning condition proposed in this study follows the awareness-raising approach and accommodates opportunities for the learners to explore the phraseological behaviour of the language from input material on their own. In other words, this project aims to scaffold the EFL learners along their ways to become independent in their MWE acquisition. The learning condition consists of four features which are elaborated below.

\subsubsection{Intentional learning and awareness-raising approach}

My argument for the present study is that teachers' explicit instructions to promote intentional learning of MWEs and to raise the learners' awareness of MWEs are essential in this research context. First, as the review of intervention studies earlier in this chapter has pointed out, the incidental learning condition is not enough on its own for learning. The learners' uptake of MWEs is likely to be very slow if it solely depends on incidental learning, even when the frequency of target items has been manipulated. Cobb (2018) warned that besides very frequent MWEs listed in Shin \& Nation (2007) or Martinez \& Schmitt (2012), other MWEs, despite being known to native speakers, are not frequent in natural language. Explicit teaching therefore can make up for the slow accumulation of MWEs from language input due to the low frequency of occurrences by directing the learners' attention to essential phrasal items. Second, previous research conducted in a Vietnamese context has also proved the effectiveness of the intentional learning condition (Ha, 2017; Le-Thi, Rodgers, \& Pellicer-Sánchez, 2017; Tran, 2012). This call for a focus on explicit teaching is understandable in such an EFL context with very limited exposure to the target language. The key sources of input in an instructed language context are authentic documents, textbooks and teacher-talk (Meunier, 2012, p. 113). That said, there are still many discrepancies between corpus-based research findings and the use of oral 
and written language input introduced in textbooks (Meunier, 2012), which means the input from textbooks might not represent the pervasiveness of MWEs in real life language use. Therefore, in an EFL context where most of the teachers are non-native speakers and therefore might not be a fruitful source of teacher talk in English, what teachers can do best for their learners is to direct their attention to the most important aspects of vocabulary to acquire through explicit instructions. It was found in Le-Thi et al.(2017) that explicit teaching combined with incidental exposure to MWEs occurring in textbooks proved more effective than when teachers only worked on the traditional instructions from textbook exercises.

Conversely, as analysed above, it is unrealistic to rely on deliberate in-class -focused study as the sole channel for acquisition. Thornbury (2002) asserted that only an awareness-raising approach can help teachers and learners to cope with the enormous number of formulae and quasi-formulae available. Therefore, according to Nation (2013), a substantial part of acquisition will need to rely on opportunities for learner-autonomous acquisition and on learners' ability to employ strategies that make the best of those opportunities. Hence, in this project, I propose to dedicate precious and limited classroom time to the training of skills and the build-up of the learning habit among students so that they would pay more attention to the MWEs occurring beyond classroom language exposure. These features are in common with Jones \& Haywood (2004), Boers et al. (2006), and Stengers et al. (2010).

Figure 2.2. The proposed setting up of an autonomy-scaffolding learning condition

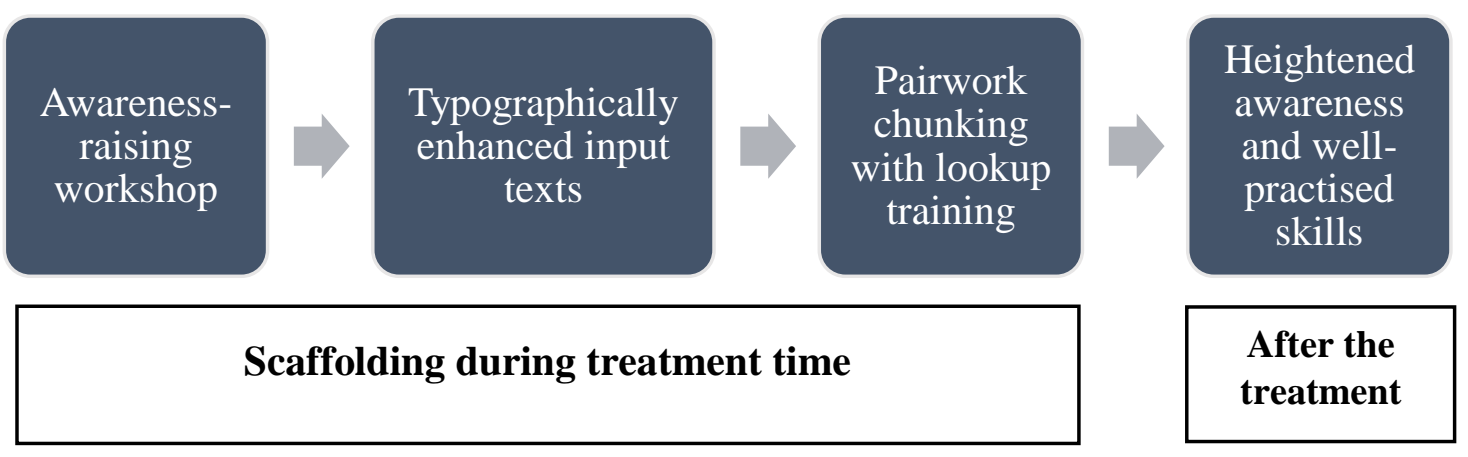

Figure 2.2 illustrates how discovery learning might be promoted throughout a treatment time of an autonomy-scaffolding learning condition. The explicit instructions to raise learners' awareness of the pervasiveness and significance of MWEs in L2 language 
acquisition would be implemented in a separate workshop before the actual intervention time. Subsequently, the learners would be given input texts with highlighted MWEs for a couple of weeks. During these weeks, they would also be trained to make use of lookup resources (see Section 2.7.2.3 below). It was hoped that by the time the students started doing the chunking activities on their own, they would have more concrete ideas about what a MWE was. After ten weeks' time of intervention, the students were expected to be more sensitive to MWEs in the target language they were exposed to and to be able to use lookup resources to verify the MWE status of different word strings. They were also expected to be able to translate these heightened awareness and well-practised lookup skills into their independent intentional acquisition of MWEs. The essence of this discovery learning lies in the pairwork chunking activities which will be mentioned in the next subsection.

\subsubsection{Student-led learning activities}

In the current project, students were asked to work in pairs to find MWEs in texts, that is, to do the text-chunking activities. This pair work was believed to be beneficial in at least three ways.

First, when learners scan texts for instances of MWEs collaboratively, this increases the likelihood that MWEs will be spotted because at least one of the members recognizes them. According to Hunston (2002), 'students are motivated to remember what they have worked to find out' (p. 170). Second, as found in Newton (1995), negotiation of meaning between learners is beneficial for the retention of vocabulary. Doing text-chunking in pairs would give the learners more chance to negotiate both the forms and meanings of the phrasal items under consideration. Third, when learners worked in pairs, it would be possible to record their negotiations. The analysis of these negotiations would possibly yield interesting qualitative data about learners' direction of attention and their strategies to identify MWEs when chunking, or MWE discovery strategies, which has been underexplored so far. Previous studies on learners' vocabulary discovery strategies (e.g. Fan, 2003; Gu \& Johnson, 1996; Schmitt, 1997, 2010) mostly focused on the learning of single words.

Another difference from previous studies is that in this proposed pairwork chunking activity, students would be trained to verify if the word strings they picked out were 'real' 
MWEs by themselves, instead of relying on their teachers. Hence, instead of being the reference for standardized English, teachers would just act as advisers or supporters that the students could consult when they had difficulty using the recommended lookup resources. This empowerment to the learners would make the chunking activity studentled, which might help them become more active and explorative learners in their MWE learning process. That said, to realize this empowerment, it needs to be ascertained that the learners are equipped with appropriate lookup skills to achieve accuracy in their independent MWE verification. The next subsection provides further explanation and justification about the need for lookup training.

\subsubsection{Lookup training}

Two kinds of look up activities were used in the present study so that learners could verify whether the word strings they extracted from authentic texts were common expressions in English. These activities were consulting online dictionaries and consulting an online corpus. These online resources have the advantages of being free and accessible to the learners. It needs to be remembered, however, that learners may find consulting dictionaries - let alone an online corpus - far from straightforward (e.g., Kim, 2018; Komuro, 2009; Laufer, 2011). In this intervention, it was therefore essential to give the students assistance with this in the early stages of the treatment.

Assistance with consulting dictionaries was given through recommending the ones that paid attention to the collocational behaviour of words. The use of online corpora is a less familiar activity for learners than dictionaries. Therefore, while the use of online dictionaries might be more familiar to the learners, it might not be the case with corpus consultation. Interest is growing in the potential benefits of presenting learners with concordance lines to illustrate use as a way of helping them tackle MWE-focused exercises (e.g., Chan \& Liou, 2005; Cobb, 2018; Daskalovska, 2015) or of using corpusbased resources for learners to consult as they engage in writing tasks (e.g., Chen, 2011; Geluso, 2013; Lai \& Chen, 2015; Wu, Witten, \& Franken, 2010) or - less often - in speaking tasks (e.g., Aston, 2015). Conversely, investigations into learners' attitudes to the usage of corpora as a resource for learning have uncovered some complications for the learners such as the not-so-user-friendly interface or the difficulties in interpreting the search output (Chambers, 2005; Chambers \& O’Sullivan, 2004; Yoon \& Hirvela, 2004). 
Therefore, as a part of the discovery learning setup, demonstration and training of corpus use for the verification of MWEs would be provided.

To sum up, these were the elements this current project would include judging from what had been done in literature. It was expected that the combination of these elements in the new research design for a new learning context would reveal more insights into the effects of text-chunking activities (Lewis, 1993, 1997). It can be said that the operationalization of the text-chunking approach in this study lies somewhere between Jones \& Haywood (2004) on the one hand and Boers et al (2006) on the other.

\subsection{Research questions}

This study aimed at seeking answers to three main research questions which were broken into several sub-questions as follows.

1. Does the task of extracting MWEs from texts with the aid of online resources positively affect learners' acquisition of these MWEs?

2. To what extent do learner- and item-related factors affect the learners' learning gains of the target MWEs?

3. Do learners use strategies during those text-chunking activities? If yes, what are they?

3.1. What factors influence learners' intuitive extraction of MWEs from authentic texts? How successful are learners in using those factors?

3.2. How do learners engage with the meanings of word combinations they perceive as established MWEs? How successful are they in doing so?

3.3. How do the learners decide on what MWEs are worth learning?

4. What are the effects of extracting MWEs from reading texts on learners' awareness of MWEs and their own learning strategies?

4.1. Does the course make significant changes to students' awareness of the ubiquity of MWEs and the importance of acquiring them?

4.2. Does the course make significant changes to the MWE learning and lookup strategies of the learners?

4.3. What are learners' perceptions of the benefits and limitations of online dictionaries and COCA in their MWE acquisition? 


\subsection{Conclusion}

This chapter has provided an overview of recent intervention studies on the acquisition of MWEs among L2 learners. The overview underpins the motivations for conducting the present study in pursuit of an effective pedagogical approach to accelerate the learning of MWEs. The overview of previous research has led to the research questions listed above. The next chapter will detail how each step of the study was implemented. 


\section{CHAPTER 3 - METHODOLOGY}

\subsection{Introduction}

This chapter outlines the blueprint of this entire study with details about the research design, the research setting, the participants, the input materials and target items, the data collection instruments, the research procedures and the data analysis. Each section will answer questions of what, why, and how for these essential components. Let us now explore these components one by one.

\subsection{Research design}

\subsubsection{Mixed methods research approach}

This study adopts a mixed methods research approach (Creswell, Plano Clark, Gutmann \& Hanson, 2003) with a view to finding answers to the research questions mentioned in Chapter 2. Recently mixed methods research design has received growing interest among applied linguistics researchers and has become a research approach of choice in this field (Ivankova \& Creswell, 2009; Riazi \& Candlin, 2014). The strengths of this approach include the ability to triangulate data and the complementarity of results from different methods to support and explain each other (Greene, Caracelli, and Graham, 1989). This means the researcher benefits from the merits of both qualitative and quantitative methods. While the quantitative components can provide a systematic, rigorous and tightly controlled data analysis approach, the qualitative components can supplement the findings with answers to the why and what was going on questions. This is perhaps particularly pertinent in this study, in which the sample size is not very large $(n=54)$, which, at the same time makes the qualitative analysis of the data manageable.

Of the different types of mixed methods research approaches available, the design of concurrent quantitative and qualitative mixed methods research, or side-by-side design (Flick, 2014) was selected and applied. In this design, qualitative data is collected within the quantitative experimental design, between the pre-test and post-tests, and interpretations are based on both quantitative and qualitative data (Creswell et al., 2003). The adoption of this approach is also to provide a broader picture of possible factors affecting learners' MWE awareness and acquisition. In the next sections, the different 
components of data are detailed (as illustrated in Figure 3.1), beginning with the quantitative and moving on to the qualitative components. Section 3.8 below will further detail the format and the development of each of these data collection instruments. In the subsections that follow, I will focus on justifying my choice of these components for the aims of this study.

Figure 3.1. Different components of the research design

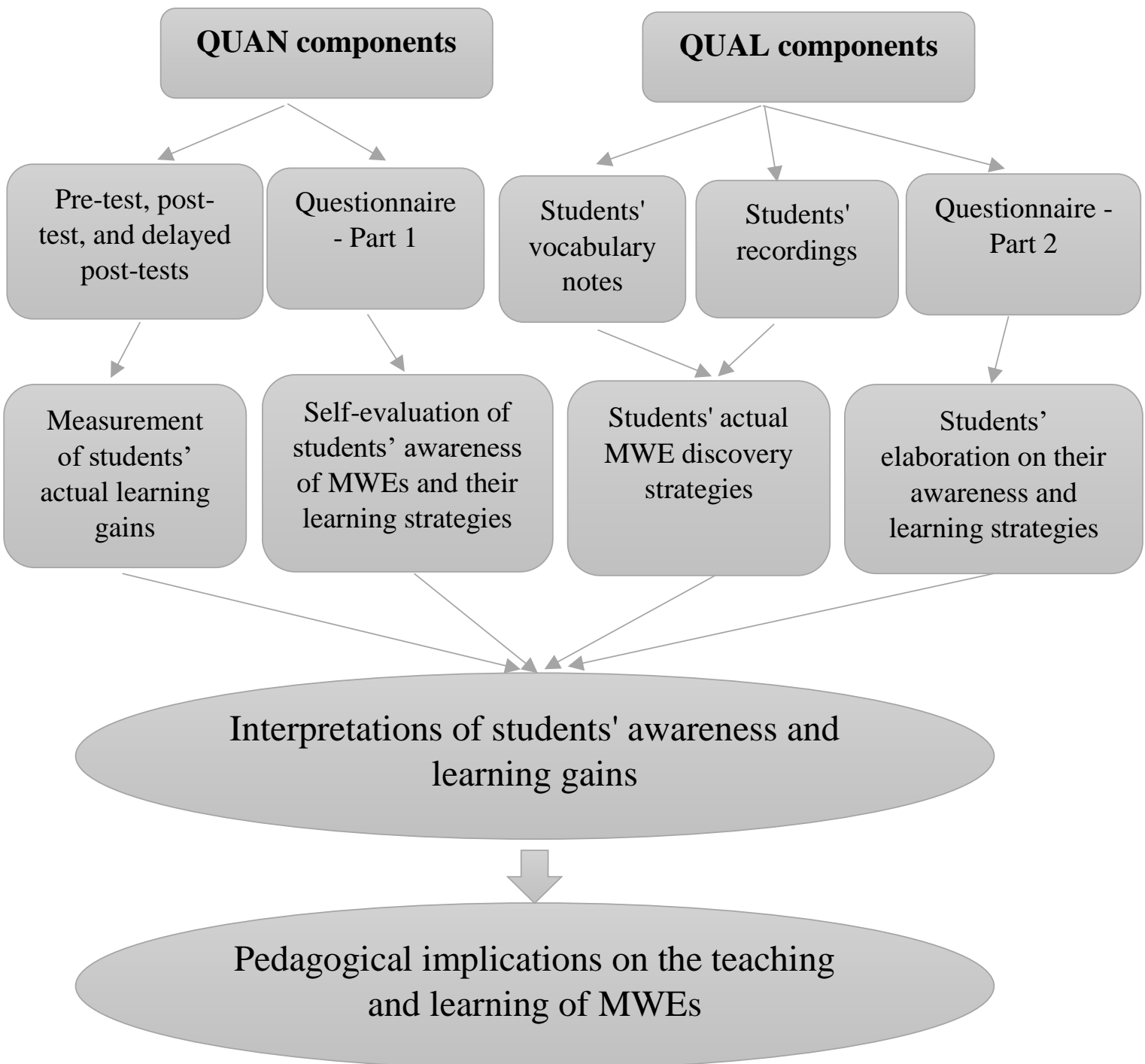

\subsubsection{Quantitative components}

The quantitative components of data for this research involve the use of MWE tests, including pre-test, immediate post-test and delayed post-test after a five-month gap, and a Likert-scale immediate and delayed questionnaire. The MWE recall test was used to measure the learners' learning gains of the target items, and the questionnaire was 
designed with a view to investigating the learners' possible changes in the awareness of MWEs and their learning strategies.

The reasons underpinning my choice of these instruments for the quantitative components of data include their popularity and the efficiency. Language tests have been used in numerous intervention studies to quantify learners' learning gains (e.g., Durrant \& Schmitt, 2010; Komuro, 2009; Laufer, 2011; Peters, 2012; Webb, Newton \& Chang, 2013). These tests can provide a convenient and time-efficient way to gauge students' language improvement. It is undeniable that designing a vocabulary test to measure exactly what is supposed to be measured is far from an easy job. That said, having a test of target items for the comparison of pre-treatment and post-treatment results is what previous studies on text-chunking lack and is one of the gaps this study aims to fill (as pointed out in Chapter 2). Regarding the use of questionnaires, this type of data collection instrument can help researchers access participants' beliefs and self-evaluation of their own behaviours. Rather than interviews, questionnaires are less time-demanding, and students might keep their identity unknown, which may have a positive impact in encouraging students to give unbiased responses. According to Mackey \& Gass (2005, p.93), questionnaires allow researchers to gather 'information that is typically not available from production data alone'. In this study, the datasets collected from the MWE test and the questionnaire will serve as triangulation for the qualitative data (see below).

\subsubsection{Qualitative components}

The qualitative components of data for this research include the students' audiorecordings of their in-class discussions while extracting MWEs from reading texts in pairs, students' vocabulary notes and Section 2 of the questionnaire with open-ended questions (see Figure 3.1). The recordings were collected only from the experimental group since no text-chunking activities were implemented in the comparison counterpart (see Section 3.9 for further detail). The vocabulary notes and questionnaires were collected from both groups.

There are several reasons for the inclusion of the qualitative components of data in this study. First, while quantitative approaches have been extensively used in studies on raising the awareness of EFL/ ESL learners of formulaic language (e.g. Boers et al, 2006; Jones \& Haywood, 2004, Stengers et al., 2010), qualitative components have not been 
included in such studies. The question of what is going on when learners are doing these activities has not been sufficiently answered. To fill this gap, I decided to examine students' in-class audio-recordings for the most influential factors affecting learners' attention to potential MWEs in texts. I believed that during their discussions and negotiations in a normal classroom environment, students' thoughts and intuitions about phraseological behaviours of words would be revealed. In addition, the students' vocabulary notes might show evidence of whether those in the experimental group could extract established MWEs and whether their performances would be shown to be better than those in the comparison group. Also, learners' responses to the questionnaire's openended questions will elaborate on their answers to the close-ended questions.

In a nutshell, while the vocabulary tests, students' recordings and their vocabulary notes may reveal their actual performances and learning gains, the questionnaires report on their beliefs and thoughts on their own strategies and learning habits. Figure 3.1 shows the complementary relationship among different components in this study's mixed-methods research design.

\subsubsection{A longitudinal classroom-based research project}

The study was a longitudinal classroom-based research project with a within-subject and between-subject design. The project lasted throughout 15 weeks of the whole semester, including the time for exam and questionnaire administration (see Figure 3.2 for the research flowchart).

More specifically, two intact classes were randomly assigned as the experimental group and the comparison group. Two different teaching approaches were implemented in parallel with the two groups during reading lessons (see Section 3.8.4 below for detailed classroom procedures). While the experimental group were extracting MWEs from texts in post-reading activities, the comparison group were undertaking more meaning-focused activities. As illustrated in Figure 3.2, prior to the ten reading lessons, the first two weeks were spent administering vocabulary tests in the two groups, and the third week was used for an orientation workshop with the experimental group and a pre-treatment reading session in the comparison group. The last two weeks of the semester were spent on posttreatment test and questionnaire administration. The comparison of different datasets from the vocabulary tests, questionnaires and classroom notes between and within the 
groups after the 15 weeks and five months later makes this study a longitudinal one with a within-subject and between-subject design. It is worth noting that I was working as a teacher researcher throughout the entire project with both groups of participants, which helped to guarantee that both learning conditions in the classrooms were the same except for the treatment.

Figure 3.2. The research flowchart

\section{Week 1 \& 2: \\ - Vocabulary Size Test \\ - Pre-treatment Vocabulary Test}

Week 3: Pre-treatment reading and items-to-learn pickup

- Follow-up discussions (Comparison group)

- Orientation workshop on MWEs (Experimental group)

\section{0 weekly reading sessions in both groups}

Week 14 \& 15:

- Immediate Post-treatment Vocabulary Test

- Immediate Questionnaire

Five months later:

- Delayed Post-treatment Vocabulary Test

- Delayed Questionnaire

\subsection{Research setting}

Vietnam is a monolingual context with the vast majority of the population speaking Vietnamese. English is the foreign language most commonly taught at schools and universities, which means the research context of this study is an English-as-a-ForeignLanguage (EFL) context. Generally speaking, Vietnamese learners' exposure to the target language is limited to classroom lessons and homework assignments if any. These homework assignments urge students to make use of available resources of English on the Internet as a means to increase their exposure to the language. Though a number of active learners may be interested in extensively reading and watching English resources accessible to them, it would be too ambitious to expect this to be the case for many learners. 
This project was conducted in the Faculty of English in a teacher training university. Similar to other Bachelor of Arts programmes in Vietnam, the English-major undergraduate programme in this faculty lasts for four academic years, or eight semesters. Annually, the faculty admits around 60 to 100 new students. In 2016, there were 56 thirdyear students, all of whom volunteered to take part in this study. Judging from a typical timetable of third-year students, on average these students had 17 class hours of exposure to English in classrooms each week. It is noteworthy that English is encouraged to be used as the only medium of instruction in the lessons. However, lecturers may use Vietnamese at times. These students were also given numerous pairwork and groupwork assignments in different subjects on a regular basis, which required them to use extracurricular resources in English. Obviously, the time these students were exposed to English may depend considerably on individual students' learning attitude and learning style.

Thus, this research setting can be said to be a typical EFL context in which the participants depended to a large extent on the classroom activities and teacher instructions to develop their skills and knowledge of English. In the context of this type, more orientation and assistance from teachers were felt necessary and beneficial to the learners.

\subsection{Participants}

The participants, as aforementioned, were 56 Vietnamese university students whose major was Teaching English to Speakers of Other Languages (TESOL). They were all aged between 19 and 20, and they were in the first semester of their third year at university, or the fifth semester of their entire bachelor programme. For logistic reasons, two intact classes were assigned to the experimental $(n=26)$ and the comparison condition $(n=30)$. Out of the 56 participants, only three were male, which is typical of teacher training courses in Vietnam. During either the immediate or the delayed post-test, two students from the comparison group were absent from the tests, leaving 54 participants whose data were used for analysis in this project (see Table 3.1). It is worth noting that all the $p$ values reported in this thesis are two-tailed. 
Table 3.1. The participants

\begin{tabular}{llcc}
\hline & & Experimental group & Comparison group \\
\hline Total number $(\mathbf{N})$ & & 26 & 28 \\
\hline Gender & Male & 1 & 1 \\
\cline { 2 - 4 } & Female & 25 & 27 \\
\hline Age & & $19-20$ & $19-20$ \\
\hline Nationality & & Vietnamese & Vietnamese \\
\hline Vocabulary size mean & $p=.281$ & $4,500(S D=1051)$ & $4,810.70(S D=1048)$ \\
\hline
\end{tabular}

These participants were selected for two reasons. First, they were expected to be at the intermediate level of English. To be admitted to this TESOL bachelor program, students had to pass the university entrance exam in English. Also, as prescribed in the four-year curriculum for TESOL pre-service teachers at this university, the students' English proficiency level was aimed to reach level A2 of the Common European Framework of Languages (CEFR) at the end of their first year and level B1 at the end of their second year. During the time of this data collection, the participants were training to achieve level B2. This sample of intermediate participants was deemed appropriate for this project, of which the aim was to foster independent learning of formulaic language. According to Nation (2013), when learners have grasped the highest frequency words, it is time to train them in the strategies to independently acquire the bulk of vocabulary. Second, judging from the time frame of the training course, I decided that collecting data from the thirdyear students allowed me time to go back for the delayed data collection five months later before they started their teaching practicum.

It is worth acknowledging that the group division in this study with two intact classes was not a random group selection. Just like what is possible in any intact class, the two groups were both heterogeneous with students possibly at different points in the intermediate level spectrum and with different learning aptitudes and attitudes. The above information was found in the curriculum designed for the entire course. That said, no evidence could be collected about the actual language proficiency level of these participants to see whether or not they were at the proficiency level expected at the time. Since vocabulary size has been found to be a strong predictor of general proficiency (Iwashita, Brown, McNamara, \& O’Hagan, 2008; Schmitt, Jiang, \& Grabe, 2011; Staehr, 2009), to ascertain that the two groups had comparable vocabulary knowledge and general proficiency prior to the experiment, the Vocabulary Size Test 14,000-word version (VST) (Nation \& Beglar, 2007) was administered as a paper-and-pencil test. This yielded mean scores of 
4,500 word families $(\mathrm{SD}=1,051 ; 95 \% \mathrm{CI}[4,096,4,903])$ and 4,810.70 $(\mathrm{SD}=1048 ; 95 \%$ CI $[4,422,5,198])$ for the experimental group and the comparison group, respectively. This suggests the comparison group was slightly more proficient, although a t-test for independent samples indicated that the difference did not reach statistical significance $(t$ $=-1.09 ; p=.281)($ see Table 3.1).

\subsection{Input materials}

Each week one new reading text was used, which required a selection of ten texts for the ten-weeks of reading lessons. The reading materials were identical for both groups, and both groups spent the same amount of time on activities with these reading materials, but the way the texts were exploited differed between the treatment conditions (see further details in Section 3.8.4).

In the light of the Input Hypothesis (Krashen, 1985), which puts significant emphasis on the impact of comprehensible language input for language acquisition, a careful choice of reading materials was made, which would hopefully promote the learning of the target MWEs among the students. The choice of these materials was based on a set of five criteria, including the authenticity of the texts, the accessibility, the availability of MWEs for students' exploration, the topics, and the length. These criteria were developed from the selection of reading materials in Boers et al. (2006).

The first criterion to be borne in mind was the authenticity of the chosen texts. As asserted by Wood (2002), abundant exposure to authentic language, be it oral or written, plays a significant part in boosting students' MWE acquisition. Given the EFL context of this study in which contrived textbook language was the chief source of input, the provision of authentic target language input was deemed essential. Therefore, graded readers were not considered suitable. Another reason is that the students' experience in this project was expected to serve as a preparatory step for their independent reading and accumulation of MWEs later. After all, the ultimate purpose of classroom learning is self-study. At this stage, the teacher would walk students through their exploration into natural language to, hopefully, equip them with strategies to pick out the worth-learning MWEs in the reading texts they encounter in both intensive and extensive reading.

The second criterion was the accessibility of the chosen texts. The choice of accessible input materials from free and reliable resources might encourage the students to make 
more use of those sources in the long run. With the popularity of portable devices among the students, online resources such as free news and magazine websites and online educational platforms were ranked high in my list of options. More specifically, the website of Psychology Today magazine (https://www.psychologytoday.com) and Ted-Ed platform (https://ed.ted.com) were explored for possible input texts. Psychology Today is a magazine founded in 1967 covering a wide range of topics including behaviours, health, work and other psychology-related topics. Ted-Ed is a platform for learners and educators with an enormous library of original animated lessons on various educational topics. These sources were expected to provide exciting, motivating and diverse language input that learners can be exposed to day by day. This kind of input material was expected to both promote learners' incidental vocabulary learning and bring them the enjoyment and eagerness to gain knowledge about the world, as stated by Nation (2005) about the benefits of extensive reading.

The third and fourth criterion was the abundance of MWE occurrences in the reading texts and the topics which might appeal to the target students. In other words, the texts should not only be well written and contain a good number of MWEs but should also be about intriguing topics that people in this age group can relate to. Two selecting steps were taken to meet these criteria. First, I chose a number of articles on some popular themes from the online version of Psychology Today and some frequently viewed videos on Ted-Ed. Next, I intuitively identified the potential chunks in the readings and checked the status of those chunks in dictionaries and COCA. This process was double-checked by my supervisor. Reading texts containing a high number of MWEs were then shortlisted.

The last criterion is appropriate text length. The time allowance of around 40 minutes per session put a constraint on the length of the selected passages. Piloting of the planned reading and text-based activities indicated that texts of about 600 words would be suitable.

The consideration of the above five criteria led to the selection of ten texts. Five articles were taken from Psychology Today website, and the other five were transcripts of TedEd videos. Table 3.2 below illustrates the choice of the input materials with details on their topics, length and sources (see Appendix 1 for the reading texts). 
Table 3.2. Input materials

\begin{tabular}{llll}
\hline $\begin{array}{l}\text { Week } \\
\text { No. }\end{array}$ & Reading topics & $\begin{array}{l}\text { Word } \\
\text { count }\end{array}$ & Sources \\
\hline 1 & 3 tips to boost your confidence & 567 & Ted-Ed videos \\
\hline 2 & Ending procrastination & 590 & Psychology today \\
\hline 3 & 5 tips to improve your critical thinking & 637 & Ted-Ed videos \\
\hline 4 & Do opposites really attract? & 519 & Psychology today \\
\hline 5 & Why is it so fun to be scared? & 625 & Ted-Ed videos \\
\hline 6 & $\begin{array}{l}\text { In politics, a closed mouth gathers no foot - or } \\
\text { free press }\end{array}$ & 423 & Psychology today \\
& $\begin{array}{l}\text { How playing sports benefits your body and } \\
\text { your brain }\end{array}$ & 563 & Ted-Ed videos \\
& Routines: comforting or confining? & 597 & Psychology today \\
\hline 8 & What is depression? & 629 & Ted-Ed videos \\
\hline 9 & A recipe for school success & 455 & Psychology today \\
\hline 10
\end{tabular}

The selected materials from the two sources were alternately used in the ten weeks. Of note, modality of input was not treated as a variable of interest in this study. Alternating these two types of input texts was merely intended to keep the students in both groups interested through providing variety not only in topics but also in discourse genre and modality. In those weeks when a Ted-Ed video was used, students would watch the video before working on the transcript and answering comprehension questions. All the comprehension questions were either based on the available lessons on Ted-Ed or designed by me. The questions were kept simple and mainly served the purpose of engaging the students with the content of the reading passages.

\subsection{Target items}

For the design of the MWE pre- and post-test, 52 target items were selected in this study. In this section, I will outline the steps I took and the principles I considered in the selection process of this bank of items. Generally speaking, four principles determined different steps that were taken for the selection of the target items.

First, the target items needed to be established MWEs. As briefly mentioned above in the section of Input Materials, in the first step, I intuitively identified possible MWEs in each of the chosen texts. This step and the next step of verifying the MWE status of potential word strings were similar to how the experimental students would be instructed in their MWE extracting activities. More specifically, to ascertain the multiword items were well established MWEs, I first checked if they were included in at least one of three online 
dictionaries: Macmillan Dictionary (http://www.macmillandictionary.com), Cambridge Dictionary (http://dictionary.cambridge.org), and Longman Dictionary (http://www.ldoceonline.com/dictionary). These are also the dictionaries recommended to the learners (see Section 3.8.1 for the justifications of these recommendations). Identified word strings (e.g. common belief; leading cause; weigh options; seek treatment) which were not found in the dictionaries would be checked for frequency in the Corpus of Contemporary American English (COCA) (https://corpus.byu.edu/coca) (Davies, n.d.). For this purpose, I used the website's query syntax to capture inflectional/ morphological variants (e.g., weigh, weighs, weighed, weighing) as well as instances with substitutable function words (e.g., the/these/those). The MWEs later selected as target items through this procedure all yielded 200+ hits in COCA (in January 2018). It is worth noting that mutual information (MI) scores which are commonly used as a measure of collocational strength were not consulted, for several reasons. One reason is that the types of target MWEs were not restricted to just collocations like verb + noun, adjective + noun. MI scores can give a clear indication of the strength of word partnerships, but in the case of longer expressions such as idioms (e.g. birds of a feather flock together) or standardized sentence stems (e.g. Studies show that, it is worth noting that) using MI scores is less straightforward. Another reason is that since considered word strings would be checked in dictionaries first, MWEs with the highest MI scores, i.e. MWEs with the strongest partnership, should appear there already. This means the check of MI score might be redundant.

Second, the target items should be those possibly not yet fully acquired by this group of learners. Undeniably, it was far from an easy job to identify such items prior to the actual pre-test. I decided to initially create a shortlist of MWEs from the bigger pool based on my more than ten years of teaching experience with students of similar profiles. I also discussed these with two other teachers who were currently working with the students in the study and therefore understood their vocabulary level. These discussions helped to narrow the number of MWE candidates down to those possibly beyond the students' productive phraseology. It is worth mentioning that the shortlisted MWEs were combinations of relatively high-frequency words. One reason is that as found out by Martinez \& Murphy (2011), many MWEs consist of high-frequency words. Another 
reason is that there might be a gap between the learners' knowledge of single words and their knowledge of MWEs comprised of those single words.

Third, the bank of target items consists of a variety of MWEs. The selected items should cover a wide variety of MWEs and range from non-compositional to compositional in terms of meaning. One justification derives from the authentic nature of the texts. It is a fact that a text of non-manipulated language is normally comprised of lexical phrases of diverse types. Hence, there are low chances of frequent re-occurrences of certain phrases or one certain type of MWEs (Boers \& Linstromberg, 2009; Boers et al., 2014). Previous studies focusing on the acquisition of one type of MWEs such as verb-noun collocations or adjective-noun collocations (e.g. Webb, Newton \& Chang, 2013; Pellicer-Sanchez, 2017) needed to use graded readers or modify the texts to ensure sufficient target items. As posited by Cobb (2018, p.198), while these studies found an interesting result that acquisition is sensitive to frequency, 'it is also highly limited as a pedagogy for formula acquisition'. Therefore, it was felt necessary to preserve the diversified nature of MWEs in authentic texts and demonstrate this diversity in the choice of target items. Table 3.3 shows the categorization of the selected target items by formal properties.

Table 3.3. Categorization of target items

\begin{tabular}{llll}
\hline MWE type & Target items & MWE type & Target items \\
\hline $\begin{array}{l}\text { Prepositional } \\
\text { phrases }\end{array}$ & at first glance & Verb & amount to \\
& at one's disposal & phrases & come to terms with \\
at stake & (incl. Verb + & face something head-on \\
& from time to time & Noun & make it through \\
for starters & collocations & make recommendations \\
in the face of sth & \& phrasal & meet one 's goals \\
in the mood & verbs) & seek treatment \\
in the short/long term & & shed (some) light on \\
in the spotlight & & sift through \\
on autopilot & & strike alan + Adjective + \\
on average & & pose \\
& out of the blue & & take (full) advantage of \\
& & & take (time) off \\
& & & turn out \\
& & & trigger a (strong) reaction \\
& & & weigh different options
\end{tabular}




\begin{tabular}{|c|c|c|c|}
\hline $\begin{array}{l}\text { Adjective + } \\
\text { Noun } \\
\text { collocations }\end{array}$ & $\begin{array}{l}\text { critical thinking } \\
\text { daily grind } \\
\text { fizzy drink } \\
\text { haunted house } \\
\text { leading cause } \\
\text { common belief }\end{array}$ & $\begin{array}{l}\text { Other } \\
\text { conventional } \\
\text { expressions }\end{array}$ & $\begin{array}{l}\text { a sea of }+ \text { Noun } \\
\text { all walks of life } \\
\text { birds of a feather flock } \\
\text { together } \\
\text { every now and then } \\
\text { fight or flight (response) } \\
\text { it stands to reason that } \\
\text { not to mention } \\
\text { opposites attract } \\
\text { put one's foot in one's } \\
\text { mouth } \\
\text { when it comes to } \\
\text { studies show that }\end{array}$ \\
\hline $\begin{array}{l}\text { Adjective + } \\
\text { Preposition }\end{array}$ & $\begin{array}{l}\text { allergic to } \\
\text { associated with } \\
\text { obsessed with } \\
\text { prone to }\end{array}$ & $\begin{array}{l}\text { Noun }+ \\
\text { Noun } \\
\text { collocations }\end{array}$ & $\begin{array}{l}\text { pep talk } \\
\text { press conference } \\
\text { vending machine }\end{array}$ \\
\hline
\end{tabular}

It is well acknowledged that different types of MWEs pose different learning challenges (see, e.g., Boers, Eyckmans \& Lindstromberg, 2014b, for discussion). For example, idioms (e.g., out of the blue) are obviously more likely to cause comprehension problems than semantically transparent collocations (e.g., make a recommendation). On the other hand, learners may be less likely to pay attention to the latter, precisely because they pose no interpretation challenge, and this may explain why L2 collocational accuracy tends to develop very slowly in the absence of pedagogic intervention (e.g., Laufer \& Waldman, 2011). However, the diversity of target items was not considered a methodological problem in the present intervention study, because the aim of the intervention under examination here is to raise learners' awareness of phraseology in general and to engage them with the phraseological units that happen to be manifested in authentic texts.

Fourth, to ensure an appropriate distribution of items from across the ten texts, around five MWEs were chosen from each text for inclusion in the multi-word pre-test. That said, it was tricky sometimes since the choice of target items also depended on abovementioned criteria, not to mention the language used for each topic. Table 3.4 below indicates the distribution of 52 target items in the input texts of ten weeks. 
Table 3.4. Distribution of target items in texts

\begin{tabular}{|c|c|c|c|}
\hline $\begin{array}{l}\text { Week } \\
\text { No. }\end{array}$ & Reading topics & Target items & \\
\hline 1 & $\begin{array}{l}3 \text { tips to boost } \\
\text { your confidence }\end{array}$ & $\begin{array}{l}\text { face something head-on } \\
\text { in the face of }\end{array}$ & $\begin{array}{l}\text { on average } \\
\text { pep talk } \\
\text { strike alan + Adjective + } \\
\text { pose }\end{array}$ \\
\hline 2 & $\begin{array}{l}\text { Ending } \\
\text { procrastination }\end{array}$ & $\begin{array}{l}\text { in the mood } \\
\text { wear out }\end{array}$ & \\
\hline 3 & $\begin{array}{l}5 \text { tips to improve } \\
\text { your critical } \\
\text { thinking }\end{array}$ & $\begin{array}{l}\text { a sea of } \\
\text { at first glance } \\
\text { at one's disposal } \\
\text { critical thinking }\end{array}$ & $\begin{array}{l}\text { meet one's goals } \\
\text { sift through } \\
\text { weigh different options }\end{array}$ \\
\hline 4 & $\begin{array}{l}\text { Do opposites } \\
\text { really attract? }\end{array}$ & $\begin{array}{l}\text { Birds of a feather flock } \\
\text { together } \\
\text { common belief } \\
\text { opposites attract }\end{array}$ & $\begin{array}{l}\text { shed (some) light on } \\
\text { when it comes to }\end{array}$ \\
\hline 5 & $\begin{array}{l}\text { Why is it so fun to } \\
\text { be scared? }\end{array}$ & $\begin{array}{l}\text { a haunted house } \\
\text { fight or flight (response) } \\
\text { for starters }\end{array}$ & $\begin{array}{l}\text { make it through } \\
\text { prone to } \\
\text { trigger a (strong) reaction }\end{array}$ \\
\hline 6 & $\begin{array}{l}\text { In politics, a } \\
\text { closed mouth } \\
\text { gathers no foot - } \\
\text { or free press }\end{array}$ & $\begin{array}{l}\text { allergic to } \\
\text { in the spotlight } \\
\text { It stands to reason that }\end{array}$ & $\begin{array}{l}\text { take (full) advantage of } \\
\text { press conference } \\
\text { put one's foot in one's } \\
\text { mouth }\end{array}$ \\
\hline 7 & $\begin{array}{l}\text { How playing } \\
\text { sports benefits } \\
\text { your body and } \\
\text { your brain }\end{array}$ & $\begin{array}{l}\text { all walks of life } \\
\text { come to terms with } \\
\text { in the short/ long run }\end{array}$ & $\begin{array}{l}\text { not to mention } \\
\text { obsessed with } \\
\text { studies show that } \\
\text { turn out }\end{array}$ \\
\hline 8 & $\begin{array}{l}\text { Routines: } \\
\text { comforting or } \\
\text { confining? }\end{array}$ & $\begin{array}{l}\text { at stake } \\
\text { daily grind } \\
\text { every now and then }\end{array}$ & $\begin{array}{l}\text { on autopilot } \\
\text { take (time) off }\end{array}$ \\
\hline 9 & $\begin{array}{l}\text { What is } \\
\text { depression? }\end{array}$ & $\begin{array}{l}\text { associated with } \\
\text { from time to time } \\
\text { leading cause }\end{array}$ & $\begin{array}{l}\text { out of the blue } \\
\text { seek treatment }\end{array}$ \\
\hline 10 & $\begin{array}{l}\text { A recipe for } \\
\text { school success }\end{array}$ & $\begin{array}{l}\text { amount to } \\
\text { fizzy drink }\end{array}$ & $\begin{array}{l}\text { make recommendations } \\
\text { vending machine }\end{array}$ \\
\hline
\end{tabular}

\subsection{Recommendations for lookup tools}

As this project aimed to find out how successfully students can make use of online resources to verify potential MWEs found in reading texts, a couple of online dictionaries and COCA were recommended to the participants. This section will present my justifications of those choices. 


\subsubsection{Recommendations of online dictionaries}

The online dictionaries I recommended to the learners were Macmillan Dictionary (http://www.macmillandictionary.com), Cambridge

Dictionary (http://dictionary.cambridge.org), and Longman Dictionary (http://www.ldoceonline.com/dictionary). These were also the dictionaries I used myself for the verification of target items as mentioned above. Among the dictionaries, it was observed that Macmillan Dictionary was new to this group of students. The other two were quite familiar to the students since their paper-based versions were commonly used in Vietnam.

The recommended dictionaries were reviewed during the preparatory stages of the study and were selected for their wide coverage of MWEs and user-friendly interface when it comes to finding information about MWEs and word partnerships. For example, on typing a word into the search box (e.g., play), hyperlinks to MWEs starting with this word are automatically displayed (e.g. play a joke on someone; play a part/role) (see Figure $3.3)$.

Figure 3.3. A screenshot of Macmillan Dictionary for the search of 'play'

\section{DICTIONARY}

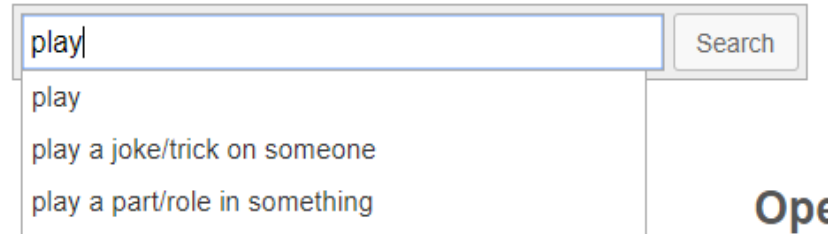

play about

play-act

play/act dumb

play/act the fool

play-acting

play along

play around

Open Dictionary

Crowdsourced dictionary

$\begin{array}{ll}\text { Lexiter } & \text { dingus } \\ \text { bunfight } & \text { single-use } \\ \text { apostille } & \text { binge learning } \\ \text { hard pass } & \text { bread earner } \\ \text { Brexhaustion } & \text { caliginous }\end{array}$

Add a word About Archive 


\section{recommendation - definition and synonyms $\star \star$}

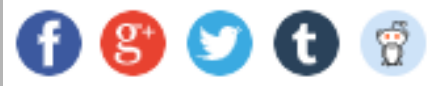

nOUN [COUntable/UnCountable] (4) Pronunciation/,rekamen'dei $\int(\partial) n /$ Word

\section{Contribute to our Open Dictionary}

1 a suggestion or piece of advice about how to solve a problem, deal with a situation etc make a recommendation (to someone): The Bill incorporates a number of recommendations made by the committee. recommendation for: recommendations for reform

Learners may thus find out relatively fast if a given phrase is one which lexicographers consider a unit worth drawing attention to. That said, it then remains up to the user to click on the hyperlink to find out more about the phrase, including its meaning and usage. When clicking on the single word (e.g., recommendation) rather than on a phrase displayed (if any), the user will typically be shown the word (or an example of the word in use) accompanied by a strong collocate (e.g., make a recommendation) in these dictionaries, where the word partnership is made salient by means of typographic enhancement (bold font) (see Figure 3.4). According to a study by Dziemianko (2014), such typographic enhancement facilitates the intake of collocational information by dictionary users, more so than adding a list of collocations in a separate box at the end of the entries.

Besides the user-friendly interface, these dictionaries are based on large corpora, with the lexicographers' careful consideration of the phraseological behaviours of words (see Figure 3.5 for an example of how word partnerships are attended to in the interface of Macmillan Dictionary). Macmillan English Dictionary was built using corpora developed by the Université Catholique de Louvain in Belgium with a general corpus of 1.6 billion words, not to mention specialized corpora including the Macmillan Curriculum Corpus and Learner Corpora. Likewise, Cambridge English Dictionary was based on the 
Cambridge English Corpus of more than 1.5 billion words, and the Cambridge Learner Corpus, which is a collection of exam scripts by students from all over the world.

Figure 3.5. A screenshot from Macmillan Dictionary for the search of 'importance'

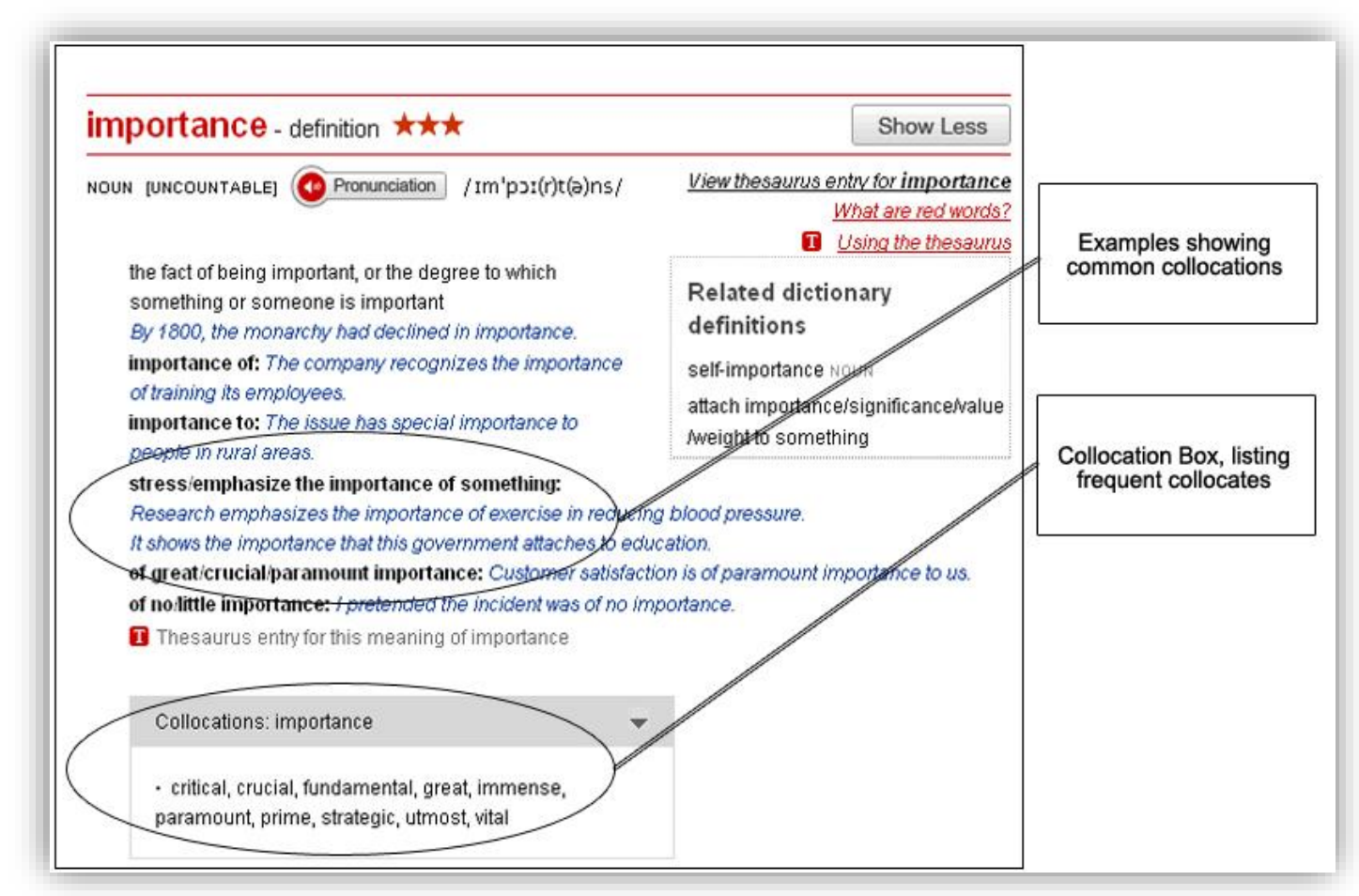

The use of Learner Corpora in the development of the dictionaries assisted the lexicographers to highlight and exemplify correct collocations and offer alternatives to over-used vocabulary items, among other benefits to the learners (Gilquin, Granger, \& Paquot, 2007). The large databases and the lexicographers' exploitation of those huge corpora make these dictionaries suitable suggestions for the students in this study.

\subsubsection{Recommended use of COCA}

Another resource which was introduced to students for their verification of MWEs was COCA (Davies, n.d.). This corpus-based website was recommended to the students mainly because it was the largest freely-available and probably the most widely-used corpus of English. The corpus contains more than 560 million words of text, and it is equally divided among spoken, fiction, popular magazines, newspapers, and academic texts.

When asked about their knowledge of COCA during sessions arranged for pre-tests, $100 \%$ of students in the experimental group reported that they had never heard of COCA 
and its potential usefulness for their learning. Given the possible complications to the learners when interacting with corpora such as the grammaticality of corpus findings or the difficulty of interpreting the results yielded by corpora (Chambers, 2005; Chambers \& O’Sullivan, 2004; Yoon \& Hirvela, 2004), Bernardini (2004: 26) recommends starting students with tasks that guide them to the same outcome. Following this recommendation, with the COCA first-time users in this project, I decided to give the students one central task, which is extracting the frequency of candidate MWEs from COCA as a way of comparing the usefulness of these phrases. It was hoped that when the students were familiar with the COCA interface, they might be interested in exploring other affordances of the corpus.

In the first two weeks of the reading sessions, I demonstrated the formation of search queries to find out the frequency of phrases in COCA. At the same time, the students were given a handout (see Appendix 2 for the quick COCA guide) adapted from the manual available on the COCA website. This adaptation was felt desirable in case the students found the actual COCA manual too long and complicated. The handout consists of stepby-step instructions for students to extract the frequency of a combination of words in COCA, including how to formulate different kinds of query syntax.

\subsection{Research procedures}

\subsubsection{Human ethics}

The data collection was approved by the Human Ethics Committee of Victoria University of Wellington, New Zealand (see Appendix 3 for the Ethics Approval). The students in both groups were informed they were taking part in a study about language learning, but the precise purpose of the study was only disclosed to them after completion of the data collection. Informed consent to use their data for the purpose of this research project was given by all the participants (see Appendix $4 \& 5$ for the Information Sheet and Consent Form).

In this project the researcher was at the same time the teacher in the reading sessions. Each week, 40 minutes of the class time for both groups was reserved for work with the teacher-researcher on short reading texts that supplemented the students' regular EFL programme. This working time with supplementary materials was presented to the students as an initiative to further enhance their reading skills and vocabulary knowledge. 
The students were well-informed that all their performances in the classroom as well as in the tests would be collected and used solely for the study and would not affect the ongoing and end-of-term assessment in students' reading component or other language skills courses.

\subsubsection{Research timeline}

The whole data collection phase took place in the course of four months, which is the length of an entire semester, including the exam time. Table 3.2 below indicates my specific jobs during this time.

Table 3.5. The research timeline

\begin{tabular}{|c|c|}
\hline Timeline & Research steps \\
\hline $\begin{array}{l}\text { August } 29^{\text {th }}- \\
\text { September } 11^{\text {th }} 2016\end{array}$ & $\begin{array}{l}\text { - Vocabulary Size Test and the pre-test on MWEs } \\
\text { - Pre-treatment reading session and the orientation } \\
\text { workshop with the experimental group about the nature } \\
\text { and functions of multiword expressions. } \\
\text { - Pre-treatment reading session with the comparison group }\end{array}$ \\
\hline $\begin{array}{l}\text { September } 12^{\text {th }}- \\
\text { December } 04^{\text {th }} 2016\end{array}$ & $\begin{array}{l}\text { - Treatments with two groups of participants: including ten } \\
\text { teaching sessions in both groups, collection of audio- } \\
\text { recordings from experimental students' discussions during } \\
\text { classroom activities and end-of-class vocabulary notes } \\
\text { from both groups (see Figure } 3.6 \text { for the class procedures } \\
\text { in both groups). }\end{array}$ \\
\hline $\begin{array}{l}\text { December } 5^{\text {th }}-11^{\text {th }} \\
2016\end{array}$ & - Administering the immediate post-test \\
\hline $\begin{array}{l}\text { December } 12^{\text {th }}-19^{\text {th }} \\
2016\end{array}$ & - Immediate questionnaire \\
\hline \multicolumn{2}{|c|}{ A FIVE - MONTH GAP } \\
\hline May 2017 & $\begin{array}{l}\text { - Delayed post-test } \\
\text { - Delayed questionnaire (a week later) }\end{array}$ \\
\hline
\end{tabular}

Details about the orientation workshop and classroom procedures will be discussed in the next sub-sections. 


\subsubsection{Orientation workshop}

The purpose of the orientation workshop was to raise the experimental students' general awareness of the phraseological behaviour of words. The workshop took place one week prior to their ten weekly text-chunking sessions. In this workshop, the students were informed by the teacher of the ubiquity of MWEs in authentic English, and this was illustrated with numerous examples (of MWEs not targeted in the actual experiment). This session ended with a brief chunking activity. A short text which was not part of the treatment materials was used. The students attempted to identify potential MWEs in this short passage before comparing their own ideas with mine. In the same week, the comparison group also worked with the same reading passage used at the orientation workshop for the experimental group. The difference was that these students only read the text, answered comprehension questions and did some discussions related to the text content, but were not alerted about the occurrences of MWEs in the text.

\subsubsection{Class procedures - Teacher and Student Roles}

Within the 15 weeks of the entire span of the semester, 10 weeks were dedicated to the weekly reading lessons. In each of these sessions, I was trying to ensure that identical teaching steps were conducted in both groups except for post-reading activities. The same conventional steps in the reading lessons included lead-in activities, reading and

Figure 3.6. The class procedures in both groups
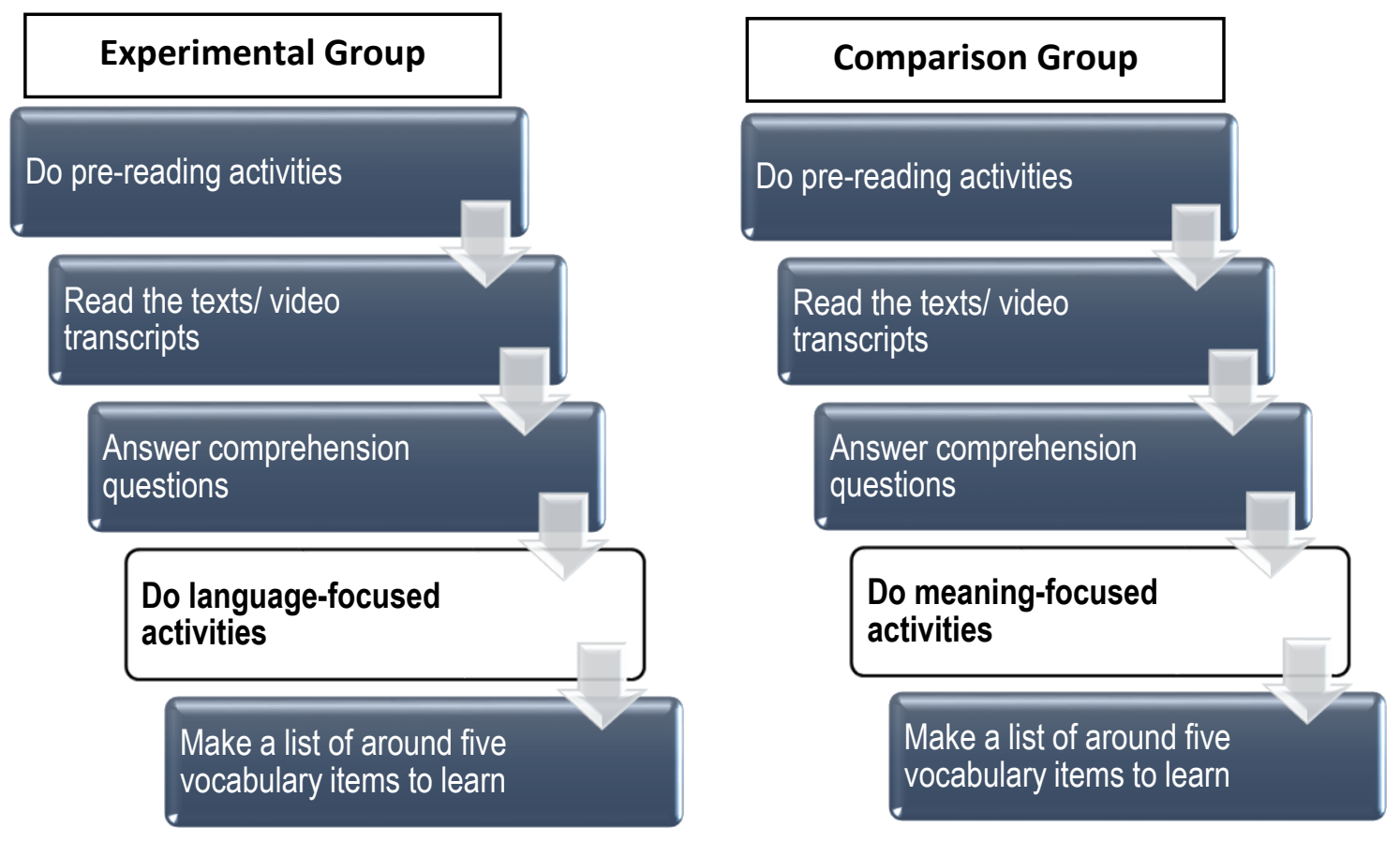
answering comprehension questions. Subsequently, while the language-focused activities were conducted for the post-reading tasks in the experimental group, meaning-focused activities were used in the comparison group.

Figure 3.6 illustrates the similarities and differences in the class procedures conducted in the two groups. Of note, the activities carried out in the experimental group were language-focused or form-focused in the sense that the time was solely devoted to explicit instructions and deliberate attention to MWEs in the reading texts, as defined by Nation (2013). However, a slight diversion from the well-accepted concepts of language-focused approaches is that no vocabulary exercises were designed for particular MWE items. The meaning-focused speaking activities in the comparison group refer to activities in which the learners' attention was focused on the main ideas of the reading texts, rather than the linguistic aspects (Nation, 2013). Specific activities for each group will be detailed below.

\subsubsection{Post-reading activities in the experimental group}

In the first two weeks, some MWEs were underlined in the texts distributed among the experimental group. This typographical enhancement was used as an implicit call for the learners' attention to the phenomenon of formulaic language. In week 1, when the learners finished reading the texts and answering the comprehension questions, I introduced to the students useful online dictionaries as aforementioned. Also, I distributed the COCA quick guide, briefly showed the students the COCA interface and demonstrated how to search for the frequency of a phrase. In week 2, students started to look up the meanings of underlined phrases in pairs if necessary and the frequency of those phrases in COCA. I supervised the students' lookups and assisted them when they had any questions. The students were also asked to compare the frequency indicators they found with those found by other pairs to see if they were following the guidelines correctly (see Figure 3.7).

From week 3 to week 10, the MWE extracting and lookup pairwork activities were repeated every week in the experimental group. It is worth mentioning that the pairs were encouraged to remain the same throughout the treatment. Thus, the students only changed partners in the case where there were some absentees. The students were instructed to discuss in pairs to identify possible chunks in the reading texts, first from their hunches, then to check for the inclusion of these phrases in the online dictionaries and their frequency in COCA. 
Figure 3.7. MWE extracting activities in the experimental group
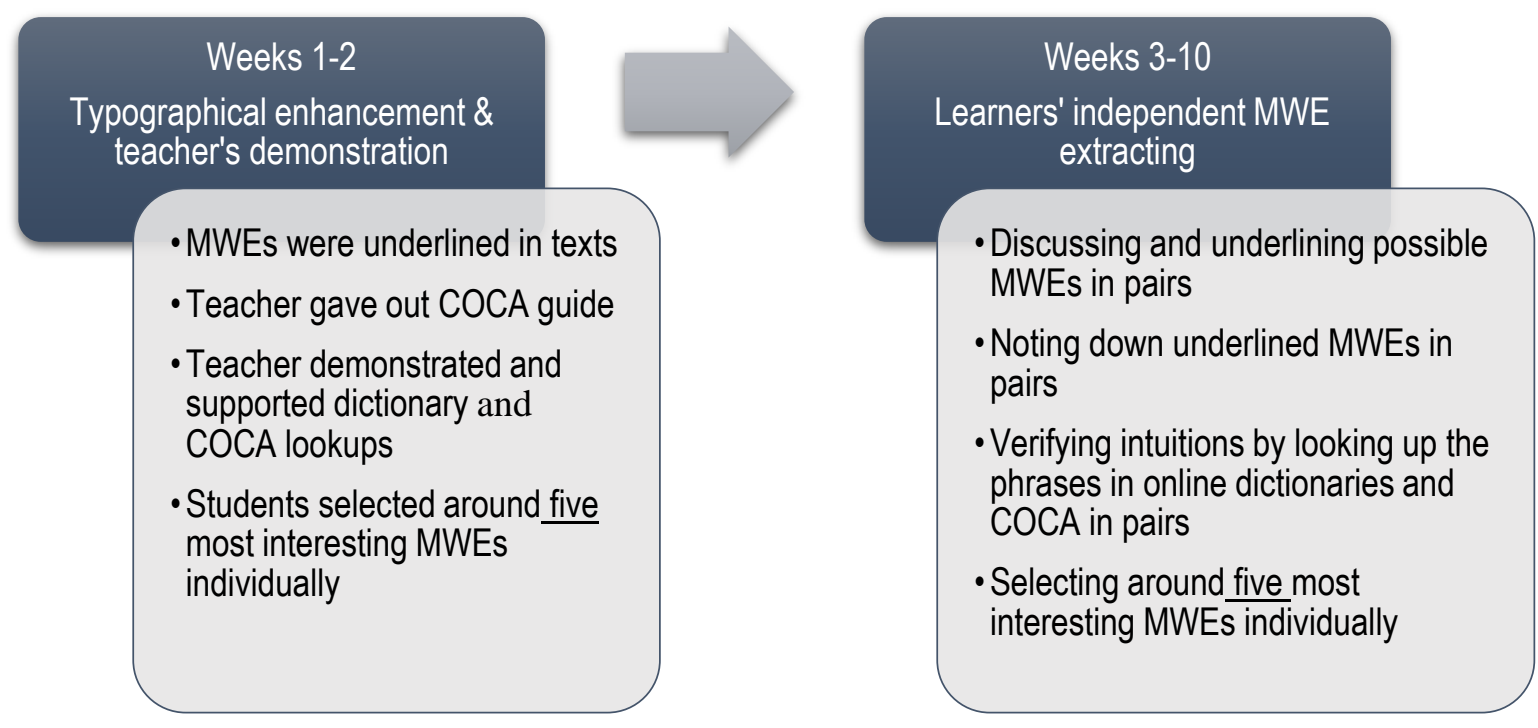

Students were told to do the activity in two steps. In the first step, pairs of students, after having answered all the comprehension questions to ascertain that they had taken in the text content, would go over the entire reading text in search of instances of MWEs together. Some guiding questions for the students' discussions on their intuitive MWE identification included:

i. What word strings do you speculate are MWEs?

ii. Why do you think so?

iii. Does your partner agree with your ideas? Why? Why not?

In the second step, students would look up the vocabulary items that had drawn their attention, either to confirm their chunk status or to understand their meanings, with the help of an online dictionary of their choice and COCA. The researcher gave explicit instructions that the discussions should be recorded in the first step and the output of the second step with the phrases, their meanings (either guessed based on the context or extracted from a dictionary) and their frequency on COCA should be noted down in a given template (see Appendix 6 for template of pairwork MWE lists and samples of students' worksheet).

In addition to this autonomous students' work, I went over possible MWEs in the text of the previous week at the beginning of each week's reading session. Students would then 
have another chance to look at the text and highlight those MWEs they might have been interested in but had skipped if any. At the end of each lesson over the ten weeks, the students were invited to note down around five vocabulary items they deemed worth learning.

\subsubsection{Post-reading activities in the comparison group}

To make sure the amount of time the learners interacted with the reading materials was comparable between the two groups, a wide range of post-reading activities were implemented in the comparison group. These activities required the students to refer to the ideas from the reading passage. Typical examples of these activities are having pairwork/ groupwork discussions in response to given open questions, designing comprehension questions in groups based on the reading contents, reconstructing the content of the texts from some keywords, and creating mind maps from the reading texts.

Table 3.6 below details the post-reading activities carried out by the comparison group during the 10 weeks.

Table 3.6. Post-reading activities in the comparison group

\begin{tabular}{|c|c|c|}
\hline $\begin{array}{l}\text { Week } \\
\text { No. }\end{array}$ & Reading topics & $\begin{array}{l}\text { Meaning-focused activities in the comparison } \\
\text { group }\end{array}$ \\
\hline 1 & 3 tips to boost your confidence & $\begin{array}{l}\text { - Discuss in groups in response to guided } \\
\text { questions }\end{array}$ \\
\hline 2 & Ending procrastination & $\begin{array}{l}\text { Do jigsaw reading, then answer multiple- } \\
\text { choice questions } \\
\text { - Discuss in groups in response to guided } \\
\text { questions }\end{array}$ \\
\hline 3 & $\begin{array}{l}5 \text { tips to improve your critical } \\
\text { thinking }\end{array}$ & $\begin{array}{l}\text { - Discuss in groups: Would you rather...? } \\
\text { (Creative and critical thinking in imaginary } \\
\text { situations) }\end{array}$ \\
\hline 4 & Do opposites really attract? & $\begin{array}{l}\text { - In groups, make questions for other groups } \\
\text { about the text }\end{array}$ \\
\hline 5 & Why is it so fun to be scared? & - Answer multiple-choice questions \\
\hline 6 & $\begin{array}{l}\text { In politics, a closed mouth } \\
\text { gathers no foot - or free press }\end{array}$ & $\begin{array}{l}\text { - In groups, read and make questions about } \\
\text { the text }\end{array}$ \\
\hline 7 & $\begin{array}{l}\text { How playing sports benefits } \\
\text { your body and your brain }\end{array}$ & $\begin{array}{l}\text { - Read and create a mind map of the benefits } \\
\text { of playing sports }\end{array}$ \\
\hline 8 & $\begin{array}{l}\text { Routines: comforting or } \\
\text { confining? }\end{array}$ & $\begin{array}{l}\text { - Read and put the picked-out sentences into } \\
\text { the numbered spaces in the text }\end{array}$ \\
\hline 9 & What is depression? & - Do a note-taking activity \\
\hline $\mathbf{1 0}$ & A recipe for school success & $\begin{array}{l}\text { - Read and rearrange the given keywords to } \\
\text { rebuild the text }\end{array}$ \\
\hline
\end{tabular}




\subsection{Data collection instruments}

This section describes the format and the development of various data collection instruments used in this project. The instruments include the vocabulary tests, students' audio-recordings, their vocabulary notes and post-treatment questionnaires.

\subsubsection{MWE test design}

To gauge the gains in students' form-recall productive knowledge possibly resulting from the treatment, a pre-treatment test was developed. This same test was also used as the post-treatment test and the delayed post-test to quantify the students' progress. (see Appendix 7 for the vocabulary test)

The format of the test was cued recall which required the test takers to produce the full forms of 52 target MWEs from given initial letters and paraphrases of meanings. Hence, the test contained 52 gapped sentences. There are some reasons for using this test format. Several of the MWEs were semantically transparent (e.g. a sea of, make recommendations, meet one's goals), and in that case the learning difficulty does not lie with comprehension or meaning recall but rather with learners' recall of the precise lexical composition of the expressions. In any case, a test which requires learners to recall an expression to match a given semantic prompt indirectly tests knowledge of the meaning of the target expression as well.

Several steps were taken before the final version of the MWE test was produced. First, the sentences used in the test were based on concordance lines extracted from COCA. The sentential contexts were chosen because they pointed to the meaning of the missing expression. Second, I ensured that the words occurring in these sentence prompts were likely to be familiar to the students. To do this, I ran the sentences through the lexical profiler on Tom Cobb's Compleat Lexical Tutor (Cobb, n.d.) and replaced low-frequency words with higher-frequency words. In the end, $98 \%$ of all the tokens in the sentence prompts belonged to the 4,000 most frequent word families of English, according to Nation's (2012) British National Corpus (BNC)/ Corpus of Contemporary American English (COCA. Given the students' mean scores of 4500 and 4810.70 on the VST, the sentence prompts appeared unlikely to pose comprehension problems for these participants. For example, in the following context of the phrase 'Studies show that', the word 'reflex' turned out to be in the $6^{\text {th }}$ thousand of the BNC-COCA word level, which 
was above the average vocabulary size of the participants. I therefore changed 'a permanent "huh?" reflex' into 'hearing problems'.

The initial context extracted from COCA concordances:

S $\mathrm{s}$ consistent exposure to sounds above 100 decibels can leave you with a permanent "huh?" reflex. (the phrase to introduce a new scientific finding) Answer: Studies show that

The modified context:

S $\mathrm{t}$ consistent exposure to sounds above 100 decibels

can leave you with some hearing problems. (the phrase to introduce a new scientific finding) Answer: Studies show that

Third, just in case the sentence prompts might yet be insufficient to point to the meaning of the to-be-supplied MWE, paraphrases of the MWEs were provided after most of the sentences as well. The learners were required to complete the blanks for each missing word of the target MWE, and the first letter of the missing words was provided in order to avoid near-synonymous substitutes.

The following is an example of a test item:

My family was really cautious about keeping the media away and keeping my life private, because there's so much that could go wrong with being $\mathrm{t}$ s__. (a situation in which you get a lot of public attention) Answer: in the spotlight

Fourth, the first draft of the vocabulary test was piloted with two of the EFL teachers of the student-participants to ascertain once more that the prompts were sufficient to elicit the target MWEs. On the teachers' recommendation, the students in the actual experiment were given 40 minutes to complete the 52-item test, so as to ensure time pressure would not be an issue. Furthermore, these two teachers also recommended arranging the test in an ascending order of difficulty based on their knowledge of the students' level. For example, MWEs like from time to time, on average, vending machine, fizzy drinks were considered less difficult to the students than prone to, a sea of, trigger a (fierce) reaction, amount to or in the face of. 
In order to not alert the comparison group about the focus on MWEs, one or two component words of certain items were revealed, leaving only single-word gaps, as in this example. There were two such case out of 52 test items.

$\mathrm{A} \mathrm{f} \_$drink is a sweet drink without alcohol that has bubbles.

Answer: fizzy

The students were instructed to leave the gaps unfilled if they did not know the answers. The items in the immediate post-treatment test were kept identical to the pre-test but the order was jumbled to prevent students from memorizing the previous test. This test was re-administered five months after the immediate post-test with a view to gauging the longer-term effect of the awareness-raising intervention. The time interval of five months between the two post-tests was decided for two reasons. First, the growth in learners' awareness needs some time to result in any learning effects. More often than not, it might take months, or even years, to turn the awareness into new learning habits and into learning gains later on, especially in the case of formulaic language development, as confirmed in longitudinal studies like Li \& Schmitt (2010) and Qi \& Ding (2011). Second, this time lapse of five months was also a matter of convenience as it was about the length of a term. During the new term, students of the two groups followed the same curriculum. They also had time to apply what they had grasped during the treatment independently if they wanted to.

\subsubsection{Audio-recordings of students' discussions}

As mentioned in Section 3.8.4 about the class procedures, during their language-focused post-reading activities, the experimental students would be discussing their intuitive MWE identification in pairs and they were asked to self-record their weekly discussions. The collection of these discussions was hoped to reveal the MWE extracting strategies that the learners might be applying.

Students were told to use their personal mobile phones as recorders. This self-recording activity was familiar to the students as they were frequently required to audio and video record themselves for the assignments in other courses. These recordings would then be sent to my email right after each lesson. To minimize the background noise that may come from simultaneous group discussions and affect the quality of the recordings, students 
were instructed to sit around the classroom with a distance from other pairs when doing the activity.

As mentioned previously, pair memberships were expected to remain unchanged during all the eight weeks of the MWE extracting and verifying activities. However, in cases of some absences, students were arranged to work with another partner but still followed the same routine.

\subsubsection{Students' vocabulary notes - individual and pair work}

There are two kinds of vocabulary notes that the students were required to keep and which were collected at the end of each class. The first kind was the individual vocabulary notes which were lists of about five vocabulary items each student would like to learn from the input texts. Students from both groups made these lists and they were collected each week and returned to the students the week after so that students would have the chance to look at those lists again and learn the vocabulary items if they so wished. The purpose of the collection of these notes was two-fold. First, it would help to ascertain whether the experimental group was more drawn to MWEs, as intended by their instructional treatment, than the comparison group. Second, students' noting down and their cognitive effort in shortlisting items they considered worth learning the most was expected to support their learning and memory.

The second kind of vocabulary notes was the pairwork notes from the experimental group. This group was instructed to take notes of their pairwork decisions on speculated MWEs in a given vocabulary note template (see Appendix 6). More specifically, each pair was requested to note down, for each text, phrases they looked up and what they found out about them, including the dictionary students consulted, the meanings from the chosen dictionary or the meaning they guessed and were to a large extent certain about, and the frequency in COCA. The templates for these notes were distributed to the students at the beginning of their discussions. The collection of these notes from the experimental students would help to gauge how successful the students were at identifying MWEs autonomously, with the aid of the online resources they were referred to. Also, it would help to investigate whether it was those MWEs which students looked up and selected (and thus presumably perceived to be comparatively useful or interesting) that stood the best chance of being recalled in the post-tests. 


\subsubsection{Intermediate and delayed questionnaires}

The questionnaire (see Appendix 9 for the full questionnaire) consisted of two sections: Section 1 with 50 Likert-scale items and Section 2 with four open-questions where students could elaborate their ratings to certain items in Section one (see details below). The questionnaire was used twice, once immediately after the course and then again five months later, with some minor changes to fit the time of the questionnaire administration. The purpose of administering the questionnaire twice was threefold. First, the questionnaires would provide the information on the changes in students' awareness of the phenomenon of formulaic language in the target language, if any. Second, the questionnaires were designed to give the researcher a chance to access all the participants' opinions and assessment on what they had done during the treatment time. Third, it was expected that students' MWE learning strategies might also be revealed through these self-reports. Bearing in mind that it takes time to translate people's awareness into their habits and behaviours, the survey was administered twice with a five-month gap to find out whether the effects of the treatment, if any, were durable. It is also worth mentioning that even though the comparison group did not practise the activity of extracting MWEs from the reading texts, the questionnaires were still given to them to see whether any changes in the experimental group's questionnaire responses should be attributed to the specific treatment they had received. In case similar changes emerged for the comparison group, this would cast doubt over said treatment effect.

\subsubsection{Questionnaire format - Section 1}

The first section consisted of 50 items divided into three sub-sections, each of which was supposed to fulfil different objectives prescribed for the questionnaire. In the first subsection, namely 'My awareness of multiword units', items $1.1-1.9$ were aimed at students' awareness of the importance of MWEs. The statements were designed with general ideas about the pervasiveness of MWEs in the language and their importance in the improvement of learners' fluency and comprehension. These ideas had been raised in the pre-course workshop. It was hoped that any differences between the two groups in their awareness after the intervention and any changes in each group along with the time could be detected through the questionnaires. 
Imitating the natural process from awareness to behaviour, in the next sub-section called 'My multiword unit learning strategies', items 1.10 - 1.35 were designed so that the researcher could focus on students' MWE acquisition strategies. These items probed into the techniques and activities included in the umbrella task of extracting MWEs from the reading texts, including paying attention to typographically enhanced vocabulary items, scanning the texts after reading them intensively in class or extensively outside class, being attracted to new combinations of known words, or looking up new combinations in dictionaries or an online corpus. Also, the statements were formulated from the researcher's preliminary observations of students' classroom discussions and her first impressions from their recordings. It is worth mentioning that items $1.23-1.35$ aimed to elicit what would drive students' decisions on whether or not they wanted to memorize a new MWE and what they would do to achieve this goal.

Later on, items $1.36-1.50$ were for students' self-evaluation of the learning effects the treatment had brought to them. To put it another way, this part was to access students' perceptions of the usefulness of either the learning strategies or the online resources recommended to them. Since the comparison group did not receive the treatment, this part was excluded from the questionnaires given to this group.

As briefly mentioned above, Section 1 used the four-point Likert-scale design with statements to which participants could give their own ratings ranging from 1 to 4 , with the corresponding meaning of each value as follows.

$$
\begin{aligned}
& 1=\text { This does not describe me at all. } \\
& 2=\text { This does not really describe me. } \\
& 3=\text { This describes me quite right. } \\
& 4=\text { This describes me perfectly. }
\end{aligned}
$$

As can be seen, there is no neutral point in this scale since the students were expected to make a decision rather than sitting on the fence. In the questionnaires distributed immediately after the treatment, each statement was accompanied by two columns, namely 'before the course' and 'after the course' with a view to eliciting the students' retrospective perception of the vital roles of MWEs and their ways to acquire this language phenomenon in their previous learning experience. These two columns were converted into one called 'your opinion' in the delayed questionnaire five months later. 
Here is an example.

\section{BEFORE AFTER \\ THE THE \\ COURSE COURSE}

I pay more attention to single words rather than combinations of words.

I am interested in combinations of words that have similar structures to MWEs that I have known.

I make an effort to associate a new MWE with other MWEs that I have known (e.g. similar meaning, opposite meaning, same structures, etc.).

\subsubsection{Questionnaire format - Section 2}

Whereas the first section was expected to generate quantitative data on students' awareness, learning strategies, and self-evaluation with pre-designed statements on the topics, the second section with four open questions was designed to give students chances to elaborate their personal ideas on their responses to several items in Section 1. The questions focused on students' preferred resources for vocabulary acquisition, their learning strategies, and their difficulties when using a corpus (with the experimental group). Here is an example.

Are there any difficulties you encounter when using a corpus (e.g. COCA)?

Students' responses to these open-ended questions provided qualitative data for more insight into the participants' awareness and learning habits. One more question was added in the delayed version so that students could state with more details their progress in vocabulary in the five-month period.

The questionnaires were designed, reviewed and amended before they were piloted with two other lecturers in the site faculty. Their feedback and comments on the questionnaire draft were taken into account and translated into modifications in the final version of the questionnaires, including the reduction of some items, and the wordings of the statements to make the ideas clearer to the learners. 


\subsection{Data analysis}

This section outlines how different datasets were processed and analysed.

\subsubsection{Scoring pre- and post-vocabulary tests}

In scoring the test responses, I focused on the accuracy of the lexical composition of the target MWEs rather than the orthographic or morpho-syntactic accuracy of the words supplied. Thus, responses showing correct recall of all the constituent words but exhibiting morphological or spelling errors that did not impede recognition of the words were given credit. Examples include the following:

turn out instead of turned out

common believe instead of common belief

haunting house instead of haunted house

In contrast, no credit was given for incomplete word strings like __talk (pep) and birds of a feather__together (flock), or inaccurate substitutions like public conference (press), accompanied with (associated), come to tend with (terms) and put my fingers in my mouth (foot).

The test scores were computerized for the calculation of descriptive statistics (e.g. mean scores, median, gain scores) and inferential statistics (e.g. Mann-Whitney $U$ test) to find out if the differences in learning gains between the two groups were significant or not. The results guided the interpretation of the effectiveness of the treatment. Also, item-wise analyses were conducted to investigate features of MWEs that could pose different learning burdens on the learners.

\subsubsection{Students' audio-recordings}

Upon receiving students' audio-recordings, I downloaded and stored them in separate folders for each week. At the end of week 10, I could collect 82 recordings, around six hours long in total. These recordings were then carefully transcribed verbatim, yielding 36 pages of texts containing around 20,300 words. The data was later imported into NVivo 11 software for the qualitative coding. The language of students' discussion (L1 or L2) was retained in the transcriptions. 
The coding of the transcribed discussions took two steps. In the first step, I perused the transcription and did the preliminary coding with the initially emerging themes, which were the most commonly mentioned among the students. This step provided initial impressions of the data and some possible directions for analysis. The next step involved looking back at the data with an eye for more details that could support the big themes already coded. For example, the first coding would help me answer such questions as what factors drew students' attention the most when it came to identifying new and worthlearning MWEs, how much discussion they had about those factors, and how often. Meanwhile, the second coding focused on answers to questions like how successful students were in intuitively identifying MWEs based on those factors, both in terms of meaning and form. This step would require processing at a deeper level with the integration of different criteria of MWE verification.

The following criteria were used to verify word combinations discussed by students and to gauge the success of their MWE identification. These criteria are more lenient than the criteria used to select the target items from texts mentioned in Section 3.6. Given that the purpose of this project was to raise the learners' awareness of MWEs with their wide variety, the criteria for a success in students' identification of MWE forms included the appearance of the phrase as an entry in a dictionary and its frequency reaching 50 in COCA, instead of $200+$ as the frequency criterion for the selection of target items. This threshold might be arbitrary, but it did allow, for example, maintain relationships and one thing is for certain to be counted as MWEs, and glorify a victory and adversarial inquisition as combinations which did not meet said criteria. While the criteria for determining successful identification of MWEs can be to some extent arbitrary, determining whether students arrived at a correct meaning of the word strings they examined is more straightforward. The latter evaluation was based on the dictionary meaning of the phrase if it appears in the dictionary on condition that the meaning fitted the context, and this condition also applied to phrases that had not made their way into a dictionary.

The inter-rater reliability was then assessed by me working with a Vietnamese fellow $\mathrm{PhD}$ student who understood both Vietnamese and English, had sufficient knowledge of English teaching and was familiar with Vietnamese learners. This rater was trained before she started working on $10 \%$ of the data. Her work was then compared with my coding 
and the inter-rater reliability coefficient was calculated, which yielded the result of more than $90 \%$ of agreement. Finally, the instances of the emerging themes were tallied to find out the most instrumental themes to be reported and discussed in detail in Chapter 5 of this thesis.

\subsubsection{Students' vocabulary notes}

To answer the question of whether it was the MWEs extracted from the texts which stood the best chance of being remembered, I took the MWEs targeted in the tests that each pair of students noted down in the course of their MWE-extraction activities and compared these students' successful post-test responses on these items to their success rates on MWEs which did not make their way into their notes. The MWEs which individual students already knew at pre-test were excluded from these calculations (i.e., I was concerned with learning gains). Mixed effects logistic regression tests were used to find the association between inclusion of these MWEs in the students' notes and their successful recall in the immediate post-test.

\subsubsection{Immediate and delayed questionnaires}

The two sections of the questionnaire yielded two kinds of data for analysis. From Section 1 with the Likert-scale format, the quantitative data was computed for descriptive statistics. First, internal reliability tests of the 50 items were run with the SPSS analysis package. Then, mean scores and standard deviations were calculated for the comparison between the two groups and for the comparison of changes in the learners' perceptions at different time points of the questionnaire administration. Mixed between-within subjects analyses of variance (ANOVA) were conducted for these comparisons.

With Section 2 of the questionnaire, all the learners' responses to the four open-questions were analysed qualitatively for the shared themes demonstrated by the two groups. When these themes were identified, the percentage of students mentioning each theme was calculated and reported too.

\subsection{Conclusion}

This chapter has detailed different steps that were taken to carry out this project including different principles of the research design, different components of the collected data and 
the methods of data analysis. The next three chapters will report on the findings from the datasets mentioned in this chapter. 


\section{CHAPTER 4 - LEARNERS' PERFORMANCES IN THE MWE RECALL TESTS \& POSSIBLE AFFECTING FACTORS}

\subsection{Introduction}

This chapter aims at depicting the participants' performances in the MWE recall tests and analysing the interplay among different factors affecting learners' learning process during the course. More specifically, this chapter aims to find the answers to these two research questions:

1. Does the task of extracting MWEs from texts with the aid of online resources positively affect learners' acquisition of these MWEs?

2. To what extent do learner- and item-related factors affect the learners' learning gains of the target MWEs?

Two approaches are taken to provide more insight into the students' learning gains of the target MWEs and the possible affecting factors. One looks at the learners and their differences in terms of learning conditions and proficiency (measured by their vocabulary size in this study). The other looks at the target items and their linguistic differences such as their meaning-related features, their frequency, the frequency of their constituent words, and whether or not these items were attended to during the course. The report of findings in answer to each research question will be in the order of these two approaches.

\subsection{Did the intervention positively affect learners' MWE acquisition?}

As aforementioned, the effects of the intervention on the learners' recall knowledge of the target items were examined first through analyses into the test scores of learners at different test times. Later, more investigations into the target items were conducted. Let us look at the results collected from each step one by one.

\subsubsection{The learning gains - Learner analyses}

The MWE recall test scores collected from the pre-test, the immediate post-test, and the 5-month delayed post-test were computed for descriptive and inferential statistics. It is worth noting that among the 52 target items, eight items were enhanced in the first two weeks as a way to scaffold the students before they could extract MWEs from texts on 
their own. These items, including wear out, on average, in the face of, pep talk, in the mood, studies show that, seek treatment, and face (the problem) head-on, were analysed separately, leaving 44 items being investigated for the learners' knowledge improvement from autonomous text-chunking. Table 4.1 below displays the descriptive statistics of the test scores achieved by the two groups in the 44 items (i.e. max score $=44$ ). The mean scores, the medians, the corresponding standard deviations, and the $95 \%$ confidence interval (CI) gauged in the pre-test, the immediate post-test, and the 5-month delayed post-test of the two groups are presented in this table. The changes of test results over time is also displayed in Figure 4.1 below.

Table 4.1. Test scores $(\max =44)$

\begin{tabular}{ccccc}
\hline & Pre-test & $\begin{array}{c}\text { Immediate post- } \\
\text { test }\end{array}$ & $\begin{array}{c}\text { 5-month delayed } \\
\text { post-test }\end{array}$ \\
\hline \multirow{2}{*}{$\begin{array}{c}\text { Experimental } \\
\text { group }(\mathbf{n}=\mathbf{2 6})\end{array}$} & mean & 9.31 & 19.92 & 15.92 \\
\cline { 2 - 5 } & median & 9 & 18.5 & 13 \\
\cline { 2 - 5 } & SD & 4.15 & 8.14 & 8.30 \\
\cline { 2 - 5 } & $95 \%$ CI & $7.72-10.90$ & $16.79-23.05$ & $12.73-19.11$ \\
\hline Comparison & mean & 10.93 & 17.29 & 14.71 \\
\cline { 2 - 5 } group $(\mathbf{n}=\mathbf{2 8})$ & median & 8.5 & 16 & 14 \\
\cline { 2 - 5 } & SD & 5.02 & 8.35 & 6.58 \\
\cline { 2 - 5 } & $95 \%$ CI & $9.07-12.79$ & $14.20-20.38$ & $12.27-17.15$ \\
\hline
\end{tabular}

Since not all sets of scores were normally distributed, the non-parametric alternative for independent-samples T-tests, i.e., the Mann-Whitney $U$ test, was used to test for statistical significance. In the pre-test, there was no statistically significant difference between the two groups on the 44 target items $(z=0.63 ; p=0.52)$. That said, as noted from Table 4.1, there was a non-negligible difference between the two groups' pre-test scores, with the comparison group having an edge over the experimental group, with the mean scores of 10.93 and 9.31 respectively.

The two groups' learning gains (i.e., the students' post-test scores minus their pre-test scores) were compared rather than their post-test scores as such (as recommended in, for example, Lindstromberg, 2016). The descriptive statistics concerning these gain scores are displayed in Table 4.2 and Figure 4.5. This revealed a significant difference $(z=2.48$; $p=.013$ ) in favour of the MWE-focused treatment in the immediate post-test, with a medium-sized effect $(d=0.71)$. This difference in favour of the MWE-focused treatment 
fell short of significance in the delayed post-test, however $(z=1.27 ; p=.204)$. The effect size indicates that the longer-term impact of the treatment was indeed smaller $(d=0.52)$.

Figure 4.1. Test results of the two groups $(\operatorname{Max}=44)$

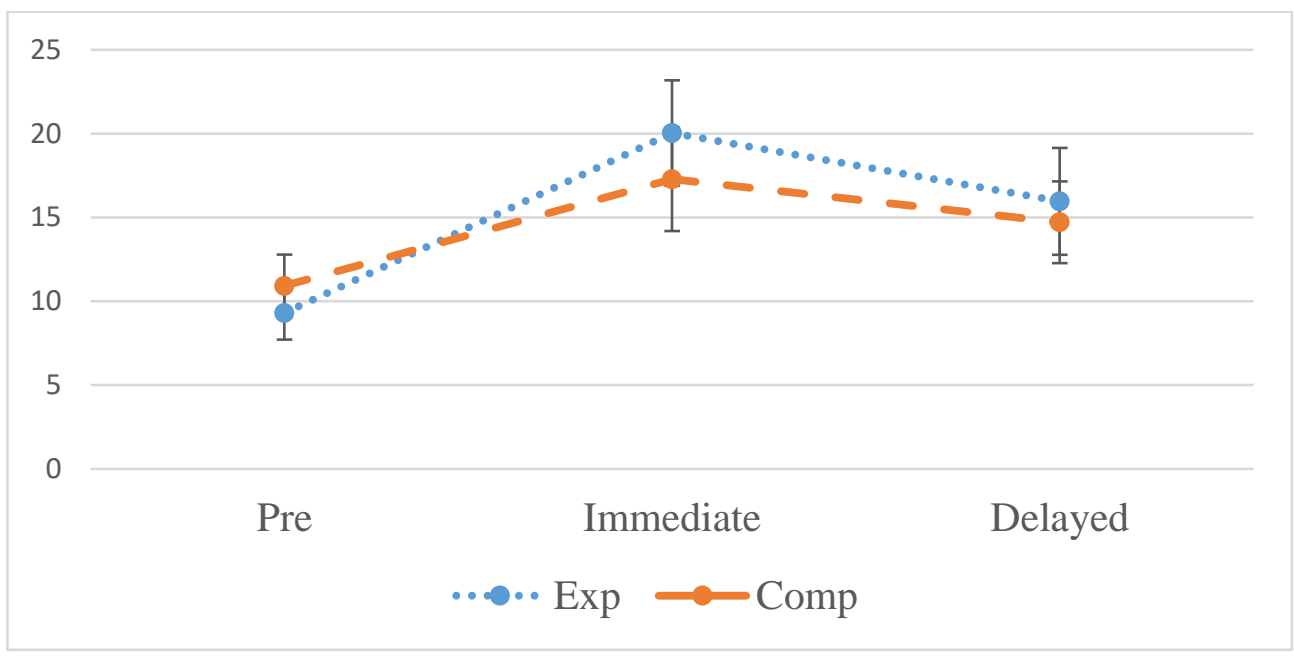

Table 4.2. Gain scores

\begin{tabular}{llcc}
\hline & & $\begin{array}{c}\text { Gain from pre-test to } \\
\text { immediate post-test }\end{array}$ & $\begin{array}{c}\text { Gain from pre-test to 5- } \\
\text { month delayed post-test }\end{array}$ \\
\hline $\begin{array}{llcc}\text { Experimental } \\
\text { group }(\mathbf{n}=\mathbf{2 6})\end{array}$ & mean & 10.62 & 6.62 \\
\cline { 2 - 4 } & median & 10 & 5 \\
\cline { 2 - 4 } & SD & 5.64 & 5.20 \\
\cline { 2 - 4 } $\begin{array}{l}\text { Comparison } \\
\text { group }(\mathbf{n}=\mathbf{2 8})\end{array}$ & mean & $8.45-12.79$ & $4.62-8.62$ \\
\cline { 2 - 4 } & median & 6.36 & 3.79 \\
\cline { 2 - 4 } & SD & 6 & 4.25 \\
\hline
\end{tabular}

Given the large variation in pre-test scores (ranging from 3 to 20), one may argue that some of the students had more room than others to improve their test scores. If so, it may be advisable to use so-called relative gain scores instead of actual gain scores to compare amounts of learning (e.g., Horst, Cobb, \& Meara, 1998; Rogers, Webb, \& Nakata, 2015). To calculate the relative gains, the formula used in previous studies was applied: (posttest score - pretest score) / (number of test items - pretest score) $\times 100$. The descriptive statistics regarding these relative gains scores, which are percentage figures, are displayed in Table 4.3.

The outcome of the inferential statistics applied to the relative gain scores parallels the above outcome concerning the actual gain scores. That is, an advantage was found for the MWE-focused treatment in the immediate post-test $(z=2.04 ; p=.041)$-albeit with a 
reduced effect size compared to the previous analysis $(d=0.587)$ —but evidence for such an advantage became less compelling in the five-month delayed post-test $(z=1.27 ; p=$ $.204 ; d=0.522)$.

Table 4.3. Relative gain scores (\%)

\begin{tabular}{|c|c|c|c|}
\hline & & $\begin{array}{l}\text { Gain from pre-test to } \\
\text { immediate post-test }\end{array}$ & $\begin{array}{l}\text { Gain from pre-test to 5- } \\
\text { month delayed post-test }\end{array}$ \\
\hline \multirow{4}{*}{$\begin{array}{l}\text { Experimental } \\
\text { group }(n=26)\end{array}$} & Mean & 32.18 & 20.70 \\
\hline & median & 26.99 & 13.53 \\
\hline & SD & 21.93 & 20.21 \\
\hline & $95 \% \mathrm{CI}$ & $23.75-40.601$ & $12.93-28.47$ \\
\hline \multirow{4}{*}{$\begin{array}{l}\text { Comparison } \\
\text { group }(n=28)\end{array}$} & Mean & 19.87 & 11.73 \\
\hline & median & 17.32 & 12.81 \\
\hline & SD & 19.90 & 13.49 \\
\hline & $95 \% \mathrm{CI}$ & $12.50-27.240$ & $6.73-16.73$ \\
\hline
\end{tabular}

Regarding the eight MWEs which had been pointed out to the experimental group by the teacher in the first two texts by means of underlining, the test data paralleled the data for the 44 target MWEs. The mean gain from pre-test to near-immediate post-test was 2.54 for the experimental group, as compared to 1.11 for the comparison group. This difference was significant $(z=2.54 ; p=.011)$ and reflects a medium-size effect $(d=0.793)$. The mean gain from pre-test to 5-month delayed post-test was still larger for the experimental group $(M=1.35)$ than the comparison group $(M=0.64)$, but this difference fell short of significance $(z=1.81 ; p=.07 ; d=0.542)$.

In summary, in terms of the acquisition of the 44 target MWEs as well as of the eight MWEs typographically enhanced by the teacher, the experimental group made a statistically significantly greater gain compared with the comparison group in the immediate post-test. The mean gain of the experimental group still remained larger than that of the comparison group but was not statistically significant in the 5-month delayed test. It can be concluded that the intervention of training the learners to extract MWEs from reading texts with the aid of online resources positively affects their acquisition of these items. In the next subsection, item-wise analyses will shed some more light on these learning gains.

\subsubsection{The learning gains - Item-wise analyses}

The item-wise analyses were conducted for a better insight into how the participants' learning gains may be influenced by different target items. I divided the target item pool 
of 44 items that the experimental group worked autonomously with into two groups. One consists of 36 items that at least one participant from either group could produce in the pre-test. The other includes 8 items that no participant could produce (see further below), meaning that the two groups had identical pre-course knowledge of these items. This section investigates the items in terms of the learning gains the students in each group could achieve to see which items were learnt more than others. Features of those items that could play a part in the learning gains are looked into in Section 4.3.2 below.

Regarding the 36 items that were known to at least one learner from either group, Table 4.4 below shows the item-wise learning gains made by the experimental students between the pre-test and the immediate post-test, i.e. the immediate gain, and between the pre-test and the five-month delayed post-test, i.e. the delayed gain. The items are arranged in the order of the largest immediate gains to the smallest (the column in bold type). As can be seen from Table 4.4, the ranking of the items based on the delayed gains, despite some changes, indicates a similar order to the order according to the immediate gains. There are a number of items which were more learnt than others. Typical instances are put one's foot in one's mouth, fizzy drinks, common belief, in the spotlight, opposites attract, a sea of, and birds of a feather flock together. This pattern was also found among learners of the comparison group with the similar MWEs among the most learnt items (see Table 4.5 below).

Table 4.4. Item-wise learning gains - the experimental group $(\max =26)$

\begin{tabular}{lcclcc}
\hline Items in the test & $\begin{array}{c}\text { Immediate } \\
\text { gains }\end{array}$ & $\begin{array}{c}\text { Delayed } \\
\text { gains }\end{array}$ & Items in the test & $\begin{array}{c}\text { Immediate } \\
\text { gains }\end{array}$ & $\begin{array}{c}\text { Delayed } \\
\text { gains }\end{array}$ \\
\hline $\begin{array}{l}\text { put one's foot in } \\
\text { one's mouth }\end{array}$ & $\mathbf{1 7}$ & 14 & critical thinking & $\mathbf{6}$ & 4 \\
\hline $\begin{array}{l}\text { common belief } \\
\text { fizzy drinks }\end{array}$ & $\mathbf{1 5}$ & 7 & in the long run & $\mathbf{6}$ & 8 \\
\hline $\begin{array}{l}\text { take (full) } \\
\text { advantage of }\end{array}$ & $\mathbf{1 5}$ & 18 & press conference & $\mathbf{5}$ & 5 \\
\hline $\begin{array}{l}\text { in the spotlight } \\
\text { opposites attract }\end{array}$ & $\mathbf{1 4}$ & 9 & $\begin{array}{l}\text { at one 's } \\
\text { disposal }\end{array}$ & $\mathbf{5}$ & 2 \\
\hline a sea of & $\mathbf{1 4}$ & 12 & $\begin{array}{l}\text { come to terms } \\
\text { with }\end{array}$ & $\mathbf{4}$ & 2 \\
\hline
\end{tabular}

1 'Immediate gains' refers to the difference in the number of students correctly recalling the MWEs between the pre-test and the immediate post-test, while 'delayed gains' refers to that between the pre-test and the delayed post-test. 


\begin{tabular}{|c|c|c|c|c|c|}
\hline Items in the test & $\begin{array}{l}\text { Immediate } \\
\text { gains }\end{array}$ & $\begin{array}{c}\text { Delayed } \\
\text { gains }\end{array}$ & Items in the test & $\begin{array}{l}\text { Immediate } \\
\text { gains }\end{array}$ & $\begin{array}{c}\text { Delayed } \\
\text { gains }\end{array}$ \\
\hline associated with & 12 & 5 & $\begin{array}{l}\text { from time to } \\
\text { time }\end{array}$ & 3 & -1 \\
\hline leading cause & 12 & 9 & at first glance & 2 & 1 \\
\hline all walks of life & 11 & 10 & stands to reason & 2 & 0 \\
\hline allergic to & 11 & 1 & when it comes to & 2 & 1 \\
\hline haunted house & 11 & 8 & daily grind & 1 & 0 \\
\hline $\begin{array}{l}\text { vending } \\
\text { machine }\end{array}$ & 11 & 10 & obsessed with & $\mathbf{1}$ & -1 \\
\hline $\begin{array}{l}\text { Every now and } \\
\text { then }\end{array}$ & 10 & 2 & $\begin{array}{l}\text { shed (some) } \\
\text { light }\end{array}$ & 1 & 1 \\
\hline $\begin{array}{l}\text { birds of a } \\
\text { feather flock } \\
\text { together }\end{array}$ & 9 & 5 & turned out & 1 & 1 \\
\hline not to mention & 9 & 4 & meet the goals & $\mathbf{0}$ & 1 \\
\hline out of the blue & 9 & 2 & made it through & -2 & -1 \\
\hline at stake & 8 & 3 & Taking (time) off & -6 & -2 \\
\hline
\end{tabular}

On the other hand, items such as shed (some) light on, daily grind, when it comes to, at your disposal, come to terms with, it stands to reason, fight-or-flight are among the least learnt MWEs by learners of both experimental and comparison group. Of note, familiarlooking items such as taking (time) off, made it through, meet the goals are also among the least learnt items. This is understandable since with familiar items, there is less room left for learning gains. It is strange that some learning losses, instead of gains, occurred in both groups (see Tables 4.4 and 4.5). Possibly, several participants lost their concentration or commitment during the post-tests.

Table 4.5. Item-wise learning gains - the comparison group $(\max =28)$

\begin{tabular}{|c|c|c|c|c|c|}
\hline Items in the test & $\begin{array}{l}\text { Immediate } \\
\text { gains }\end{array}$ & $\begin{array}{c}\text { Delayed } \\
\text { gains }\end{array}$ & Items in the test & $\begin{array}{l}\text { Immediate } \\
\text { gains }\end{array}$ & $\begin{array}{c}\text { Delayed } \\
\text { gains }\end{array}$ \\
\hline fizzy drinks & 23 & 14 & leading cause & 3 & -3 \\
\hline vending machine & 17 & 14 & Taking (time) off & 2 & 1 \\
\hline $\begin{array}{l}\text { birds of a feather } \\
\text { flock together }\end{array}$ & 17 & 10 & $\begin{array}{l}\text { take (full) } \\
\text { advantage of }\end{array}$ & 1 & 2 \\
\hline opposites attract & 13 & 3 & a sea of & $\mathbf{1}$ & 3 \\
\hline haunted house & 12 & 10 & fight or flight & 1 & -1 \\
\hline common belief & 12 & 6 & $\begin{array}{l}\text { from time to } \\
\text { time }\end{array}$ & $\mathbf{0}$ & 0 \\
\hline obsessed with & 10 & 7 & at stake & $\mathbf{0}$ & 2 \\
\hline critical thinking & 10 & 8 & meet the goals & $\mathbf{0}$ & -5 \\
\hline
\end{tabular}




\begin{tabular}{lcclcc}
\hline Items in the test & $\begin{array}{c}\text { Immediate } \\
\text { gains }\end{array}$ & $\begin{array}{c}\text { Delayed } \\
\text { gains }\end{array}$ & Items in the test & $\begin{array}{c}\text { Immediate } \\
\text { gains }\end{array}$ & $\begin{array}{c}\text { Delayed } \\
\text { gains }\end{array}$ \\
\hline out of the blue & $\mathbf{9}$ & 3 & stands to reason & $\mathbf{0}$ & 0 \\
\hline in the spotlight & $\mathbf{9}$ & 3 & prone to & $\mathbf{0}$ & 0 \\
\hline press conference & $\mathbf{9}$ & 3 & turned out & $\mathbf{- 1}$ & 0 \\
\hline At first glance & $\mathbf{8}$ & 9 & at one's disposal & $\mathbf{- 1}$ & -1 \\
\hline $\begin{array}{l}\text { put one's foot in } \\
\text { one's mouth }\end{array}$ & $\mathbf{8}$ & 1 & $\begin{array}{l}\text { come to terms } \\
\text { with }\end{array}$ & $\mathbf{- 2}$ & -5 \\
$\begin{array}{l}\text { Every now and } \\
\text { then }\end{array}$ & $\mathbf{5}$ & 6 & daily grind & $\mathbf{- 2}$ & 3 \\
\hline $\begin{array}{l}\text { shed (some) light } \\
\text { all walks of life }\end{array}$ & $\mathbf{5}$ & 3 & in the long run & $\mathbf{- 3}$ & -4 \\
\hline associated with & $\mathbf{4}$ & 2 & not to mention & $\mathbf{- 3}$ & 1 \\
\hline allergic to & $\mathbf{3}$ & 2 & when it comes to & $\mathbf{- 4}$ & -2 \\
\hline
\end{tabular}

Another thing worth noticing is that there is a relatively consistent upward trend from the pre-test to the post-tests among the learners of the experimental group. Yet the trend is fairly erratic in the comparison group with more cases where the items were better known in the pre-test than in the post-tests like made it through, when it comes to, in the long run, come to terms with, or daily grind (see Table 4.5). It stands to reason that the sustained attention to MWEs in the experimental condition promoted a more steady growth of MWE knowledge.

Let us now look at the eight items totally unknown to all the participants at the beginning, i.e. they all scored zero in these items in the pre-test. This set of items can be considered a 'clean' set - 'clean' in the sense that there was no difference between the two groups regarding their prior knowledge. The results of the Friedman test indicated that there was a statistically significant difference in the productive knowledge of these eight items among learners of the experimental group across the three times of testing (pre-test, immediate post-test, and delayed post-test $), X^{2}(2, n=8)=9.75, p=.007$. On the other hand, no statistically significant difference was found in this knowledge among learners of the comparison group, $X^{2}(2, n=8)=3.57, p=.17$.

Table 4.6 illustrates the changes the two groups made in their productive knowledge of the eight items in the 'clean' set. As indicated in the Table, the experimental group made progress in almost all items, with only one in eight items scored zero in the immediate post-test and in the delayed post-test (i.e. amounts to). Meanwhile, the comparison group 
failed to show any learning gains in as many as four out of eight items, including for starters, trigger a (fierce) reaction, amounts to, and sifting through.

Table 4.6. Item-wise learning gains - Both groups - The 'clean' set

\begin{tabular}{lcccc}
\hline & $\begin{array}{c}\text { Experimental group } \\
(\mathbf{n = 2 6})\end{array}$ & \multicolumn{2}{c}{$\begin{array}{c}\text { Comparison group } \\
(\mathbf{n = 2 8})\end{array}$} \\
\hline Items in the test & $\begin{array}{c}\text { Immediate } \\
\text { gains }\end{array}$ & $\begin{array}{c}\text { Delayed } \\
\text { gains }\end{array}$ & $\begin{array}{c}\text { Immediate } \\
\text { gains }\end{array}$ & $\begin{array}{c}\text { Delayed } \\
\text { gains }\end{array}$ \\
\hline weighing the options & 5 & 1 & 4 & 1 \\
\hline on autopilot & 5 & 2 & 6 & 3 \\
\hline for starters & 4 & 2 & 0 & 0 \\
\hline sifting through & 3 & 1 & 0 & 0 \\
\hline trigger $($ a fierce) reaction & 2 & 2 & 0 & 0 \\
\hline make recommendations & 2 & 2 & 5 & 0 \\
\hline Striking $($ a dramatic) pose & 2 & 5 & 4 & 2 \\
\hline Amounts to & 0 & 0 & 0 & 0 \\
\hline
\end{tabular}

More in-depth analyses in an attempt to explain why some items were more learnt than others will be presented in Section 4.3.2 below. Also, triangulation of these findings will be found in the next chapter reporting on the learners' classroom discussions when they were extracting MWEs from texts.

\subsection{What factors may affect learners' learning gains of the target MWEs?}

The learning gains of the target items might also be determined by factors related to the differences in learners' proficiency and in the learning burden of the items, apart from the assigned learning condition. In this project, the learners' proficiency was estimated by means of the vocabulary size test. The learning burden of the items is examined through their semantic features, their frequency in COCA, and the frequency of the constituent words compared with the learners' vocabulary size. One might argue that the frequency of the items in the language input the students were exposed to in this study should be examined too. However, since the frequency of the target items in the input did not differ much from one another, it is not taken into consideration here. For example, there were only four target MWEs that occurred twice in a text: a sea of, sift through, when it comes to, and make it through. Among these, only a sea of saw better learning gains among both groups while the results of others did not show much advantage compared to other items that appeared once only, showing no compelling evidence that this repetition mattered much. Meanwhile, the frequency in a general corpus like COCA may inform about the 
chance the phrases had been encountered by the learners before the intervention study, outside class during the intervention study, and in the five-month interval between the immediate and the delayed post-test Apart from these item-wise features, another influential factor is the condition of whether the target items were attended to during the text-chunking activity (in the experimental group) and during the selection of vocabulary items worth learning (in both groups). These factors are investigated below.

\subsubsection{Learner-related factor - vocabulary sizes}

Two hypotheses were put to the test with regards to the learners' vocabulary size. First, learners who obtained better scores in the VST would also obtain better scores in the MWE pre-test. In other words, learners with larger vocabulary sizes would know more target MWEs. Second, learners who had a larger vocabulary size at the starting point would make better progress during the course. To put it another way, learners with higher scores in the VST would obtain higher gain scores in both the immediate and the delayed MWE recall test. As previously mentioned in the Methodology Chapter, scores on the VST indicated that this batch of learners had receptive knowledge of the 4,600 most frequent word families in English on average. The vocabulary size ranged from 3,000 to 7,000 in the experimental group while the figure ranged from 3,200 to 6,800 in the comparison group.

Regarding the first hypothesis, a Pearson correlation coefficient was computed to assess the relationship between learners' vocabulary size and their performance in the original MWE pre-test of 52 items. The scores from the 52-item test were used here since a bigger pool of items would better show learners' knowledge of the target MWEs. The results showed a strong positive correlation between the two variables, $r(54)=.61, \mathrm{p}<.0001$, indicating that learners with more receptive knowledge of individual words also have better knowledge of the target MWEs. This result confirms the findings by Nguyen and Webb (2017) about the positive correlation between learners' knowledge of single words and their knowledge of MWEs.

The next question is whether there were any differences between the two groups in how much the vocabulary size is associated with the learning gains during the course since they received different treatments during this time. Considering the sustained focus on MWEs in the experimental treatment, it is somewhat surprising to find only a medium- 
size effect relative to the comparison group's gains (as mentioned in Section 4.2.1). One possible explanation is that students benefited from the MWE extraction activities to varying degrees. More specifically, the students with relatively high proficiency in English according to their VST scores and their MWE pre-test scores tended to benefit the most. As shown in Tables 4.7 and 4.8, the correlations between the students' VST scores and their gain scores were consistently positive, as were the correlations between their pre-test scores and their gain scores. Interestingly, these associations were considerably weaker in the comparison group.

Table 4.7. Spearman's Rho Correlations between VST scores and gains

\begin{tabular}{lcccc}
\hline & $\begin{array}{c}\text { Gain from } \\
\text { pre-test to } \\
\text { immediate } \\
\text { post-test }\end{array}$ & $\begin{array}{c}\text { Relative gain } \\
\text { from pre-test } \\
\text { to immediate } \\
\text { post-test }\end{array}$ & $\begin{array}{c}\text { Gain from } \\
\text { pre-test to 5- } \\
\text { month } \\
\text { delayed post- } \\
\text { test }\end{array}$ & $\begin{array}{c}\text { Relative gain } \\
\text { from pre-test } \\
\text { to 5-month } \\
\text { delayed post- } \\
\text { test }\end{array}$ \\
\hline $\begin{array}{l}\text { Experimental } \\
\text { group }(\mathbf{n}=\mathbf{2 6})\end{array}$ & .126 & .134 & $.695^{*}$ & $.711^{*}$ \\
\hline $\begin{array}{l}\text { Comparison } \\
\text { group }(\mathbf{n}=\mathbf{2 8})\end{array}$ & .253 & .270 & & .390 \\
\hline
\end{tabular}

Note: $* p<.01$

These correlational data suggest that the greater learning burden experienced by students in the experimental group with a relatively low proficiency level in English (according to the VST and the MWE pre-test, at least) hindered their successful retention of the many MWEs they discovered. The MWE extraction activity is therefore probably more suitable when the number of unfamiliar MWEs is relatively small, thus keeping the quantity of new information to be retained at a manageable level.

Table 4.8. Spearman's Rho Correlations between pre-test scores and gains

\begin{tabular}{lcccc}
\hline & $\begin{array}{c}\text { Gain from } \\
\text { pre-test to } \\
\text { immediate } \\
\text { post-test }\end{array}$ & $\begin{array}{c}\text { Relative gain } \\
\text { from pre-test } \\
\text { to immediate } \\
\text { post-test }\end{array}$ & $\begin{array}{c}\text { Gain from } \\
\text { pre-test to 5- } \\
\text { month } \\
\text { delayed post- } \\
\text { test }\end{array}$ & $\begin{array}{c}\text { Relative gain } \\
\text { from pre-test } \\
\text { to 5-month } \\
\text { delayed post- } \\
\text { test }\end{array}$ \\
\hline $\begin{array}{l}\text { Experimental } \\
\text { group }(\mathbf{n}=\mathbf{2 6})\end{array}$ & .070 & .116 & .346 & .379 \\
\hline $\begin{array}{l}\text { Comparison } \\
\text { group }(\mathbf{n = 2 8})\end{array}$ & -.106 & .036 & .055 & .154 \\
\hline
\end{tabular}

Note: $* p<.01$ 


\subsubsection{Item-related factors}

\subsubsection{The features of meanings}

Let us now have a closer look at two groups of items mentioned in Section 4.2.2., one group of the most learnt items and the other of the least learnt items. The items most learnt by students of both groups included fizzy drinks, in the spotlight, birds of a feather flock together, and a sea of. There phrases, despite the differences in the categories of MWEs they belong to and the number of component words, share the feature of being 'concrete' or 'imageable' in meaning. To put it another way, these MWEs can create a comparatively clear and specific image in learners' mind of what they depict and, therefore, help them recall the phrases better than others. As asserted by Steinel, Hulstijn, and Steinel (2007), concreteness of meaning, or 'imageability', is known to be a strong predictor of the possibility that an MWE is retained in learners' memory. The findings from this study seem to confirm this assertion. Another shared feature that should be stated about these items is their transparent meanings. If learners understand the component words, there is much likelihood that they could comprehend the meanings of the whole phrases. It stands to reason that compositional MWEs might be more likely to be added to learners' phrase banks than non-compositional counterparts.

Included in the group of least learnt target items, as mentioned in Section 4.2.2 are come to terms with, when it comes to, at your disposal, it stands to reason, prone to, in the face of, daily grind, amount to, for starters. The common feature shared by these phrases is, on the contrary to the feature of the most learnt group, the opaqueness in the meanings despite being composed of familiar words. Students might not be able to guess the meanings of phrases such as when it comes to or comes to terms with if they simply added the meanings of the component words together. These phrases have different levels of meaning opaqueness which may make the form-meaning mapping process more challenging to the students. Also, familiar-looking words might attract less attention of students, which will be further discussed in the subsection about the frequency of the component words below. The meaning opaqueness may result from the short and polysemous words like come, terms, and face, or different prepositions in these phrases.

In brief, learners' learning gains of different items demonstrated by the students in this study are in accordance with Steinel, Hulstijn, and Steinel's (2007) finding that phrases 
with more transparent and imageable meanings stood a better chance of being remembered by the learners. The opposite seemed true for items consisting of familiar words and with an opaque meaning. It is interesting that the intervention entailed the learners' consultation of dictionaries, and so they were in a position to resolve the opaqueness in the meanings of different phrases. However, the main point may lie in whether those phrases were attended to at the very start. The next subsection will look at another factor of the items - their frequency.

\subsubsection{The frequency of the target items}

Regarding this factor of frequency, I hypothesized that the frequency of an MWE in COCA might indicate how often it was likely to have been encountered by the students in English texts. This frequency in its turn might predict the possibility that the phrase was picked up by the learners during their reading. To put it another way, it might be true that the higher frequency a MWE had in COCA, the more likely that it was known to the learners. This hypothesis was put to the test in another Pearson correlation between the frequency of the target items in COCA and the number of correct answers by both groups in the MWE pre-test. It is more reasonable to use all the 52 items in the MWE recall test, rather than the reduced pool of 44 items. The correlation was found to be positive and statistically significant, $r(52)=.32, p=.02$, , meaning that the most frequently-used phrases in English stand a better chance of being acquired by these EFL learners. The correlation is relatively weak, however.

Tables 4.9 and 4.10 below present a close-up of the top and bottom ten from the two lists, one of which is informed by COCA frequency, the other by the pre-test scores of learners for each item. It is worth noting that the MWEs displayed in this table are in the format used for the search query syntax in COCA. Verbs and nouns are capitalized for the inclusion of all the inflections of these words in the COCA calculation of frequency.

Table 4.9. Target items most known by the learners vs. the most frequent items in COCA

\begin{tabular}{lclc}
\hline $\begin{array}{l}\text { Target items most } \\
\text { known by learners at } \\
\text { the MWE pre-test }\end{array}$ & $\begin{array}{c}\text { No. of correct } \\
\text { answers from } \\
\text { both groups } \\
(\mathbf{n = 5 4 )}\end{array}$ & $\begin{array}{l}\text { Target items most } \\
\text { frequent in COCA }\end{array}$ & $\begin{array}{c}\text { Frequency } \\
\text { in COCA }\end{array}$ \\
\hline from time to time & 49 & associated with & $\begin{array}{c}\text { (retrieved } \text { in } \\
\text { May 2018) }\end{array}$ \\
\hline TURN out & 47 & TURN out & 39388 \\
\hline
\end{tabular}




\begin{tabular}{lclc}
\hline $\begin{array}{l}\text { Target items most } \\
\text { known by learners at } \\
\text { the MWE pre-test }\end{array}$ & $\begin{array}{c}\text { No. of correct } \\
\text { answers from } \\
\text { both groups } \\
(\mathbf{n = 5 4})\end{array}$ & $\begin{array}{l}\text { Target items most } \\
\text { frequent in COCA }\end{array}$ & $\begin{array}{c}\text { Frequency } \\
\text { in COCA }\end{array}$ \\
\hline TAKE...off & 44 & when it COME to & 18980 \\
\hline allergic to & 32 & TAKE $(*)$ advantage of & 11932 \\
\hline WEAR $(*)$ out & 31 & AMOUNT to & 8024 \\
\hline At first glance & 31 & in the face of & 7969 \\
\hline in the mood & 31 & press CONFERENCE & 6642 \\
\hline $\begin{array}{l}\text { TAKE }(*) \text { advantage } \\
\text { of }\end{array}$ & 29 & On average & 6641 \\
\hline haunted HOUSE & 26 & not to mention & 6437 \\
\hline obsessed with & 22 & at stake & 5847 \\
\hline
\end{tabular}

As shown in Table 4.9, only two out of ten items, TURN out and TAKE (*) advantage of, are both most known to the participants of this study and most frequently used as informed by COCA. Likewise, only three out of ten items in Table 4.10, which are TRIGGER* (*) REACTION, FACE * (*) HEAD ON, and WEIGH the options, appear both in the list of the least known items to learners and the least frequent phrases in COCA. Surprisingly, AMOUNT to is among the MWEs with the highest frequency indicator in COCA among all target items but the least known to the learners. It stands to reason that due to multiple factors that might influence the learning process of the learners, the frequency indicators in COCA may predict only to a minimal extent the possibility of an MWE being learnt by the learners.

Table 4.10. Target items least known by the learners vs. the least frequent items in COCA

\begin{tabular}{|c|c|c|c|}
\hline $\begin{array}{l}\text { Target items least } \\
\text { known by learners at } \\
\text { the MWE pre-test }\end{array}$ & $\begin{array}{l}\text { No. of correct } \\
\text { answers from } \\
\text { both groups } \\
(n=54)\end{array}$ & $\begin{array}{l}\text { Target items least } \\
\text { frequent in COCA }\end{array}$ & $\begin{array}{c}\text { Frequency } \\
\text { in COCA } \\
\text { (retrieved in } \\
\text { May 2018) }\end{array}$ \\
\hline AMOUNT to & 0 & MEET the GOAL & 189 \\
\hline STUDY SHOW that & 0 & $\begin{array}{l}\text { TRIGGER } *(*) \\
\text { REACTION }\end{array}$ & 176 \\
\hline For starters & 0 & daily GRIND & 160 \\
\hline SIFT through & 0 & fight or flight & 121 \\
\hline $\begin{array}{l}\text { MAKE }(*) \\
\text { RECOMMENDATION }\end{array}$ & 0 & $\begin{array}{l}\text { opposites } \\
\text { ATTRACT }\end{array}$ & 111 \\
\hline STRIKE a $*$ pose & 0 & $\begin{array}{l}\text { FACE * }(*) \text { HEAD } \\
\text { ON }\end{array}$ & 54 \\
\hline on autopilot & 0 & $\begin{array}{l}\text { PUT * foot in * } \\
\text { mouth }\end{array}$ & 44 \\
\hline
\end{tabular}




\begin{tabular}{lclc}
\hline $\begin{array}{l}\text { Target items least } \\
\text { known by learners at } \\
\text { the MWE pre-test }\end{array}$ & $\begin{array}{c}\text { No. of correct } \\
\text { answers from } \\
\text { both groups } \\
(\mathbf{n = 5 4 )}\end{array}$ & $\begin{array}{l}\text { Target items least } \\
\text { frequent in COCA }\end{array}$ & $\begin{array}{c}\text { Frequency } \\
\text { in COCA }\end{array}$ \\
\hline $\begin{array}{l}\text { TRIGGER } *(*) \\
\text { REACTION }\end{array}$ & 0 & WEIGH the options & 33 \\
\hline FACE $* *)$ HEAD ON & 0 & fizzy DRINK & 25 \\
\hline WEIGH the options & 0 & $\begin{array}{l}\text { birds of a feather } \\
\text { flock together }\end{array}$ & 15 \\
\hline
\end{tabular}

\subsubsection{The frequency of constituent words}

Given that these MWEs are combinations of different single words, whether or not those component words are known to the students may affect the possibility of the whole combinations being known to them. I therefore checked the VocabProfile for the pool of test items on the website www.lextutor.ca (Cobb, n.d.). The English Profilers on this site provide the frequencies of individual words in BNC/COCA corpus. The frequency levels are lists of 1,000 word families, from the first 1,000 as the most frequent to the $25^{\text {th }} 1,000$. The results showed that up to $93.91 \%$ of the constituent words belong to the BNC-COCA first 3,000-word families, which corresponds to the lowest VST score recorded among all the participants. In other words, $93.91 \%$ of the words that comprise the target MWEs were likely to have been known to all the participants. Also, up to $95.94 \%$ of the component words belong to the first 4,000-word families, which is still less than the average vocabulary size of the participants according to their VST scores. The words that fall out of this range are allergy, prone, sift, pep, fizzy, vending, autopilot, spotlight (see Table 4.11)

Table 4.11. Frequency levels of some medium-and low-frequency constituent words

\begin{tabular}{ll}
\hline Frequency level & Medium- and low-frequency constituent words \\
\hline K-5 words & allergy, prone \\
\hline K-6 words & sift \\
\hline K-8 words & pep \\
\hline K-9 words & fizzy \\
\hline K-10 words & vending \\
\hline OFFLIST & autopilot, spotlight \\
\hline
\end{tabular}

However, judging from the 10 MWEs that were completely unknown in the learners' productive repertoire at the pretest (see Table 4.6), there are only two words that appear in this list of medium- and low-frequency words which are sift and autopilot. Also, fizzy drinks and in the spotlight are among the most learnt target items among the students 
while only one phrase containing low-frequency words (i.e. prone to) is in the list of least learnt target items, as mentioned in Section 4.3.2.1. This phenomenon may suggest that the frequency of constituent words is not a strong predictor of the EFL students' MWE knowledge or their gains in MWE knowledge.

There are three possible explanations for the insignificant role of constituent word frequency in predicting learners' knowledge of MWEs made up from those words. The first is the features of the meanings of these phrases, which has been reported in subsection 4.3.2.1. Second, it should be acknowledged that the VST only gauges learners' receptive knowledge of single words while the type of knowledge tested in the MWE tests is the productive knowledge of the phrasal behavior of those words. Also, although the constituent words may belong to the range of the first 4,000 words, which is within the average vocabulary size of the participants, their knowledge of these words might be only at the passive or receptive level. Third, familiar-looking words may have attracted less attention from students in both learning conditions and may not have piqued the students' curiosity enough to be looked up in a dictionary or in COCA.

By and large, it can be concluded that the ways different words collocate might still pose a significant learning burden on the learners even when the component words are already familiar to them. When it comes to the learning of MWEs comprised of very frequently used words, more guided attention is needed so that such phrases will not be overlooked.

\subsubsection{The amount of attention paid by the learners}

The next factor to be considered is the amount of attention the learners paid to the target items. I hypothesized that the MWEs which the students took notice of during the chunking activity and the reading session as a whole stood the best chance of being remembered.

A tally was first kept of the target MWEs that each pair of students noted down in the course of their chunking activity. Each learner had data on multiple items, so the data from an individual was likely to correlate. Since recall is a dichotomous outcome (either $=0$ or $=1)$ and the correlated responses within each individual needed to be accounted for, a mixed effects logistic regression model was built for both the immediate post-test and the delayed test. The MWEs which students already knew at pre-test were excluded from these calculations. Because of the positive correlation between the students' VST scores 
and their MWE learning gains (see above), we included the VST scores in the regression model. Learners' vocabulary size and whether a MWE was chunked $(=1)$ or unchunked $(=0)$ were fitted as fixed effects, and the learners and MWEs were random effects.

Assumptions of the mixed effects logistic regression model were checked for both the immediate post-test and the delayed test; VST scores were linearly associated with the recall outcome in logit scale and random effects were approximately normally distributed. Figure 4.2 illustrates the estimated probability that the item was recalled (recall=1) at the immediate port-test, calculated using the mixed effects logistic regression model described above.

Figure 4.2. Learners' vocabulary size and chunked items vs. immediate post-test results

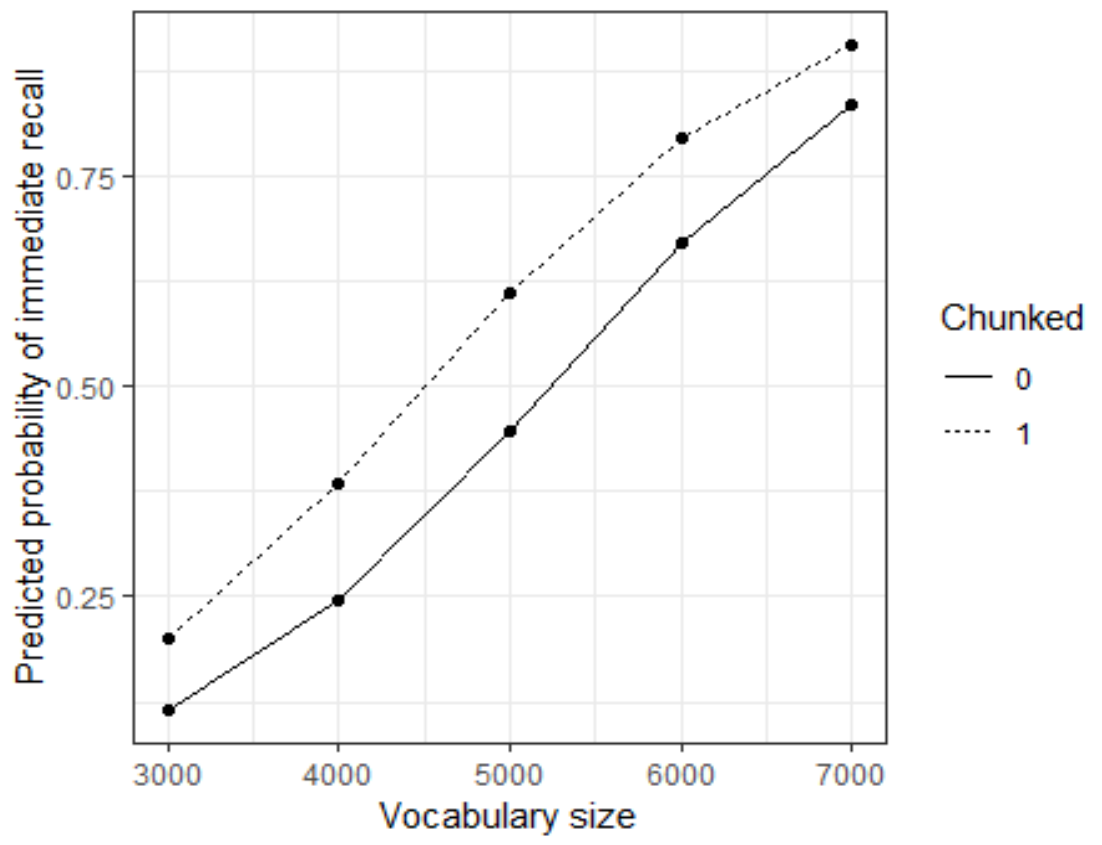

After accounting for the effect of chunked items, the effect of vocabulary size on recall remains statistically significant $(p=.0005)$ (see Table 4.12). Likewise, after accounting for the effect of vocabulary size, the effect of an item being chunked on its recall in the immediate post-test is statistically significant $(p=.0117)$. The estimated odds of recall in the immediate post-test on an item that was chunked are 1.93 times that of an item that was not chunked, 95\% CI $(1.16,3.21)$. The estimated odds of recall in the immediate post-test on an item are 2.50 times higher when vocab size increases by 1000 words, $95 \%$ CI $(1.49,4.18)$. 
Table 4.12. Logistic regression outcome for the immediate post test

\begin{tabular}{lcccc}
\hline & Estimate & Std. Error & z value & $\boldsymbol{p}$ \\
\hline Intercept & -4.78 & 1.26 & -3.79 & 0.0001 \\
\hline Chunked1 & 0.65 & 0.26 & 2.52 & 0.0117 \\
\hline Vocabulary size $^{2}$ & 0.91 & 0.26 & 3.47 & 0.0005 \\
\hline
\end{tabular}

Similarly, the predicted probability of an item being recalled in the delayed test (recall = 1) when it was chunked (chunk $=1$ ) was also of statistical significance $(p=.0128)$ (see Table 4.13). Results of the mixed effects logistic regression showed statistically significant probability of higher learning gains among the learners with larger vocabulary sizes, $p<.0001$. (see Figure 4.3). This result confirmed the findings from the correlational data reported in Section 4.2.1 about the influential role of learners' proficiency on the benefits they could reap from the MWE-extracting activity. Figures 4.2 and 4.3 also indicate that learners' proficiency had a larger impact on the recall of target items than the status of being chunked or unchunked of these items.

Figure 4.3. Learners' vocabulary size and chunked items vs. delayed post-test results

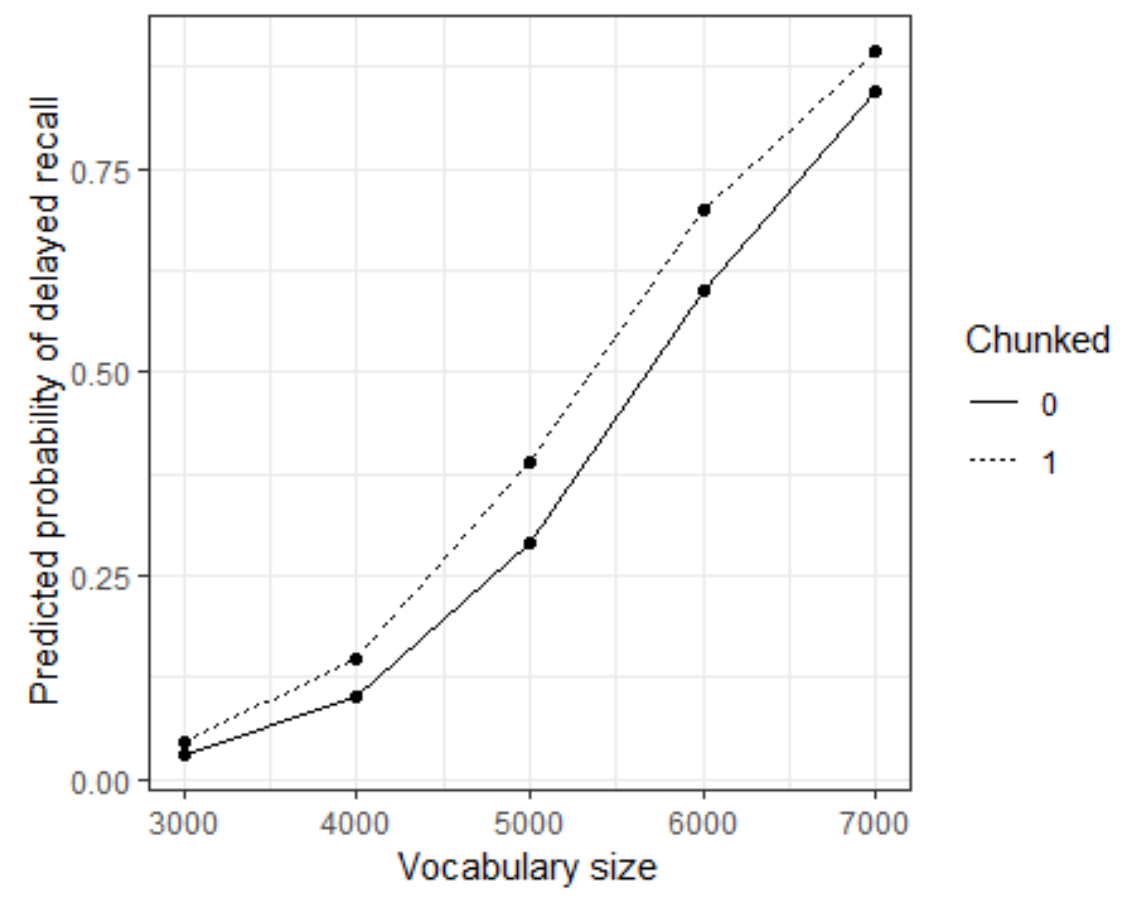

\footnotetext{
${ }^{2}$ The vocabulary size was rescaled in the model, divided by 1000 so that a 1 unit increase in vocabulary is equivalent to a 1000 unit increase in vocabulary size.
} 
Table 4.13. Logistic regression outcome for the delayed post test

\begin{tabular}{lcccc}
\hline & Estimate & Std. Error & z value & $\boldsymbol{p}$ \\
\hline Intercept & -7.3812 & 1.0619 & -6.951 & $3.62 \mathrm{e}-12^{* * *}$ \\
\hline Chunked1 & 0.4463 & 0.2934 & 1.521 & 0.0128 \\
\hline Vocabulary size & 1.2966 & 0.2106 & 6.157 & $7.39 \mathrm{e}-10^{* * *}$ \\
\hline
\end{tabular}

The estimated odds of recall in the delayed test on an item that was chunked are 1.56 times that of an item that was not chunked, $95 \% \mathrm{CI}(0.88,2.78)$. The estimated odds of recall in the delayed test on an item are 3.66 times higher when vocab size increases by 1000 words, $95 \%$ CI $(2.42,5.53)$.

The results of these analyses - especially regarding the immediate post-test data-nevertheless support the hypothesis that learners' conscious engagement with particular MWEs in a text gives these items an edge over others which have received less attention when it comes to the creation of durable memories. Inevitably, the benefits reaped from learner-autonomous text chunking will depend on how successful learners are at identifying word strings or word combinations that qualify as MWEs rather than free combinations.

To explore this, I conducted further examination of all the multiword items which the students in both groups selected at the end of each lesson. These are the items students in both groups noted down when they were invited to select about 5 lexical items they would like to add to their vocabulary.

To decide whether a multiword item qualified as an MWE, I again relied on their inclusion in dictionaries and, if an expression did not figure in dictionaries, a frequency of 20 or more occurrences in COCA. Table 4.12 shows the proportions (in percentage figures) of single words, MWEs, and other multiword items in the two groups' end-ofclass vocabulary lists. The data is shown in the order of time from week 1 to week 10 of the course. Also 'other multiword items' refer to items that contain more than one word but do not qualify as MWEs according to aforementioned criteria. 
Table 4.14. Nature of items in students' end-of-class vocabulary selections

\section{Experimental Group Comparison Group}

$\begin{array}{lllllll}\text { WEEK } & \begin{array}{l}\text { Single } \\ \text { words }\end{array} & \begin{array}{l}\text { MWEs } \\ (\%)\end{array} & \begin{array}{l}\text { Other } \\ \text { multiword }\end{array} & \begin{array}{l}\text { Single } \\ \text { words } \\ \text { items }(\%)\end{array} & \begin{array}{l}\text { MWEs } \\ (\%)\end{array} & \begin{array}{l}\text { Other } \\ \text { multiword }\end{array} \\ & & & & \text { items }(\%)\end{array}$

\begin{tabular}{|c|c|c|c|c|c|c|}
\hline 1 & 0 & 95.92 & 4.08 & 35 & 60.83 & 4.17 \\
\hline 2 & 0.96 & 96.15 & 2.89 & 56.8 & 41.42 & 1.78 \\
\hline 3 & 1.65 & 86.77 & 11.58 & 70.31 & 23.43 & 6.26 \\
\hline 4 & 0 & 91 & 9 & 56.48 & 36.11 & 7.41 \\
\hline 5 & 5.6 & 86.4 & 8 & 45.33 & 49.33 & 5.34 \\
\hline 6 & 3.3 & 90.9 & 5.8 & 62.01 & 31.78 & 6.21 \\
\hline 7 & 9.9 & 88.3 & 1.8 & 53.47 & 39.58 & 6.95 \\
\hline 8 & 4.42 & 82.3 & 13.28 & 59.87 & 29.93 & 10.2 \\
\hline 9 & 2.54 & 89.83 & 7.63 & 62.85 & 25.71 & 11.44 \\
\hline 10 & 0 & 92.66 & 7.34 & 19.23 & 69.23 & 11.54 \\
\hline Mean & 2.837 & 90.023 & 7.14 & 52.135 & 40.735 & 7.13 \\
\hline
\end{tabular}

As can be seen from Table 4.12, the experimental group selected almost exclusively multiword items, as per instruction. It is noteworthy that also the comparison group selected many multiword items for inclusion in their end-of-class selections-about $47 \%$. However, of these, $14.5 \%$ (7.13\% out of about $47 \%)$ did not qualify as MWEs. The experimental group was more accurate in this regard, most probably thanks to the consultation of dictionaries and corpus data. Still, despite the encouragement to consult these online resources, $7.5 \%$ of the multiword items ( $7.14 \%$ out of about $97.15 \%)$ written down in the experimental group's selections did not meet the stipulated criteria either.

To assess whether it was specifically the MWEs selected from the text at the end of each class that stood the best chance of being remembered by both groups of students, I tallied the MWEs targeted in the tests that each student included in this selection and compared their successful post-test responses on these items to their success rates on target MWEs which they did not select. Again, the MWEs which individual students already knew at pre-test were excluded from these counts. Target MWEs which students in the experimental group included in their end-of-class selections stood a $38 \%$ and $26 \%$ chance of being recalled in the near-immediate and the delayed post-test, respectively. This compares to $20 \%$ and $11 \%$ for target MWEs they did not select. Also, in the comparison group the target MWEs that were included in the lists stood a much better chance of being 
recalled in the near-immediate post-test (44\%) and the delayed post-test (26\%) than target MWEs which were not included in the lists (22\% and $13 \%$, respectively). It was thus MWEs which students considered useful additions to their own lexical repertoires that tended to be remembered the best.

\subsection{Conclusion}

In this chapter, I have presented the findings from the participants' test results in different directions and dimensions. The analyses have taken into consideration factors concerning both the learners and the target items. Inevitably, there are other factors that might have come into play. Such factors may include the time the items appeared during the course, the number of their occurrences, or the number of words in each item, including both content words and function words. That said, the pool of target items in this project may not be large enough for all these factors to be addressed. The next chapter, in which learners' actual strategies in dealing with MWEs in reading texts are revealed, will provide more explanations for their performance in the MWE recall tests. 


\section{CHAPTER 5 - STUDENTS' DISCOVERY STRATEGIES IN MULTIWORD EXPRESSION EXTRACTING ACTIVITIES}

\subsection{Introduction}

This chapter reports the findings from experimental students' self-recordings during their pairwork text-chunking discussions. The qualitative analysis of this dataset aims to find answers to these research questions:

1. What factors influence learners' intuitive extraction of MWEs from authentic texts? How successful are learners in using those factors?

2. How do learners engage with the meanings of word combinations they perceive as established MWEs? How successful are they in doing so?

3. How do the learners decide on what MWEs were worth learning?

It is worth noting that while the first question examines how learners process the form of attended word strings, the second question looks into their on-line process of discovering the meanings of those strings from what they have at their disposal.

The investigation of students' discussions reveals four chronological stages in their process of extracting MWE candidates from text (see Figure 5.1). These stages include their initial hunches about a word combination, their seeking confirmation of the chunk status of the combination from the other pair member, their engagement with its meaning, and their evaluation of the usefulness of the chosen MWEs. Students may or may not go to the fourth stage since at times what makes an MWE worth learning to them is repeated and can be understood between the pairs. These stages will be further detailed and illustrated in the following sections of this chapter.

\subsection{What drove learners' initial hunches in identifying the forms of MWEs?}

In this section, the most influential factors that draw learners' attention to certain word strings in the first place will be presented. These factors are of paramount importance to students' independent chunking activities since they act as the very first filter where useful MWEs may be recognized, overlooked, misinterpreted, or mal-constructed. 
Figure 4.1. Learners' discovery strategies with new MWEs

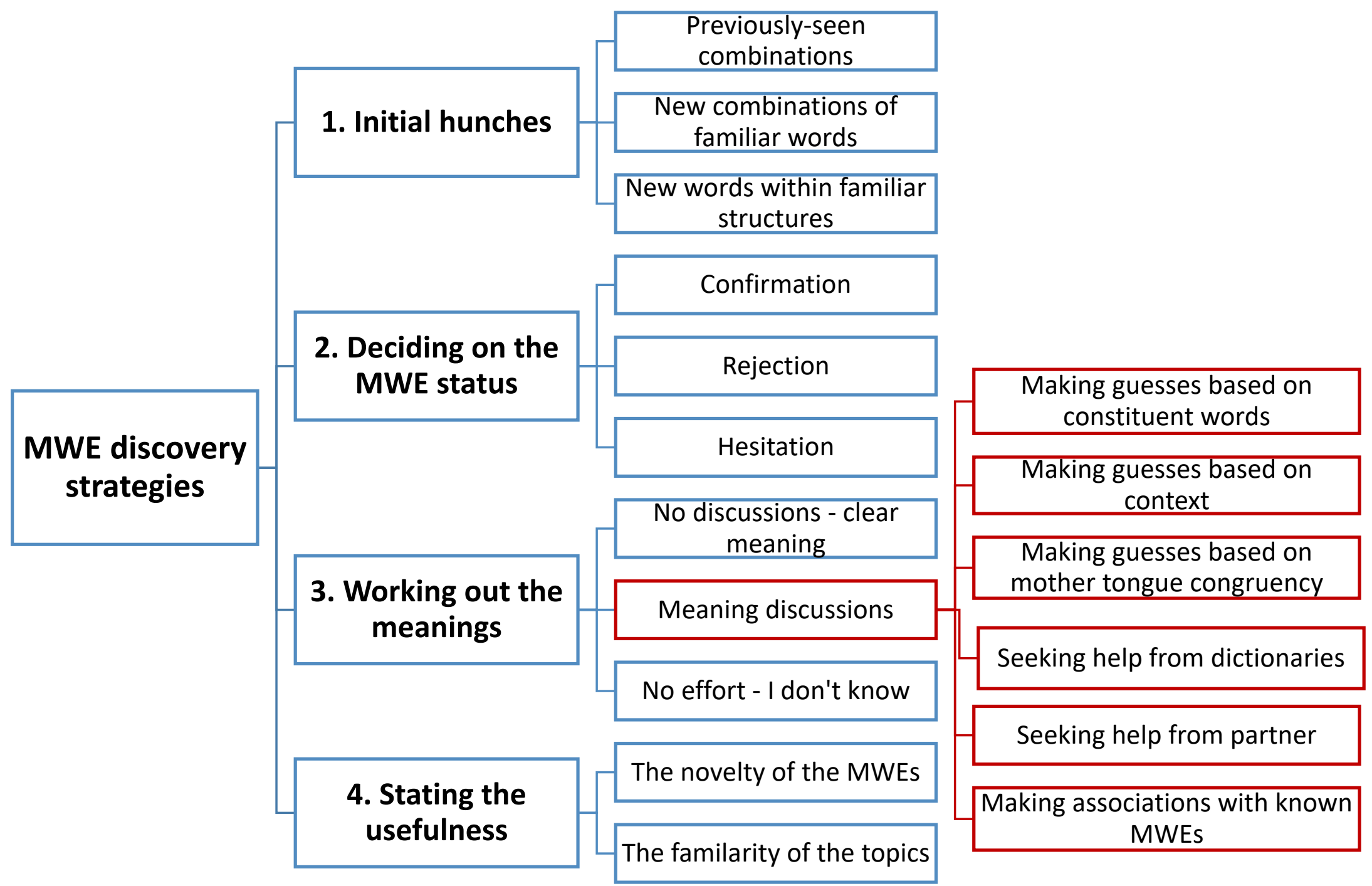


It is observable from the data that during their discussions, students did not always mention the reasons why they speculated that a certain word string is an MWE. This phenomenon happened more often towards the end of the semester, possibly due to the learners' familiarity with the activity and the tendency to avoid repetition of ideas. That said, among the reasons mentioned, the most significant ones involve something already familiar to them, rather than something brand new. Those familiar elements might be previously-seen intact combinations, familiar constituent words, or the familiar way brand new words are bound together, i.e. the structures. The following section provides a detailed presentation of those factors with evidence from the students' on-task recordings.

\subsubsection{Previously-seen intact combinations}

Two categories of familiar-looking combinations were mentioned in students' discussions. The first category stems from the repetition of certain phrases in the same texts. Students tend to refer back to the previous occurrence of such phrases as a clue to anchor their intuition. This reference also helped students manage the boundary of the chunks under consideration by realizing the actual length of the chunk apart from their changeable parts (see Excerpts below). In these excerpts, pseudonyms are used for the sake of confidentiality. Whenever students used Vietnamese in their discussions, their exchanges are translated into English and displayed on the right. Also, as this is a pairwork activity, I put both names in the pairs as references instead of tracking who said what.

Back to the point about how the learners managed the boundary of possible MWEs, Excerpts 1-4 below demonstrate how the four phrases 'when it comes to', 'sift through', 'a sea of', and 'make it through' were detected thanks to their recurrence in the texts.

\section{Excerpt 1}

Vietnamese

Mình chon cum là 'when it comes to', vì có 'when it comes to love' và when it comes to friendship'.

\begin{abstract}
English translation ...I chose the phase "when it comes to' because there is 'when it comes to love' and 'when it comes to
\end{abstract} friendship'.

(Hương \& Mai - Week 4) 


\section{Excerpt 2}

...but I think 'sift through' is one of the good ones because I can see it twice, right? Yeah, one is 'sift through the information', and one is 'sift through a sea of decisions'. So, I think it's a good phrase, and I've seen 'sift through' before.

(Trúc \& Hoàng - Week 3)

\section{Excerpt 3}

Vietnamese

Cụm tiếp theo là 'a sea of information'... Vùra nãy là 'a sea of decisions'. Vậy phải là 'a sea of'.
English translation

(The next is 'a sea of information' ...Just now it's 'a sea of decisions'. So, the chunk should be 'a sea of'.

(An, Nga, \& Hải - Week 3)

\section{Excerpt 4}

'To make it through the end', 'to make it through alive'... so the chunk is 'make it through'.

(Hồng \& Đào- Week 5)

In all of these excerpts, students showed their keen eye for detail when easily recognizing an expression appearing earlier in the text and picked it out. They also realized the importance of the phrase when its number of occurrences is greater than that of other set expressions in the same text.

The second category consists of other high-frequency phrases that students had seen before through their exposure to other language resources either in the language classroom or elsewhere. Students stated that these chunks were interesting to them as they remembered seeing them a few times before but had not managed to add them to their active vocabulary. They also implied that as those phrases had rung a bell because of their high frequency of use, they would like to once again note them down and try to memorize them for future use. In other words, they realized the importance of adding those phrases to their lexical repertoire, especially when they could clearly see the evidence that those phrases are real MWEs. Let's examine this phenomenon in the following extracts in which the learners spotted such high-frequency MWEs as 'at stake', 'associated with', 'at one's disposal', and 'at first glance'. 


\section{Excerpt 5}

Vietnamese

'At stake' nghĩa là gì nhi?? Quen lắm

nhé. Mình sẽ kiểm tra lại, vì tôi nhớ tôi

gặp tì̀ này rồi.

\begin{abstract}
English translation
English translation

What does 'at stake' mean? It looks

familiar. I will check, because I

remember seeing this phrase before.
\end{abstract}

(An \& Hằng - Week 8)

\section{Excerpt 6}

And the second phrase is 'associated with'. I've seen this phrase many times before in some other texts or other sources.

(Na \& Cam- Week 5)

\section{Excerpt 7}

I think it's [at their disposal] quite formulaic. We hear it a lot. This phrase appears a lot in conversations and talks.

(Hồng \& Đào- Week 3)

\section{Excerpt 8}

And the last chunk I want to share with you is 'at first glance'... It's not new to us, I think so. It is quite easy to understand its meaning, but the problem is I don't often use it in speaking and writing as well...

(Bình \& Trang - Week 3)

As can be seen in Excerpts 5-7, other students simply mentioned that they had seen the phrases before. In Excerpt 8, Bình and Trang even pointed out that even though the meaning of 'at first glance' did not pose a difficulty to their comprehension, they had not mastered the knowledge of the phrase and produced it in English.

The extracts in this subsection have shown that in authentic texts, high-frequency MWEs which should be included in students' phraseology may naturally occur more often than others and get learners' attention in that way. That is, the occurrence of various highfrequency MWEs is the most prominent and salient factor that can drive learners' hunches in their intuitive MWE extraction. 


\subsubsection{New combinations of familiar constituent words}

New combinations of familiar words are the second most important element (as shown in Table 5.2, Section 5.3.1) that made learners attend to an expression in their search for possible candidates of established MWEs. The students sounded more excited and confident in the recordings when they began to discuss new strings of which the constituent words were familiar to them. The fact that students were familiar with those words either was stated by the students themselves or could be inferred from their vocabulary size measured prior to the treatment. For example, as their average vocabulary size measured was at 4500 word families (see Chapter 3), and if the constituent words belonged to the first 3,000 words, it is highly likely that those words were known to this cohort of learners.

To emphasize the fact that the combinations were novel to them, students used such phrases as 'first time I have seen this', 'I haven't seen this before', or 'new' (see Excerpts 9-11). In these Excerpts, the phrases are relatively transparent, or the meaning of such phrases did not pose any difficulty to students' comprehension of the text. It is merely the novel ways that these words are combined that interested the students. As EFL learners, they found in these phrases the native-like expressions of ideas. Thus, with these compositional word strings, discussions stopped when the learners felt that the meanings were clear and fitted the contexts.

\section{Excerpt 9}

- The first chunk I found in the text is 'a sea of'. Do you know that?

- No...In your opinion, what does it mean? And when we can find...or where we can find its meaning?

- Actually, this is the first time I see it. I think it means 'a lot of'.

(Bình \& Trang - Week 3)

\section{Excerpt 10}

- In the first line, we have 'a sea of decisions'. I think it's pretty new to me. I haven't seen it before.

(Hồng \& Đào- Week 3)

\section{Excerpt 11}


- How about 'sharpen focus'? - I haven't seen it before, so it's interesting to look further into this.

(Hồng \& Đào- Week 7)

Apart from new combinations of familiar words with transparent meanings, MWEs with opaque meaning were also intriguing to the learners. They pointed out that the addition of the meanings of the constituent words did not make sense in the given contexts, and that this alone offered a good reason for considering whether the phrases qualified as MWEs. Excerpts $12 \& 13$ clearly demonstrate how students reasoned their choices in the cases of 'when it comes to' and 'bad rap'.

\section{Excerpt 12}

Vietnamese

English translation

Mình chọn cụm là 'when it comes to', vì có 'when it comes to love' và 'when it comes to friendship'. Chon cum ấy vì đầu tiên là nghe nó thuận tai này, tiếp là khi mà tách riêng các tù đấy ra thì rất khó để hiểu nghĩa, và ko có nghĩa lắm, thế nên khi đi cả cụm nhu vậy mói có nghĩa.
I chose 'when it comes to' because I could see 'when it comes to love' and 'when it comes to friendship'. I chose it first because it sounds right to say so, and second because it is hard to understand this phrase from understanding the meaning of the constituent words separately. It doesn't really make sense that way, so it must be the whole chunk that makes it meaningful here.

(Hương \& Mai - Week 4)

\section{Excerpt 13}

Vietnamese

English translation

Đầu tiên là 'bad rap'. Chắc chắn 'bad rap' ở đây không thể mang cái nghĩa bình thường là một bài rap, nên chắc nó phải mang một nghĩa gì đó khác với nghĩa thwờng của tì rap.

The first phrase is 'bad rap'. Definitely, the word 'bad rap' here must not carry the normal meaning as a rap song, so it must have some different meaning.

(Hương \& Mai - Week 5)

It can be seen that in both cases, the learners started from speculating that a string is an 
established MWE. Then they tried to decipher the literal meaning of the string by inferring from the meaning of the constituent words. When the deciphered meaning did not fit the existing context, they can more strongly confirm the MWE status of the intact string. The next step will possibly be working out the real meaning of the non-compositional MWEs. The different steps students took when investigating the forms of new MWEs are illustrated in Figure 5.2.

Figure 5.2. How learners identify the forms of new MWEs of familiar words

\section{COMPOSITIONAL MWES}

These words I know are bound in a special way. The combination might be an MWE.

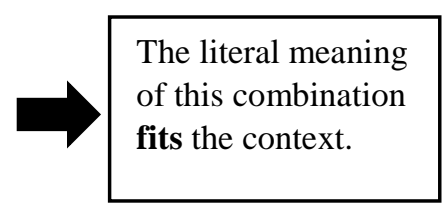

\section{NON-COMPOSITIONAL MWES}

These words I know are bound in a special way. The combination might be an MWE.
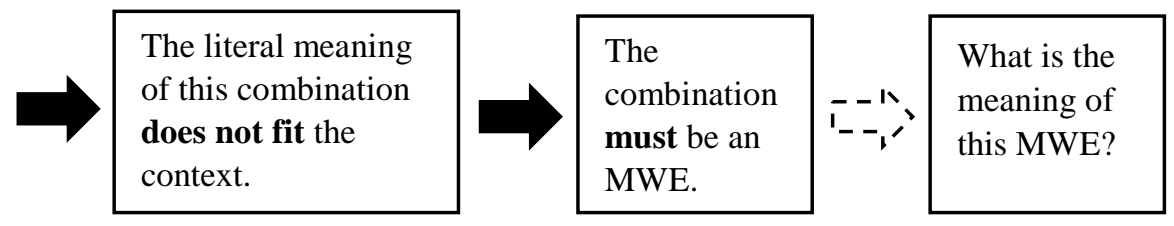

In addition to the factor of the opaqueness in meaning, new combinations of known words may draw learners' attention to their perceived grammatical irregularity. In Excerpt 14 below, Ngần and Thương elaborated how the form of adjacent words alerted them about the possibility that 'switch over to $+\mathrm{N}$ ' was a set expression and helped them to manage the boundary of the expression at the same time. 


\section{Excerpt 14}

Uh, tù tiếp theo là 'switch over to enjoying'. Vậy cum này là 'switch over to'. Đầu tiên chỉ nghĩ 'switch over' là một cum, còn 'to' là to $V$ gì đó, nhurng lúc sau lại thấy là 'to enjoying', môt danh tùu, có nghĩa là cum cố định sẽ là 'switch over to'.
Yep, the next is 'switch over to enjoying'. So, the phrase is 'switch over to'. At first, I thought 'switch over' is a set expression, and 'to' is followed by a verb in its infinitive form. Later I saw 'to enjoying', a gerund, which means the set expression should be 'switch over to'.

(Ngần \& Thương-Week 5)

In this subsection, various illustrations have shown how novel combinations of familiar words can drive the learners' attention in their MWE extracting process. These combinations can be transparent or opaque in meaning as well as irregular in their grammatical structure. In the next subsection, how students attended to combinations of opposite features, which are brand new words in familiar structures, will be reported.

\subsubsection{Combinations of brand-new words within familiar structures}

It is worth mentioning one more time that these participants are English-major students. Hence it is not a surprising fact that they had good metalinguistic knowledge which might have informed their intuition when they encountered word strings with words unknown to them but appearing in familiar structures. Those structures can be in the form of phrasal verbs, prepositional phrases, binomials, compound nouns, verb-noun collocations, or other frames such as a/the + Noun + of + Noun (see Table 5.1). As can be seen in Table 5.1, not all the phrases that were picked out are established MWEs, as in the case of scrutiny and skepticism.

Table 5.1. Combinations of new words in familiar structures

\begin{tabular}{ll}
\hline Structures & Example MWEs that were identified \\
\hline Verb+Prep+(Prep) & squeal with, be bombarded with \\
\hline prep + Noun & at stake, out of the blue \\
\hline binomials & scrutiny and skepticism \\
\hline
\end{tabular}




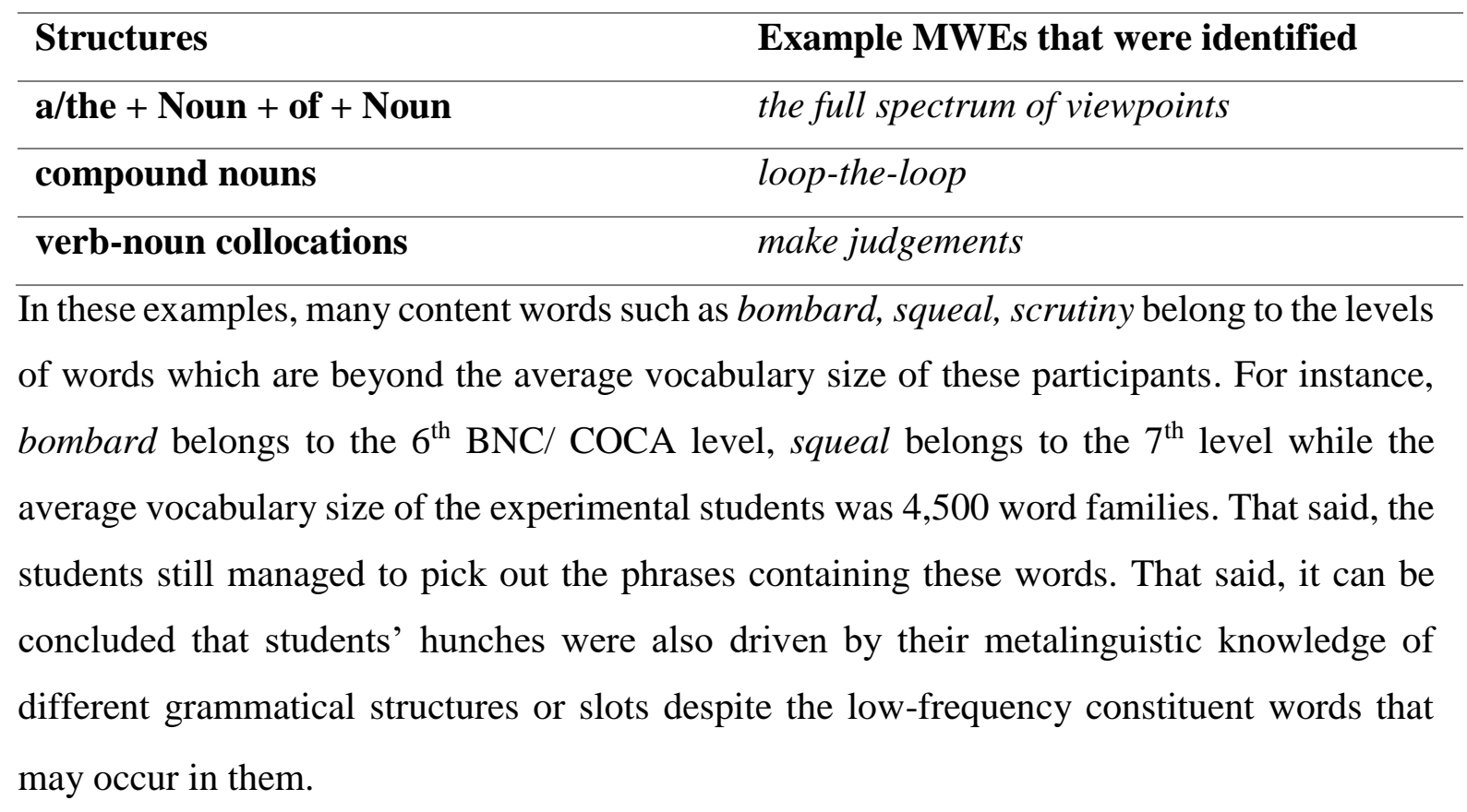

\subsection{What drove learners' decisions on the MWE status of word strings?}

Subsequent to the initial stage of students' paying attention to certain word strings is the stage in which they, in pairs, sought confirmation of the chunk status of the strings. In other words, they were discussing the forms of considered word strings and trying to reach an agreement on whether or not they were established MWEs. There are three possible scenarios: both students may confirm the possibility that the combination is a MWE; one of them or both may reject the possibility; or both may just leave the case open, without drawing a conclusion. I will elaborate each scenario in the following subsections.

\subsubsection{What makes learners decide a word string is an MWE?}

In the first scenario, with their shared knowledge of the English language and certain degrees of familiarity aforementioned, pairs may intuitively agree on the chunk status of certain MWEs. Out of 512 instances of pairs agreeing on the chunk status of word strings, 436 were established MWEs, which means $85.15 \%$ of these intuitive decisions were successful (see Table 5.2). It is worth mentioning that the number of instances means the number of times different pairs mentioned various MWEs, not necessarily the number of MWEs mentioned, since the same MWEs might be discussed by different pairs. Also, the criteria to gauge the success of the learners' MWE identification were mentioned in Section 3.10.2. 
Statistically speaking, when students explained the reasons why they considered certain word strings MWEs, the most frequently-mentioned was 'previously-seen intact combinations', which accounts for $41.46 \%$ of students' successes in identifying established chunks. The second most common factor was 'new combinations of familiar words' at $38.41 \%$. Down the list is the factor of 'brand new words with familiar structures' at $20.13 \%$.

Also, as can be seen from Table 5.2, 14.85\% of the learners' decisions when they confirmed the chunk status of different word strings were mistaken. Among the 76 cases of these 'mistakes', as many as 52 instances were due to students' wrong intuition leading them to choose free combinations of words. Let us examine some examples. In Excerpts 15-18 below, students did not reason much about why they thought these strings might be chunks, which means they may have based their decisions merely on intuitions. The appearance of the words like 'underdog', 'bugs', or 'hair' in Excerpts 15 and 16 might have alerted these students about different idioms in English, and also in Vietnamese, with the use of animal and human body part images.

Table 5.2. Roles of different factors in learners' confirmation of MWE status

\begin{tabular}{|c|c|c|c|c|c|}
\hline \multirow{8}{*}{$\begin{array}{l}\text { Confirma- } \\
\text { tion of } \\
\text { MWE status } \\
(512 \\
\text { instances })\end{array}$} & & & Reasons & $\begin{array}{c}\text { No. of } \\
\text { instances }\end{array}$ & $\%$ \\
\hline & \multirow{4}{*}{$\begin{array}{l}\text { Successes } \\
436 \\
\text { instances } \\
(85.15 \%)\end{array}$} & \multirow{3}{*}{$\begin{array}{l}\text { Reasons } \\
\text { explained } \\
\text { (164 instances) }\end{array}$} & $\begin{array}{l}\text { Previously-seen intact } \\
\text { combinations }\end{array}$ & 68 & 41.46 \\
\hline & & & $\begin{array}{l}\text { New combinations of } \\
\text { familiar constituent } \\
\text { words }\end{array}$ & 63 & 38.41 \\
\hline & & & $\begin{array}{l}\text { Brand new words within } \\
\text { familiar structures }\end{array}$ & 33 & 20.13 \\
\hline & & \multicolumn{2}{|l|}{$\begin{array}{l}\text { No explanations } \\
\text { (272 instances) }\end{array}$} & & \\
\hline & \multirow{3}{*}{$\begin{array}{l}\text { Failures } \\
76 \\
\text { instances } \\
(14.85 \%)\end{array}$} & \multicolumn{2}{|c|}{ Wrong intuition - Free word combinations } & 52 & 71.23 \\
\hline & & \multicolumn{2}{|c|}{ Failures in managing the boundary } & 16 & 21.05 \\
\hline & & \multicolumn{2}{|l|}{ Others } & 8 & 7.72 \\
\hline
\end{tabular}




\section{Excerpt 15}

Vietnamese

English translation

Đầu tiên là cái 'the victory of the

underdog'. Mình nghĩ nó là một cái idiom

nào đấy.

First is 'the victory of the underdog'. I think it is an idiom.

(Lê \& Hải - Week 7)

\section{Excerpt 16}

- So, the second phrase I think is about 'digging bugs and dirt out of your pal's hair'. This one I didn't really know it, but I guess it's something that you're trying to find out about your friends, people or partners, more about their characteristics maybe.

(Trúc \& Hoàng - Week 4)

Similarly, Excerpts 17 and 18 illustrate how combinations of a verb and a noun like 'rest one's brain' and 'get over a broken arm' were considered potential MWEs. This association may have resulted from students' exposure to multiple verb-noun collocations in English, which will be discussed more thoroughly in the next subsection about students' rejection of the chunk status of some MWEs.

\section{Excerpt 17}

Vietnamese

English translation

'Rest one's brain'. Cái này dễ hiểu nhung tôi nghĩ nó là một chunk.

'Rest one's brain'. This is easy to understand, but I think it's a chunk.

(An \& Hằng - Week 8)

Excerpt 18

Vietnamese

English translation

- Với lại cái 'get over a broken arm'. - Ở đúng rồi.

- And 'get over a broken arm'?

- Yes, it is.

(Thanh \& Dương - Week 9)

Another factor that may lead to students' failure in identifying an established MWE is their failure in managing the chunk boundaries. To put it another way, students sometimes found it difficult to pinpoint where a chunk started and stopped. As a result, what they picked were 
not the entire chunks but ones either with some redundant parts or without certain constituents. Let's have a closer look at some Excerpts.

\section{Excerpt 19}

Vietnamese

English translation

- Cưm đầu tiên tớ nghĩ là 'comes to', đúng không? Nghĩa kiểu nhu 'khi mà' ây, 'when it comes to friendship', khi mà nhắc đến tình bạn, người ta thường....

- Còn có 'comes to love' này...

- The first chunk I think is 'comes to', right? It kinda means 'when', 'when it comes to friendship', meaning when mentioning friendship, people often... - Here I can see 'comes to love' also...

(Thanh \& Dương - Week 4)

In Excerpt 19, while the chunk should be 'when it comes to', the students only picked out 'comes to', making it a meaningless combination of two words that might pose a challenge when they use it in the future.

Turning to Excerpt 20, it is worth looking at the context in which this combination is included, which is "An artist friend recently told me that she was taking part of September off to travel, rest her brain, and "get out of my routines."'”. As can be inferred from this sentence, the fact that the phrasal verb 'take off' is separated by the noun phrase 'part of September' may have hindered the students from picking the right MWE out. Though their way of explaining why they thought 'off to travel' might qualify as a chunk is interesting, this is not the case here.

\section{Excerpt 20}

Vietnamese

English translation

- 'off to travel' phải không?

- Chắc phải đấy.

- Thấy off không liên quan gì đến September, nên chắc là off to travel...Kiểu để đi du lịch hay là gì?

- 'off to travel' right?

- Seems to be.

- I can see that 'off' has nothing to do with 'September', so I think 'off to travel' is a chunk...Something like to go traveling or something like that?

(Bình \& Trang - Week 8) 


\subsubsection{What makes learners decide a word string is not an MWE?}

Thus far, the data has shown that several factors can drive learners towards the selection of possible MWEs. These factors include both lexical and structural familiarity. There are also other factors driving them away from particular choices such as the replaceability of constituent words and even their mere intuition.

The substitutability of constituent words is the most commonly-mentioned factor that makes students think that the word string is a free combination of words. This seems contradictory with what has been mentioned above among the factors that make students think that a string is an MWE. On the one hand, some slots like verb-noun collocations or 'noun of noun' can remind some students of some types of MWEs they are familiar with and decide that they may be prefabricated structures. On the other hand, to other students, the fact that a constituent word in a phrase can be replaced by other words can make them decide that the whole structure is an unprincipled formulation of single words and therefore are not qualified MWEs. The replaceability of constituent words in slots led to quite a few instances of students' rejection of the chunk status of word strings, which turned out to be their right decisions in several cases. For example, in Excerpt 21, one student pointed out that 'make me a millionaire' was not an MWE because any nouns referring to people or things can replace the two latter parts of this phrase. It can be inferred from this Excerpt that these learners paid much attention to the fixedness of MWEs when identifying MWE instances in texts. The same reason was mentioned by students in Excerpt 22 for the rejection of 'overshadow significant opportunities' and 'build the resilience'.

\section{Excerpt 21}

Vietnamese

- 'Make me a millionaire' có được không?

- Không, chi là make somebody do something, bình thuoòng mà, quen thuộc rồi.
English translation - Is 'make me a millionaire' a chunk? - No, it's just 'make somebody something', nothing special.

(An, Nga \& Hải - Week 3) 


\section{Excerpt 22}

Vietnamese

English translation

- Có 'overshadow significant opportunities'?

- Tó nghĩ không phải là cưm ấy, chỉ là overshadow cộng với cái significant ...

(Hải \& Lê - Week 6)

\section{Excerpt 23}

Vietnamese

English translation

- 'Build the resilience'...

- 'Build the resilience'...

- Giống nhu build something nhi?

- Is it 'build something'?

- Uh, build có thể đi được với nhiều tù̀ lắm.

- Thôi bỏ đi.

- Yes, 'build' can go with many words.

- Let's skip it.

(Dương \& Ha - Week 7)

On the other hand, learners' doubt about the substitutability of constituent words in certain chunks can lead students to skipping real structures, especially in the case of collocations, which second language acquisition researchers agree pose learning difficulties for EFL/ ESL learners (e.g. Laufer \& Waldman, 2011; Nesselhauf, 2005; Siyanova \& Schmitt, 2008). For instance, in Excerpt 24 below, Thanh and Dương reject the MWE status of 'significant improvement'. Nevertheless, the collocation 'significant improvement' appears 929 times in COCA (retrieved in November 2018), making it an established MWE according to our aforementioned criteria.

\section{Excerpt 24}

Vietnamese

- Significant improvement?

- Chẳng phải. Cái đấy cũng có thể là 'important improvement', nếu có thể thay được bằng tù khác thì là không phải.

\begin{abstract}
English translation
- Significant improvement?

- No. This phrase can also be 'important improvement'. If you can change a word in the string, it's not a chunk.
\end{abstract}

(Thanh \& Dương - Week 10) 
This pair even pointed out that a word string did not qualify as an MWE if one word in it could be replaced. This comment reveals the students' misconceptions about slots with certain degrees of flexibility in the pool of established MWEs. Surprisingly, this conversation took place in the last week of the treatment.

Excerpt 25 is another case in point. While Trúc found 'suit your needs' to be an interesting phrase which diversified the ways she expressed an idea, Hoàng cast some doubt on the chunk status of the phrase since the verb 'suit' can be replaced by other verb options. Once again, the search command for SUIT * NEED yielded 311 hits in COCA, which meets the criterion we set for it to qualify as a chunk.

\section{Excerpt 25}

- $\quad$ The second one is 'suit the needs'...I just use 'needs' with 'acquire your needs' or 'apply your needs'...

- I think that 'suit' is something like 'fit'. Yeah, I think it's a phrase, but it's not really...nice phrase because 'suit your needs' you have many phrases like that ...It does not really go together. It's just... you can choose many phrases to get into 'your needs' position, so I don't think 'suit your needs' should be...

(Trúc \& Hoàng - Week 3)

In Excerpts 21-23, learners were thinking about different slots or frames that words can be filled in despite rejecting the MWE status of the phrases. In Excerpt 26 that follows, they parsed the sentence and confirmed that the string under examination was a free combination. More specifically, one student considered that 'linger for', which has the structure of a phrasal verb, might be a formulaic sequence. The other student in the pair pointed out that the preposition belonged to the noun phrase that followed and rejected the chunk status of 'linger for' in this context.

\section{Excerpt 26}

- Yeah, maybe in this text, 'It lingers for at least two consecutive weeks, and significantly interferes with one's ability to work, play, or love', the phrase is 'linger for'.

- Idon't think it is a phrase, it is one word 'linger', and 'for' is for the following phrase 'at least two consecutive weeks'.

(Tú \& Hoa- Week 9)

At times, learners just rejected the MWE status of a string by pure intuition. As shown in Excerpt 27, Hồng and Đào did not pinpoint the linguistic reason why they thought 'more 
likely to be' was not a chunk. It is noteworthy that this is a highly competent pair in the group.

\section{Excerpt 27}

- 'More likely to be'? Is it a chunk?

- No.

- You need to give a reason?

- Ijust don't feel it.

(Hồng \& Đào- Week 4)

\subsubsection{What makes learners hesitate about the MWE status of a word string?}

If known words could lend themselves well to students' selection of possible MWE candidates, unknown words, on the other hand, raised some amount of hesitation in students' decision-making process. That said, students could not make a decision on the MWE status in only nine cases out of 521 instances of word strings discussed. It is notable that this indecisiveness resulted from the appearance of unknown words. The learners showed their uncertainty by means of such words as 'not sure', 'don't think', 'don't know'.

Excerpt 28 demonstrates the discussion between Bình and Trang in week 3 about the string 'a full spectrum of viewpoints'. These students attended to this combination, maybe because its structure was somewhat familiar with them (i.e. a Noun of Noun, as mentioned in Section 5.2.3). Nonetheless, unlike in other pairs, their linguistic intuition diverted them away from confirming the chunk status of the word string.

Excerpt 28

- The next is 'a full spectrum of viewpoints'.

- What do you think about this chunk? Its meaning, do you know it?

- On second thoughts, I don't think it's a chunk.

- It's not a chunk, right?

- Because I don't know the meaning of 'spectrum'.

- Yeah, it is a new word to me as well.

- And I'm not sure whether it is a chunk.

(Bình \& Trang - Week 3)

Unknown words not only made students more cautious in their intuitive choices of MWEs but also prevented them from exploring and taking risks. Students even stopped underlining or highlighting strings of unknown words, as seen in Excerpt 29 below. 


\section{Excerpt 29}

Vietnamese

English translation

Chính ra bài này tớ thấy có khá nhiều tù mới... Thực ra bài này tớ không tìm được nhiều slangs, mà tớ thấy nhiều tù mới hơn. Tó nghĩ là nếu tìm đurợc nghĩa của tù mói thì sẽ hiểu được bài hơn, và tìm được nhiều slangs hơn...
English translation

In this reading passage, I can find many new words... I can't find many slangs [chunks - my explanation] but only new words. I think if I can understand the meanings of these new words, I can understand the text more, and can see more chunks.

(Bình \& Trang - Week 8)

Thus, the appearance of new words in the text hindered students' intuitive extraction of possible MWEs. Of note, Bình and Trang in this conversation used 'slangs' to refer to formulaic sequences. Since their discussions showed that they were paying attention to fixed phrases of some kind, this mislabeling possibly did not affect their behaviors during the intervention.

\subsection{How did learners work out the meanings of novel MWEs?}

The analysis of students' audio-recordings revealed three possibilities of how the learners dealt with the meanings of word strings they deemed established MWEs: 1. Students moved on to other possible MWEs without stating or discussing the meanings; 2. Students tried to guess the meanings; and 3. Students directly stated that they had no clues to guess the meanings (see Table 5.3). Obviously, these possibilities occurred during their text-chunking discussions and before students sought help from their pair partners or dictionaries. Table 5.3 shows that in more than half of the cases (51.25\%), students did not make any comments on the meanings of the phrases they mentioned. This might be because the meanings of the phrases were transparent to the students, and they did not feel the need to clarify the meanings of those phrases explicitly. The second most common possibility (39.64\%) in which students discussed the possible meanings of the phrases will be discussed further below. In $9.14 \%$ of all the instances, students stated that they could not guess the meanings and would check in the dictionary later. 
Table 5.3. Learners' engagement with the meanings of MWEs

\begin{tabular}{lll}
\hline Meaning-related possibilities & No. of instances & \% \\
\hline No meaning discussions & 287 & 51.25 \\
\hline Meaning guessing attempts & 222 & 39.64 \\
\hline No meaning attempts & 51 & 9.14 \\
(Students admitted having no clues to guess the meaning) & & \\
\hline
\end{tabular}

Excerpts 30 and 31 below illustrate students' expression of having no intention to make any guessing attempts on the candidate word strings. The unfamiliar word 'retreat' in 'retreat in terror' and the opaqueness of 'runner's high' might have hindered the students from guessing the meanings of these strings. These excerpts also showed that students did not proceed to investigate the contexts when the constituent words did not provide enough clues for their guessing attempts.

\section{$\underline{\text { Excerpt } 30}$}

- I think there's one more phrase in page 1. It's 'retreat in terror'.

- I think it's a phrase.

- I can't guess the meaning.

(Tú \& Hoa- Week 5)

\section{Excerpt 31}

Vietnamese

English translation

- Runner's high nghĩa là gì?

- Không biết, tra thư xem, tra ở đâu nhi?

- Uh, tra Google đi. Nhì la lắm.

- What does 'runner's high' mean?

- I don't know. Let's try looking it up.

Where?

- Let's Google it. It looks strange.

(Mai \& Nhung- Week 7)

In chronological order, during their meaning-related discussions, students would first make every possible attempt to guess the meanings of new phrases. Subsequently, once they reached an agreement of what a phrase may mean, they might associate the new phrase with some phrases they already knew. In some cases, when the meaning of a phrase seems obvious, students might take a short cut by providing one or more phrases of higher frequency or an L1 equivalent as a way to demonstrate the possible meaning. In case students 
themselves found no clues to guess the meanings, they would resort to asking questions to the other pair member. Alternatively, both students would agree to seek help from dictionaries at hand. Figure 5.3 below illustrates the steps the learners took to work out the meanings of new MWEs.

I will now further examine each of these strategies in turn.

Figure 5.3. Steps of how students worked out the meanings of new MWES

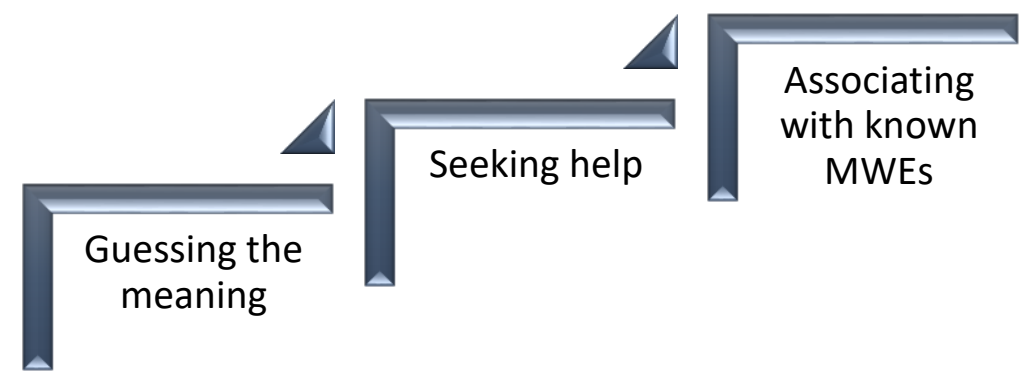

\subsubsection{Guessing the meanings}

Let's return to the possibility when students attempted to guess the meanings of candidate MWEs. The data showed that they would employ strategies when engaging with the meanings of newly-discovered MWEs, including basing their interpretation on constituent words, contextual clues and mother tongue congruency. Table 5.4 below indicates how often these guessing strategies were used and the success rates of each.

Table 5.4. The frequency of use of meaning guessing strategies

\begin{tabular}{lcc}
\hline Guessing strategies & No. of instances & \% \\
& & \\
\hline Based on constituent words & 99 & 71.74 \\
\hline Based on context & 31 & 22.46 \\
\hline Based on mother tongue congruency & 8 & 5.8 \\
\hline
\end{tabular}

\subsubsection{Making guesses based on constituent words}

As shown in Table 5.4, the most commonly-used strategy when the learners guessed the meanings of new phrases was using their understanding of the constituent words, accounting for $71.74 \%$ of the instances discussed. Just like when guessing the meaning of individual 
words on the basis of word parts like word roots, prefixes and suffixes, learners applied a similar strategy to guess the meanings of phrases that interested them. For example, in Excerpt 32, the meaning of 'crack a problem' was inferred from the meaning of the verb 'crack', which is trying to break some hard thing open. Students were confident in this guess to a large extent since the inferred meaning closely fits the context embracing it.

\section{Excerpt 32}

- It ['crack a problem'] means like do something to make the problem clear, or easy to understand, or divide it into smaller pieces so that we can find the solutions.

(Hằng \& Kim- Week 10)

Or in Excerpt 33, the meaning negotiation occurring between the pair members was also based on their knowledge of the constituent words 'light' and then 'spotlight'. This case also provides evidence for the benefit of pairwork meaning negotiation. Both members were contributing ideas from their own knowledge and experience to mutually infer and find out the correct meaning.

\section{Excerpt 33}

Vietnamese

English translation

- Cưm đầu tiên là 'in the spotlight'. Cái này thì nghĩa kiểu nhu ở duoói ánh hào quang... Spotlight giống nhu ánh đèn flash khi chup ảnh ấy...

- Spotlight là kiểu tiêu điểm...

- Ah nhầm, giống nhu ánh đèn sân khấu... Vậy cưm 'in the spotlight' có nghĩa là tập trung nhiều ánh nhìn, kiểu nổi bạt...
- The first phrase is 'in the spotlight'. This means a lot of light...Spotlight is like the flashlight when you take photos...

- No, spotlight is like the focus point of light... - Oh yeah, just like the stage light...So the phrase 'in the spotlight' means attracting many eyes, like being very outstanding...

\section{(Ngần \& Thương-Week 6)}

In a similar vein, students may guess the meaning of a compound word or an idiom by translating the meaning of each constituent word to see its literal meaning before moving forward to working out its figurative meaning that might fit the context. A case in point is the scenario which can be imagined from Excerpt 34 . The students were possibly creating in mind a picture of someone really putting his foot in his mouth, which would look awkward 
and unnatural, not to say very weird and even wrong. Since the mouth might be a metonymy of someone's speech, it can be further inferred that he had said something wrong, something that he should not have put into words. This case has shown how students went from the literal meaning of the idiomatic phrase based on its constituent words to its figurative meaning.

\section{Excerpt 34}

Vietnamese

English translation

- Tiếp đến là 'put his foot in his mouth', kiểu cho chân vào mồm...

- Nghĩa là nhõ̃ lời, nói gì đó mà người ta không thích.

- The next one is 'put his foot in his mouth', like cho chân vào mồm [literal translation of 'puts his foot in his mouth' - My explanation] ...

- Meaning he said something wrong, something that other people didn't

like...

(Mai \& Nhung- Week 6)

\section{Excerpt 35}

Vietnamese

English translation

Stomach drop...Kiểu giống nhur là lo lắng, dạ dày tụt xuống, lo lắng, sợ hãi.

Stomach-drop...It's like being worried, as your stomach drops, being worried,

frightened.

(Bình \& Trang - Week 5)

Similarly, in Excerpt 39, students literally translated the two constituent words of the compound adjective 'stomach-drop' into Vietnamese, drew a virtual image of what was being described, then inferred the meaning that fit the context depicting people's sensations when being in a roller coaster. In this guessing attempt, the students can be seen to use both tactics, including drawing from constituent words and the context, which will be mentioned in the next subsection.

\subsubsection{Making guesses based on context}

The second most frequently-used meaning guessing tactic employed by students is basing on the context, accounting for $22.46 \%$ of their attempts (see Table 5.4). This is, in all likelihood, 
one of the habits developed from the students' dealing-with-unknown-words skills in their reading. In most of the cases, students would refer to the whole sentences which contain the phrases under consideration to make the guesses, to try fitting the inferred meanings into the given contexts, and to confirm or reject the guesses.

The fact that students used the context for their meaning guesses is represented by such phrases as 'in this sentence', 'in this context', or 'let's look back at the context'. Likewise, students sometimes read the sentences aloud and interpreted what was being said in the context itself. Excerpt 36 illustrates how the students made use of contextual clues to work out the meaning of 'approach a question'.

\title{
$\underline{\text { Excerpt } 36}$
}

Vietnamese

- Approach a question nghĩa là gì, giống nhu là 'give out a question' á?

- Không hiểu. Thư xem lai context xem nào. (...)

- Hay là trả lời?

- Kiểu nhu là make decisions to resolve a question, để giải quyết một vấn đề.

\begin{abstract}
English translation
- What does 'approach a question'

(Thanh, Dương \& Ha - Week 3)
\end{abstract}

In Excerpt 37, students' dependence on the context to make their guesses is indirectly expressed. A closer look at the context of the expression 'put his foot in his mouth' reveals that based on some keywords in the context like 'speak', 'not...want to see', 'the more', students could infer that Donald Trump talked a lot and that he had said something that his supporters did not want him to say. In other words, he might have made many mistakes in his speeches, which can be expressed by the expression 'put his foot in his mouth'.

\section{Excerpt 37}

- And the phrase I am most impressed is 'put his foot in his mouth'. Like it has been explained, because he talks too much, so it means he makes a lot of mistakes. 


\section{The context}

'Where other candidates speak in sound bites, Donald Trump speaks in headlinesalthough not always the type of headlines his supporters want to see. The more Trump puts his foot in his mouth, the more media coverage he gets, ...'

(Trúc \& Hoàng - Week 6)

\subsubsection{Making guesses based on mother tongue congruency}

Only $5.8 \%$ of the students' guessing attempts were based on mother tongue congruency according to the recordings, and interestingly all the instances were about the same phrase 'chicken-and-egg question'. Eight out of ten groups in week 4 associated the phrase 'chickenand-egg question' with the story they already knew in Vietnamese and immediately managed to understand the meaning of the phrase. Moreover, they asserted that they found the phrase very interesting and would like to add the phrase to their repertoire. Excerpts 38-41 provide some illustrations of how different groups discussed this same phrase.

\section{Excerpt 38}

- And the last phrase I want to talk about is 'chicken-and-egg question'. In fact, this one I don't know really the meaning, but I am thinking about the story of what comes first, chicken or egg, so I think this is the question of, maybe, haven't got the answer. What about yours?

(Trúc \& Hoàng - Week 4)

\section{Excerpt 39}

Vietnamese

English translation

- Thích cum 'chicken-and-egg question"

- I really like the phrase 'chicken-and-

- Cái mà gà có trước hay trúng có trước egg question'. đấy á?

- Ư đúng, hay giống nhu đây được gọi là quả cam vì nó có màu cam hay màu này được gọi là màu cam vì nó có màu giống màu quả cam.

- Ò', câu hỏi tuần hoàn, ko tìm được câu trả lòi

- Is this about whether a chicken or an egg appears first?

- Yes, it's just like this is an orange because its color is orange, or this color is called orange because it is similar to the color of an orange. - Oh yeah, a circular question to which it is hard to find an answer.

(Thanh \& Dương - Week 4)

\section{$\underline{\text { Excerpt } 40}$}

- $\quad$ The next one I would like to share is 'chicken-and-egg question'.

- It's completely new for me. 
- New?

- The first time I saw this chunk, I think about the story about whether egg or chicken...

- Appear first?

- Yes, appear first, do you think so? It's like an idiom, right? I think it's a difficult question we can't find the answer easily, or it's very confusing to distinguish which is correct.

(Bình \& Trang - Week 4)

\section{Excerpt 41}

- Chicken-and-egg question...

- It's a noun phrase. People often wonder about chicken comes first or egg comes first, and so this is the question that is hard to answer.

(Ngần \& Thương- Week 4)

Therefore, it can be seen that among this group of participants, the mother tongue congruency only occurred in the lexical aspects of the phrases. Students counted on their cultural and experiential knowledge to realize the resemblance in the images used in their native language and the L2 and infer the meaning. Although the students did not mention the Vietnamese counterpart, which is 'chuyện con gà quả trüng', their association could be understood from these excerpts.

\subsubsection{What is the success rate of learners' meaning guesses?}

The data showed that students were trying to apply the meaning guessing strategies mentioned above whenever possible. Nevertheless, this does not mean all their attempts yielded positive results. Table 5.5 indicates the proportion of learners' successful guesses in employing each strategy.

Table 5.5. The success rates of learners' meaning guesses

\begin{tabular}{lcccc}
\hline & \multicolumn{2}{c}{ Successes } & \multicolumn{2}{c}{ Failures } \\
\cline { 2 - 5 } Guessing strategies & $\begin{array}{c}\text { No. of } \\
\text { instances }\end{array}$ & $\%$ & $\begin{array}{c}\text { No. of } \\
\text { instances }\end{array}$ & $\%$ \\
\hline Based on constituent words & 77 & 77.78 & 22 & 22.22 \\
\hline Based on context & 25 & 80.65 & 6 & 19.35 \\
\hline $\begin{array}{l}\text { Based on mother tongue } \\
\text { congruency }\end{array}$ & 7 & 87.50 & 1 & 12.5 \\
\hline
\end{tabular}

Several causes led to these failures, and in most of the cases the causes were derived right from the strategies being used. As can be seen from Table 5.5, the most commonly-used 
guessing strategy, relying on constituent words, has the highest rate of guessing failures (22.22\%). While it could prove helpful in guiding students' guesses with some phrases (mentioned in Section 5.4.1.1), it could be misleading to others. Excerpt 42 below shows that the student literally understood the compound 'walking advertisement' simply by visualizing a situation accommodating both words 'advertisements' and 'walk'. She seemed to be satisfied with this guess, especially when it was readily agreed by her partner. Similar situations occurred in the conversations of several pairs about the phrase 'to mate with' in Excerpts 43-45.

\section{Excerpt 42}

- I think that it ['walking advertisement'] means you can see Trump in every kind of advertisement you walk by.

(Tú \& Hoa- Week 6)

\section{Excerpt 43}

Vietnamese

English translation

- Tiếp theo là 'mate with'... Mate with là gi? Giống nhu là like to stay with someone, kiểu nhu thế.

- Mate trong soulmate, classmate.

- The next is 'mate with'... What does it mean? It is similar to 'like to stay with someone', kinda that.

- Mate like in soulmate or classmate.

(Thanh \& Dương - Week 4)

\section{Excerpt 44}

Vietnamese

English translation

- Mate with, nhu kiểu là make friends with đúng không, nhu kiểu kết bạn nhi?

- Oे.

- Mate with, is it like 'make friends with', like kết bạn [Vietnamese translation]? - Yes.

(An \& Minh Nga - Week 4)

\section{Excerpt 45}

- The next chunk is 'mate with'. And the sentence I find this chunk is “....”. (Students read the sentence aloud.) This means 'make friends' as well. Mate goes with prep 'with', not mate 'to'.

- I think it's similar to 'pair up'.

- Mate just like in classmate, roommate, soulmate. 
(Bình \& Trang - Week 4)

In Excerpt 45, students applied both strategies of guessing from the constituent words and guessing from the context. Under such circumstances, students referred to the context as a way to try fitting the guessed meaning. Unfortunately, the guessed meaning 'make friends with' did not bring about any conflicts or any inappropriateness with the given context, which is 'Barnacle geese prefer to mate with individuals that are similar in size, while in great tit birds, having a similar personality makes all the difference'. Hence, even though the guessed meaning was incorrect, it was still accepted by the students. The next excerpt is also another case in which students made a wrong guess basing it on both the constituent words and the context.

\section{$\underline{\text { Excerpt } 46}$}

Vietnamese

English translation

Đầu tiên là 'a bad rap'. Cụm này ở trong câu là 'Fear has a bad rap, but it's not at all bad.' Cái tù 'rap' ấy nhu kiểu là rapper, một tràng, một chuỗi nhũng điều tồi tệ, nhung câu sau lại ko phải cái nào cũng tồi tẹ.

The first phrase is 'a bad rap'. This phrase is used in this sentence, 'fear has a bad rap, but it's not at all bad.'

The word 'rap' is like in 'rapper', a series of bad things, but the next part of the sentence states that not all things [in the series] are bad.

(Ngần \& Thương - Week 5) The second most frequently-used guessing strategy, using contextual clues, has a slightly higher success rate at $80.65 \%$. In Excerpt 47, the students did base their interpretation on the surrounding words, or the context, with a view to guessing the meaning of the combination 'get caught up in'. However, the context could not help them come up with the exact meaning of the phrase.

\section{Excerpt 47}

Vietnamese

English translation

Tiếp theo là 'get caught up in'. Sau đó là 'thougths, nên chắc nó có nghĩa là mang trong mìn suy nghĩ gì đó. 
this person having some thoughts inside

their mind.

(Hương \& Mai - Week 5)

What they already knew in their L1 culture or experience might also mislead students in their guessing attempts. Let's have a closer look at one typical example found in students' discussions in Excerpt 48 below.

\section{Excerpt 48}

- So, the second phrase I think is about 'digging bugs and dirt out of your pal's hair'. This one I didn't really know it, but I guess it's something that you're trying to find out about your friends, people or partners, more about their characteristics maybe.

(Trúc \& Hoàng - Week 4)

At first glance, it looks like there is no connection between the phrase the students picked out with the meaning they attached to it. There are two issues that can be observed here. First, the combination chosen does not qualify as a chunk. Second, and more importantly, the formmeaning mapping students were trying to build here is inaccurate. Let's investigate what might have happened that led to this misunderstanding. The scenario could be students, in the first place, looked into the literal meaning of the combination from its constituents. Then, they may have considered it likely that this is an idiom since there are quite a few idioms in English using the images of body parts like hair, arms, and fingers. More significantly, they may have thought about a Vietnamse idiom 'bới lông tìm vết' using the same image of trying to find tiny things in animals' hair to describe the action of trying to emphasize small and unimportant details unnecessarily. This is similar to 'split hairs' in English. To sum up, it can be asserted that this pair was using their knowledge both in L1 and L2 to think about this combination as a chunk and then unfortunately attached a wrong meaning to it. It is noteworthy that several pairs shared these ideas that led them to consider 'dig bugs and dirt out of your pal's hair' as a chunk, which may suggest that these students, sharing the same L1 and culture, were thinking in the same direction.

In a nutshell, while the meaning guessing strategies may be helpful to students in many cases, they cannot guarantee that the meaning guesses are accurate. It is possible that these 
misleading guesses can negatively affect learners' vocabulary acquisition, which I will discuss further in the Discussion Chapter.

\subsubsection{Seeking help}

When there were no clues for meaning guessing attempts, students tended to seek help from their partners. Alternatively, they might seek help from dictionaries although this chunking activity focuses more on their intuitions both about the form and the meaning of the chosen combinations. Table 5.6 indicates how often students sought help from their pair partners and the success rates of each strategy. It is worthy of note that the dictionary lookups mentioned here concern cases when students used a dictionary during the pairwork chunking activities, not during the follow-up dictionary and COCA lookup activity instructed by the teacher.

Table 5.6. The frequency of students' help-seeking strategies and the success rates

\begin{tabular}{lccccc}
\hline Help-seeking strategies & No. of & \multicolumn{2}{c}{ Successes } & \multicolumn{2}{c}{ Failures } \\
\cline { 3 - 6 } & instances & $\begin{array}{c}\text { No. of } \\
\text { instances }\end{array}$ & $\%$ & \multicolumn{2}{c}{$\begin{array}{c}\text { No. of } \\
\text { instances }\end{array}$} \\
\hline Seeking help from pair partners & 80 & 53 & 66.25 & 27 & 33.75 \\
\hline Seeking help from dictionaries & 10 & 8 & 80.00 & 2 & 20.00 \\
\hline
\end{tabular}

\subsubsection{Seeking help from pair partners}

As shown in Table 5.6, the students depended more on their partners for help during meaning discussions than on dictionaries. Different learners know different things and discovering the meanings of new words by asking classmates is known to be one of the very helpful vocabulary learning strategies (Schmitt, 1997). Here in this chunking activity, students might have treated the newly found phrases as different units just like different single words, the meanings of which they were curious about. Excerpts 49 and 50 below illustrate that this strategy really worked and could serve as a very convenient and time-efficient strategy for learners to acquire the meaning of the new chunks.

\section{Excerpt 49}

Vietnamese

English translation

- Cưm thú ba là 'in all walks of life'. Nhu' kiểu là...
- The third chunk is 'in all walks of life'. It's kinda... 
- Cái này hay này.

- Cái này nhu kiểu là nhũng buớc đi của cuộc đời ấy.

- Moi tầng lớp xã hôii.

- Ah, mọi tầng lớp xã họi, social classes.
- This is interesting.

- This seems to mean different steps in

life.

- All classes in the society.

- Oh yeah, all classes in the society,

social classes.

(Ngần \& Thương-Week 7)

\section{Excerpt 50}

- And 'to be obsessed with something'.

- Yes, it means that you always think about it, it's always in [on - my correction] your mind.

- Oh, got it, nice.

(Kim \& Hằng - Week 7)

In both excerpts, one learner in the pairs had no idea or perhaps just a fuzzy idea of the meanings of the phrases under consideration: 'all walks of life' and 'obsessed with something'. Luckily, the other learner seemed to know the meanings for certain and shared his/ her knowledge during the discussion. In that way, learners helped each other in working out the meanings of interesting phrases.

Nevertheless, it is not always true that seeking help from the pair partner or the negotiation in pairs yielded great results. As indicated in Table 5.6, 33.75\% of meaning negotiations in pairs failed. There are two possible explanations for these failures. First, the pairs could not reach an agreement on the meanings of the phrases despite their best attempts, possibly because neither of the learners was certain about the meanings of the phrases. Let's have a look at Excerpt 51, whereby the learners were negotiating the meaning of 'walking advertisement'. Earnest efforts can be seen in the thoughtful contribution of both students. Both were examining the context to work out the meaning of the phrase by mentioning other politicians or the election campaign. However, they kept putting forward possible meanings without pinpointing the approximate meaning of 'walking advertisement', and decided to move on to the next phrase. The same scenario is observable in Excerpt 52 in which students were trying to come up with equivalent structures to the frame 'to be prone to something' but failed to accurately finalize its meaning.

\section{Excerpt 51}


- Cụm của tớ đấy là 'walking advertisement', chắc nghĩa là nhũng chính trị gia khác phái chi rất nhiều tiền cho việc quảng cáo trên $T V$, nhưng ông này thì...có thể nói là bình chân nhu vại không nhi?

- Không...

- Khá là thong thả ấy, trong cái viẹcc...

- Thế á? Tó nghĩ là kiểu vì̀a đi vìa quảng cáo hay sao ấy chú..., vìa đi vìa vận động ấy...

- Hay là ông ấy cú đi thôi nhung việc quảng cáo ấy...Nói chung là đến một cách rất tự nhiên, nói chung là không phải tốn quá nhiều công súc trong việc này, tớ nghĩ là nhu thế. Tiếp.
- The chunk I found is 'walking advertisement'. I think other politicians needed to spend a substantial amount of money on their advertisements on TV, but this guy...can I say this guy is really calm? - No...

- He is quite slow and calm... - Really? I think it means he is advertising while he is travelling from place to place, or he's launching the election campaign on the go...

- Or it means he's just travelling, and the advertising occurs naturally, and it doesn't take much of his effort in this issue. I think so. What's next?

(Bình \& Trang - Week 6)

\section{Excerpt 52}

- Yeah... and the next is 'to be more prone to something'.

- I think it's like 'tend to something 'or 'likely to something '. Likely to be in this state or something like that.

- It seems.... I think it's similar to "fond of" or 'to be excited or something'.

- Ok, we will check later.

(Kim \& Hằng - Week 5)

Another possibility is that the pairs reached an agreement, but the meaning they guessed was inaccurate. For example, in Excerpt 53, the wrong guessed meaning of 'lining up to' as 'starting' was agreed and confirmed by Thanh and Dương. Whether or not this guess would leave a memory trace in these learners is an open question.

\section{Excerpt 53}

Vietnamese

English translation

- Tù đầu tiên là 'lining up to' scare themselves..., nghĩa là bắt đầu đúng không?
- The first one is 'lining up to' scare themselves..., meaning starting right? 
(Thanh \& Dương - Week 5) In the next subsection, I will report on how students made use of dictionaries in search of the meanings of the MWEs that they could not guess.

\subsubsection{Seeking help from dictionaries}

Students were found to occasionally resort to dictionaries for the meanings of the new phrases, especially when they found no clues to help them discern the meanings of the chunks. Table 5.6 shows that the success rates of students' dictionary lookup was not 100\%, meaning that the lookup was not straightforward to the learners despite their experience in seeking help from this resource. In Excerpts 54 and 55 below, the dictionary meaning posed no difficulty to the learners' understanding of the phrases. The compound noun 'vending machine' has only one meaning in Macmillan Dictionary. The same applies to the phrase 'be caught up in'. Hence, it was an easy job for students to extract the meaning of these phrases from dictionaries. It is noteworthy that in Excerpt 55, the learner changed the main verb in the phrase to its infinitive form to make it 'catch up in' in their discussion. Although this transformation did not cause any mis-extraction of the meaning, it did in other cases which will be mentioned below.

\section{Excerpt 54}

- $\quad$ The third one is 'vending machine'. I searched it in the dictionary. It means the machines selling the stuff, items automatically.

(Trúc \& Hoàng - Week 10)

\section{$\underline{\text { Excerpt } 55}$}

- I think really [these phrases - my addition] are very popular and (it is) useful for us to use in speaking or writing like 'catch up in'. I think we can look it up in Macmillan Dictionary, and it means 'to become unexpectedly involved in an unpleasant or annoying situation'.

(Na \& Cam- Week 5)

In the cases of 'sift through' and 'a huge surge' in Excerpts 56 and 57, looking up the MWEs seemed to get harder since the students still needed to discuss their ideas further to choose the suitable meaning or to work out the meaning that fitted the context. 


\section{Excerpt 56}

- 'Sift through'...I can find it in Macmillan. How lucky! But no definition. 'Sift' is a verb, meaning 'to pour a dry substance through a sieve to remove the large pieces' mmmm, I think... - Ah here, sift or sift through has the same meaning, to examine information, documents etc. in order to find what you are looking for.

- Yeah, ok, very good, analyse something to work out the answer...

- To find the advantages and disadvantages of each choice to make the final decision.

(Ngần \& Thương-Week 3)

\section{Excerpt 57}

- A huge surge?

- Yeah....but in here [the dictionary], the word 'surge' is a sudden increase in something such as price, value or interest...

- Quantity?

- Yeah, it's an increase, maybe in quality, maybe in quantity I don't know... Yeah, it's also increase in the quality too because I see the word 'interest' in here.

(Trúc \& Hoàng - Week 3)

In Excerpt 56, the meaning of the phrasal verb 'sift through' does not come first in the entry for the verb 'sift', which made it a little harder for the students to find out its meaning. In this case, the student tried the meaning of the verb 'sift' in the given context, but it appears that the meaning did not feel right. Then she managed to find the meaning of the whole combination later on.

However, in a few cases, students may fail to extract the accurate meaning of the new phrases even with dictionaries at their disposal, as in Excerpt 58.

\section{Excerpt 58}

- And the second phrase is 'associated with'. I've seen this phrase many times before in some other texts or other sources, I can look up the meaning in Oxford Dict. It means that you spend time with somebody.

(Na \& Cam- Week 5)

As surprising as it is, although the student did use the dictionary as she pointed out, she stated a meaning which is totally different from the real meaning of the combination 'be associated with'. It can be speculated that the student changed the form of content word from 'associated' to 'associate' and found the meaning 'to spend time with someone' as a result. 


\title{
5.4.3. Associating new MWEs with known MWEs
}

When they were confident about the meaning they had guessed or found, students were observed to make associations between the newly found MWEs with other ways of expressing the same ideas they already knew. In 37 out of 222 instances (16.67\%) whereby students discussed the meanings, they made such associations. The associations may be MWEs of higher frequency or learners' free choice of words. Students typically said things like 'normally we use...' to emphasize the novelty of the new phrases and to imply that these more native-like ways of expressing ideas should be noticed and learned. Excerpts 59-61 below show how students used paraphrases to associate their previous knowledge with the new information.

\section{Excerpt 59}

- It ['at first glance'] looks like it can be used instead of 'firstly' and 'to begin with'.

(Na \& Cam-Week 3)

\section{Excerpt 60}

Vietnamese

- 'Obsessed with'...

- Nghĩa?

- Kiểu nhu bằng với 'to be into' hoạc 'to be keen on something'. Nhung nghĩa của cưm này cao hơn. Kiểu như yêu thích đến múc nghiện ấy.

\author{
English translation \\ - 'Obsessed with'... \\ - Meaning? \\ - It's kinda similar to 'to be into' or 'to \\ be keen on something'. But the \\ meaning of this chunk is more intense. \\ It means you love something or \\ someone like you are addicted to \\ them. \\ (Bình \& Trang - Week 7)
}

\section{Excerpt 61}

Vietnamese

- At stake là kiểu in danger đúng không?

- Uh, at risk.
English translation

- Is 'at stake' similar to 'in danger'?

- Yes, at risk.

(Hồng \& Đào- Week 8) Once both the forms and the meanings of identified phrases had been discussed, students would sometimes mention their special interest in particular phrases and expressed their 
intention of trying to add them into their repertoire. The next section will outline some features that make a phrase appear useful to the learners.

\subsection{How did learners evaluate the usefulness of an MWE?}

During their discussions, students explicitly mentioned some reasons which make some phrases more interesting to them than others. These reasons include the novelty of MWEs of different kinds and the familiarity of the topics the phrases may express, especially in the case of collocations.

\subsubsection{The novelty of the MWEs}

The most commonly-mentioned feature of MWEs that made them striking to the learners was their novelty. As mentioned before, this feature, especially with MWEs consisting of familiar words, can help students diversify their vocabulary when they speak or write. Since they learnt from the pre-treatment workshop that the width of their phrasal vocabulary could boost their scores, they were willing to add the phrases to their phrase banks. Excerpts 63-66 below illustrate how students appreciated the feature of being 'new' of the identified phrases for future use.

\section{Excerpt 63}

Vietnamese
Thì bình thường mình it khi dùng cum này ['polish it up'] mặc dù nghĩa của nó khá là thông dụng. Cậu có thể tra trên một số tù điển nhu Oxford, thì nghĩa của nó cũng khá rõ ràng. Mình nghĩ dùng cho writing hoặc speaking thì đều làm cho nó hay hơn.

\begin{abstract}
English translation
I don't usually use this ['polish it up'] even though it is quite common. We can check it in Oxford. Its meaning is transparent. We can use it to spice up our speaking and writing.
\end{abstract}

(Na \& Cam-Week 8)

\section{Excerpt 64}

- ... The last phrase I want to recommend is 'weigh different options'. I think we can search in Oxford collocations. It looks like a collocation of 'option'. Before that I just heard phrases like 'consider options', today I see this. I think I will use it next time...

(Na \& Cam- Week 3) 


\section{Excerpt 65}

- In the second paragraph, I like two phrases most. The first is 'equip you to sift through this information'. In general, I just use 'information' with 'deal with information' or ... But that phrase is kinda new and interesting to me.

(Trúc \& Hoàng - Week 3)

\section{Excerpt 66}

Vietnamese

English translation

Em nghĩ là 'access to' thì bình thuờng nhung 'accessibility to' với 'accessible to', hai cưm này khá là móit.
I think 'access to' is normal, but 'accessibility to' and 'accessible to'... These two phrases are pretty new to me.

(Kim \& Hằng - Week 6)

As stated by the students, these phrases were interesting to them with their brand-new forms which could express ideas that learners had to formulate in their own ways before. These phrases which could provide lower-frequency alternatives for those that they had already known. This appreciation is evident both in their statement that the phrases were new to them and in their associations between the new phrases and other familiar synonymous phrases.

\subsubsection{The relevance of the topics}

The second most commonly-mentioned feature of useful MWEs was the familiar topics that the phrases could help to express. Driven by their obsession with different types of English proficiency tests, particularly IELTS, students tended to pay more attention to those noun phrases or verb-noun collocations that belong to common topics in the test such as sports, education, or health. For example, in Excerpt 67, the student was showing her special interest in collocations on the topic Sports which she would be certain to encounter in IELTS speaking tests. The topic was about medical services in Excerpt 68.

\section{Excerpt 67}

Vietnamese

English translation

Trong bài đọc này mình rất thich, thích nhất trong tất cả các tuần vì bài đọc này cục kỳ nhiều collocations về sports mà minh có thể dùng trong IELTS speaking tests. Đầu tiên là collocations về ich lợi của
I really like this reading text. I like it most among all the weeks since I can find in it so many collocations about sports that I can use in IELTS speaking tests. First are collocations about the 
sports với cơ thể chúng ta, gồm có strengthen our bones, clear our bad cholesterols, decrease the risk of stroke, end high blood pressure, release chemicals when we work out, control pain, sharpen your focus, improve your mood and memory, reinforce a growth mindset, improve myself, the self-esteem can get a big boost, build the resilience, build your confidence... benefits of sports to our body, including strengthen our bones, clear our bad cholesterols, decrease the risk of stroke, end high blood pressure, release chemicals when we work out, control pain, sharpen your focus, improve your mood and memory, reinforce a growth mindset, improve myself, the self-esteem can get a big boost, build the resilience, build your confidence...

(Na \& Cam-Week 7)

\section{Excerpt 68}

Vietnamese

Tiếp theo là một số tù mớ liên quan đến về, gần nhu là về y hoc, medical, sẽ giúp cho minh sủ dụng vào một số bài viết về topic này, ví du nhu diagnosis of depression, physical manifestation, hay là abnormal transmission, và một số cum nhu neurotransmitters, or một số bệnh nhu asthma, diabetes... Đấy là nhũng cái mình nên hoc theo chủ đề thì mình úng dụng vào bài viết, sẽ làm cho bài viết của mình academic hơn.

\section{English translation}

Next are some phrases related to medical services, which will help us in some essays about this topic, for example, diagnosis of depression, physical manifestation, or abnormal transmission, and some others like neurotransmitters, or some diseases like asthma, diabetes... If we can memorize these words and phrases belonging to

this topic and can use them in our essays, our writing will be much more academic.

(Na \& Cam- Week 9) It looks like in these cases when impressed and overwhelmed by the flow of ideas to develop a topic that is commonly met in language skills tests, students tend to blur the line between the identification of possible fixed phrases and the collection of words and ideas to talk about a certain topic. Not all phrases mentioned in the two above Excerpts are established MWEs, for example, clear our bad cholesterols and diagnosis of depression. Some of them are even single words, like asthma and diabetes. This phenomenon can prove the vital role of the topic choice of reading texts for learners. More specifically, the familiar and interesting topics of 
the reading materials might draw more of students' attention to potential MWEs during textchunking activity.

\subsection{Conclusion}

This chapter has painted a picture of what was going on during students' interactions in their chunking activity. Different strategies employed by learners to identify established MWEs both in terms of forms and meanings have been mentioned and evaluated. In short, the students would mostly speculate that a word string is a MWE when: 1) they had seen the intact phrase before; 2) they saw familiar words in a new combination; 3) they saw new words bound in familiar structures. Regarding the meaning, the students heavily depended on the constituent words to decipher the meaning of the considered word strings before seeking more clues from the textual contexts. The students appeared to have the habit of guessing the meaning of newly-found phrases before looking them up in dictionaries. In terms of learners' decisions to select MWEs to add to their vocabulary, the novelty of the phrases and the relevance of the topics seemed to play important parts.

The next chapter investigates how students demonstrated their awareness of the importance of MWEs and their own learning strategies in the after-course self-reports. 


\section{CHAPTER 6 - LEARNERS' AWARENESS OF MULTIWORD EXPRESSIONS AND THEIR LEARNING STRATEGIES}

\subsection{Introduction}

So far in this thesis, I have reported on the participants' performances in the MWE tests (Chapter 4) and their strategies in the pair work chunking activities implemented during class time (Chapter 5). Given that there might be some gaps between what learners believe they are doing and will be doing and what they actually do in practice, this chapter will report on what has been collected from students' self-report questionnaires. As mentioned earlier, this questionnaire was designed with a view to letting the learners describe the possible growth in their awareness of MWEs and the strategies they think they are using to acquire more MWEs. The questionnaire was administered twice, first immediately after the course and then again after five months. My hypothesis was that the experimental group would have better awareness of MWEs and report using more MWE learning strategies than the comparison group since they had been given explicit instruction about this dimension of language and had been practising chunking activities throughout the course. This hypothesis will be examined through both the quantitative data collected from section 1 of the questionnaire and the qualitative data from Section 2. The presentation of the report, therefore, will be in this order. In addition, the last part of the chapter also investigates the evaluation of the usefulness of chunking activities by the experimental students.

\subsection{Students' MWE awareness and learning strategies - What do statistics say?}

\subsubsection{Learners' general awareness of multiword expressions}

As described in Chapter 3, the methodology chapter, the first section of the questionnaire (items 1.1 - 1.9) probes students' awareness of MWEs in terms of the general pervasiveness and, more importantly, the significance of acquiring a sizeable repertoire of MWEs in their language learning process. Table 6.1 below provides the descriptive statistics collected from the responses of the experimental group and the experimental group respectively. As previously mentioned, each item gives the respondents four numerical options of 1, 2, 3, 4, 
of which the meanings range from whether the statement does not describe the learner at all to whether it describes him/ her perfectly. Thus, the higher the ratings, the better the awareness and the better the learning strategies.

For each item, the number of respondents $(N)$, mean ratings $(M)$, modes and standard deviations $(S D)$ are reported. The mean ratings show the average ratings of each entire group for each item. The modes show the most common responses and the standard deviations show how much the opinions of the learners in each group are spread out. In other words, the smaller the standard deviations, the more agreement there is within the group. For ease of reporting, I will use $M(\operatorname{Exp})$ for the mean ratings of the experimental group and $M(\mathrm{Comp})$ for those of the comparison group. Also, the three mean ratings for each item at three time points will be put in brackets in the order of before the course, after the course, and five months later. Likewise, $S D(\operatorname{Exp})$ and $S D(\mathrm{Comp})$ will have corresponding references.

A quick glance at Table 6.1 suggests that the mean ratings and modes of all learners' responses for most items increase from before the course to after the course and slightly decrease five months later. In addition, the reflective awareness mean ratings of the comparison group are higher in almost all items but lower, though marginally, five months later. A closer look at the items reveals more details about the differences in the responses from the two groups regarding the pervasiveness of MWEs, the functions of MWEs in improving their language skills and the importance of MWEs in representing learners' proficiency in their test scores.

Specifically, learners' responses to items 1.1-1.3 on their perceptions of the ubiquity of MWEs in the target language reveal three interesting trends. First, it seems that students from both groups were still not so convinced about the formulaic nature of the target language even after the intervention and five months later. Item 1.1 has the lowest mean ratings among all the nine items, with $M(\operatorname{Exp})=(2.50,3.23,2.73)$ and $M(\mathrm{Comp})=(2.36,2.86,2.71)$. Although the experimental learners' awareness was raised to some extent immediately after the course with $M($ Exp. $)=3.23$, this effect might have faded over time, making the awareness of the two groups level out after five months. Second, as shown in item 1.2, despite having doubt about the pervasiveness of the formulaic proportion in English, both groups appeared 
to agree on the importance of grasping chunks compared to the acquisition of individual words. Interestingly, the comparison learners' mean ratings were higher at all three points of time in item 1.2, showing this group's greater attention to formulaic sequences in their learning process even without receiving the treatment. Third, both groups showed that they had been informed about the importance of MWEs by their teachers. Obviously, the kind of notification or explicit instruction might vary between the two groups since the comparison students might have been taught by other teachers in previous courses or courses other than the current one. That said, all the learners acknowledged the role of teachers' guidance in improving their awareness. The data in Table 6.1 suggests that the effects of this awareness raising did not fade with time among the experimental students since the mean rating increased after five months, with $M(\operatorname{Exp})=(2.31,3.35,3.42)$. This is not the case among students of comparison group who did not receive the treatment, with $M(\mathrm{Comp})=(2.39$, $3.11,3.07)$.

When their opinions were sought about the impact of showcasing knowledge of MWEs in their language proficiency tests, both groups indicated their beliefs that the use of a large formulaic repertoire could significantly improve their grades. Item 1.8 yielded the mean ratings of $M(\operatorname{Exp})=(2.69,3.95,3.69)$ and $M(\mathrm{Comp})=(3.21,3.71,3.64)$, with just a slight difference between the two groups' opinions. Slightly lower ratings, at around 3.00, were what students gave to the importance of the accuracy of MWEs over the number used. In other words, they recognized the significance of both the quality and the quantity of the use of different lexical items.

After investigating the learners' responses to different items in this scale about their general awareness of MWEs and their crucial roles in their language learning, the question that remains is whether statistically significant changes occurred over time and whether there were statistically significant differences between the two groups. A mixed between-within subjects analysis of variance (ANOVA) was conducted. Data was approximately normally distributed, assessed visually using a Q-Q plot, and Box's test of equality of covariance matrices was non-significant $(\mathrm{p}>.001)$ indicating that there are similar covariances. 
Table 6.1. Learners' awareness of MWEs

Before

After

Delayed

Items

N Mean Mode

$\begin{array}{ccccccccc}\text { SD } & \boldsymbol{N} & \text { Mean } & \text { Mode } & \boldsymbol{S D} & \boldsymbol{N} & \text { Mean } & \text { Mode } & \boldsymbol{S D} \\ .58 & 26 & 3.23 & 3 & .59 & 26 & 2.73 & 3 & .87 \\ .78 & 28 & 2.86 & 3 & .59 & 28 & 2.71 & 3 & .54 \\ .88 & 25 & 3.08 & 3 & .91 & 26 & 3.19 & 4 & .85 \\ .73 & 28 & 3.43 & 4 & .84 & 28 & 3.21 & 4 & .96\end{array}$
learn than single words.

\begin{tabular}{lllllllllllllll}
1.3 & I have been notified by my & Exp. & 26 & 2.31 & 2 & .74 & 26 & 3.35 & 3 & .56 & 26 & 3.42 & 4 & .64 \\
\cline { 2 - 18 } & & Comp. & 28 & 2.39 & 3 & .88 & 28 & 3.11 & 3 & .88 & 28 & 3.07 & 4 & .94
\end{tabular}

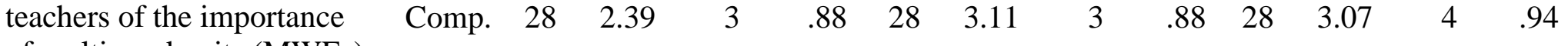
of multiword units (MWEs).

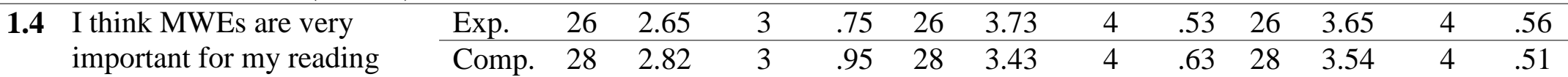
comprehension.

\begin{tabular}{llllllllllllll}
1.5 & I think MWEs are very \\
important for my listening & Exp. & 26 & 2.50 & 2 & .58 & 26 & 3.38 & 4 & .75 & 26 & 3.23 & 3 & .71 \\
\cline { 2 - 24 } & Comp. & 28 & 2.57 & 3 & .88 & 28 & 3.36 & 4 & .68 & 28 & 3.11 & 3 & .79
\end{tabular} comprehension.

\begin{tabular}{llllllllllllll}
1.6 & I think MWEs are very \\
important for my speaking & Exp. & 26 & 2.69 & 3 & .62 & 26 & 3.62 & 4 & .57 & 26 & 3.73 & 4 & .45 \\
\cline { 2 - 23 } & Comp. & 28 & 2.71 & 3 & .90 & 28 & 3.46 & 4 & .69 & 28 & 3.50 & 4 & .64
\end{tabular} fluency.

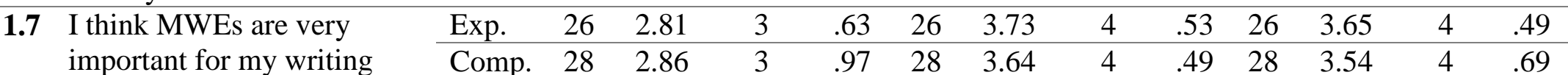
fluency.

1.8 I think using more MWEs can improve my scores in English proficiency tests.

1.9 I think demonstrating accuracy in using MWEs is more important than demonstrating a large vocabulary. 
The results showed a substantial effect of time, Wilks Lambda=.264, $F(2,52)=72.401$, $\mathrm{p}<.0005$, partial eta squared $=.736$, with both groups showing an increase in their awareness over time. Figure 6.1 illustrates the upward trend in the awareness in both groups. The changes look greater among the experimental group than its counterpart. That said, the main effect comparing the two conditions, with and without the treatment, was not significant, with Wilks Lambda $=.912, F(2,52)=2.519, p=.09$, partial eta squared $=.088$, suggesting no difference in the effectiveness of the treatment on the perceived awareness of the students. To put it another way, the experimental group did not demonstrate a statistically better awareness than the comparison group even though the latter did not receive explicit notification of the ubiquity and the influential role of MWEs.

So far in this chapter, I have reported on students' reported awareness of MWEs in general and their roles. Given that learners of both groups attach relative importance to the acquisition of MWEs in the target language for their language skill development as well as their performance in English proficiency test, the next section will report on learners' perceptions of their own learning strategies.

Figure 6.1. Changes in students' awareness of MWEs_Between-group comparison

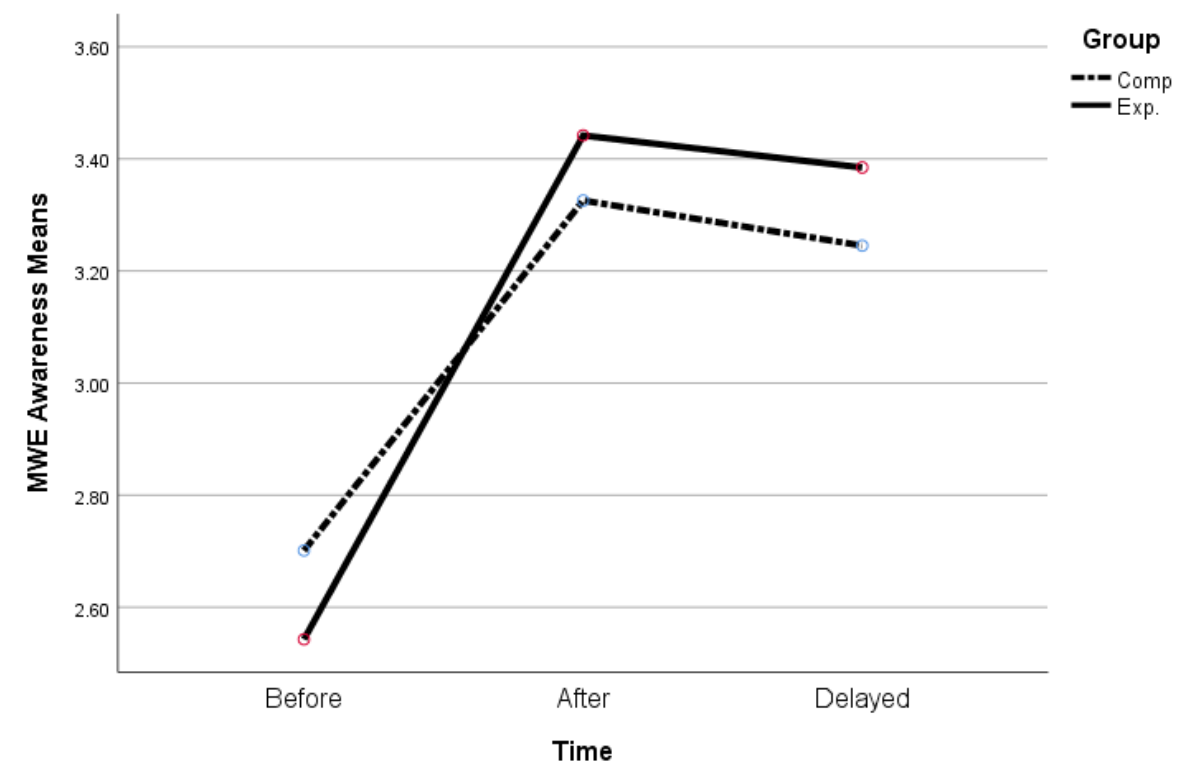




\subsubsection{Learners' perceptions of their learning strategies}

Items $1.10-1.35$ of the questionnaire probe into students' reflections on their learning experience ranging from their attention direction and their lookup activities to their intentional efforts to acquire the items that they think are worth learning. These 4-point Likert statements are, therefore, divided into two groups corresponding to two possible phases of the learning process. Items 1.10-1.22 look into learners' activities when they encounter new MWEs, including their noticing and lookup decisions. Items 1.23-1.35 deal with learners' actions when they would like to learn new MWEs of their choice. The following report will be in this step-by-step fashion.

\subsubsection{When do learners pay attention to MWEs?}

Since the main language resources that learners are exposed to in EFL contexts are through listening and reading activities both inside and outside class, the issue open to question is in which kind of activities they direct more of their attention to the instances of MWEs. Broadly speaking, Table 6.2 reveals an upward trend of mean ratings from both groups across the entire scale (items 1.10-1.13), suggesting their positive changes over time in intentionally noticing the formulaic feature of the language rather than just focusing on content when they listen to or read different materials. It is also observable that the experimental group rated higher in almost all items than the comparison group immediately after the course or five months later even though there were no marked differences between the two groups before the course. These rating differences in the statements about learners' deliberate attention indicate that the experimental students have better noticing strategies than their counterparts to some extent.

Specifically, three most notable trends can be seen from Table 6.2. First, experimental students pay attention to MWEs both when they read English and when they listen to English while the comparison group seems more attentive when they listen. As illustrated by the mean ratings in the immediate survey, $M(\operatorname{Exp})=(3.04,3.00,3.04)$ respectively for items 1.10 about listening, 1.12 and 1.13 for reading and $M($ Comp $)=(3.07,2.71,2.75)$. Second, the instances of MWEs which are typographically enhanced, i.e. underlined or highlighted, are reported to draw a good deal of attention from the learners. The majority of both groups 
indicated in item 1.11 that they are attracted to such vocabulary items when reading a text, with $M(\operatorname{Exp})=(2.58,3.42,3.31)$ and $M(\mathrm{Comp})=(2.64,3.07,3.18)$. This typographical enhancement received the highest mean ratings among the four items of this scale, showing that the intentional efforts from language teachers or material designers could bring about more noticing among the learners than the incidental learning settings, a finding well established in literature. Third, authentic resources appear to inspire the learners more than classroom reading materials to look for occurrences of MWEs. This trend is observable in both groups although the experimental group demonstrated higher mean ratings, e.g. $M(\operatorname{Exp})$ $=(2.12,3.00,2.77)$ for item 1.12 compared to $M(\mathrm{Comp})=(1.93,2.71,2.32)$. It is notable that the habit of keeping an eye out for instances of MWEs proved to endure over the fivemonth gap among experimental students, with $M(\operatorname{Exp})=(2.15,3.04,3.04)$ for item 1.13 , making the difference between the two groups quite remarkable when comparing with $M($ Comp $)=(2.11,2.75,2.43)$.

Next, I will look into the most influential features of MWEs to learners when they shortlist the MWEs to learn in the next sub-section.

\subsubsection{Which MWEs draw learners' attention the most?}

The next question is which features of MWEs interest learners when they are looking for potential candidates to learn. It looks like both the constituent words and the structures accommodating those words are taken into consideration by the learners. This tendency is evident in the relatively high mean ratings and modes demonstrated in all the four items 1.141.17 as displayed in Table 6.3 .

Both groups showed increasing interest in new combinations of familiar-looking words and familiar-looking combinations which they encountered intact. The mean ratings for items 1.14 and 1.16 are the higher in the scale in both groups, with $M(\operatorname{Exp})=(2.15,3.31,3.23)$ and $M(\mathrm{Comp})=(2.68,3.50,3.21)$ for item 1.14 and $M(\operatorname{Exp})=(2.62,3.36,3.38)$ and $M(\mathrm{Comp})=$ $(2.82,3.36,3.04)$ for item 1.16 . This result backs up one of the findings from Chapter 5 , which showed that previously-seen combinations and new combinations of familiar words actually drew the most attention of the learners when they were trying to extract possible MWEs from texts. 
Table 6.2. Changes in learners' perceived attention towards MWEs

\begin{tabular}{|c|c|c|c|c|c|c|c|c|c|c|c|c|c|c|}
\hline & & & \multicolumn{4}{|c|}{ Before } & \multicolumn{4}{|c|}{ After } & \multicolumn{4}{|c|}{ Delayed } \\
\hline & \multicolumn{2}{|l|}{ Items } & $N$ & Mean & Mode & $S D$ & $N$ & Mean & Mode & $S D$ & $N$ & Mean & Mode & $S D$ \\
\hline \multirow[t]{2}{*}{1.10} & \multirow{2}{*}{$\begin{array}{l}\text { I pay attention to new } \\
\text { combinations of words } \\
\text { when I listen to something } \\
\text { in English. }\end{array}$} & Exp. & 26 & 1.81 & 2 & .57 & 26 & 3.04 & 3 & .53 & 26 & 2.92 & 3 & .63 \\
\hline & & Comp. & 28 & 2.25 & 2 & .97 & 28 & 3.07 & 3 & .72 & 28 & 2.61 & 2 & .74 \\
\hline \multirow[t]{2}{*}{1.11} & \multirow{2}{*}{$\begin{array}{l}\text { When reading a text, I am } \\
\text { attracted to the underlined } \\
\text { or highlighted vocabulary } \\
\text { items in the text if any. }\end{array}$} & Exp. & 26 & 2.58 & 3 & .70 & 26 & 3.42 & 4 & .70 & 26 & 3.31 & 4 & .74 \\
\hline & & Comp. & 28 & 2.64 & 2 & .91 & 28 & 3.07 & 3 & .86 & 28 & 3.18 & 3 & .67 \\
\hline \multirow[t]{2}{*}{1.12} & \multirow[b]{2}{*}{$\begin{array}{l}\text { I have the habit of scanning } \\
\text { an English text for possible } \\
\text { MWEs after answering the } \\
\text { comprehension questions } \\
\text { in class. }\end{array}$} & Exp. & 26 & 2.12 & 2 & .82 & 26 & 3.00 & 3 & .80 & 26 & 2.77 & 3 & .91 \\
\hline & & Comp. & 28 & 1.93 & 2 & .90 & 28 & 2.71 & 3 & .94 & 28 & 2.32 & 2 & .82 \\
\hline \multirow[t]{2}{*}{1.13} & \multirow{2}{*}{$\begin{array}{l}\text { I have the habit of scanning } \\
\text { the text for possible MWEs } \\
\text { after reading an English } \\
\text { text that I find interesting } \\
\text { outside classroom. }\end{array}$} & Exp. & 26 & 2.15 & 2 & .73 & 26 & 3.04 & 3 & .87 & 26 & 3.04 & 3 & 1.00 \\
\hline & & Comp. & 28 & 2.11 & 2 & .74 & 28 & 2.75 & 3 & .84 & 28 & 2.43 & 3 & .84 \\
\hline
\end{tabular}


Table 6.3. Which MWEs draw learners' attention the most?

\begin{tabular}{|c|c|c|c|c|c|c|c|c|c|c|c|c|c|c|}
\hline & & & \multicolumn{4}{|c|}{ Before } & \multicolumn{4}{|c|}{ After } & \multicolumn{4}{|c|}{ Delayed } \\
\hline & \multicolumn{2}{|l|}{ Items } & $N$ & Mean & Mode & $S D$ & $N$ & Mean & Mode & $S D$ & $N$ & Mean & Mode & $S D$ \\
\hline \multirow[t]{2}{*}{1.14} & \multirow{2}{*}{$\begin{array}{l}\text { I am interested in a new } \\
\text { combination of familiar } \\
\text { words. }\end{array}$} & Exp. & 26 & 2.15 & 2 & .73 & 26 & 3.31 & 3 & .55 & 26 & 3.23 & 3 & .71 \\
\hline & & Comp. & 28 & 2.68 & 3 & .90 & 28 & 3.50 & 4 & .64 & 28 & 3.21 & 3 & .57 \\
\hline \multirow[t]{2}{*}{1.15} & \multirow{2}{*}{$\begin{array}{l}\text { I am interested in a } \\
\text { combination of unknown } \\
\text { words. }\end{array}$} & Exp. & 26 & 2.27 & 2 & .60 & 26 & 3.23 & 3 & .65 & 26 & 3.00 & 3 & .85 \\
\hline & & Comp. & 28 & 2.00 & 2 & .90 & 28 & 2.86 & 3 & .89 & 28 & 2.39 & 2 & .88 \\
\hline \multirow[t]{2}{*}{1.16} & \multirow{2}{*}{$\begin{array}{l}\text { I am interested in a } \\
\text { combination of words if I } \\
\text { can see that combination for } \\
\text { the second time. }\end{array}$} & Exp. & 26 & 2.62 & 3 & .64 & 26 & 3.46 & 4 & .81 & 26 & 3.38 & 4 & .70 \\
\hline & & Comp. & 28 & 2.82 & 3 & .86 & 28 & 3.36 & 3 & .73 & 28 & 3.04 & 3 & .74 \\
\hline \multirow[t]{2}{*}{1.17} & \multirow{2}{*}{$\begin{array}{l}\text { I am interested in } \\
\text { combinations of words that } \\
\text { have similar structures to } \\
\text { MWEs that I have known. }\end{array}$} & Exp. & 26 & 2.42 & 3 & .64 & 26 & 3.42 & 4 & .64 & 26 & 3.15 & 3 & .61 \\
\hline & & Comp. & 28 & 3.00 & 3 & .82 & 28 & 3.29 & 4 & .76 & 28 & 2.79 & 3 & .79 \\
\hline
\end{tabular}


On the other hand, phrases containing unknown words either in familiar packaging structures or not were reported as being more interesting to the experimental group than to the comparison counterparts. The mean ratings for items 1.15 and 1.17 for the comparison group, $M(\mathrm{Comp})=(2.00,2.86,2.39)$ and $M(\mathrm{Comp})=(3.00,3.29,2.79)$, are remarkably lower than those of the experimental group $M(\operatorname{Exp})=(2.27,3.23,3.00)$ and $M(\operatorname{Exp})=(2.42,3.42,3.15)$. These means remained high among the experimental students even in the delayed questionnaire.

This difference might be because the experimental students had the actual practice on the chunking activities while the comparison group did not. Being interested in the forms of newly-encountered word combinations, learners' next step will be investigating their meanings, which will be dealt with in the subsection that follows.

\subsubsection{How do learners work out the meanings of new MWEs?}

Learners' reported strategies when it comes to figuring out the meaning of the new lexical items were investigated through items 1.18-1.22. The examined strategies include guessing the meanings or consulting various resources such as Google, general English dictionaries both online and offline, collocation dictionaries and a corpus like COCA.

As can be easily seen from Table 6.4, the highest mean ratings in the whole scale among all the learners at the immediate questionnaire were for item 1.18 about using guessing skills, reaching 3.27 and 3.25 for the experimental group and the comparison group respectively immediately after the course. In other words, learners from both groups reported that they would start off by using their existing knowledge both language-wise and content-wise to guess the meanings of new vocabulary items before seeking help from dictionaries or other databases. While this rating did not change in the comparison group in the delayed questionnaire, it changed significantly in the experimental group. Increased importance was attached to looking up new phrases in dictionaries, especially collocation dictionaries, with the highest ratings, $M(\operatorname{Exp})=3.25$, in the whole scale in the delayed questionnaire for item 1.21. To illustrate this increase in self-reported look-up behaviour, $M(\operatorname{Exp})=(2.00,2.92$, 3.12 ) for item 1.20 and $M(\operatorname{Exp})=(2.10,3.05,3.25)$ for item 1.21 , compared to $M(\operatorname{Comp})=$ $(2.14,2.64,2.62)$ and $M(\mathrm{Comp})=(1.68,2.28,2.29)$ respectively in the comparison group. 
Table 6.4. How do learners work out the meanings of MWEs?

\begin{tabular}{|c|c|c|c|c|c|c|c|c|c|c|c|c|c|c|}
\hline & & & \multicolumn{4}{|c|}{ Before } & \multicolumn{4}{|c|}{ After } & \multicolumn{4}{|c|}{ Delayed } \\
\hline & Items & & $N$ & Mean & Mode & $S D$ & $N$ & Mean & Mode & $S D$ & $N$ & Mean & Mode & $S D$ \\
\hline \multirow[t]{2}{*}{1.18} & \multirow{2}{*}{$\begin{array}{l}\text { I try to guess the meaning of } \\
\text { word combinations before I } \\
\text { look them up. }\end{array}$} & Exp. & 26 & 2.15 & 2 & .78 & 26 & 3.27 & 3 & .67 & 26 & 3.04 & 3 & .82 \\
\hline & & Comp. & 28 & 2.57 & 1 & 1.20 & 28 & 3.25 & 3 & .80 & 28 & 2.71 & 2 & .71 \\
\hline \multirow[t]{2}{*}{1.19} & \multirow{2}{*}{$\begin{array}{l}\text { I check MWEs that I find } \\
\text { interesting on Google to see its } \\
\text { number of hits. }\end{array}$} & Exp. & 26 & 1.73 & 2 & .67 & 26 & 2.85 & 3 & .68 & 26 & 2.46 & 2 & 1.03 \\
\hline & & Comp. & 28 & 1.93 & 1 & .98 & 28 & 2.18 & 1 & 1.06 & 28 & 2.29 & 2 & .90 \\
\hline \multirow[t]{2}{*}{1.20} & \multirow{2}{*}{$\begin{array}{l}\text { I always look up MWEs that I } \\
\text { find interesting in a general } \\
\text { English dictionary. }\end{array}$} & Exp. & 26 & 2.00 & 2 & .80 & 26 & 2.92 & 3 & .85 & 26 & 3.12 & 3 & .82 \\
\hline & & Comp. & 28 & 2.14 & 1 & 1.08 & 28 & 2.64 & 3 & 1.06 & 26 & 2.62 & 3 & .80 \\
\hline \multirow[t]{2}{*}{1.21} & \multirow{2}{*}{$\begin{array}{l}\text { I look up MWEs that I find } \\
\text { interesting in a collocation } \\
\text { dictionary. }\end{array}$} & Exp. & 20 & 2.10 & 2 & .64 & 20 & 3.05 & 3 & .69 & 16 & 3.25 & 4 & .78 \\
\hline & & Comp. & 25 & 1.68 & 1 & .75 & 25 & 2.28 & 2 & .98 & 21 & 2.29 & 2 & .78 \\
\hline \multirow[t]{2}{*}{1.22} & \multirow{2}{*}{$\begin{array}{l}\text { I check MWEs that I find } \\
\text { interesting in a corpus, e.g. } \\
\text { COCA, to see if they are } \\
\text { commonly used. }\end{array}$} & Exp. & 25 & 1.16 & 1 & .37 & 25 & 3.08 & 3 & .57 & 26 & 2.85 & 3 & .88 \\
\hline & & Comp. & 27 & 1.41 & 1 & .64 & 27 & 1.74 & 1 & .94 & 24 & 2.08 & 2 & .93 \\
\hline
\end{tabular}


By contrast, the lowest mean ratings of both groups both in the immediate and delayed survey belong to items 1.19 and 1.22 about the use of databases like Google and COCA (see Table 6.4). It could be expected that Google would be a popular port of call for the comparison group or any other language learners who had not heard about more reliable databases. Likewise, one can expect that COCA would be more used by the experimental students as they received the training and practice. Nonetheless, these databases appear not to be as popular as 'traditional' resources - dictionaries. There are some visible changes in the experimental students' perception of their use of COCA. As seen from item 1.22, the mode changed from 1 in their reflective responses about before-the-course practice to 3 in the immediate questionnaire and even five months later, which indicated that these students were to some extent aware of COCA and its possible usefulness. Interestingly, a minimal increase in the mean ratings and modes for item 1.22 was seen in the comparison group too.

When it comes to the learners' strategies in choosing the dictionaries to look up interesting MWEs, the emerging questions will be whether they use paper or electronic dictionaries, general English or collocation ones, bilingual or monolingual ones, what their favourite dictionaries are, and whether the experimental group's choices are different from the comparison group's. Students' responses to extended parts of items 1.20 about the use of general English dictionaries and 1.21 about the use of collocation dictionaries show that a significant majority of students in both groups made use of electronic dictionaries of both kinds. Only one out of 26 experimental students stated that she would use a paper-based dictionary while about five out of 28 comparison students stated so both in immediate and delayed questionnaire. Among the most popular resources were Cambridge, Oxford, Longman, Macmillan, and Collins dictionaries. Bilingual dictionaries like Vdict, T-Flat, Vinh Ba were also listed. Interestingly, some internet-based resources which had not been introduced to the students were also mentioned, like thefreedictionary.com and urbandictionary.com. These dictionaries might be what students came across when they googled new phrases.

Two surprising findings arose from students' responses. First, both groups listed COCA or corpus in answer to the follow-up question of item 1.21 about the kind of collocation 
dictionary that they would look up new MWEs in. This is noteworthy because even the experimental students considered COCA to be a collocation dictionary and because the comparison group had not been introduced to COCA during the course. The reason might be that in the questionnaire COCA was mentioned or that they knew about COCA through outof-classroom discussions with students from the other group. Second, there were not many differences in students' listings of general English dictionaries and collocation dictionaries. It looks like they did not differentiate between the two kinds of dictionaries, thereby treating general English dictionaries as collocation ones.

Up to this point, the focus has been on learners' reported strategies in directing their attention, identifying the forms, and dealing with the meanings of new phrasal items have been looked into. Learners may not attempt to learn all the phrases they attend to, however. The next subsection will therefore deal with how the learners decide what MWEs to learn intentionally.

\subsubsection{How do learners make a shortlist of MWEs to learn?}

Several features of MWEs which may influence students' decisions in shortlisting the lexical items they would like to add to their repertoire were mentioned in items 1.23-1.26. The proposed features include the appearance of the item in a dictionary, its frequency in a corpus, its meaning and perceived relevance to the learners' future target language use, and its usefulness in various disciplines. As can be seen from Table 6.5, the trends are similarly upward in both groups over time, and their ranking order of the importance of the features is comparatively alike. It is worth mentioning that these features are not necessarily mutually exclusive. Rather, they are different levels of the strictness of the criteria. For instance, MWEs whose topics students can relate to or which are interdisciplinary should be ones that appear in dictionaries and/ or have adequate frequency indicators in a corpus. It is simply because the latter criteria are those which make MWEs established ones.

First and foremost, both groups place emphasis on the usage potential as well as the versatility of MWEs which can help them to express their ideas in a variety of language situations, clearly indicated by the high mean ratings and modes in items 1.25 and 1.26. More specifically, the most important feature reported is that the phrasal items are not topic- 
restricted or even simply functional and therefore can be used in different contexts, with $M(\operatorname{Exp})=(2.46,3.54,3.65)$ and $M(\mathrm{Comp})=(3.04,3.68,3.61)$.

There are minimal differences between the two groups in this item despite higher ratings in the experimental group in many other items so far. Moreover, the comparison group even had a greater mean rating in this item in their reflective responses and in the immediate questionnaire. The second most influential criterion is that the phrases have potential usefulness in students' future use of the target language, with $M(\operatorname{Exp})=(2.19,3.19,3.54)$ and $M(\mathrm{Comp})=(2.82,3.46,3.29)$. Judging from what students mentioned in their chunking discussions analyzed in Chapter 5, the potential usability here might be understood as of prepacked phrases related to topics they might encounter in their speaking or writing tests, e.g. IELTS.

As expected, the first two criteria mentioned in items 1.23 and 1.24 about the appearance of the phrase in a dictionary or its frequency in COCA, being lower in the strictness ladder of criteria mentioned above, have noticeably lower mean ratings in both groups. Again, it is interesting that the comparison group also appreciated the high frequency of MWEs in a corpus as a shortlisting criterion even without actually interacting with any corpora during the course.

In the next subsection, I investigate students' reports on how they realize the goals of acquiring more phrases that they find both interesting and necessary.

\subsubsection{What efforts do learners make to learn new MWEs?}

Learners' strategies for memorising the MWEs in both individual and interactional ways were examined in items 1.27-1.32, while their efforts to generate meaningful language using the newly learnt items were probed into through items 1.33-1.35 (see Table 6.6). In the same vein as the trends observable in previous scales, the experimental group showed higher mean ratings in the delayed questionnaire in all these items, showing a better long-term awareness of their learning strategies than their comparison counterparts. 


\begin{tabular}{|c|c|c|c|c|c|c|c|c|c|c|c|c|c|c|}
\hline & & & \multicolumn{4}{|c|}{ Before } & \multicolumn{4}{|c|}{ After } & \multicolumn{4}{|c|}{ Delayed } \\
\hline & Items & & $N$ & Mean & Mode & $S D$ & $N$ & Mean & Mode & $S D$ & $N$ & Mean & Mode & $S D$ \\
\hline \multirow[t]{2}{*}{1.23} & \multirow{2}{*}{$\begin{array}{l}\text { I would like to learn an } \\
\text { MWE that appears in a } \\
\text { dictionary. }\end{array}$} & Exp. & 26 & 1.77 & 2 & .71 & 26 & 2.69 & 2 & .84 & 26 & 2.85 & 2 & .78 \\
\hline & & Comp. & 28 & 1.68 & 1 & .91 & 28 & 2.04 & 2 & .88 & 28 & 2.07 & 1 & .98 \\
\hline \multirow[t]{2}{*}{1.24} & \multirow{2}{*}{$\begin{array}{l}\text { I would like to learn an } \\
\text { MWE which has a high } \\
\text { frequency in a corpus. }\end{array}$} & Exp. & 24 & 1.63 & 2 & .50 & 24 & 3.21 & 3 & .51 & 25 & 3.00 & 3 & .71 \\
\hline & & Comp. & 28 & 1.93 & 1 & .90 & 28 & 2.39 & 3 & .92 & 27 & 2.59 & 3 & .98 \\
\hline \multirow[t]{2}{*}{1.25} & \multirow{2}{*}{$\begin{array}{l}\text { I would like to learn an } \\
\text { MWE that I think I may } \\
\text { need in the future. }\end{array}$} & Exp. & 26 & 2.19 & 2 & .75 & 26 & 3.19 & 3 & .80 & 26 & 3.54 & 4 & .58 \\
\hline & & Comp. & 28 & 2.82 & 3 & .77 & 28 & 3.46 & 4 & .69 & 28 & 3.29 & 3 & .66 \\
\hline \multirow[t]{2}{*}{1.26} & \multirow{2}{*}{$\begin{array}{l}\text { I would like to learn an } \\
\text { MWE that I think I can use } \\
\text { for many topics. }\end{array}$} & Exp. & 26 & 2.46 & 3 & .71 & 26 & 3.54 & 4 & .51 & 26 & 3.65 & 4 & .56 \\
\hline & & Comp. & 28 & 3.04 & 3 & .88 & 28 & 3.68 & 4 & .67 & 28 & 3.61 & 4 & .50 \\
\hline
\end{tabular}


Table 6.6. Learners' intentional efforts to memorize new MWEs

\begin{tabular}{|c|c|c|c|c|c|c|c|c|c|c|c|c|c|c|}
\hline & & & \multicolumn{4}{|c|}{ Before } & \multicolumn{4}{|c|}{ After } & \multicolumn{4}{|c|}{ Delayed } \\
\hline & Items & & $N$ & Mean & Mode & $S D$ & $N$ & Mean & Mode & $S D$ & $N$ & Mean & Mode & $S D$ \\
\hline \multirow[t]{2}{*}{1.27} & \multirow{2}{*}{$\begin{array}{l}\text { I underline/ highlight MWEs } \\
\text { that I would like to learn in a } \\
\text { text. }\end{array}$} & Exp. & 26 & 2.35 & 2 & .75 & 26 & 3.19 & 3 & .85 & 26 & 3.31 & 3 & .74 \\
\hline & & Comp. & 28 & 3.00 & 4 & .90 & 28 & 3.46 & 4 & .58 & 28 & 3.18 & 4 & .82 \\
\hline \multirow[t]{2}{*}{1.28} & \multirow{2}{*}{$\begin{array}{l}\text { I note down new MWEs in a } \\
\text { vocabulary notebook. }\end{array}$} & Exp. & 26 & 1.88 & 2 & .91 & 26 & 2.69 & 3 & .88 & 26 & 2.88 & 4 & 1.14 \\
\hline & & Comp. & 28 & 2.46 & 3 & 1.04 & 28 & 3.04 & 3 & .88 & 28 & 2.86 & 3 & .93 \\
\hline \multirow[t]{2}{*}{1.29} & \multirow{2}{*}{$\begin{array}{l}\text { I look at my vocabulary } \\
\text { notebook regularly until I can } \\
\text { memorize new MWEs. }\end{array}$} & Exp. & 26 & 1.62 & 1 & .64 & 26 & 2.42 & 2 & .81 & 26 & 2.46 & 3 & .91 \\
\hline & & Comp. & 28 & 1.75 & 2 & .65 & 28 & 2.25 & 2 & .80 & 28 & 2.29 & 2 & 1.01 \\
\hline \multirow[t]{2}{*}{1.30} & \multirow{2}{*}{$\begin{array}{l}\text { I discuss new MWEs with } \\
\text { my friends. }\end{array}$} & Exp. & 26 & 1.42 & 1 & .58 & 26 & 2.50 & 3 & .81 & 26 & 2.50 & 2 & .76 \\
\hline & & Comp. & 28 & 1.68 & 1 & .77 & 28 & 2.21 & 1 & 1.03 & 28 & 2.11 & 2 & .79 \\
\hline \multirow[t]{2}{*}{1.31} & \multirow[b]{2}{*}{$\begin{array}{l}\text { I make an effort to associate } \\
\text { a new MWE with other } \\
\text { MWEs that I know (e.g. } \\
\text { similar meaning, opposite } \\
\text { meaning, same structures, } \\
\text { etc.). }\end{array}$} & Exp. & 26 & 1.92 & 1 & .85 & 26 & 2.92 & 3 & .94 & 26 & 2.62 & 2 & 1.02 \\
\hline & & Comp. & 28 & 1.82 & 1 & .86 & 28 & 2.57 & 3 & .92 & 28 & 2.21 & 2 & .83 \\
\hline \multirow[t]{2}{*}{1.32} & \multirow{2}{*}{$\begin{array}{l}\text { I make an effort to associate } \\
\text { a new MWE with an } \\
\text { equivalent Vietnamese } \\
\text { MWE. }\end{array}$} & Exp. & 26 & 1.81 & 2 & .75 & 26 & 2.54 & 3 & .76 & 26 & 2.65 & 2 & .85 \\
\hline & & Comp. & 28 & 2.18 & 2 & .98 & 28 & 2.82 & 3 & .86 & 28 & 2.64 & 3 & .83 \\
\hline \multirow[t]{2}{*}{1.33} & \multirow{2}{*}{$\begin{array}{l}\text { I make an effort to use newly } \\
\text { learnt MWEs when I use } \\
\text { English. }\end{array}$} & Exp. & 26 & 2.12 & 2 & .71 & 26 & 3.04 & 3 & 1.00 & 26 & 3.00 & 3 & .85 \\
\hline & & Comp. & 28 & 2.04 & 2 & .88 & 28 & 3.00 & 3 & .67 & 28 & 2.75 & 3 & .80 \\
\hline \multirow[t]{2}{*}{1.34} & \multirow{2}{*}{$\begin{array}{l}\text { I try to use more MWEs } \\
\text { when speaking in English. }\end{array}$} & Exp. & 26 & 1.81 & 2 & .50 & 26 & 2.96 & 3 & .82 & 26 & 3.04 & 3 & .77 \\
\hline & & Comp. & 27 & 2.30 & 2 & .82 & 27 & 3.19 & 3 & .62 & 28 & 2.79 & 3 & .63 \\
\hline \multirow[t]{2}{*}{1.35} & \multirow{2}{*}{$\begin{array}{l}\text { I try to use more MWEs } \\
\text { when writing in English. }\end{array}$} & Exp. & 26 & 1.77 & 2 & .65 & 26 & 3.12 & 3 & .82 & 26 & 3.12 & 3 & .59 \\
\hline & & Comp. & 27 & 2.22 & 2 & .93 & 27 & 3.04 & 4 & .85 & 28 & 2.86 & 3 & .65 \\
\hline
\end{tabular}


This awareness growth is all the more remarkable considering the fact that the comparison group's reflective responses in the immediate questionnaire showed quite a few items with higher mean ratings than those of the experimental group. For instance, when asked whether they underlined or highlighted the MWEs they would like to learn and noted them down in a vocabulary notebook or tried to use them when speaking English, comparison students responded very positively. While items $1.27,1.28$ and 1.34 respectively yielded $M($ Comp $)=$ (3.46, 3.04, 3.19) immediately after the course, lower ratings were obtained in the experimental group, with $M(\operatorname{Exp})=(3.19,2.69,2.96)$.

Mean ratings of 3 or more indicate students' positive responses to questionnaire items. Judging from this criterion, students in both groups seemed to be conscious of new and potential MWEs in reading texts and make efforts to memorize them. However, their efforts were more restricted to underlining/ highlighting those items and putting them down in a notebook, and later trying to generate the target language with the items they could remember. Other strategies such as revisiting the vocabulary notebooks regularly, discussing with friends, making associations with already known items, or translating the new items into Vietnamese were not often employed.

Until now, quite a few between-group differences in students' MWE acquisition strategies as well as the differences within each group across time have been identified. To explore whether these differences are statistically significant, a mixed between-within subjects analysis of variance (ANOVA) was conducted. Data was approximately normally distributed, assessed visually using a Q-Q plot, and Box's test of equality of covariance matrices was non-significant $(\mathrm{p}>.001)$ indicating that there are similar covariances. The outcome showed similar results to the test run on students' MWE awareness, with a substantial effect of time, Wilks Lambda=.193, $F(2,52)=108.629$, p<.0005, partial eta squared $=.807$. Both groups demonstrated an increase in their reported use of different MWE learning strategies over time, as illustrated in Figure 6.2.

The changes look markedly greater in the experimental group than in its counterpart. The ANOVA output indicated a significant interaction between the treatment and time, Wilks 
Lambda $=.783, F(2,52)=7.187, \mathrm{p}<.005$, partial eta squared $=.217$, meaning that the treatment had a significant effect on the learners' acquisition strategies over time.

Figure 6.2. Changes in students' acquisition strategies of MWEs_Between-group comparison

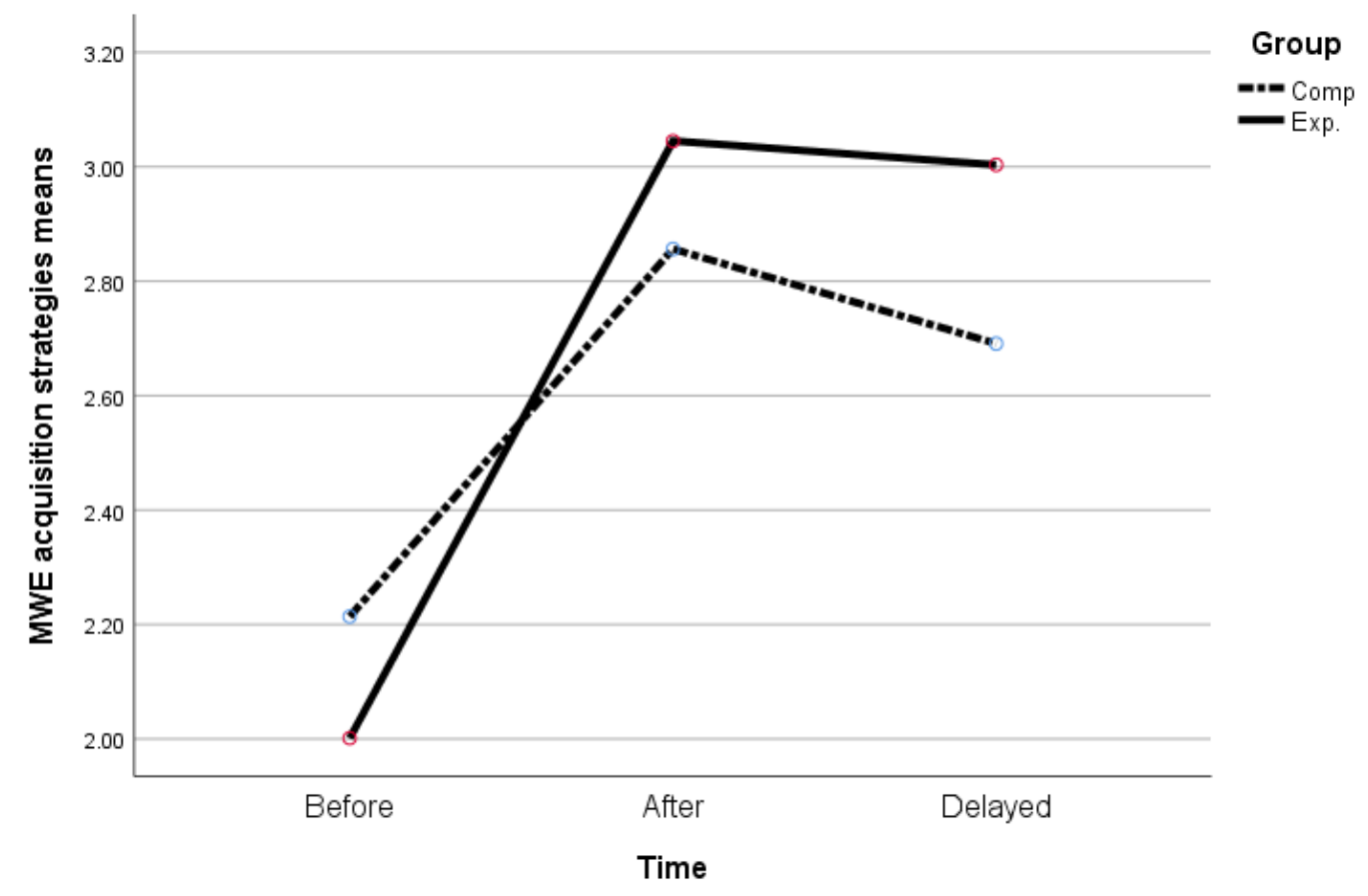

Post-hoc tests were then run to confirm where the differences occurred in the reported use of learning strategies between the two groups. Two independent-samples t-tests were conducted to compare the change in the two groups from before the course to immediately after the course and from before the course to five months after the course, using Bonferroni adjusted alpha levels of .025 per test (.05/2). The result showed that there was a significant difference in the change of ratings from before the course to immediately after the course between experimental students $(M=1.04, S D=0.34)$ and their comparison counterparts $(M=0.64$, $S D=0.48) ; t(52)=3.54, p<0.025$. The significant difference in the change of ratings remained in the result comparing the two time points of before the course and five months after the course between the two groups, with $M(\operatorname{Exp})=1.00, S D(\operatorname{Exp})=0.45$ and $M$ $(\mathrm{Comp})=0.48, S D(\mathrm{Comp})=0.66 ; t(52)=3.39, p<0.025$. 
Altogether, the results suggested that the treatment did have an effect on the learners' reported use of MWE learning strategies, making the experimental students employ more learning strategies introduced in the intervention than the comparison group.

In summary, Section 6.2.3 has dealt with how learners from the two groups report on the changes in their general awareness of MWEs and in their MWE learning strategies ranging from noticing them in texts to making intentional efforts to acquire them. Descriptive statistics show the differences in the extent of changes and the trend of changes in both groups, more remarkable in the experimental students. That said, inferential statistics, ANOVA in this case, show that the transformations are statistically significant over time, and statistically significant between groups in their reported learning strategies but not in their awareness. In the next section, I will discover whether or not learners' responses to open questions show a different picture from their simply ticking the options.

\subsection{Students' MWE awareness and learning strategies - What did the learners say?}

There are three open questions in Section 2 of the questionnaire used for both groups. They probe into the progress they had made during the five-month gap, the lookup resources they would prefer to seek support from and their preferred MWE learning strategies. This section will compare and contrast the qualitative data from the two groups' responses regarding these aspects.

\subsubsection{Did the learners make any progress in the five months?}

Students' self-report on their own progress after the five-month gap could be divided into three categories: positive answers stating that they had made improvements, neutral answers stating what they had done to improve their vocabulary or test their vocabulary level but not stating if the progress occurred, and negative answers stating that they had not. Table 6.7 below shows the proportion of each category among the answers of learners from both groups.

Striking differences can be seen in the percentage of positive and negative answers between both groups. While $72 \%$ of experimental students confidently stated their progress in identifying MWEs in texts and applying new items in producing the target language, only $32.14 \%$ of the comparison group shared these ideas. Table 6.8 demonstrates some typical statements from each group. 
Table 6.7. Learners' self-report of their progress in MWE acquisition

\begin{tabular}{lcccc}
\hline Categories & \multicolumn{2}{c}{$\begin{array}{c}\text { Experimental group } \\
\text { Count }\end{array}$} & $\%$ & \multicolumn{2}{c}{ Comparison group } \\
\hline & $(/ 25)$ & & & \\
\hline Yes, I have made progress & 18 & 72.00 & 9 & 32.14 \\
\hline Neutral answers & 6 & 24.00 & 8 & 28.57 \\
\hline $\begin{array}{l}\text { No, I have not made any } \\
\text { progress }\end{array}$ & 1 & 4.00 & 11 & 39.29 \\
\hline
\end{tabular}

Table 6.8. Students' positive answers on their progress

\section{Experimental group}

- Personally, I think I made progress in vocabulary identification. I can identify the phrases, the collocation in a reading passage easily even though I haven't used chunking in speaking. - Mỹ Anh

- I found that I can use more vocabulary and collocations than before. -Trần Dịu

- After 5 months, I know more collocations and can use them more often than before in my speaking and writing. - Nguyễn Hòa

- I can be better at realizing the collocation, MWEs and look them up more easily. - Nguyễn Lộc

- I gain more vocabulary than I did 5 months ago, about 20\%. - Minh Hằng

\section{Comparison group}

- I've learnt quite a thing, knew some new phrases (not very much, but still) and knew some ways to use unknown words. - Văn Thành

- In the last 5 months, I have taken up a habit of learning new words every day. These new words are usually highly used. And my vocabulary in the last 5 months has improved quite much through my habit. - Minh Thảo

- I learnt how to look for key words and new words. - Thành Đồng

- After 5 months, my vocabulary is better. I've learnt many new words that support my English very much. - Tâm An

Conversely, as shown in Table 6.7, almost $40 \%$ comparison students were not happy with their progress, compared with only $4 \%$ experimental learners stating so (See examples in Table 6.9). This difference in learners' self-evaluation of their own learning gain can partly show reflection of the experimental group on their vocabulary learning process. 
Only when learners are more aware of their own learning objectives and how to achieve them, can they realize clearly how much progress they have made.

Table 6.9. Students' negative answers on their progress

\section{Experimental group}

- Since I was so lazy, and I didn't practice well, the vocabulary that I had remembered in class soon was forgotten. - Kim

\section{Comparison group}

- I can't realize any progress. - Đức Anh

- I must confess I haven't done much to gain more vocabulary recently. The number of new words I learn is rather small comparing to the number I should manage to learn. - Kim Ngân

- My progress in gaining more vocabulary in the last months isn't good. When I first saw a new word, I tried to remember it. But if I don't see it for several times, I will forget it. - Mai Quỳnh

- It's still a slow process, but I try to gain more collocations and idioms than single words. - Khôi Nguyên

The similarity between the two groups may be attributed in part to the fact that some learners reported on their ways of learning in response to the question, rather than estimating how much they had learnt. Among the most common ways that students mentioned are doing reading and vocabulary tests, noting new lexical items in notebooks, and trying to apply them when speaking and writing. This finding is in line with the results from students' responses to Likert-scale statements mentioned above.

To sum up, the impact of the treatment can be discerned from the experimental learners' self-evaluation of their learning progress. Moreover, the differences the treatment brought about in the learners' awareness of their MWE acquisition compared to their counterparts' can be much more clearly seen from the learners' open question response than from the Likert-scale responses. In the next subsection, I will investigate both groups' opinions on their use of lookup resources, typically different kinds of dictionaries. 


\subsubsection{What are the learners' preferred lookup resources for MWEs?}

Previously, in Section 6.2.3.3, I have touched upon the popularity of online dictionaries among these learners as observed in the Likert-scale section. This popularity is strongly confirmed in the learners' responses to question 2.1 in Section 2 of the questionnaire, which probes into their preferred port of call when it comes to looking up new lexical items. Among the options given, including paper-based dictionaries, electronic dictionaries and corpora, students highlighted the usefulness of electronic dictionaries, especially the dictionary applications on smartphones and other portable devices. Below are some of the typical comments from both groups, some of which were written in Vietnamese and have been translated here.

First, these are typical answers from the experimental group. As expected, more students are in favor of electronic dictionaries because of their convenience, portability and updated database compared to the paper versions.

- Among them, I find electronic or online dictionaries are the most useful because online dictionaries are fast and convenient. I can look for not only new words but also synonyms or antonyms of them, or idioms related to these new words. - Hoài Anh

- Dùng electronic dictionaries sẽ tiện lợi nhất vì nó có bản offline không cần kết nối Internet nên sẽ nhanh hơn. (Electronic dictionaries are the most convenient. They even have offline versions, so I don't need Internet connection, which is quicker) Ngọc Bích

- Electronic dictionaries because it is convenient to use them, and they are also updated. Moreover, they provide a quickest way to find a word, especially with the case of phrases when using other kinds is hard. Most importantly, they are proved to be the trustworthy sources. - Đăng Hoàng

- Electronic dictionaries are the most useful in looking up new items of vocabulary because it's comfortable and the meaning of word is updated day by day. - Như Lê

- 'I prefer electronic dictionaries since they are convenient, fast and cheap. It's not time-consuming and I can look up words everywhere.' - Kim Ngân

Interestingly, the comparison group not only mentioned the same ideas about the benefits of online dictionaries. They even went beyond that by expressing detailed 
responses on different kinds of dictionaries and pointing out which kind is good for which lookup. This elaboration indicates their frequent and experienced interaction with online dictionaries, including the lookup for formulaic sequences.

- Oxford dictionaries because they are clear, detailed and also have phrases, collocations, idioms for the words. Urban dictionary: this electronic dictionary is good for learning spoken language. - Như Quỳnh

- When I want to look up new items of vocabulary, I often use electronic dictionaries. My favorite dictionary is Oxford (online edition). It doesn't take much time to look up meanings, and it is quite accurate and sufficient. When I use it, Ifeel secure about the word I use. This source has a wide range of items of vocabulary like words, phrasal verbs, collocations and idioms. I like using electronic dictionaries and corpora to learn vocabulary because they are convenient and help me learn day by day. - Mai Quỳnh

- Some online dictionaries (Oxford, Cambridge, Collins, ...) to me, are the most useful sources to look up new items of vocabulary because they are up-to-date with modern language, plus they are reliable and clear in terms of explaining and giving examples. And for some slangs, I often go to urbandictionary.com to look up new phrases. This website provides lots of slangs and spoken language phrases. I would choose the online version of Oxford Dictionary because it's kinda official and it also provides detailed explanation and extra examples for me to understand the phrases more. - Việt

- My favorite resources is Thefreedictionary.com. It is a mainstream website or a kind of online dictionary. Its browser is very easy to use. You just have to type one word, and then MWEs, idioms, and collocations related will appear for you to choose.Tố Như

- For single words I would use Oxford dictionary as it gives correct meaning with expression that an English-Vietnamese dictionary may miss. For collocation I would use Ozdic.com as it is easier to use than Oxford - Thảo Linh

As aforementioned, there were several comparison students stating that they would use paper dictionaries while the majority of students in both groups were in favour of electronic ones. Here are a couple of their explanations. 
- I think paper dictionaries is the most useful in looking up new items of vocabulary when I look up a verb. There will be a range of phrasal verbs or even idioms formed by that word below. Personally, I think it's more reliable than other tools. - Minh Hà

- I would say it's electronic dictionaries; however, only when they are based on the paper ones, for example Oxford Learner Dictionary online. So basically, I prefer the paper ones because they are trustable but it's pretty inconvenient to carry them along with me all the time. - Minh Tú.

There are also learners who mentioned that they could reap the benefits of both dictionaries and COCA to have better knowledge of the usage of a new vocabulary item. Not surprisingly, these responses came from students of the experimental group who had had hands-on experience exploring COCA during the intervention. Following are some of their comments.

- Actually, I find the most useful in looking up new items of vocabulary in electronic dictionaries and corpora. I am really able to find many vocabulary items in corpora and looking them up in electronic dictionaries. It helps me to understand them totally and conveniently. - Nga

- I usually prefer using electronic dictionaries along with corpora because it's more convenient that way. I can get access to e-dictionaries almost anytime I want thanks to the help of smart phones. - Đào

There is still a lack of evidence of the experimental group's effective use of COCA. This aspect will be further discussed in a later section on this group's evaluation of their chunking activities. In brief, in terms of dictionary lookups, the experimental group did not show any stronger awareness or practice over the comparison group. The next subsection is going to discuss students' self-reported MWE learning strategies to see whether any differences between the two conditions arise from this qualitative data.

\subsubsection{What are the learners' mostly-used MWE learning strategies?}

In question 2.2, students had a chance to elaborate their most used learning strategies. The most observable trend from the learners' elaboration is that while the experimental 
students' strategies are more aligned to the series of treatment activities (see Table 6.10), the comparison group put forward a more diverse pool of strategies (see Table 6.11).

Table 6.10. MWE learning strategies - The experimental group

\begin{tabular}{lcccc}
\hline Strategies & \multicolumn{2}{c}{$\begin{array}{c}\text { Immediate } \\
\text { questionnaire } \\
\text { (/19) }\end{array}$} & \multicolumn{2}{c}{$\begin{array}{c}\text { Delayed } \\
\text { questionnaire } \\
(/ 23)\end{array}$} \\
\hline & Count & $\%$ & Count & $\%$ \\
\hline Look up new MWEs in dictionaries & 11 & 57.89 & 9 & 39.13 \\
\hline Read extensively & 9 & 47.37 & 4 & 17.40 \\
\hline Take notes/ Keep a vocabulary notebook & 9 & 47.37 & 4 & 17.40 \\
\hline $\begin{array}{l}\text { Make efforts to use MWEs when } \\
\text { speaking or writing }\end{array}$ & 7 & 36.84 & 7 & 30.43 \\
\hline Discuss new MWEs with friends & 6 & 31.58 & 10 & 43.48 \\
\hline $\begin{array}{l}\text { Highlight/ Underline interesting MWEs } \\
\text { in texts }\end{array}$ & 6 & 20.69 & 6 & 26.09 \\
\hline Guess the meanings of new MWEs & 2 & 10.53 & 1 & 4.35 \\
\hline Look up new MWEs in COCA & 2 & 10.53 & 1 & 4.35 \\
\hline Watch/ Listen extensively & 2 & 10.53 & 1 & 4.35 \\
\hline Consult teachers & 0 & 0 & 1 & 4.35 \\
\hline
\end{tabular}

As can be seen from Table 6.10, in the immediate questionnaire, the most common strategies of the experimental group were looking up new MWEs in dictionaries, reading extensively, keeping a vocabulary notebook and discussing new MWEs with friends. The ranking changed slightly five months later, with making efforts to use MWEs when speaking and writing and highlighting interesting MWEs rising to the top four. It is interesting that in the delayed questionnaire, one student mentioned consulting teachers as one of her strategies, which may imply learners' need for teachers' instructional support even with other resources available.

As for the comparison group, their most common strategies are quite similar, but in a different ranking (see Table 6.11). Keeping a vocabulary notebook was top-ranked both in the immediate and delayed questionnaire. Some of the intervention activities which are comparatively higher-ranked among the experimental group are not mentioned much among the comparison group. For example, the activities of highlighting interesting MWEs in texts, discussing with friends or looking up new MWEs in COCA all had their ranks of importance dropped after five months. The strategy of guessing the meanings of new MWEs or consulting teachers were not mentioned at all by the comparison students. Meanwhile, there were two strategies which were not stated by the experimental group 
but listed by the comparison learners. They were associating new MWEs with funny stories or their interesting origins, which can support the retention, and doing more exercises on MWEs.

Table 6.11. MWE learning strategies_The comparison group

\begin{tabular}{lcccc}
\hline Strategies & \multicolumn{2}{c}{$\begin{array}{c}\text { Immediate } \\
\text { questionnaire } \\
(\mathbf{2 8})\end{array}$} & \multicolumn{2}{c}{$\begin{array}{c}\text { Delayed questionnaire } \\
(/ 27)\end{array}$} \\
& Count & $\%$ & Count & $\%$ \\
\hline $\begin{array}{l}\text { Take notes/ Keep a vocabulary } \\
\text { notebook }\end{array}$ & 12 & 42.86 & 14 & 51.85 \\
\hline Read extensively & 10 & 35.71 & 9 & 33.33 \\
\hline $\begin{array}{l}\text { Highlight/ Underline interesting } \\
\text { MWEs in texts }\end{array}$ & 9 & 32.14 & 1 & 3.70 \\
\hline $\begin{array}{l}\text { Look up new MWEs in } \\
\text { dictionaries }\end{array}$ & 8 & 28.57 & 9 & 33.33 \\
\hline Watch/ Listen extensively & 7 & 25.00 & 7 & 25.93 \\
\hline $\begin{array}{l}\text { Make efforts to use MWEs when } \\
\text { speaking or writing }\end{array}$ & 7 & 25.00 & 7 & 25.93 \\
\hline Discuss new MWEs with friends & 5 & 17.86 & 2 & 7.41 \\
\hline $\begin{array}{l}\text { Look up new MWEs in COCA } \\
\text { Do more exercises on MWEs }\end{array}$ & 2 & 7.14 & 0 & 0 \\
\hline $\begin{array}{l}\text { Guess the meanings of new } \\
\text { MWEs }\end{array}$ & 0 & 7.14 & 3 & 11.11 \\
\hline $\begin{array}{l}\text { Consult teachers } \\
\text { Associate new MWEs with funny } \\
\text { stories or interesting origins }\end{array}$ & 0 & 0 & 0 & 0 \\
\hline
\end{tabular}

Here are some extracts from the comparison group's responses showing their original reflections on their own MWE learning process:

- I would like to learn MWEs from some sources that I actively approach to, such as letters, games, videos, something that I love to read or listen to. Whenever I meet a new one, I would note down and try to apply it into my speaking or writing activities. - Quỳnh Nam

- I mostly learn it from the conversations with my friends because it's really natural. It goes into my mind without any difficulties. Most of the time I learn MWEs by writing them down a small sticky note or put them into my phone (the "note" app on Iphone). Sometimes I look up some of the passages containing those MWEs to find further meaning. - Kim Ngân, 
- I normally try to read newspaper in English (from online resources such as The guardian.com or Nytimes.com) so that I can pick up new words and understand fully when and where I can use it. Also, I watch English-speaking movies to know how native speakers use their words. - Hồng Ngoc

- I use flashcards to write down new words/ phrases that I've learnt and try to flip it back and forth every day. - Phạm Hà Phwơng

These extracts demonstrate that comparison students, not being trained in using the language-focused strategies like the experimental group, still have interesting ways to acquire more MWEs. In other words, what the treatment has done is direct the experimental group's focus to a limited number of strategies and put those strategies in regular practice. This concentration of strategies also results in restricting other strategies which can be more customized to each individual learner otherwise. To gain a better insight into what experimental students thought about the chunking activities, the next section will investigate their responses to the remaining part of the questionnaire, items $1.36-1.50$.

\subsection{Experimental learners' self-evaluation of chunking activities and the use of COCA}

Unlike other sections of the questionnaire, items 1.36-1.50 (Table 6.12 \& 6.13) were designed exclusively for the experimental group who had hands-on experience of the treatment. Another difference is that this section consists of 5-point Likert-scale items instead of 4-point ones, ranging from 1 (Strongly disagree) to 5 (Strongly agree). Generally speaking, students thought highly of the activities. This appreciation can be seen through the high mean ratings in all items 1.36-1.50, ranging from 3.35 to 4.40 in the immediate questionnaire and from 3.48 to 4.00 in the delayed one. The following report will detail students' evaluation of both the chunking activities and the usefulness of the recommended resources like online dictionaries and COCA.

Slight changes in the mean ratings of students' responses between the two time points of the survey show that they basically held the same opinions of the activities, even after 5 months. Specifically, students agreed that chunking activities are useful to them by helping them notice phrases in texts and memorize them better. Students appreciated not only highlighting interesting MWEs in texts but also discussing them with their friends, 
with $M($ immediate $)=4.00 \& M($ delayed $)=3.96$ for item 1.41 . Remarkably, students were more confident in claiming their improved production of MWEs five months after the treatment. This upward trend displayed in item 1.44 and 1.45 is a good signal of students' upgraded awareness of MWEs and their effort in using them. That said, after five months, students showed a decline in their confidence about the success rate of identifying chunks in texts $(M($ immediate $)=4.15 \& M($ delayed $)=3.72$ for item 1.45$)$.

Looking at the evaluation of recommended resources, one of the biggest changes in students' self-report after the five-month gap occurred in their appreciation of the dictionary lookup in helping them pick up phrases, with the mean rating of item 1.39 increasing from 3.35 in the immediate questionnaire to 3.80 in the delayed one. Also, the mean ratings for item 1.47 about the helpfulness of online dictionaries are the highest in both survey points, $(M($ immediate $)=4.40 \& M($ delayed $)=4.00)$.

Table 6.12. Experimental students' self-evaluation of chunking activities

\begin{tabular}{|c|c|c|c|c|c|c|c|c|c|}
\hline & \multirow[b]{2}{*}{ Items } & \multicolumn{4}{|c|}{ After } & \multicolumn{4}{|c|}{ Delayed } \\
\hline & & $N$ & Mean & Mode & $S D$ & $N$ & Mean & Mode & $S D$ \\
\hline 1.36 & $\begin{array}{l}\text { I think trying to identify } \\
\text { possible MWEs in a text } \\
\text { ("chunking" activity) is } \\
\text { a very useful activity. }\end{array}$ & 20 & 4.10 & 4 & .72 & 25 & 3.84 & 4 & .85 \\
\hline 1.37 & $\begin{array}{l}\text { When chunking, I may } \\
\text { become aware of MWEs } \\
\text { that I may not otherwise. }\end{array}$ & 20 & 3.65 & 3 & .67 & 25 & 3.72 & 3 & .94 \\
\hline 1.38 & $\begin{array}{l}\text { I can better memorize } \\
\text { the MWEs I have } \\
\text { underlined/ highlighted } \\
\text { in a text. }\end{array}$ & 20 & 3.55 & 4 & .95 & 25 & 3.76 & 3 & 1.01 \\
\hline 1.39 & $\begin{array}{l}\text { I can better memorize } \\
\text { the MWEs I have looked } \\
\text { up in a dictionary. }\end{array}$ & 20 & 3.35 & 4 & .81 & 25 & 3.80 & 4 & .91 \\
\hline 1.40 & $\begin{array}{l}\text { I can better memorize } \\
\text { the MWEs I have looked } \\
\text { up in a corpus. }\end{array}$ & 20 & 3.65 & 4 & 1.04 & 25 & 3.52 & 4 & .92 \\
\hline 1.41 & $\begin{array}{l}\text { I can better identify } \\
\text { possible MWEs through } \\
\text { discussions with my } \\
\text { friends. }\end{array}$ & 20 & 4.00 & 4 & .80 & 25 & 3.96 & 4 & .89 \\
\hline 1.42 & $\begin{array}{l}\text { I can better memorise an } \\
\text { MWE of which I can } \\
\text { find an equivalent MWE } \\
\text { in Vietnamese. }\end{array}$ & 20 & 3.60 & 4 & .88 & 25 & 3.48 & 4 & .96 \\
\hline
\end{tabular}




\begin{tabular}{|c|c|c|c|c|c|c|c|c|c|}
\hline & \multirow[b]{2}{*}{ Items } & \multicolumn{4}{|c|}{ After } & \multicolumn{4}{|c|}{ Delayed } \\
\hline & & $N$ & Mean & Mode & $S D$ & $N$ & Mean & Mode & $S D$ \\
\hline 1.43 & $\begin{array}{l}\text { It is easier for me to } \\
\text { memorise the meaning } \\
\text { of an MWE than its } \\
\text { structure and } \\
\text { grammatical functions. }\end{array}$ & 20 & 3.75 & 4 & 1.02 & 25 & 3.44 & 4 & 1.00 \\
\hline 1.44 & $\begin{array}{l}\text { I manage to think of } \\
\text { more MWEs to use } \\
\text { when I practise English. }\end{array}$ & 20 & 3.45 & 4 & 1.00 & 25 & 3.48 & 3 & .71 \\
\hline 1.45 & $\begin{array}{l}\text { I manage to use some } \\
\text { MWEs I learnt in the } \\
\text { course in the end-of- } \\
\text { term tests. }\end{array}$ & 20 & 3.60 & 4 & .82 & 25 & 3.72 & 4 & .61 \\
\hline 1.46 & $\begin{array}{l}\text { I feel that I am better at } \\
\text { identifying MWEs in } \\
\text { reading texts than I was } \\
\text { before. }\end{array}$ & 20 & 4.15 & 4 & .75 & 25 & 3.64 & 4 & 1.00 \\
\hline 1.47 & $\begin{array}{l}\text { The use of online } \\
\text { dictionaries has been } \\
\text { helpful in my } \\
\text { vocabulary learning. }\end{array}$ & 20 & 4.40 & 5 & .88 & 25 & 4.00 & 4 & .76 \\
\hline 1.48 & $\begin{array}{l}\text { The use of corpora has } \\
\text { been helpful in my } \\
\text { vocabulary learning. }\end{array}$ & 20 & 4.20 & 5 & 1.00 & 25 & 3.92 & 4 & .76 \\
\hline 1.49 & $\begin{array}{l}\text { A corpus is a reliable } \\
\text { resource for me to check } \\
\text { if my use of English } \\
\text { sounds native. }\end{array}$ & 20 & 4.05 & 5 & 1.05 & 25 & 3.76 & 4 & 1.20 \\
\hline 1.50 & $\begin{array}{l}\text { When I have problems } \\
\text { finding the right words } \\
\text { for my writing, I seek } \\
\text { help in a corpus. }\end{array}$ & 20 & 3.85 & 4 & .81 & 25 & 3.64 & 4 & 1.15 \\
\hline
\end{tabular}

When emphasizing the helpfulness of dictionary lookup for the retention of new phrasal items, students were more hesitant in stating the impact of other factors like the use of corpora (item 1.40, Table 6.12), $M=3.65$ for item 1.40 in the immediate survey, and down to $M=3.52$ in the delayed survey. Students' responses to question 2.2 in Section 2 of the questionnaire about the difficulties they had encountered when exploring COCA can shed some light on this.

It is worth remembering that in previous sections, some students mistook COCA to be a dictionary, which means these students had completely different expectations when seeking help from COCA and possibly even different ways to interact with it. There was insufficient evidence to show that the learners had learnt how to make use of COCA for 
their vocabulary lookup, even simply for checking the items' frequency. This may also provide some insight into students' difficulties when looking up interesting word combinations in COCA as further discussed below.

In their answers to question 2.2, two out of 26 experimental students changed their ideas from 'no problems at all' or 'easy' to some comments on the not-so-user-friendly COCA interface. Table 6.13 below provides a list of the most common stumbling blocks experimental students mentioned in their responses.

Table 6.13. Difficulties when using COCA

\begin{tabular}{lcc}
\hline Difficulties when using COCA & Count /16 & \% \\
\hline Too many rules & 9 & $56.25 \%$ \\
\hline Not user-friendly interface & 7 & $43.75 \%$ \\
\hline Login requirement & 4 & $25.00 \%$ \\
\hline Internet connection requirement & 2 & $12.50 \%$ \\
\hline Others & 2 & $12.50 \%$ \\
\hline
\end{tabular}

Not surprisingly, the biggest disadvantages of COCA mentioned by the learners seemed to derive from the complexity of the database. Students found themselves struggling to formulate good search queries that could yield fruitful results. This difficulty had been expected and students were therefore provided with brief handouts showing the most commonly-used syntaxes. That said, it looked like those handouts did not provide enough assistance for the students to navigate the corpus. Here are some examples of students' comments:

'Sometimes there are misunderstandings when I type the words. I have to write correct tense (verb infinitive) and sometimes there are meanings that are not correct with the context.' - Dung

It is hard to use its functions. The interface is not so catchy, and it is hard to work out the main contents. - Vân

'Yes. I find it difficult to find the right form to put in a corpus seaching tool.' - An

'Can't remember some complicated rules when typing words into the box.' - Binh A few students raised the issues of Internet connection and login requirement as obstacles to making COCA more accessible. Here are some typical comments.

'COCA always logs me out and I have to log in once again whenever I search for words.' - Trúc

'Yes. I can't use COCA if there isn't wifi around me.'- Hồng 
'Sometimes my mobile is out of data, so it is quite hard to use it (COCA) while with dictionary, there are some apps for us to download and use offline.' - Binh

Though not common, the idea that having to stay connected to use COCA could bring them unwanted distraction was also raised by one or two learners.

'I don't like using the Internet when I study because it is easy for me to be interacted by Facebook.' - Phương

By and large, the experimental group held positive opinions on the usefulness of different chunking activities. However, although the potential of COCA was recognized, students would not use it often due to the various obstacles mentioned above. It is likely that more training on the use of COCA is needed for students to overcome at least some of those obstacles.

\subsection{Conclusion}

Coming back to the hypothesis proposed at the chapter introduction, I can conclude that both the statistics and the qualitative data from the learners' open question responses demonstrated a significant impact of the treatment on the experimental students in heightening their awareness of MWEs and their learning strategies. Although the comparison group's awareness of MWEs improved over time too, the changes were not as remarkable as in the experimental group.

Up to this point in the thesis, findings about students' MWE test performances, their ontask chunking strategies and their self-report of their own learning process have been examined. The next chapter - Discussion - is going to weave them together by explaining different emerging issues from these findings. 


\section{CHAPTER 7 - HOW DOES THE INTERVENTION PROMOTE THE DISCOVERY LEARNING OF FORMULAIC LANGUAGE AMONG THE LEARNERS AFTER ALL?}

\subsection{Introduction}

Up to this point, the findings regarding whether MWE-extracting activities can benefit the learners' uptake and awareness of MWEs and what strategies they use for these activities have been presented in Chapters 4, 5 and 6. In this chapter, I am going to look at these findings against the backdrop of existing literature on formulaic language teaching and learning. The chapter starts by discussing the two themes: 1) learners' strategies for MWE extraction from authentic texts and consultation of online reference tools, and 2) the learning gains of target MWEs achieved from the intervention. Given the gap left in the field on these aspects (as pointed out in Chapter 2), I consider these findings my most salient contributions to the current literature. The last section provides a commentary on the extent to which the intervention can promote the autonomous learning of formulaic language among the learners.

\subsection{Learners' MWE extraction and lookup strategies}

One aim of the study was to find out whether the learners in the experimental group utilized any strategies during their intuitive text-chunking practice; if yes, what strategies they used, and what strategies were used when learners decided to make deliberate efforts to learn certain MWEs. Chapter 5 presented my findings on the experimental learners' online strategies both for identifying the forms and for guessing the meaning of new MWEs. Chapter 6 indicated the most reported MWE learning strategies in both groups, including their lookup habits. In this section, I discuss these strategies in relation to the bigger picture of the literature on L2 vocabulary learning strategies, starting with the learners' discovery strategies in MWE extraction and moving on to their dictionary and COCA lookup behaviour. By discovery strategies, I mean the strategies the students used when they were intuitively exploring texts to identify the forms and guess the meanings of new MWEs. 


\subsubsection{Learners' discovery strategies in $M W E$ extraction}

It was found in this study that at the intermediate level, with their metalinguistic knowledge, learners can actively employ different tactics both in identifying the forms of new chunks and in working out their meanings. These findings lend support to previous research results about L2 learners' ability to easily identify and respond to MWEs rather than non-formulaic word strings (e.g., Hernández, Costa, \& Arnon, 2016; Jiang \& Nekrasova, 2007). Let us now look further into how learners attended to the forms and coped with the meanings of appealing MWEs.

\subsubsection{Learners' MWE form-identifying strategies}

Most importantly, this study has once again underlined the pivotal role of the frequency of encounters in drawing learners' attention to the forms of MWEs in reading texts, i.e. when learners intuitively considered a word string as a MWE without guessing its meaning yet. As mentioned in Chapters 5 and 6, the most important feature of multiword lexis that makes them stand out to L2 learners is that those phrases have been encountered earlier. When the learners explained why they thought a word string was possibly a MWE, as many as $41.46 \%$ of the cases were that the phrases had been seen before either in the texts the learners were reading or in their previous language experience. This finding was in line with earlier research on the significant impact of the number of exposures on learners' incidental uptake of both single words and MWEs (Horst, Cobb, \& Meara, 1998; Joe, 2010; Nation \& Wang, 1999; Pellicer-Sánchez, 2017; Pellicer-Sánchez \& Schmitt, 2010; Peters, 2014; Pigada \& Schmitt, 2006; Rott, 1999; Waring \& Tanaki, 2003; Webb, 2007, Webb, Newton \& Chang, 2013). As stated by Siyanova-Chanturia \& Sidtis (2018), "even when speakers have a relatively limited exposure to a language, they are still remarkably attuned to phrase frequency distributions." (p. 43). When it comes to scanning a text for MWEs, one would expect that learners would exclusively pick out phrases they had seen at least once before, if not many times already. In this way, the incidental acquisition of MWEs seems to resemble that of single words. As Nation (2001) puts it, 'chunks can be most effectively memorized by following the same learning guidelines as for isolated words' (p. 343). Noticing, together with retrieving and generating, is one of the three most important conditions for successful vocabulary learning (Nation, 2001, 2013). Re-encountering MWEs in textual input may at least enhance the likelihood of them being noticed. 
Another important finding in this study was that the students' engagement with candidate MWEs went beyond familiar-looking intact phrases. In other words, the students seemed to be able to pick out word combinations they saw for the first time. These combinations were new MWEs of familiar words that they found semantically puzzling (e.g. out of the blue, when it comes to, runner's high) or transparent but interesting (e.g. a sea of, a chicken-and-egg question. Interestingly, particular formal features, such as the phonological repetition in [a] fight or flight [response], also piqued students' curiosity about the MWE status of certain phrases. Some word strings were considered likely MWEs because they showed structural resemblance to already familiar MWEs. For example, almost all of the students speculated (in this case mistakenly) that the word string scrutiny and scepticism was likely to be an MWE owing to its analogy with common binomial phrases in English (e.g., research and development, fish and chips) and owing to its conspicuous alliteration (which happens to be a feature of many standard binomials in English, e.g., bed and breakfast, black and blue, and part and parcel; Boers et al., 2014). Other cases in point are familiar structures including V+prep (e.g. squeal with), the $N+$ of $+N$ (e.g. the full spectrum of viewpoints), prep $+N$ (e.g. at stake), and $V+N$ collocations (e.g. make judgements).

Therefore, not only familiar intact MWEs could draw the learners' attention but also chunks with familiar constituent words or with new words structured in familiar ways could do so. This finding corroborates earlier arguments that the effect of frequency on the learning of MWEs seems not as strong as that of single words (Siyanova-Chanturia \& Pellicer-Sanchéz, 2018) and that this effect possibly interacts with other features of MWEs such as semantic relevance or formal salience (e.g. Szudarski \& Carter, 2016; Webb \& Chang, 2015). More specifically, a relatively weak but nonetheless significant correlation $(r=.32)$ was found between the frequency of the target items on COCA and the learners' knowledge of these items revealed in the pretest. This relatively weak correlation was similar to what was found in previous work (Garnier \& Schmitt, 2016; González-Fernández \& Schmitt, 2015; Macis \& Schmitt, 2017). One interesting example was the MWE amount to, which appeared in the list of most frequent MWEs in COCA compared to other target items but was unknown to all the participants in this study. Meanwhile, idioms like birds of a feather flock together and opposites attract appeared 
among the least frequent target MWEs in COCA but were among the most learnt MWEs at the end of the treatment.

Interestingly, when noting down appealing phrases in their pairwork vocabulary worksheets, the learners sometimes adapted the forms of MWEs they identified rather than copying them verbatim from the text in which they occurred. For example, they would turn expressions used in the passive voice (e.g., be bombarded with, be associated with) into the active voice (bombard someone with something, associate with someone), probably because that is the form they found in the dictionary. Unfortunately, adaptations sometimes resulted in non-idiomatic renderings of the MWEs, as in the case of students' noting down a walk of life instead of all walks of life in this study, or even wrong meaning extraction from dictionaries which will be illustrated hereafter in the section about dictionary lookup. A similar typical example of learners' misuse as mentioned by Cobb (2018, p. 196) is the case of the idiom pulling one's leg, which might be rendered by a student as pulling one's legs. Also, learners may take some risks when hypothesizing familiar-looking slots are MWEs. For one thing, they may pick up free combinations of words, as in the case of scrutiny and scepticism. For another thing, they may treat these structures as other grammatical slots and change the components flexibly, as in a walk of life. That said, this adaptation also suggests that these learners had benefited from sufficient exposure to English for such grammar-based intuitions to develop.

Possible explanations for the phenomenon that the learners actively responded to the familiarity in candidate MWEs either coming from the familiar constituent words or familiar structures include the following. First, MWEs that were seen before and those new ones comprised of familiar words might not take learners too much effort to memorize since all the component words were already known to them. The fact that these words were combined in a novel way might be striking enough to support learners' memory. For instance, the phrase chicken-and-egg question, though comprised of familiar words, was discussed by all pairs of the experimental students, simply because the way these words are bound together was so appealing to the learners. One student even spontaneously expressed her interest in the phrase in her list of phrases she would like to learn at the end of the lesson (see Figure 7.1 below). Similarly, students noticed leading cause, which differed from ones they were already familiar with (e.g., main 
cause), and this made them wonder if the novel combination might be a worthwhile addition to their own lexical resources.

Second, in their language skills acquisition lessons, these students were encouraged to acquire and use more uncommon words or phrases. Using those uncommon lexical items may boost learners' scores at some high-stakes standardized tests like IELTS, one of the most recognized English proficiency tests in Vietnam. More often than not, the students discussed whether incorporating a given phrase in their essay writing could serve to make their language more sophisticated. Bearing this strategy in mind, the students might immediately attend to those combinations which are both uncommon to them and transparent in meanings and, therefore, more memorable. Choosing MWEs like a sea of, chicken-and-egg question or opposites attract to learn would lighten the learning burden. In case they encounter new combinations of known words with opaque meanings, the fact that the chunks are semantically puzzling even when they know all the constituent words is possibly striking enough to hook learners' attention. Given the immense number of MWEs available in the language, it can be easily understood that MWEs with these advantages will be noticed and later shortlisted to be learned. Data from experimental students' recordings and both groups' questionnaire responses (as presented in Chapters 5 and 6) have indicated students' high appreciation of previously seen intact phrases and seen-for-the-first-time phrases of familiar words.

Figure 7.1. Samples of individual learners' phrase lists

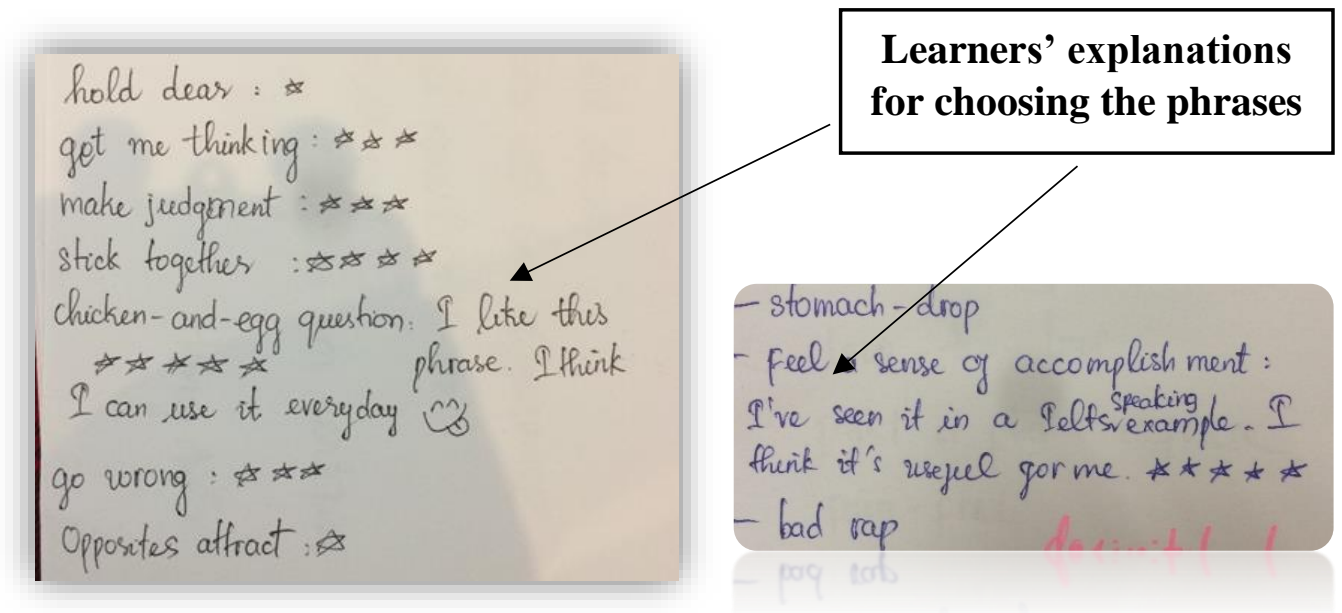

This study also revealed some other thought-provoking findings about how the learners paid attention to MWEs in texts. First, these learners focused typically on more 
meaningful MWEs comprised of content words rather than those mostly made up of function words, or lexical bundles (Biber \& Conrad, 1999; Biber, Conrad, \& Cortes, 2004). If frequency is an influential factor that makes a MWE more attention-drawing, then lexical bundles like one of the, something like that, at the end of the may be attended to more than other MWEs consisting of content words like press conference, daily grind, or critical thinking since they occur more often. It might be because at this intermediate level, these students had mastered those lexical bundles since they are by definition highfrequency word strings. Also, it might be typical of language users to focus more on the meaning (or content) of the texts and even when asked to search for conventional word combinations, they still automatically looked for meaningful phrases (containing content words). Second, some MWEs comprised of very familiar words whose meanings are not essential to the understanding of the whole sentence might be overlooked in the process of students' MWE-extraction. For starters and amount to are examples of phrases that were not noticed at all by the learners in this study according to the audio-recordings and the students' notes. MWEs of the same kind should be typographically enhanced to support learners' attention and acquisition.

Third, as reported in Chapter 5, the appearance of new words made the learners hesitant in making decisions about the chunk status of certain word strings. To some extent, this observation is consistent with Kim (2016) in that unknown words drew more attention from L2 learners than new idioms comprised of familiar words (Kim, 2016). Consequently, it is worth considering the vocabulary load of the texts when setting up the condition to promote autonomous MWE extraction among L2 learners.

Taken together, this study has expanded the current knowledge on L2 learners' attention to MWEs in texts, suggesting that learners can notice multiword units beyond those they have seen intact before. With explicit instructions from teachers, learners at immediate level or higher can autonomously attend to MWEs in textual input that 1) they have seen before in intact forms, 2) combine familiar words in a new way, and 3) combine new words in a familiar way. Obviously, these factors alone cannot guarantee learners' consistently high success rate in noticing chunks. Such a success rate is undoubtedly contingent on other factors such as learners' experience in chunking practice or individuals' sensitivity and deliberate attention in applying their existing knowledge to spotting potential MWE candidates. Also, it is worth considering that, in order for learners 
to start seeking confirmation of their hunch that a given word string is a standard MWE, they first need to have that hunch. Not all word strings or word combinations seem to prompt this. If a learner has no memory of seeing a particular word sequence before and does not find the word sequence semantically puzzling either, then this learner may see no ground for hypothesizing that the given word sequence might be a standardized expression. In other words, in cases where repeated encounters are unlikely, learner autonomous recognition of MWEs may not be very realistic, and so more guidance from teachers (or materials developers) may be desirable. Now that learners' strategies in paying attention to the forms of new MWEs has been discussed in depth, let us move on to their meaning-guessing strategies, as a part of learners' MWE discovery learning.

\subsubsection{Learners' MWE meaning-related strategies}

This study has revealed that students used diverse strategies to figure out the meanings of new MWEs (as reported in Chapter 5). The most used strategies with the meanings of new MWEs found in this study were guessing the meanings from the constituent words, guessing from textual contexts, asking a friend, discussing the meaning in pairs and using dictionaries. At first blush, strategies implemented by the students to work out the meanings of new MWEs seem to be transferred from the strategies used by learners for guessing the meanings of single words as reported in Schmitt (1997, 2010). Of these strategies, guessing the meaning based on constituent words appears to be developed from the single-word guessing strategy of analysing affixes and roots, or depending on word parts (Nation, 2013). Other strategies are quite similar in the ways the learners deal with single words and MWEs.

While the pool of learners' meaning discovery strategies for MWEs found in this study shares some similarities with those used for individual words, the order of importance of these strategies remarkably differ. It has been well established in research that guessing from context is one of the most frequent and preferred strategies for learners (Cooper, 1999; Fraser, 1999; Paribakht \& Wesche, 1999; Schmitt 1997, 2010). However, the most commonly-used strategy for lexical inferencing found in this study is guessing from constituent words (see Table 5.4).

One possible explanation for the more frequent use of guessing the MWE meanings from constituent words is that not every single word can be parsed into word roots, prefixes 
and suffixes, but every MWE can to some extent. By definition, a MWE consists of more than one word, and the constituent words might give the learners some idea about the meaning of the MWE. The guessing job might be less challenging with MWEs consisting of all familiar words, and possibly harder in cases when the main content words are unfamiliar to the learners. That said, learners can still somehow base their interpretations on the meanings of other words in the phrases including known words, or prepositions. Students may then use the contextual clues to confirm their guesses. Meanwhile, in the case of single words, when a word is totally new, there is much likelihood that contextual clues are the only anchors for the guesses to be made. This phenomenon may further support previous findings on learners' processing of MWEs (e.g. Conklin \& Schmitt, 2012) that less proficient learners process MWEs in a word-by-word manner as nonformulaic language, unlike proficient learners and native speakers who process fixed expressions as whole units. It seems to be the case in this study that the learners extracted chunks from the reading texts when trying to identify the forms, then broke them down into single words when guessing the meanings.

Another interesting result of this study is the markedly higher success rate of meaning guesses of $74 \%$ for the identified MWEs compared with the findings so far from studies on meaning guesses of individual words (Bensoussan and Laufer, 1984; Nassaji, 2003; Parry, 1991). The rate was only $25.6 \%$ in Nassaji (2003) and ranged from $12 \%$ to $33 \%$ in Parry (1991). Regarding multiword expressions, Cooper (1999) reported a success rate of $56 \%$ in his study on learners' idiom processing. However, the result in this study needs to be interpreted with caution. The reading materials selected for this study were all authentic with MWEs naturally appearing in those texts. The proportion of opaque MWEs, as a result, was small. For example, there were only a couple of idioms occurring in the reading passages of all ten weeks such as birds of a featherflock together, opposites attract, or out of the blue. A large proportion of the identified MWEs fell into the categories of collocations (e.g. $\mathrm{V}+\mathrm{N}, \operatorname{Adj}+$ preposition, $\operatorname{adj}+\mathrm{N}, \mathrm{N}+\mathrm{N}$ ). It has been well established in literature that collocations pose more challenges to learners' language production rather than their comprehension (e.g. Laufer \& Girsai, 2008; Laufer \& Waldman, 2011). The transparency in collocations' meanings might explain the high success rate in the learners' meaning discovery in the current study. 
It is important to investigate the causes for failures in guessing meaning. It is interesting that while guessing from component words ranks as first in the list of preferred meaningrelated strategies in this study, it is also the leading cause of learners' failed attempts (see Chapter 5). Typical examples in my data are the learners' mistaken guesses of mate with, a bad rap, walking advertisement. What happened here was that the learners based their interpretation on the literal meaning of the constituent words, and this can obviously be misleading. In a similar vein, Clarke and Nation (1980) warned about the risk of guessing word meaning based on word parts and suggested learners use this strategy as a way to verify the meaning guessed from contextual clues, rather than the other way around. Evidence from this study has shown that this word of caution also applies to MWEs.

When guessing strategies are not sufficient to help learners come up with appropriate meanings of the MWEs they attend to, other approaches learners may resort to include asking pair partners or looking up the phrases in dictionaries. In the next subsections, I am going to discuss the learners' lookup behaviour observed in this study.

\subsubsection{Learners' MWE dictionary lookup strategies}

To start with, let us look back at the context of this research project to highlight the importance of the discussion on the learners' dictionary lookup behaviours. In a testoriented language learning context in Vietnam, it is likely that students are strongly discouraged from depending on dictionaries to deal with unknown items when doing reading comprehension exercises. Instead, students are encouraged to ignore unknown words if their meanings do not affect the understanding of the main ideas in a text or the possibility of answering the comprehension questions. Alternatively, if it is necessary to work out the meaning of the unknown items, students are advised to make use of all the clues available in the reading text, including the word parts or the context, to approximately guess the meaning of the items and answer the questions. Students are also recommended to practice this skill frequently so that they can do well in the reading tests. It is reasoned that dictionaries are not allowed during the tests, and, therefore, students need to practise the guessing skills to prepare for this scenario. Arguably, this priority on meaning guessing skills should merely apply to the exam-skill-practice reading. However, students in this project transferred this long-developed learning habit into

activities in the intervention despite being encouraged to make use of online dictionaries 
to verify their meaning guesses. They might have failed to appreciate this activity as something they should do when reading in a more casual condition when they read both for joy and for their vocabulary enrichment.

As a result, the findings from this study have revealed some issues about learners' dictionary lookup behaviour which are consistent with previous studies (e.g. Hulstijin, Hollander, \& Greidanus, 1996; Laufer, 1997, 2011). First, they might be satisfied with their meaning guesses without seeking verification of those guesses from dictionaries. Notable examples in my data include when students noted down the meaning of mate with as 'to be friend with', hold dear as 'keep your boy/girlfriend', or a walking advertisement as 'have a walk for advertising'. Investigation of students' lookup sheets showed that they did not use dictionaries to check these meanings. Laufer (1997) put this phenomenon as "deceptive transparency" (incorrectly inferring the meaning of an expression based on knowledge of the words within the expression) which can make it more difficult to learn L2 words. The corollary of this phenomenon may be that as they have put effort into processing the meaning of the new items, the wrong guesses might leave some memory traces in their minds, and later they may still remember them and produce the vocabulary items inappropriately. Interestingly, no evidence of this phenomenon was found in the lookup worksheets of higher proficiency pairs in the experimental group.

Second, even when students decide to seek help from dictionaries for the meanings of the identified MWEs, chances are that they cannot pick out the correct meanings which fit the context under consideration. A typical example is when a student claimed to look up the phrase be associated with in Oxford Dictionary and told her partner that the phrase meant 'to spend time with somebody' (see Chapter 5). In this case, the mistaken extraction of dictionary meaning might have resulted from the students' changing associated to its infinitive form associate and picking out the meaning of associate with someone from the Macmillan dictionary. Interestingly, 'lemmatizing' words for dictionary lookups is apparently not always a good idea. A similar case in point was when students mistook the meaning of 'to be caught up in' as 'to go faster to reach something' from Macmillan Dictionary by changing the form of the main verb into its infinitive form and go for 'catch up' instead of 'caught up in'. Nevertheless, that not all look-ups were successful is not so surprising, since it has been well documented that navigating 
dictionaries for information about multiword lexis is not straightforward (e.g. Kim, 2018; Komuro, 2009; Laufer, 2011).

Notwithstanding all these issues, there are several changes that the intervention has brought about among the experimental group about their dictionary use. First, as reported in Chapter 6, these learners' awareness of the importance of lookup over meaning guessing has been raised, making the experimental group's awareness greater than that of the comparison group. Also, experimental students' self-reports showed their considerable enthusiasm for online dictionaries, which they used extensively during the course. Laufer and Hill (2000) argued that popular pedagogical tools will possibly foster learning. It might thus be the case here that students' boosted interest in consulting dictionaries about MWEs stimulated MWE learning. Second, although the task instructions were intended to direct the students' attention to multiword items, look-ups were also prompted by lower-frequency words that some of the students were not yet familiar with, such as communal and resilience. What is encouraging in this regard is that, after looking for the meanings of these words, the students would go on to explore whether the neighbouring words in the text (in this case, communal experience and build resilience) were typical partners. What this suggests is that, even though it is understandably hard for non-advanced L2 learners to recognize all MWEs in a text simply because they are unlikely to have encountered them all before, the awareness-raising activities led these students to at least consider the phraseological behaviour of words that attracted their attention due to their novelty.

While the use of dictionaries, even the online versions, was a familiar experience for these learners, this was not the case for the use of COCA. The next subsection discusses the findings about learners' use and attitudes towards the use of COCA in collecting information about MWE candidates they considered learning deliberately.

\subsubsection{Learners' COCA lookup use}

As mentioned in Chapter 2, the rationale for the introduction of COCA in this study is to foster learner autonomy. For one thing, COCA can keep learners, to some extent, informed of how frequently a phrase is used. From there, learners can make informed decisions on the priority they place on the efforts to acquire the item. For another, from the extraction of such simple information as frequency, it was hoped that learners would 
be familiar with the interface of COCA and gradually explore other affordances that the database can offer.

Nevertheless, the findings revealed some hindrances to the expansion of COCA use among the learners. First, the lookup results from the experimental group showed significant inaccuracy, even only with the extraction of frequency information. For instance, the COCA frequency of start out was noted down as 1690 by a pair of experimental students whereas it was 7270 when checked later by the teacher. While it is true that COCA keeps growing over time, and so counts will differ somewhat if they are performed some time apart, this cannot explain the very marked difference between these two frequency counts. It is possible that the students did not enter the capitalized form of the main verb as START out to retrieve the frequency of the phrase with all its inflectional forms, as instructed in their COCA manual. In any case, the outcome of their corpus query may have led them to underestimate the usefulness of the expression.

Second, students showed a lack of enthusiasm to continue using COCA for their vocabulary learning, especially after 5 months (see Chapter 6). The most common explanation from the learners was that the query syntax was not so intuitive to them, even with the manual at hand. These results are consistent with previous findings on the drawbacks of using data-driven learning approaches (Chambers, 2005; Chambers \& O’Sullivan, 2004; Yoon \& Hirvela, 2004). In the current study, COCA might be too new to these Vietnamese students. This new introduction requires a greater amount of training and practice with teacher's support to foster familiarity with all the query rules and interface, and how to make use of COCA. The efforts in organizing a workshop and even the preparation of the simplified manual sheet probably could not provide sufficient and constant help to make the language learners take up the habit of using COCA.

One encouraging finding from the learners' self-reports, however, is their positive attitudes towards the potential benefits a corpus-derived website like COCA can bring them. This positive attitude manifested itself in students' listings of useful resources, with COCA along with the 'traditional' resources - dictionaries. Also, this appreciative attitude resonates with other exploratory studies which investigate learners' corpus use behaviour (e.g. Franken, 2014; Geluso \& Yamaguchi, 2014). 
In a nutshell, it is premature to predict any fruitful outcomes from corpus-based autonomous learning in the current context from this intervention. It needs more time and pedagogical attempts to foster a 'researcher' attitude among the learners (Kennedy \& Miceli, 2000).

\subsection{Learning gains of target MWEs from the intervention activities}

Another aim of the study was to gauge the effect of the MWE identification activities on the students' retention of the MWEs. As reported in Chapter 4, the pre-test to post-test comparisons showed that the experimental group indeed gained more form recall knowledge of MWEs encountered in the texts than the comparison group. The strong associations between students' inclusion of particular MWEs in the vocabulary notes and their recall of precisely these in the post-tests show the effectiveness of MWE extracting activities. The form recall tests have helped measure the productive knowledge progress of the target items which was relatively elusive in previous studies (e.g. Boers, et al., 2006; Jones \& Haywood, 2004; Stengers, et al., 2010). Instead of looking at oral or written works which might not show students' knowledge of phrases included in the course materials, this study has provided statistical evidence for the effectiveness of textchunking activities on the knowledge gains of target MWEs. Three questions emerge from these results, including why the experimental group achieved better gains, why their learning gains were not so spectacular, and why the comparison group also gained knowledge of the target MWEs without experiencing the intervention. Let us look into these questions one by one.

\subsubsection{Why did the experimental group achieve better gains?}

The answer to this question might lie in the nature of the activities the experimental group did during the ten-week intervention. The learning activities in this study were designed to promote engagement with MWEs in multiple ways: attending to them, sharing opinions about them, looking them up, noting down information about them, and evaluating their usefulness. The superior retention of target MWEs among experimental students found in this study corroborate such well-recognized hypotheses and theories as the Noticing Hypothesis (Schmidt, 1995, 2001), the Levels of Processing theory (Craik and Lockhart, 1972), and the Involvement Load Hypothesis (Hulstijn \& Laufer, 2001). I will now discuss the explanations for the learning gains from the intervention in this project in light of these hypotheses. 
First, the learners in the experimental group clearly paid more attention to instances of MWEs in reading texts than their comparison counterparts. As Schmidt (2001, p. 30) asserts, 'people learn about the things they attend to and do not learn much about the things they do not attend to'. In this study, while the experimental group was explicitly instructed to attend to interesting word combinations in the texts, the comparison group was not. The comparison group learners might only have paid incidental attention to the linguistic packaging of the content they were interested in during the meaning-focused activities. The form-focused attention of the comparison group was, therefore, much less than that of the experimental group, not to mention that this attention was distributed to both single words and word strings. Another significant point is that during pairwork discussions on MWEs of their choice, some experimental learners alerted their peers about some MWEs they would skip otherwise. As illustrated in excerpts of students' opinion exchanges in Chapter 5, when learners shared their lists of MWE candidates, they drew each other's attention to more phrases than they had included individually. In this way, the explicit attention-drawing instructions were supplemented by the pairwork activity carried out among experimental learners. Therefore, the amount of attention the experimental group paid to the MWEs appearing in the reading texts, including the target ones, may have resulted in their better retention of those items.

Second, the experimental group might have engaged more with the phrases they attended to than the comparison group. In light of Craik and Lockhart's (1972) Levels of Processing theory, it is likely that the experimental students achieved a greater 'depth of processing' (p. 675). The deeper level of processing might have left stronger memory traces of the target items in the learners' minds. More specifically, these students took time to discuss not only the reasons why they thought those phrases were established MWEs (i.e. their forms) but also their possible meanings in most cases. Meaning negotiation has been found to promote incidental vocabulary learning (Ellis, Tanaka, \&Yamazaki, 1994; Newton, 1995). Meanwhile, the comparison students simply noted down the lexical items they considered useful, either single words or word strings, at the end of each session. This activity did not allow them enough time for processing those items at a deep level both structurally and semantically. Thus, a greater level of processing among the experimental group may explain their better performances on the post-tests. 
Third, the intervention tasks entailed more involvement load. The better learning gains of the experimental group may echo what has been proposed in the Involvement Load Hypothesis (Laufer \& Hulstijn, 2001), which states that the incidental retention of vocabulary is contingent on the amount of task-induced involvement. This hypothesis operationalizes the processing level through three factors including need, search and evaluation. Each factor is assessed as none (-), moderate $(+)$ or strong $(++)$. It is hypothesized that the higher the involvement index a task has, the more likely that the task promotes the incidental retention of the target items among the learners. It is worth noting that the intervention in this study, though aimed to promote intentional learning of MWEs, was also hoped to boost incidental learning beyond the intervention when students have the freedom to choose their own reading topics and look up the items that interest them.

Let me calculate and compare the involvement indices of the two kinds of tasks carried out in the two groups. The intervention implemented in the experimental group consists of a series of activities explicitly instructed by the teacher (see Table 7.2). According to Laufer \& Hulstijn (2001), this teacher-led motivation means (+) need for the task. Also, as learners attended to different word strings during the MWE extracting activities, they might attend to the target MWEs by chance. In such cases, the motivation to pay attention to those phrases came from both the teacher and the learners, making (++) need for the intervention task. Regarding the involvement of search, it is clearly seen that the activity of looking up new MWEs in dictionaries and COCA among experimental students entails $(++)$ search while those in the comparison group do not involve any search. Also, the activity of selecting the most useful MWEs to learn in the experimental group necessitates thoughtful evaluation, making the evaluation index become $(++)$. The chance of more evaluation on the target MWEs is higher among experimental learners since these learners' attention was focused merely on word combinations, unlike in the comparison group who picked up single words too. Therefore, the involvement index of the treatment task might be 5 or 6 , as shown in Table 7.1.

In the meanwhile, during their content-related activities, the comparison learners might or might not need the target MWEs. They might choose to express their ideas with the lexical items already acquired in their vocabulary knowledge, which makes (-) need. Alternatively, they might recycle the lexis from the texts as they were discussing the same 
topic, which entails (++) need. There was no search occurring among the comparison group. Obviously, these students might have guessed the meanings of novel items from the context if the items were necessary for the understanding of the texts. The activity of selecting the most interesting vocabulary items they wanted to learn possibly involved $(++)$ evaluation. It is worth noting that the attention of the comparison group was not explicitly directed to MWEs, which leads to fewer chances of target items being evaluated. Thus, the possible involvement index of the meaning-focused task in the comparison group is 2 or 4 .

Table 7.1. Task-induced involvement load of both groups

\begin{tabular}{|c|c|c|c|c|c|}
\hline Tasks & Activities & Need & Search & Evaluation & Total \\
\hline $\begin{array}{l}\text { Text- } \\
\text { chunking } \\
\text { (Experimental } \\
\text { group) }\end{array}$ & $\begin{array}{l}\text { - Notice MWEs; } \\
\text { - Discuss in pairs; } \\
\text { - Look MWEs up in } \\
\text { dictionaries and } \\
\text { COCA; } \\
\text { - Note down the } \\
\text { meanings and } \\
\text { frequencies; } \\
\text { - Select about five } \\
\text { most useful/ } \\
\text { interesting MWEs }\end{array}$ & $\begin{array}{l}+/++ \\
\text { (depending } \\
\text { on whether } \\
\text { or not } \\
\text { learners } \\
\text { attend to } \\
\text { the target } \\
\text { MWEs) }\end{array}$ & ++ & ++ & $5 / 6$ \\
\hline $\begin{array}{l}\text { Meaning- } \\
\text { focused post- } \\
\text { reading } \\
\text { (Comparison } \\
\text { group) }\end{array}$ & $\begin{array}{l}\text { - Take part in } \\
\text { pairwork/ } \\
\text { groupwork } \\
\text { meaning-focused } \\
\text { activities } \\
\text { - Select about five } \\
\text { most useful/ } \\
\text { interesting } \\
\text { vocabulary items }\end{array}$ & $\begin{array}{l}-/++ \\
\text { (depending } \\
\text { on whether } \\
\text { or not the } \\
\text { target } \\
\text { MWEs are } \\
\text { essential } \\
\text { for the } \\
\text { meaning- } \\
\text { focused } \\
\text { tasks) }\end{array}$ & - & ++ & $2 / 4$ \\
\hline
\end{tabular}

All in all, the involvement index of text-chunking tasks is higher than that of meaningfocused post-reading ones. This higher involvement load might have led to better form recall knowledge demonstrated by the text-chunking group. The findings are thus in accordance with Laufer \& Hulstijn's (2001) Involvement Load Hypothesis.

Judging from all the benefits of text-chunking practice discussed in this subsection, one would expect that the learning gains obtained by the experimental group would be remarkable. Surprisingly, the results reported in Chapter 4 did not fulfil this expectation. 
The questions that emerge, then, are why the gains were not so remarkable and what can be done to improve the gains. The next subsection will answer these questions.

\subsubsection{Why were the learning gains not so spectacular?}

As already mentioned, the observed learning gains among the experimental group were not spectacular in real terms, especially if the time invested - ten 40-minute sessions - is taken into consideration. The average gain per participant from pre-test to immediate post-test (regarding the 44 MWEs retained for analysis) was 10.62 in the experimental group. By the delayed post-test this number decreased to 6.62. The explanations for the modest learning gains among the experimental learners might lie in the nature of the intervention activities as well as the use of the form-recall post-tests.

\subsubsection{The nature of the intervention activities}

It is undeniable that noticing does not always lead to learning. The intervention in this study, in essence, subsumes awareness-raising activities. Though the learners' selfreports revealed their heightened awareness of formulaic language (see Chapter 6), this awareness did not necessarily translate to their learning gains. As stated by Boers et al. (2006, p. 257), 'noticing may be a prerequisite for learning, but it does not necessarily guarantee the acquisition of every single element that gets noticed'. Also, as mentioned in Chapter 5, not all the MWEs spotted by the learners stimulated discussion on their meanings. In many cases, students just moved on after reaching an agreement that the word string under consideration might be an established MWE. The lack of form-meaning mapping activity may have resulted in the learners' acquisition of only partial knowledge of the target MWEs. The partial knowledge might be only the forms of the items, or the knowledge was only at the receptive level. In either case, the knowledge is not sufficient to be measured in the cued recall post-tests, yielding modest results.

The form-focused nature of the intervention may also help to explain some of the test findings. It is likely that students were too engaged in scanning the texts for instances of MWEs. The not-so-spectacular learning gains resulting from the form-focused activities appear to be consistent with the Type of Processing-Resource Allocation (TOPRA) model (Barcroft, 2002). According to the TOPRA model, processing resources are limited. When more mental resources are devoted to semantic elaboration that helps semantic learning, the resources left for form or structural processing, and thus form learning, will 
be decreased. Conversely, if more processing resources are dedicated to structural processing, this may cause a trade-off in meaning acquisition. The intervention put to the test in this study required learners to focus on the structural processing of MWEs through activities such as underlining or highlighting candidate MWEs, noting them down, and checking their COCA frequency. Meaning guessing only occurred as a by-product of these student-led discussions. The teacher did not explicitly require it. Thus, not every MWE mentioned in students' discussion was dealt with both semantically and structurally. In the meantime, the form-recall post-tests required the students to demonstrate knowledge of form-meaning mappings, contributing to the rather modest evidence of learning gains. What's more, as discovered in Boers et al. (2017), the fact that the students engaged with too many multiword strings per text may have caused cognitive overload. Results from this study also revealed that the least proficient learners (according to VST scores) appeared to benefit the least from the MWE extraction activity. Perhaps the interaction with a large number of MWEs in a text was overwhelming to those less proficient learners, confirming the findings from Boers et al. (2017). While this kind of engagement means students' awareness of formulaic language has seen improvement, their acquisition of certain target items may still be poor.

Another factor that needs considering is the lack of output tasks in this input-based intervention. In her oft-cited Output Hypothesis, Swain (1985, 1995, 2005) emphasized the impact of opportunities to experiment with newly-learned vocabulary on learners' memorization and retention. In this study, despite the 'depth of processing' (Craik \& Lockhart, 1972, p. 675) students had through their discussions to identify the forms and meanings of candidate MWEs, they were not required to produce meaningful language with the items they attended to. In addition, it should be borne in mind that the items that experimental students extracted and noted down were not retrieved at all until the post tests. Hence, the unimpressive learning gains achieved by the text-chunking group also accord with what was suggested in Stengers et al. (2010) that mere 'text chunking' is not sufficient to create lasting memories. Students probably need to 'do' something with the chunks for them to be retained in memory, such as generating sentences with the phrases or make themselves retrieve the phrases from memory. 


\subsubsection{The use of form-recall MWE post-tests}

The chosen format of the cued recall pre-test and post-tests may play a part in explaining the modest learning gains that were measurable. As discussed earlier, there is a chance that learners had only gained partial knowledge of the target MWEs and could not demonstrate the required form-meaning mappings yet. The post-test format required the students to recall the lexical composition of the MWEs, which was a highly challenging job. Literature on single word and collocation acquisition has well documented the wide gap between recognition and recall knowledge (e.g. Brown, Waring, and Donkaewbua, 2008; Nguyen \& Webb, 2017; Siyanova \& Schmitt, 2008; Waring \& Tanaki, 2003). The learning gains might have been more encouraging if the test had been a MWE recognition test. Alternatively, more learning of formulaic language in general might have been seen in students' oral or written work if the knowledge of MWEs other than the target ones had also been measured.

The learners' limited knowledge of formulaic language at the start may also help to explain the modest learning gains. In this study, the students did not score high in the MWE pre-test, with the mean scores in the experimental group being 10.70/52 (approx. $20.6 \%$ ) in the original (52-item) test. The pre-test scores in the comparison group were similarly low. This limited collocation knowledge of the learners in this study was not surprising bearing in mind the previous findings about Vietnamese participants of a similar profile in Nguyen \& Webb (2017) and Tran (2013). In other EFL contexts, the form and meaning knowledge of collocations were also not high, only 33\% (Macis \& Schmitt, 2016) or 56.6\% (González-Fernández \& Schmitt, 2015) of those tested. Given the slow uptake of MWEs in L2 in non-immersion settings (Granger, 1998; Laufer \& Waldman, 2011; Li \& Schmitt, 2010; Nesselhauf, 2003; Siyanova \& Schmitt, 2008; Siyanova-Chanturia \& Spina, 2015), the low gains achieved by the students in this study can be understandable.

Another factor that may have somewhat affected the test results is students' engagement in the MWE tests. The fact that these tests were not connected to these learners' course grades, the relaxing testing settings and the multiple times the learners needed to take the test may play a part. Also, the delayed post-test after five months might not be expected to generate high scores, because attrition is inevitable unless knowledge of the target 
MWEs is reactivated in the interval. Nonetheless, this test was only on learners' knowledge of certain MWEs, of which the frequency of encounters was merely contingent on their classroom and extensive target language input. Understandably, the learning gains on those MWEs faded over time.

\subsubsection{Why did the comparison group achieve learning gains too?}

The comparison group also made gains (on average 6.36 and 3.79 out of 44 target items on the immediate and delayed post-test, respectively), even though there was no explicit incentive for these learners to focus on multiword lexis. Also, the comparison students might have learnt more single word through their meaning-focused discussions. Learning tasks taking place in both groups mean that learning might have occurred among learners from both groups. Let us find the explanations for the learning gains achieved by the comparison group students in some well-acknowledged hypotheses mentioned below.

Most importantly, meaning-focused activities might have provided the comparison group the motivation to pay attention to vocabulary and learn those vocabulary items necessary for the meaning incidentally. As suggested in Swain's Output Hypothesis (1985, 1995, 2005), output text-based tasks can help learners realize what they lack in their lexical resources and, from there, notice essential items in the language input to form the lexical packaging for their ideas. In the same vein, as VanPatten (2003, p. 63) puts it, meaningfocused output, or output with access, involves 'activating the lexical items and grammatical forms necessary to express particular meanings.' Learners' strategies of recycling words and intact phrases from the input texts were also found among the participants of Boers et al. (2006). This noticing could also have helped to account for the incidental MWE learning gains attested for the comparison group, because incorporating new MWEs in an output task following a reading activity increases the likelihood of their retention in memory (Zhang, 2017).

Next, it needs to be borne in mind that at the end of each lesson, the comparison group were also invited to select interesting vocabulary from the texts. Analysis showed that they noted down a fair number of multiword items as well, as reported in Chapter 4, Section 4.4.3. This activity, though brief, could make them pay more attention to the lexical component of the texts including various word strings. When these word strings 
happened to be target MWEs, it enhanced the likelihood of successful recall in the posttest.

It can also be speculated that the comparison group were already aware of the importance of MWEs to a certain extent. Their interest in MWEs was possibly instilled during their previous and current instructed EFL learning. Both groups were taking several other courses in English and were exposed to other sources of language input and language instruction. Also, the pre-test may also have raised the students' awareness of multiword lexis and may have had a priming effect such that particular MWEs that would otherwise have gone unnoticed in the texts now attracted interest.

Another possibility is that since the two groups of participants knew each other, they might have had some informal exchanges about what was going on in the other group. In this way, the comparison students might have gathered some ideas about text-chunking and the use of COCA. Because students in the comparison group spontaneously attended to multiword lexis in the texts, the difference between the experimental and the comparison conditions was probably not so substantial. The difference in the test performance between the two groups might have been more remarkable had the participants had less initial awareness of the relevance of multiword lexis.

Thus far, I have placed the findings of this study in the big picture of what has been documented in terms of L2 learners' discovery strategies for MWEs, their lookup behaviours and their learning gains of target items thanks to the intervention. In the next section, I will address the central question of this entire project. So, after all, what are the pros and cons of activities to promote learners' awareness and discovery learning of formulaic language with the aid of online resources?

\subsection{To what extent did the intervention work after all?}

The ultimate objective of exploring any pedagogical approaches in a language classroom is to evaluate their effectiveness in promoting gains in the balance with the investment of teachers and learners' time and efforts. Let me now weigh the merits and demerits of the intervention to give a judicious answer to the question raised above in the title of this section.

The intervention has had some encouraging impact on the experimental learners' acquisition of formulaic language, as shown in the results chapters. The most prominent 
impact is the superior learning gains of the target items among experimental learners. Next, the learners' awareness of formulaic language and strategies to expand their phrasicons has been well raised thanks to the intervention. The experimental learners showed better sensitivity to and more interest in various slots or frames in texts, more attention to the use of dictionaries to verify their meaning guesses and, most importantly, more endurable awareness over time. The evidence of raised awareness in these aspects was not seen among comparison students. Only when learners are more aware of their own learning objectives and how to achieve them, can they realize clearly how much progress they have made. In this study, it was the experimental students who were much more confident in evaluating their progress after five months (see Chapter 6). Thus, the results have indicated that the MWE extraction task, at least as implemented in this classroom experiment (i.e. with the assistance of online resources and initial guidance by the teacher), is not beyond the ability of these (high)-intermediate EFL learners. The task instructions effectively prompted discussions about the phraseological dimension of the texts, stimulated look-ups about candidate MWEs, and raised interest in the collocational behaviour of novel words. Readers are reminded that the participants in this intervention study were language majors, likely with an above-average interest in and aptitude for language learning, and with above-average experience with dictionary use. Whether other groups of EFL learners would respond to the MWE identification tasks in similar ways remains an open question.

Nevertheless, there are also some undeniable shortcomings of the intervention when it comes to deciding whether or not it is worth the investment of classroom time. First, as pointed out earlier in this chapter, the learning gains in the experimental group were not so spectacular, bearing in mind that the entire intervention took place throughout the whole semester of 15 weeks. This length of time was initially hoped to make conditions for the visible learning gains to emerge. Yet, the modest learning gains from this language-focused intervention has indicated one of the trade-offs occurring in other formfocused intervention studies (Boers, 2015). Given that learning gains in the knowledge of the target items were also demonstrated in the comparison group, and that they may have made progress in other aspects that were not measured in this study (e.g. their knowledge of individual words, their ability of using the learned vocabulary knowledge for communicative purposes), the pedagogical value of the intervention as is needs to be 
reconsidered. Second, the use of COCA promoted in this intervention as the first step in introducing the learners to data-driven learning of formulaic language was not very wellimplemented by the experimental group, especially after five months. This lack of enthusiasm may have resulted from different causes as mentioned in Chapter 6 and Section 7.2.2.2 of this chapter. However, it is conceivable that online dictionaries, or contemporary dictionaries in general, have provided updated, reliable, and user-friendly enough resources for learners to resort to. Third, regarding raising learners' awareness of formulaic language, although the experimental group showed more of the expected awareness, the comparison group demonstrated raised awareness too without receiving any treatment. It is likely that to raise the awareness of the learners, more time-effective methods through training workshops, vocabulary tests, or even meaning-focused activities will suffice.

Collectively, the demerits of the intervention as is may outweigh its merits when both time investment and the project outcome are taken into consideration. To put it another way, the intervention needs to be refined to guarantee more reassuring results.

\subsection{Chapter conclusion}

This chapter has provided a critical discussion of the main findings generated by this classroom-based study. Emerging positive and negative results in terms of learners' learning gains and strategies have been explained and connected to the existing literature. Most importantly, the pedagogical value of the entire project has been evaluated. In the next chapter, I will go into further detail of what can be done differently to have a better outcome out of this intervention. 


\section{CHAPTER 8 - CONCLUSION}

\subsection{Introduction}

It is worth now revisiting what was stated by Meunier (2012, p.123), as mentioned right at the beginning of this thesis, 'though L2 teaching no longer ignores the formulaic nature of language, the exact paths to follow to better teach it are still insufficiently lit'. This chapter aims at summarizing all the work done in this project in addressing Meunier's and other pedagogues' call for effective approaches to the teaching and learning of Multiword Expressions (MWEs) (e.g. Boers \& Lindstromberg, 2012; Coxhead, 2018; Pellicer-Sánchez \& Boers, 2018). Also, in this chapter I reflect on the implementation of the whole project regarding its contributions, the pedagogical implications, the limitations and avenues for future research.

\subsection{Summary of findings}

In an attempt to shed more light on the teaching pathway of MWEs to L2 learners, this project was designed as a complex study yielding multiple sets of data. The data provided perspectives from different angles on the learners' learning process and how teachers can support their students in this process. More specifically, the study entailed a step-by-step framework in which the learners became independent in their MWE acquisition. Different elements in this framework included, but were not restricted to, explicit instructions for noticing MWEs, awareness-raising student-led activities, exposure to intact exemplars in authentic texts, lookup training and the longitudinal nature of the study. Three main research questions were put forward at the start of the study to address the gaps pointed out in the literature. The questions were on the effectiveness of the activity of MWEextracting and dictionary and COCA lookups on the recall of target items, the strategies the learners used when they were extracting MWEs and the changes in the learners' awareness of MWEs and their learning strategies. Sections that follow will provide a review of the answers to these research questions found in this study.

\subsubsection{Positive effects on acquisition of target MWEs}

The present study revealed evidence of the beneficial effects of the intervention on the learners' recall of target MWEs. First, the results from the cued recall tests on the target 
items, both immediate and delayed, revealed superior recall knowledge achieved by the experimental group compared with their comparison counterparts. That said, the learning gains were not so spectacular bearing in mind the amount of time invested in the intervention. Also, the comparison group showed some gains in the recall of the target items too. Attrition was seen in the MWE knowledge for both groups in the results of the delayed test (administered after five months). This is completely understandable, bearing in mind the time lapse and the lack of production and consolidation tasks between the intervention and the delayed test.

Second, the logistic regression model showed the statistically significant probability that chunked MWEs would be recalled in the post-tests. This finding shows more concrete evidence and lends more support to the potential of text-chunking (Lewis, 1993, 1997) for MWEs learning. This finding is also one of the original contributions of this study to the literature on the effectiveness of text-chunking activities (Lewis, 1993, 1997) on L2 learners' acquisition of MWEs. Previous studies (Jones \& Haywood, 2004; Boers et al, 2006; Stengers et al, 2010) acknowledged the effects of text-chunking as an awarenessraising technique that promoted learners' use of MWEs in their oral or written output. However, these studies did not pinpoint the direct connection between the chunked vs. unchunked status of specific MWEs occurring in the reading materials and the recall of these items.

Obviously, whether the target MWEs were successfully extracted from texts was not the only predictor of the learning gains of these MWEs. Other factors that might play a part include learners' vocabulary sizes or the semantic features and frequency of the target items. While the learners' vocabulary sizes were found to be influential to the learning progress during the intervention, the effects of other item-wise features are open to more investigation. Of note, the comparison group also gained knowledge of the target MWEs incidentally through their meaning-focused activities, though not as much as the experimental group. The progress made by the comparison group who did not receive the form-focused treatment confirmed the significance of output tasks on the learning of MWEs as well as the learning of vocabulary in general. 


\subsubsection{Learners demonstrated their use of text-chunking strategies}

This study found that intermediate-level language learners could identify MWEs in texts and verify them on their own with the aid of dictionaries and corpora after training. As mentioned at the beginning of this thesis, the study was purposefully designed to set up a learning condition that fosters learners' autonomous MWE extraction from texts. It was hoped that their text-chunking habit could be expanded to their reading outside language classrooms. The step-by-step guidance started from the awareness-raising workshop to the typographical enhancement of some target items and the dictionary and COCA lookup training. It was an encouraging finding that the learners, with raised awareness and adequate guidance, could identify real MWEs.

The findings about the strategies the learners used when they were doing the textchunking activity are another original finding in this study. There has been little research on learners' online MWE-extracting process prior to this thesis. The experimental students were found to make use of their metalinguistic knowledge in text-chunking and were quite strategic in identifying the forms and guessing the meanings of newly-found MWEs. These strategies included those the learners used to identify the forms of MWEs in texts and those they used to decipher the meaning of those MWEs. Let's look at them in turn.

First, regarding how the learners paid attention to the forms of novel MWEs, it was uncovered that the experimental learners not only attended to previously seen intact MWEs (e.g. when it comes to, at first glance). They appeared to be also interested in new combinations of familiar words (e.g. a sea of, chicken-and-egg question) or unfamiliar words combined in familiar structures such as verb + preposition, preposition + noun, or binomials (i.e. noun 'and' noun) (e.g. sift through, in the face of, research and development). Of note, the participants were at an intermediate level of English. It is likely that their good command of English vocabulary and grammar brought about more strategic attention and decisions among the learners. This finding means that at a high level of the target language, L2 learners might be able to recognize conventional word combinations in texts intuitively without having seen those particular MWEs before.

Second, learners habitually guessed the meanings of MWEs that they had identified in texts. Meaning-guessing strategies used by the learners for MWEs were quite similar to 
what they used for single words, including using textual contexts and component words (in the case of single words, word parts). The difference was that these Vietnamese learners extensively guessed the meanings of MWEs from the constituent words, rather than basing their inferences on the contexts. This excessive dependence might trap them in the 'deceptive transparency' of MWEs (Laufer, 1997), which might make them end up with the wrongly guessed meanings without any intention of looking up the MWEs in dictionaries for meaning verification.

\subsubsection{Heightened awareness of MWEs and learning strategies}

Raising learners' awareness of MWEs and the importance of scanning the texts for MWEs and looking them up in dictionaries and COCA was one of the main objectives of this intervention study. The results from the immediate and delayed questionnaires and from learners' end-of-class phrase lists indicated that the experimental learners' awareness was heightened. This heightened awareness endured over the five-month gap between the immediate and the delayed questionnaire after five months. Awareness was crucial to the learners' independent acquisition of MWEs later on.

Also, the intervention seemed to encourage the experimental learners to continue focusing on the MWE learning strategies that they practised during the treatment, compared with a wider range of strategies reported by the comparison students. Those practised strategies included underlining new MWEs, taking notes, looking them up in dictionaries and COCA, and discussing MWEs with peers. Moreover, at the end of the intervention, dictionary use, and peer interaction were more appreciated among experimental students than in the comparison group. Though showing more awareness of MWEs and appreciating the use of corpora as resources for MWE verification, the learners were still hesitant about further use of COCA. There were a range of reasons, including the not-souser-friendly interfaces, the complex query syntaxes, and the challenges to extract the necessary information from corpus output. Given that the use of COCA in this study was simplified to the extraction of just the frequency of identified MWEs, the persistence of these limitations provides pedagogical implications that are mentioned below.

\subsection{Pedagogical implications}

This classroom-based intervention study holds a great deal of promise in pedagogical implications. Carrying out an experiment in real classrooms has returned valuable 
implications on the teaching and learning of MWEs, especially in a non-immersion context with limited exposure like Vietnam. Three important implications can be drawn from the findings of this study as follows.

\subsubsection{How can teachers set up a conducive learning condition for independent MWE} learning?

Given the benefits of boosting both the learning gains and the awareness among the learners found in this study, it is recommended that language teachers make necessary changes to the current intervention to optimize their guidance and to better support their students. First, the step-by-step and explicit instructions that were put in place in this study should be followed by teachers, starting from the awareness-raising workshop, then the scaffolding by typographical enhancement, then moving on to the lookup training before having learners work in pairs in autonomous chunking and lookup. In this way, teachers can raise learners' awareness, which is pivotal to their learning, and help them take up the habit of attending to MWEs whenever they are exposed to the target language. To put it another way, learners' attention to MWEs would be directed and reinforced to their reading in classroom environment as well as beyond.

Second, judging from the modest learning gains in the experimental group, it might not be time-efficient to devote classroom time of the whole semester to training learners in MWE extraction and lookups. A more optimal approach may be that teachers reduce this in-class training time and create outside class activities for learners to do. For example, teachers may have learners extract MWEs from classroom reading materials and instruct them to look those items up in dictionaries and COCA, just as was done in this study, but only for several weeks. When the learners have a clear understanding of these steps, teachers can ask them to choose some reading materials, either as a part of home assignments or out of their own interests. The learners would then repeat the steps done in class and use the vocabulary template from the intervention (see Appendix 6) to fill in the information they can find about appealing MWEs. They might initially record simple information such as the MWEs, their meanings from dictionaries and their frequency from COCA. Subsequently, more ambitious implementations could include steps to find out more about the usage patterns of given MWEs, such as the kind of genre where they are most commonly used. Alternatively, students might be instructed to make sentences 
using the MWEs they are interested in, as has been done in some previous studies (e.g. Geluso \& Yamaguchi, 2014). That way, classroom time can be saved for other activities that need more of teacher guidance. Simultaneously, awareness of MWEs can be heightened while learning is reinforced. Other extracurricular activities can be created and assigned to the learners centring around the MWEs learners can detect on their own and find interesting too. For example, students can work in groups to make lists of useful MWEs found in texts they have read and share with others with explanations about the meaning and usage of those MWEs. Subsequently, teachers may create vocabulary exercises to help the learners consolidate and retrieve those MWEs.

\subsubsection{How can teachers choose the input materials to promote MWE-extraction?}

One aim of the text-chunking training in the present study was to help learners become more sensitive to the occurrences of MWEs in textual input. Given that, it is crucial that teachers make well-informed selections of reading materials for the learners in the initial stage of text-chunking practice. Resourceful reading materials can help teachers direct their learners' attention to target MWEs and sharpen their text-chunking strategies. Based on what has been done in this project, the following set of criteria would help navigate teachers' choice of reading texts for their students.

The first criterion to be borne in mind is the vocabulary load of the texts. The vocabulary profile of reading texts could be kept at the level that the learners could understand 95\%$98 \%$ of the running words of the texts depending on the learners' vocabulary size, as was done in Nguyen \& Boers (2018). It will depend on specific groups of students that teachers choose texts with a corresponding vocabulary load. In this study, the choice of texts was based on the teacher researcher's experience of students of the same profile. The purpose of choosing texts with a suitable vocabulary load is two-fold. First, the texts might not pose challenges to the learners' comprehension of the text content, leaving them more attention resources to give to the linguistic packaging of the messages, as pointed out in the Type of Processing-Resource Allocation (TOPRA) model (Barcroft, 2002). Second, it was found in this study that new words might hinder students' intuition since they tend to pay more attention to new single words if the reading contains many unknown words. A corollary of learners' dependence on constituent words in MWEs to recognize both their forms and meanings is that when students cannot guess the meaning of some 
individual words, they probably will not consider the possibility of MWEs containing those words. Also, practising MWE-extracting activity with texts of familiar words might help learners acquire MWEs made of those words, which may mitigate the issue revealed in Nguyen \& Webb (2017) about learners' limited collocation knowledge of words within their vocabulary sizes.

The second criterion is the frequency of MWE occurrences in authentic texts. Highfrequency phrases occur naturally in authentic texts. Therefore, by exploring such texts, students in this study were capable of acquiring the most frequently-used chunks which were useful for their speaking and writing. Teachers may just choose reading materials with more instances of MWEs for students to explore, and save time on simplifying materials, which might be effortful for non-native English teachers. To EFL practitioners, the less manipulation required, the better.

The third criterion is the relevance of reading topics to the target learners. Data in this study showed that reading topics that the learners thought they might encounter in the future could spark more of their interest in mining the texts for useful MWEs. For example, the students in this study were more excited to identify MWEs in the reading texts about sports or medical care since they thought they might encounter these topics in the IELTS-like tests. The texts used in this study were for general English classes. Teachers of English for Special Purposes or English for Academic Purposes may find reading materials in specific fields and ask students to create their own useful phrase lists from those materials.

In short, useful input which suits learners' proficiency, contains multiple instances of MWEs and is interesting in terms of the content can make text-chunking training more effective by giving learners the chance to detect more candidate MWEs within a text. That they can see frequent instances of MWEs helps to make them realize how pervasive MWEs are in language too.

\subsubsection{How can the utility of COCA be optimized?}

The hesitant attitude about the usage of COCA by the learners in this study, as mentioned in Section 8.2.3, cast doubt on the suitability of COCA in language classrooms. Despite the time invested in COCA lookup demonstration and training and the provision of COCA manual, the students still found it challenging to use COCA on a regular basis. That said, 
I believe that the affordances of COCA make it still worth the efforts of teachers and learners in EFL contexts. It might be that the effective use of COCA requires more training time with more diversified activities which are gradually introduced to the learners. Examples are working with concordances or finding the most common collocates of some node words. More interaction with COCA might help learners become more aware of the benefits of COCA as a reliable database and how they can make sense of COCA output.

The use of COCA may have more meaning to non-native EFL teachers who might not have strong intuitions for the phraseological behaviors of words. To better support their learners, non-native teachers first need to be successful high-level learners themselves who can take advantage of dictionaries and COCA in their MWE acquisition to upgrade their repertoire of formulaic language. Teacher talk is an important source of language input in classrooms, apart from textbooks (Meunier, 2012). The ubiquity of MWEs L2 students are exposed to might increase if teachers have a better command of MWEs and make efforts to include more in the classroom talk. Also, it is recommended that teachers upgrade their COCA literacy and consult dictionaries and COCA more frequently, possibly for the verification of MWEs in texts in their selection of input texts for their learners or to enhance typographically worth-learning MWEs in texts (Pellicer-Sánchez $\&$ Boers, 2018). In the same vein, corpus consultation training might be beneficial as part of teacher training at EFL contexts. In short, the ultimate utility of COCA, or corpora in general, requires more training both for the teachers and students. Also, as aforementioned, COCA training should not only be conducted in classrooms but also through tasks assigned to learners in their self-study.

\subsection{Limitations}

Despite being carefully designed, this study inevitably has its own drawbacks, some of which have been mentioned in Section 7.3.2 as a way to explain the modest learning gains among the experimental group. There are also other limitations. First, the generalizability of the results is confined to the language teaching and learning contexts similar to the setting of this study. More specifically, the participants were EFL intermediate learners majoring in TESOL. Their good command of grammar, vocabulary and metalinguistic knowledge might have enabled the experimental group to be more sensitive in 
recognizing MWEs in texts. Also, both groups had some prior awareness of MWEs. It is also worth noting that the complex design of the study with multiple data sets made it quite demanding to pull things together for analysis of results and to determine precisely what factors included in the instructional intervention contributed most to MWE learning.

Second, the recall post-test might not have fully measured the possible learning gains of the target items achieved by the participants. They encountered the phrases receptively through reading texts (or watching, then reading, texts) but were required to produce the forms of the phrases matching the meanings given. To put it another way, the expected transfer was from receptive knowledge of the target MWEs, both in forms and in meanings, to productive knowledge, without any output practice. Thus, it might be too ambitious to expect significant differences between the pre-test and post-test and between treatment groups. Also, through their interaction with the textual input, the learners of both groups might have gained some partial knowledge of the target chunks. According to Bardovi-Harlig (2018), "learners report knowing expressions that they do not produce in appropriate contexts" (p. 105-106). This partial knowledge might emerge better in a less challenging version of post-test such as a form recognition test rather than a form recall one like in this study. There are trade-offs in form-focused activities (Boers, 2015). In the current research project, the chunking activity might have directed most of the learners' attention to the forms of MWE candidates in texts. The learners were too engaged in finding the MWEs and paid less attention to working out the meaning for later recall. That students did not discuss the meanings of the MWEs they found in more than half of the cases (see Section 5.4) might provide some explanations for their modest gains in the test on the form-meaning mappings.

Third, the questionnaires to probe into the learners' awareness of MWEs and their learning strategies might have included sharper questions to better find out the differences between the two groups. The questionnaire items might have been formulated in a more neutral way in which both single words and MWEs were mentioned. Moreover, a usual weakness of self-reports is that they may make students think more about the responses they should give rather those describing what they actually did. Follow-up interviews with some of the students might have shed more light on their awareness and MWE learning tactics. It is worth noting that the inconsistent use of Likert-scale items, i.e. 4- 
point scale in the first section of the questionnaire and 5-point scale in the second section, should be changed for a better quality questionnaire.

Other limitations of the present study are due to the fact that the study was implemented in a real classroom context. For example, the pre- and post-tests were conducted in an informal testing environment rather than in tightly controlled lab experiments. The plus side of this setting was that the learners could be relaxed and produce whatever they had in mind. The minus side is that in the absence of test pressure, the learners might not be engaged enough in the test. The same issue applies to the questionnaire responses in which some students skipped answering questions, especially in the delayed survey.

Notwithstanding these limitations, the study has its own value in focusing on a specific context of Vietnam where the learners' awareness of the importance of MWE acquisition and of the affordances of corpora in classrooms appear to be limited. This research may also raise some questions in need of further investigation, which will be mentioned in the next section.

\subsection{Avenues for future research}

The most welcome research attempts inspired from this study might be conceptual replications to provide more perspectives on learners' text-chunking strategies and on the optimal ways to bring corpora into classrooms. Other studies either with a different learner profile or the same will be of great significance. Replication studies can look into different language contexts (e.g. a context with more L1-L2 congruency) or different learners' levels. It is possible that students at lower or higher levels apply different strategies. It might be useful to replicate the experiment with students who at the start of the experiment have a lower level of awareness of the ubiquity and significance of MWEs.

Next, in this study, the audio-recordings of the experimental students when they were extracting MWEs from texts revealed fascinating findings about their attention, awareness and vocabulary knowledge. It would be interesting to collect and analyse audio-recordings of learners when they carry out meaning-focused activities. In a balanced programme, the deliberate study of MWEs (and vocabulary more generally) would of course need to be complemented by ample opportunities for content-oriented, communicative activities (Nation, 2013). It would therefore be interesting for follow-up 
studies to examine to what extent (and how well) learners actually try to incorporate the MWEs they have identified in texts into their own productive resources.

Another direction of research might be in the form of some case studies that follow learners more closely and for a longer time. Dörnyei, Durow and Zahran (2004) stated that, 'success in the acquisition of formulaic sequences appears to be the function of the interplay of three main factors: language aptitude, motivation and sociocultural adaptation' (p. 105). These factors underline the potential for individual differences to have an impact on knowledge of formulaic sequences. Doing case studies with some individuals, i.e. observing them during the intervention, qualitatively analysing their work, or interviewing them after the treatment, might reveal more insights into learners' MWE learning process.

It may be worth examining the recall test data more closely at the item level, because this may help determine what sort of learning condition benefits the learning of what sort of MWEs and what aspects of knowledge about certain MWEs are privileged by a certain learning condition. The analysis might also indicate what types of strategies are used for what categories of MWEs. Undeniably, 'given the complexity and the multifaceted nature of the phenomenon at hand, a one-size-fits-all approach to the learning and teaching of FL is very unlikely to be tenable’ (Pellicer-Sánchez \& Boers, 2018, p. 168).

Finally, whether the intervention tried in this study will also have a long-term effect on the learners' engagement with the phraseological dimension of texts on future occasions is yet another question left to be addressed through further enquiry.

\subsection{Concluding remarks}

In summary, this classroom-based study has chipped away at a stumbling block in the search for beneficial approaches to MWE teaching and learning. It has uncovered encouraging results about the effects of the activity of text-chunking and looking up lexical items in dictionaries and COCA. The study will possibly be of great importance to the language setting in Vietnam and similar contexts.

Up to this point, I have evolved from a teaching practitioner who used to make pedagogical decisions based solely on classroom experience to a novice researcher who has understood the value of putting hypotheses to the test. The entire project has made a 
significant impact on me both as a teacher and as a researcher. As a teacher, I have learnt about methods to support my future students in acquisition of MWEs as mentioned in the pedagogical implications above. These methods range from measuring students' vocabulary sizes, choosing appropriate input, training them in using online dictionaries and COCA, to improving their intuitions about MWEs through regular text-chunking. The 'old' teacher in me, who worked from her beliefs and observations, would hope for marked differences that the intervention in this project could bring about among the experimental students in their learning gains and awareness of MWEs compared to their comparison counterparts. The study results have made me realize that learners' progress depends on various factors apart from the teaching techniques such as learners' differences, the structural and semantic features of target items, and even the topics of the textual input. As a novice researcher, now that I have completed my first longitudinal intervention study, I have gone through different research stages and grasped corresponding research skills. More importantly, with the ups and downs during the study, I have learnt how to deal with unexpected circumstances that may occur any time. By and large, I have become a teacher researcher who will try to keep myself more cautious and well-grounded in my teaching decisions. The study will act as a motivational start for me to continue doing research in my classrooms in pursuit of beneficial approaches to the teaching and learning of MWEs. 


\section{REFERENCES}

Aston, G. (2015). Learning phraseology from speech corpora. Studies in Corpus Linguistics, 69, 63-84.

Altenberg, B., \& Granger, S. (2001). The grammatical and lexical patterning of make in native and non-native student writing. Applied Linguistics, 22, 173-195.

Bahns, J., \& Eldaw, M. (1993). Should we teach EFL students collocations? System, 21(1), 101-114.

Barcroft, J. (2002). Semantic and structural elaboration in L2 lexical acquisition. Language Learning, 52, 323-363. doi: 10.1111/0023-8333.00186

Bardovi-Harlig, K. (2018). Formulaic language in second language pragmatics research. In A. Siyanova-Chanturia \& A. Pellicer-Sánchez, A. (Eds.), Understanding formulaic language: A second language acquisition perspective (pp. 97-114). New York: Routledge.

Bartning, I., Forsberg, F., \& Hancock, V. (2009). Resources and obstacles in very advanced L2 French: Formulaic language, information structure, and morphosyntax. EUROSLA Yearbook, 9(1), 185-211.

Bensoussan, M., \& Laufer, B. (1984). Lexical guessing in context in EFL reading comprehension. Journal of Research in Reading, 7(1), 15-32. https://doi.org/10.1111/j.1467-9817.1984.tb00252.x

Bernardini, S. (2004) Corpora in the classroom: An overview and some reflections on future developments. In: Sinclair, J. (Ed.), How to use corpora in language teaching (pp. 15-36). Amsterdam: John Benjamins.

Biber, D., \& Conrad, S. (1999). Lexical bundles in conversation and academic prose. Language and Computers, 26, 181-190.

Biber, D., Conrad, S., \& Cortes, V. (2004). If you look at...: Lexical bundles in university teaching and textbooks. Applied linguistics, 25(3), 371-405.

Biber, D., S. Johansson, G. Leech, S. Conrad \& E. Finegan (1999). Longman grammar of spoken and written English. Harlow, Essex: Pearson Education. 
Bishop, H. (2004). The effect of typographic salience on the look up and comprehension of unknown formulaic sequences. In N. Schmitt (Ed), Formulaic sequences (pp. 227-47). Amsterdam: John Benjamins.

Boers, F. (2015). Weighing the merits of form-focused intervention. Language Teaching Research, 19(3), 251-253.

Boers, F., Dang, T. C. T, \& Strong, B. (2017). Comparing the effectiveness of phrasefocused exercises: A partial replication of Boers, Demecheleer, Coxhead and Webb (2014). Language Teaching Research, 21(3), 362-380.

Boers, F., Demecheleer, M., Coxhead, A., \& Webb, S. (2014). Gauging the effects of exercises on verb-noun collocations. Language Teaching Research, 18(1), 54-74.

Boers, F., Demecheleer, M., \& Eyckmans, J. (2004). Etymological elaboration as a strategy for learning figurative idioms. In P. Bogaards \& B. Laufer (Eds.), Vocabulary in a second language: Selection, acquisition and testing (pp. 53-78). Amsterdam: John Benjamins.

Boers, F., Demecheleer, M., He, L., Deconinck, J., Stengers, H., \& Eyckmans, J. (2017). Typographic enhancement of multiword units in second language text. International Journal of Applied Linguistics, 27(2), 448-469.

Boers, F., Eyckmans, J., Kappel, J., Stengers, H., \& Demecheleer, M. (2006). Formulaic sequences and perceived oral proficiency: putting a Lexical Approach to the test. Language Teaching Research, 10(3), 245-261.

Boers, F., Eyckmans, J., \& Stengers, H. (2007). Presenting figurative idioms with a touch of etymology: More than mere mnemonics? Language Teaching Research, 11(1), $43-62$.

Boers, F. \& Lindstromberg, S. (2009). Optimizing a lexical approach to instructed second language acquisition. Basingstoke, UK: Palgrave Macmillan.

Boers, F., \& Lindstromberg, S. (2012). Experimental and intervention studies on formulaic sequences in a second language. Annual Review of Applied Linguistics, $32,83-110$. 
Boers, F., Lindstromberg, S., \& Eyckmans, J. (2014a). Is alliteration mnemonic without awareness-raising? Language Awareness, 23(4), 291-303.

Boers, F., Lindstromberg, S., \& Eyckmans, J. (2014b). Some explanations for the slow acquisition of L2 collocations. VIAL - Vigo International Journal of Applied Linguistics, 11, 41-62.

Brown, R., Waring, R., \& Donkaewbua, S. (2008). Incidental vocabulary acquisition from reading, reading-while-listening, and listening to stories. Reading in a foreign language, 20(2), 136-163.

Buckingham, L. (2006). A multilingual didactic approach to idioms using a conceptual framework. Language Design, 8, 35-45.

Byrd, P., \& Coxhead, A. (2010). On the other hand: Lexical bundles in academic writing and in the teaching of EAP. University of Sydney Papers in TESOL, 5(5), 31-64.

Chambers, A. (2005) Integrating corpus consultation in language studies. Language Learning \& Technology, 9(2): 111-125.

Chambers, A. \& O’Sullivan, Í. (2004) Corpus consultation and advanced learners' writing skills in French. ReCALL, 16(1): 158-172.

Chan, T.-P., \& Liou, H.-C. (2005). Effects of web-based concordancing instruction on EFL students' learning of verb-noun collocations. Computer Assisted Language Learning, 18(3), 231-251.

Chen, H-J. H. (2011). Developing and evaluating a web-based collocation retrieval tool for EFL students and teachers. Computer Assisted Language Learning, 24(1), 5976.

Choi, S. (2017). Processing and learning of enhanced English collocations: An eyemovement study. Language Teaching Research, 21(3), 403-426. https://doi.org/10.1177/1362168816653271

Clarke, D. F. \& I. S. P. Nation. (1980). Guessing the meanings of words from context: Strategy and techniques. System 8(3), 211-220.

Cobb, T. (2018). From corpus to CALL: The use of technology in teaching and learning formulaic language. In A. Siyanova-Chanturia \& A. Pellicer-Sánchez, A. (Eds.), 
Understanding formulaic language: A second language acquisition perspective (pp. 192-210). New York: Routledge.

Cobb, T. (n.d.). Compleat Lexical Tutor (LexTutor). Retrieved from www. lextutor. ca (last accessed October 2015).

Conklin, K., \& Schmitt, N. (2012). The processing of formulaic language. Annual Review of Applied Linguistics, 32, 45-61. doi:10.1017/S0267190512000074

Cooper, T.C. (1999). Processing of idioms by L2 learners of English. TESOL Quarterly, 33(2), 233-262. https://doi.org/10.2307/3587719

Cowie, A.P. 1992. Multiword lexical units and communicative language teaching. In P. Arnaud \& H. Bejoint (Eds.), Vocabulary and Applied Linguistics (pp. 1-12). Basingstoke: Macmillan.

Coxhead, A. (2007). Factors and aspects of knowledge affecting L2 word use in writing. In P. Davidson, C. Coombe, D. Lloyd \& D. Palfreyman (Eds.), Teaching and learning vocabulary in another language (pp. 331-342). Dubai: TESOL Arabia.

Coxhead, A. (2011). Using vocabulary in writing in a second language: Writing from sources. Köln: LAP Lambert Academic Publishing.

Coxhead, A. (2018). Replication research in pedagogical approaches to formulaic sequences: Jones \& Haywood (2004) and Alali \& Schmitt (2012). Language Teaching, 51(1), 113-123. Fist published online 5 June 2015.

Craik, F.I.M., \& Lockhart, R.S. (1972). Levels of processing: A framework for memory research. Journal of Verbal Learning and Verbal Behavior, 11(6), 671-684. http://dx.doi.org/10.1016/S0022-5371(72)80001-X

Creswell, J. W., Plano Clark, V. L., Gutmann, M. L. \& Hanson, W. E. (2003). Advanced mixed methods research designs. In A. Tashakkori and C. Teddlie (Eds.), Handbook on mixed methods in the behavioral and social sciences (pp. 209-240). Thousand Oaks, CA: Sage Publications.

Crossley, S. A., Salsbury, T., \& McNamara, D. S. (2015). Assessing lexical proficiency using analytic ratings: A case for collocation accuracy. Applied Linguistics, 36(5), $570-590$. 
Dai, Z., \& Ding, Y. (2010). Effectiveness of text memorization in EFL learning of Chinese students. In D. Wood (Ed.), Perspectives on formulaic language: Acquisition and communication (pp. 71-87). New York, NY: Continuum.

Daskalovska, N. (2015). Corpus-based versus traditional learning of collocations. Computer Assisted Language Learning, 28(2), 130-144.

Davies, M. (n.d). The Corpus of Contemporary American English: 450 million words, 1900-present. http://corpus.byu.edu/coca/

Dörnyei, Z., Durow, V., \& Zahran, K. (2004). Individual differences and their effects on formulaic sequence acquisition. Formulaic sequences, 87-106.

Durrant, P. \& Schmitt, N. (2009). To what extent do native and nonnative writers make use of collocations? International Review of Applied Linguistics, 47, 157-177.

Durrant, P., \& Schmitt, N. (2010). Adult learners' retention of collocations from exposure. Second Language Research, 26(2), 163-188.

Dziemianko, A. (2014). On the presentation and placement of collocations in monolingual English learners' dictionaries: Insights into encoding and retention. International Journal of Lexicography, 27(3), 259-279.

Ellis, R. (1999). Learning a second language through interaction. Amsterdam: John Benjamins.

Ellis, R. (2015). Understanding second language acquisition. Oxford: Oxford University Press.

Ellis, R., Tanaka, Y., \& Yamazaki, A. (1994). Classroom interaction, comprehension, and the acquisition of L2 word meanings. Language Learning, 44(3), 449-491.

Erman, B. \& Warren, B. (2000). The idiom principle and the open choice principle. Text, 20(1), 29-62.

Eyckmans, J, Boers, F, \& Lindstromberg, S. (2016). The impact of imposing processing strategies on L2 learners' deliberate study of lexical phrases. System, 56, 127-139.

Fan, M. (2003). Frequency of use, perceived usefulness, and actual usefulness of second language vocabulary strategies: A study of Hong Kong learners. Modern Language Journal, 87(2), 222-240. 
Fan, Y. (2005). Differential effects of attention in second language acquisition of verbnoun collocations. Michigan: Michigan State University

Flick, U. (2014). An introduction to qualitative research (5th ed.). London: Sage Publications Ltd.

Forsberg, F. (2010). Using conventional sequences in L2 French. International Review of Applied Linguistics, 48(1), 25-51.

Foster, P. (2001). Rules and routines: A consideration of their role in the task-based language production of native and non-native speakers. In M. Bygate, P. Skehan, \& M. Swain (Eds.), Researching pedagogic tasks: Second language learning, teaching, and testing (pp. 75-93). Harlow, UK: Longman.

Franken, M. (2014). The nature and scope of student search strategies in using a web derived corpus for writing. The Language Learning Journal, 42(1), 85-102.

Fraser, C. (1999). Lexical processing strategy use and vocabulary learning through reading. Studies in Second Language Acquisition, 21(2), 225-241.

Garnier, M., \& Schmitt, M. (2016). Picking up polysemous phrasal verbs: How many do learners know and what facilitates this knowledge? System, 59, 29-44.

Geluso, J. (2013). Phraseology and frequency of occurrence on the web: native speakers' perceptions of Google-informed second language writing. Computer Assisted Language Learning, 26(2), 144-157.

Geluso, J., \& Yamaguchi, A. (2014). Discovering formulaic language through data-driven learning: Student attitudes and efficacy. ReCALL, 26(2), 225-242.

Gilquin, G., Granger, S., \& Paquot, M. (2007). Learner corpora: The missing link in EAP pedagogy. Journal of English for Academic Purposes, 6(4), 319-35.

González-Fernández, B., \& Schmitt, N. (2015). How much collocation knowledge do L2 learners have?: The effects of frequency and amount of exposure. ITL International Journal of Applied Linguistics, 166(1), 94-126. https://doi.org/10.1075/itl.166.1.03fer 
Granger, S. (1998). Prefabricated patterns in advanced EFL writing: Collocations and formulae. In A.P. Cowie (Ed.), Phraseology: Theory, analysis, and applications (pp. 145-160). Oxford: Oxford University Press.

Granger, S. \& Bestgen, Y. (2014). The use of collocations by intermediate vs. advanced non-native writers: A bigram-based study. International Review of Applied Linguistics in Language Teaching, 52(3), 229-252.

Granger, S. \& Meunier, F. (2008). Phraseology in language learning and teaching: Where to from here? In Meunier, F., \& Granger, S. (Eds.). Phraseology in language learning and teaching (pp. 247-252). Amsterdam: Benjamins.

Greene, J., Caracelli, V., \& Graham, W. (1989). Toward a Conceptual Framework for Mixed-Method Evaluation Designs. Educational Evaluation and Policy Analysis, 11(3), 255-274.

Gu, Y. \& Johnson, R.K. (1996). Vocabulary learning strategies and language learning outcomes. Language Learning, 46(4), 643-679.

Ha, D. T. (2017). The impact of different instructions on Vietnamese EFL students' acquisition of formulaic sequences. English Language Teaching, 10(8), 18. https://doi.org/10.5539/elt.v10n8p18

Hernández, M., Costa, A., \& Arnon, I. (2016). More than words: Multiword frequency effects in non-native speakers. Language, Cognition and Neuroscience, 31(6), 785-800.

Hill, J. (2000). Revising priorities: from grammatical failure to collocational success. In M. Lewis (Ed.), Teaching collocation: Further developments in the lexical approach (pp. 47-69). London: Heinle, Cengage Learning.

Horst, M., Cobb, T., \& Meara, P. (1998). Beyond a clockwork orange: Acquiring second language vocabulary through reading. Reading in a Foreign Language, 11, 207223.

Hulstijn, J. H., Hollander, M., \& Greidanus, T. (1996). Incidental vocabulary learning by advanced foreign language students: The influence of marginal glosses, dictionary use, and reoccurrence of unknown words. The Modern Language Journal, 80, $327-339$. 
Hulstijn, J. H., \& Laufer, B. (2001). Some empirical evidence for the involvement load hypothesis in vocabulary acquisition. Language Learning, 51(3), 539-558.

Hunston, S. (2002). Corpora in applied linguistics. Cambridge: Cambridge University Press.

Hyland, K. (2008). Academic clusters: Text patterning in published and postgraduate writing. International Journal of Applied Linguistics, 18(1), 41-62.

Ivankova, N. V., \& Creswell, J. W. (2009). Mixed methods. In J. Heigham \& R. A. Croker (Eds.), Qualitative Research in Applied Linguistics: A Practical Introduction (pp. 135-161). Palgrave Macmillan.

Iwashita, N., Brown, A., McNamara, T., \& O’Hagan, S. (2008). Assessed levels of second language speaking proficiency: How distinct? Applied Linguistics, 29, 24-49.

Jiang, J. (2009). Designing pedagogic materials to improve awareness and productive use of L2 collocations. In A. Barfield \& H. Gyllstad (Eds.), Researching Collocations in Another Language (pp. 99-113). New York: Palgrave Macmillan.

Jiang, N., \& Nekrasova, T. M. (2007). The processing of formulaic sequences by second language speakers. Modern Language Journal, 91(3), 433-445.

Joe, A. (2010). The quality and frequency of encounters with vocabulary in an English for academic purposes programme. Reading in a Foreign Language, 22(1), $117-$ 138.

Jones, M., \& Haywood, S. (2004). Facilitating the acquisition of formulaic sequences: An exploratory study. In N. Schmitt (Ed.), Formulaic sequences (pp. 269-300). Amsterdam: John Benjamins.

Kennedy, C., \& Miceli, T. (2000). An evaluation of intermediate students' approaches to corpus investigation. Language Learning and Technology, 5(3), 77-90.

Kim, C. (2016). L2 learners' recognition of unfamiliar idioms composed of familiar words. $\quad$ Language $\quad$ Awareness,25(1-2), 89-109. https://doi.org/10.1080/09658416.2015.1122025 
Kim, S. (2018). EFL learners' dictionary consultation behaviour during the revision process to correct collocation errors. International Journal of Lexicography, 31(3), 312-326. https://doi.org/10.1093/ijl/ecx009

Komuro, Y. (2009). Japanese learners' collocation dictionary retrieval performance. In A. Barfield \& H. Gyllstad (Eds.), Researching collocations in another language: Multiple perspectives (pp. 86-98). Basingstoke, UK: Palgrave Macmillan.

Krashen, S. D. (1985). The input hypothesis: Issues and implications. London: Longman.

Kremmel, B., Brunfaut, T., \& Alderson, J. C. (2017). Exploring the role of phraseological knowledge in foreign language reading. Applied Linguistics, 38(6), 848-870. doi: 10.1093/applin/amv070.

Kuiper, K., Columbus, G., \& Schmitt, N. (2009). Acquiring phrasal vocabulary. In Susan Foster-Cohen (Ed.), Advances in language acquisition (pp. 216-240). Basingstoke, UK: Palgrave Macmillan.

Lai, S-L., \& Chen, H-J. H. (2015). Dictionaries vs concordancers: Actual practice of the two different tools in EFL writing. Computer Assisted Language Learning, 28(4), $143-163$.

Laufer, B. (1997). The lexical plight in second language reading: words you don't know, words you think you know, and words you can't guess. In Coady, J. and Huckin, T. (Eds.), Second language vocabulary acquisition (pp. 20-34). Cambridge: Cambridge University Press.

Laufer, B. (2005). Focus on form in second language vocabulary acquisition. In S. FosterCohen (Ed.), EUROSLA Yearbook 5 (pp. 223-250). Amsterdam, the Netherlands: John Benjamins.

Laufer, B. (2011). The contribution of dictionary use to the production and retention of collocations in a second language. International Journal of Lexicography, 24(1), $29-49$.

Laufer, B. \& Girsai, N. (2008). Form-focused instruction in second language vocabulary learning: A case for contrastive analysis and translation. Applied Linguistics, 29(4), 694-716. 
Laufer, B., \& Hill, M. (2000). What lexical information do L2 learners select in a CALL dictionary and how does it affect word retention? Language Learning \& Technology, 3(2), 58-76.

Laufer, B., \& Hulstijn, J. (2001). Incidental vocabulary acquisition in a second language: the construct of task-induced involvement. Applied Linguistics, 22(1), 1-26.

Laufer, B., \& Waldman, T. (2011). Verb-noun collocations in second language writing: A corpus analysis of learners' English. Language Learning, 61(2), 647-672.

Le-Thi, D., Rodgers, M. P. H., \& Pellicer-Sánchez, A. (2017). Teaching formulaic sequences in an English- language class: the effects of explicit instruction versus coursebook instruction. TESL Canada Journal, 34(3). https://doi.org/10.18806/tesl.v34i3.1276

Lewis, M. (1993). The lexical approach: The state of ELT and a way forward. Hove, UK: LTP.

Lewis, M., (1997). Implementing the Lexical Approach: Putting theory into practice. Hove, UK: LTP.

Li, J., \& Schmitt, N. (2010). The development of collocation use in academic texts by advanced L2 learners: A multiple case study approach. In D. Wood (Ed.), Perspectives on formulaic language: Acquisition and communication (pp. 22-46). New York, NY: Continuum.

Lindstromberg, S. (2016). Guidelines, recommendations, and supplementary discussion. Online supplement to Lindstromberg, S. (2016). Inferential statistics in Language Teaching Research: A review and ways forward. Language Teaching Research, 20(6), 741-768.

Liu, D. (2012). The most frequently-used multi-word constructions in academic written English: A multi-corpus study. English for Specific Purposes, 31(1), 25-35. https://doi.org/10.1016/j.esp.2011.07.002

Macis, M., \& Schmitt, N. (2016). The figurative and polysemous nature of collocations and their place in ELT. ELT Journal, 71(1), 50-59. https://doi.org/10.1093/elt/ccw044 
Macis, M., \& Schmitt, N. (2017). Not just "small potatoes": Knowledge of the idiomatic meanings of collocations. Language Teaching Research, 21(3), 321-340.

Mackey, A, \& Gass, S. (2005). Second language research: Methodology and design. Mahwah, New Jersey: Lawrence Erlbaum Associates.

Martinez, R., \& Murphy, V. A. (2011). Effect of frequency and idiomaticity on second language reading comprehension. TESOL Quarterly, 45, 267-290. https://doi.org/10.5054/tq.2011.247708

Martinez, R., \& Schmitt, N. (2012). A phrasal expressions list. Applied Linguistics, 33(3), 299-320. https://doi.org/10.1093/applin/ams010

Meunier, F. (2012). Formulaic language and language teaching. Annual Review of Applied Linguistics, 32, 111-129.

Nassaji, H. (2003). L2 vocabulary learning from context: Strategies, knowledge sources, and their relationship with success in L2 lexical inferencing. TESOL Quarterly, 37(4), 645-670. https://doi.org/10.2307/3588216

Nation, I.S.P. (2001). Learning vocabulary in another language. Cambridge: Cambridge University Press.

Nation, I.S.P. (2005) Vocabulary learning through extensive reading. In G. Poedjosoedarmo (Ed.) Innovative Approaches to Reading and Writing. RELC Anthology Series 46. RELC, Singapore: 10-21.

Nation, I. S. P. (2013). Learning vocabulary in another language ( $2^{\text {nd }}$ ed.). Cambridge: Cambridge University Press.

Nation, I.S.P. \& Beglar, D. (2007) A vocabulary size test. The Language Teacher, 31(7), 9-13.

Nation, P., \& Newton, J. (1997). Teaching vocabulary. In J. Coady \& T. Huckin (Eds.). Second language vocabulary acquisition: A rationale for pedagogy (pp. 238254). Cambridge, UK: Cambridge University Press.

Nation, I.S.P., \& Wang, K. (1999). Graded readers and vocabulary. Reading in a Foreign Language, 12, 355-380. 
Nation, I. S. P., \& Webb, S. (2011). Researching and analysing vocabulary. Boston: Heinle, Cengage Learning.

Nattinger, J. \& DeCarrio, J. (1992). Lexical phrases and language teaching. Oxford: Oxford University Press.

Nesselhauf, N. (2003). The use of collocations by advanced learners of English and some implications for teaching. Applied Linguistics, 24(2), 223-242.

Nesselhauf, N. (2005). Collocations in a learner corpus. Amsterdam: John Benjamins.

Newton, J. (1995). Task-based interaction and incidental vocabulary learning: A case study. Second Language Research, 11, 159-177.

Nguyen, C.D., \& Boers, F (2018). The effect of content retelling on vocabulary uptake from a TED talk. TESOL Quarterly (online early view). DOI: 10.1002/tesq.441.

Nguyen, H. (2014). The acquisition of formulaic sequences in high-intermediate ESL learners. Doctoral dissertation. Retrieved from http://repository.upenn. edu/edissertations/1385/.

Nguyen, T. M. H., \& Webb, S. (2017). Examining second language receptive knowledge of collocation and factors that affect learning. Language Teaching Research, 21(3), 298-320.

Paribakht, T.S., \& Wesche, M. (1999). Reading and “incidental" L2 vocabulary acquisition: An introspective study of lexical inferencing. Studies in Second Language Acquisition, 21(2), 195-224. https://doi.org/10.1017/S027226319900203X

Parry, K. (1991). Building a vocabulary through academic reading. TESOL Quarterly, 25(4), 629-653. https://doi.org/10.2307/3587080

Pawley, A. \& Syder, F. (1983). Two puzzles for linguistic theory: Nativelike selection and nativelike fluency. In Richards, J. and Schmidt, R. (Eds.), Language and communication (pp. 191-226). New York: Longman.

Pellicer-Sánchez, A. (2015). Incidental L2 vocabulary acquisition from and while reading: An eyetracking study. Studies in Second Language Acquisition. Published online: 18 August 2015 (doi:10.1017/S0272263115000224). 
Pellicer-Sánchez, A. (2017). Learning L2 collocations incidentally from reading. Language Teaching Research, 21(3), 381-402.

Pellicer-Sánchez, A., \& Boers, F. (2018). Pedagogical approaches to the teaching and learning of formulaic language. In A. Siyanova-Chanturia \& A. Pellicer-Sánchez, A. (Eds.), Understanding formulaic language: A second language acquisition perspective (pp. 153-173). New York: Routledge.

Pellicer-Sanchez, A., \& Schmitt, N. (2010). Incidental vocabulary acquisition from an authentic novel: Do things fall apart? Reading in a Foreign Language, 22, 31-55.

Peters, E. (2009). Learning collocations through attention-drawing techniques: A qualitative and quantitative analysis. In A. Barfield and H. Gyllstad (Eds.), Researching collocations in another language: Multiple perspectives (pp. 194207). Basingstoke, UK: Palgrave Macmillan.

Peters, E. (2012). Learning German formulaic sequences: The effect of two attentiondrawing techniques. Language Learning Journal, 40(1), 65-79. https://doi.org/10.1080/09571736.2012.658224

Peters, E. (2014). The effects of repetition and time of post-test administration on EFL learners' form recall of single words and collocations. Language Teaching Research, 18 (1), 75-94.

Peters, E. (2016). The learning burden of collocations: The role of interlexical and intralexical factors. Language Teaching Research, 20(1), 113-138.

Peters, E., \& Pauwels, P. (2015). Learning academic formulaic sequences. Journal of English for Academic Purposes, 20(1), 28-39.

Pigada, M., \& Schmitt, N. (2006). Vocabulary acquisition from extensive reading: A case study. Reading in a Foreign Language, 18, 1-28.

Qi, Y., \& Ding, Y. (2011). Use of formulaic sequences in monologues of Chinese EFL learners. System, 39(2), 164-174.

Riazi, A. M., \& Candlin, C. N. (2014). Mixed-methods research in language teaching and learning: Opportunities, issues and challenges. Language Teaching, 47(2), 135173. 
Rogers, J., Webb, S., \& Nakata, T. (2015). Do the cognacy characteristics of loanwords make them more easily learned than noncognates? Language Teaching Research, 19(1), 9-27.

Rott, S. (1999). The effect of exposure frequency on intermediate language learners' incidental vocabulary acquisition through reading. Studies in Second Language Acquisition, 21, 589-619.

Schmidt, R. (1995). Consciousness and foreign language learning: A tutorial on the role of attention and awareness in learning. In R. Schmidt (Ed.), Attention and awareness in foreign language learning (pp. 1-63). Honolulu: University of Hawai'i Press.

Schmidt, R. (2001). Attention. In P. Robinson (Ed.), Cognition and second language instruction (pp. 3-32). New York: Cambridge University Press.

Schmitt, N. (1997). Vocabulary learning strategies. In Schmitt, N., \& McCarthy, M. (Eds.), Vocabulary: Description, acquisition, and pedagogy. Cambridge: Cambridge University Press.

Schmitt, N. (2000). Vocabulary in language teaching. Cambridge: Cambridge University Press.

Schmitt, N. (2010). Researching vocabulary: A vocabulary research manual. Great Britain: Palgrave MacMillan.

Schmitt, N., \& Carter, R. (2004). Formulaic sequences in action: An introduction. In N. Schmitt (Ed.). Formulaic sequences: Acquisition, processing and use (pp. 1-22). Amsterdam/Philadelphia: John Benjamins Publishing Company.

Schmitt, N., Jiang, X., \& Grabe, W. (2011). The percentage of words known in a text and reading comprehension. Modern Language Journal, 95, 26-43.

Shin, D., \& Nation, P. (2007). Beyond single words: The most frequent collocations in spoken English. ELT Journal, 62(4), 339-348. http://dx.doi.org/10.1093/ elt/ccm091. 
Simpson-Vlach, R., \& Ellis, N. C. (2010). An academic formulas list: New methods in phraseology research. Applied Linguistics, 31(4), 487-512. https://doi.org/10.1093/applin/amp058

Sinclair, J. (1991). Corpus, concordance, collocation. Oxford: Oxford University Press.

Sinclair, J. (1996). The search for units of meaning. Textus, 9, 75-106.

Siyanova-Chanturia, A. (2015). Collocation in beginner learner writing: A longitudinal study. System, 53, 148-160. https://doi.org/10.1016/j.system.2015.07.003

Siyanova-Chanturia, A., \& Pellicer-Sánchez, A. (2018). Formulaic language: Setting the scene. In A. Siyanova-Chanturia \& A. Pellicer-Sánchez, A. (Eds.), Understanding formulaic language: A second language acquisition perspective (pp. 1-15). New York: Routledge.

Siyanova, A., \& Schmitt, N. (2008). L2 learner production and processing of collocation: A multistudy perspective. Canadian Modern Language Review, 64(3), 429-458. https://doi.org/10.3138/ cmlr.64.3.429

Siyanova-Chanturia, A., \& Sidtis, D. V. L. (2018). What online processing tells us about formulaic language? In A. Siyanova-Chanturia \& A. Pellicer-Sánchez, A. (Eds.), Understanding formulaic language: A second language acquisition perspective (pp. 38-61). New York: Routledge.

Siyanova-Chanturia, A., \& Spina, S. (2015). Investigation of native speaker and second language learner intuition of collocation frequency. Language Learning, 65, 533562.

Sonbul, S., \& Schmitt, N. (2013). Explicit and Implicit lexical knowledge: Acquisition of collocations under different input conditions. Language Learning, 63(1), 121159.

Staehr, L. S. (2009). Vocabulary knowledge and advanced listening comprehension in English as a foreign language. Studies in Second Language Acquisition, 31, $577-607$.

Steinel, M. P., Hulstijn, J. H., \& Steinel, W. (2007). Second language idiom learning in a paired-associate paradigm: Effects of direction of learning, direction of testing, 
idiom imageability, and idiom transparency. Studies in Second Language Acquisition, 29, 449-484.

Stengers, H. \& Boers, F. (2015). Exercises on collocations: A comparison of trial-anderror and exemplar-guided procedures. Journal of Spanish Language Teaching, 2(2), 152-164.

Stengers, H., Boers F., Housen, A., \& Eyckmans, J. (2010). Does 'chunking' foster chunk-uptake? In S. De Knop, F. Boers \& A. De Rycker (Eds.), Fostering language teaching efficiency through cognitive linguistics (pp. 99-117). Berlin: Mouton de Gruyter.

Stengers, H., Boers F., Housen, A., \& Eyckmans, J. (2011). Formulaic sequences and L2 oral proficiency: Does the type of target language influence the association? International Review of Applied Linguistics, 49(4), 321-343.

Swain, M. (1985). Communicative competence: some roles of comprehensible input and comprehensible output in its development. In S. Gass \& C. Madden (Eds.), Input in second language acquisition (pp. 235-256). New York: Newbury House.

Swain, M. (1995). Three functions of output in second language learning. In G. Cook \& G. Seidhofer (Eds.), Principles and practices in applied linguistics: Studies in honour of H. G. Widdowson, (pp. 125-144). Oxford: Oxford University Press.

Swain, M. (2005). The output hypothesis: Theory and research. In E. Hinkel (Ed.), Handbook of research in second language teaching and learning (pp. 471-83). Mahwah, NJ: Lawrence Erlbaum Associates.

Swan, M. (2006). Chunks in the classroom: Let's not go overboard. Teacher Trainer, 20(3), 5.

Szudarski, P. (2012). Effects of meaning- and formed-focused instruction on the acquisition of verb - noun collocations in L2 English. Journal of Second Language Teaching and Research, 1(2), 3-37.

Szudarski, P. \& Carter, R. (2016). The role of input flood and input enhancement in EFL learners' acquisition of collocations. International Journal of Applied Linguistics, 26(2), 245-265. 
Thomson, H., Boers, F., \& Coxhead, A. (2017). Replication research in pedagogical approaches to spoken fluency and formulaic sequences: A call for replication of Wood (2009) and Boers, Eyckmans, Kappel, Stengers \& Demecheleer (2006). Language Teaching, 1-9.

Thornbury, S. (2002). How to teach vocabulary. Harlow: Longman.

Tran, H. Q. (2012). An explorative study of idiom teaching for pre-service teachers of English. English Language Teaching, 5(12), 76-86.

Tran, H. Q. (2013). Figurative idiomatic competence: An analysis of EFL learners in Vietnam. Language Education in Asia, 4(1), 23-38. https://doi.org/10.5746/LEiA/13/V4/I1/A3/Tran

Ushigusa, S. (2008). The relationships between oral fluency, multiword units, and proficiency scores. (Purdue University). ProQuest Dissertations and Theses. Retrieved from http://search.proquest.com/docview/288165448?accountid=14707. (288165448).

VanPatten, B. (2003). From input to output: A teacher's guide to second language acquisition. McGraw-Hill.

Waring, R., \& Takaki, M. (2003). At what rate do learners learn and retain new vocabulary from reading a graded reader? Reading in a Foreign Language, 15, $130-163$.

Webb, S. (2005). Receptive and productive vocabulary learning: The effect of reading and writing on word knowledge. Studies in Second Language Acquisition, 27, 3352.

Webb, S. (2007). The effects of repetition on vocabulary knowledge. Applied Linguistics, $28(1), 46-65$.

Webb, S., \& Chang, A. (2015). Second language vocabulary learning through extensive reading with audio support: How do frequency and distribution of occurrence affect learning? Language Teaching Research, 19(6), 667-686.

Webb, S., \& Kagimoto, E. (2009). The effects of vocabulary learning on collocation and meaning. TESOL Quarterly, 43(1), 55-77. 
Webb, S., Newton, J., \& Chang, A. (2013). Incidental learning of collocation. Language Learning, 63(1), 91-120.

Widdowson, H. G. (1989). Knowledge of language and ability for use. Applied Linguistics, 10, 128-137. doi:10.1093/applin/10.2.128

Wood, D. (2002). Formulaic language acquisition and production: Implications for teaching. TESL Canada Journal, 20(1), 01-15.

Wood, D. (2006). Uses and functions of formulaic sequences in second language speech: An exploration of the foundations of fluency. Canadian Modern Language Review, 63, 13-33.

Wood, D. (2010). Formulaic language and second language speech fluency: Background, evidence and classroom applications. New York, NY: Continuum.

Wood, D. (2015). Fundamentals of formulaic language: An introduction. London/New York: Bloomsbury.

Wray, A. (2002). Formulaic language and the lexicon. Cambridge: Cambridge University Press.

Wray, A., \& Fitzpatrick, T. (2008). Why can't you just leave it alone? Deviations from memorized language as a gauge of native-like competence. In F. Meunier, \& S. Granger (Eds.), Phraseology in language learning and teaching (pp. 123-147). Amsterdam: John Benjamins.

Wu, S., Witten, I. H., \& Franken, M. (2010). Utilizing lexical data from a web-derived corpus to expand productive collocation knowledge. ReCALL, 22(1), 83-102.

Yoon, H. and Hirvela, A. (2004). ESL student attitudes toward corpus use in L2 writing. Journal of Second Language Writing, 13(4): 257-283.

Zhang, X. (2017). Effects of receptive-productive integration tasks and prior knowledge of component words on L2 collocation development. System, 66, 156-167. 


\section{APPENDICES}

\section{Appendix 1 - Reading texts}

\section{Reading 1}

\section{Three tips to boost your confidence}

WATCH: http://ed.ted.com/lessons/3-tips-to-boost-your-confidence-ted-ed

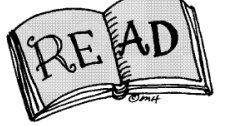

When faced with a big challenge where potential failure seems to lurk at every corner, maybe you've heard this advice before: "be more confident." And most likely, this is what you think when you hear it: "If only it were that simple." But what is confidence? Take the belief that you are valuable, worthwhile, and capable, also known as self-esteem, add in the optimism that comes when you are certain of your abilities, and then empowered by these, act courageously to face a challenge headon. This is confidence. It turns thoughts into action.

So where does confidence even come from? There are several factors that impact confidence. One: what you're born with, such as your genes, which will impact things like the balance of neurochemicals in your brain. Two: how you're treated. This includes the

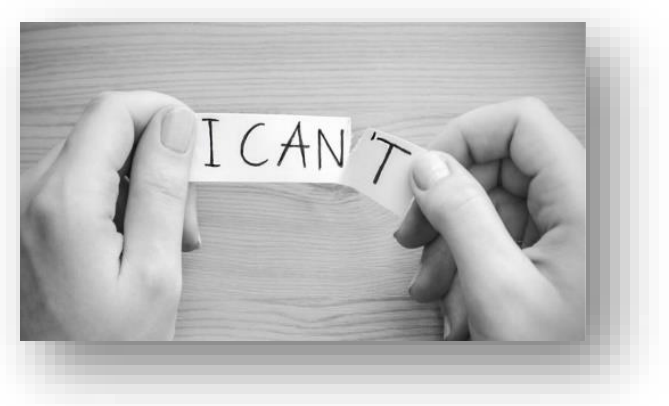
social pressures of your environment. And three: the part you have control over, the choices you make, the risks you take, and how you think about and respond to challenges and setbacks. It isn't possible to completely untangle these three factors, but the personal choices we make certainly play a major role in confidence development. So, by keeping in mind a few practical tips, we do actually have the power to cultivate our own confidence.

\section{Tip 1: A quick fix}

There are a few tricks that can give you an immediate confidence boost in the short term. Picture your success when you're beginning a difficult task, something as simple as 
listening to music with deep bass; it can promote feelings of power. You can even strike a powerful pose or give yourself a pep talk.

\section{Tip 2: Believe in your ability to improve}

If you're looking for a long-term change, consider the way you think about your abilities and talents. Do you think they are fixed at birth, or that they can be developed, like a muscle? These beliefs matter because they can influence how you act when you're faced with setbacks. If you have a fixed mindset, meaning that you think your talents are locked in place, you might give up, assuming you've discovered something you're not very good at. But if you have a growth mindset and think your abilities can improve, a challenge is an opportunity to learn and grow. Neuroscience supports the growth mindset. The connections in your brain do get stronger and grow with study and practice. It also turns out, on average, people who have a growth mindset are more successful, getting better grades, and doing better in the face of challenges.

\section{Tip 3: Practice failure}

Face it, you're going to fail sometimes. Everyone does. J.K. Rowling was rejected by twelve different publishers before one picked up "Harry Porter." The Wright Brothers built on history's failed attempts at flight, including some of their own, before designing a successful airplane. Studies show that those who fail regularly and keep trying anyway are better equipped to respond to challenges and setbacks in a constructive way. They learn how to try different strategies, ask others for advice, and persevere. So, think of a challenge you want to take on, realise it's not going to be easy, accept that you'll make

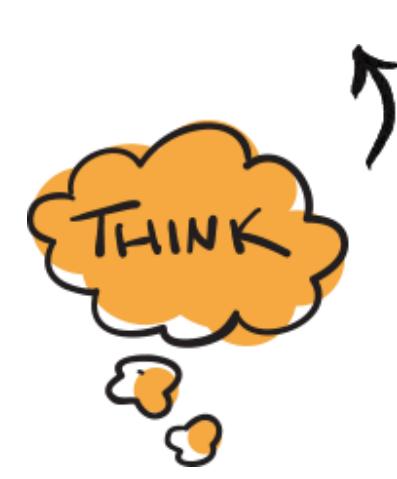
mistakes, and be kind to yourself when you do. Give yourself a pep talk, stand up, and go for it. The excitement you'll feel knowing that whatever the result, you'll have gained greater knowledge and understanding. This is confidence.

\section{A person's confidence level is impacted by:}

A. Their genes

B. The social pressures in their environment

C. The risks they choose to take

D. Their responses to challenges and setbacks

E. All of the above 


\section{This statement is an example of a "fixed mindset":}

A. It doesn't matter how hard I try; there are some things that I will never be able to learn"

B. "With hard work and a lot of practice, I can learn anything"

\section{This statement is an example of a "growth mindset":}

A. "I wasn't born with natural talent for sports, so I'll never be good at them, and this is why I don't play them"

B. "Learning and playing sports that are challenging to me, even when they are difficult, helps to develop my talent"

4. The best way to increase your confidence after you have failed at something is to:

A. Immediately quit. Obviously, you'll never be good at it, so you should just give up

B. Find someone else to blame... it's best if the failure wasn't your fault

C. Acknowledge your failure, figure out what went wrong, think of different strategies or get some advice on how to be more successful, then try again

D. Switch to doing something you know you are good at, and then stick to doing only the things that you are certain you will find success

\section{Some quick ways to feel more confident before a challenge are:}
A. Give yourself a pep talk
B. Strike a power pose
C. Imagine yourself succeeding at first
D. None of the above
E. All of the above 


\section{Reading 2}

\section{Ending Procrastination}

\section{BY HARA ESTROFF MARANO}

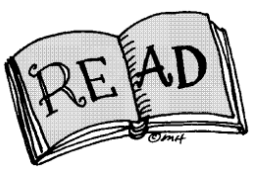

Maybe you tell yourself you perform better under pressure. Or that the work you do when you're not feeling in the mood to work isn't very good. Or you think that you can't do anything well unless you're feeling at the top of your form.

Uh-oh, you've got the earmarks of a procrastinator. Of course, you've got lots of company. Twenty percent of people identify themselves as chronic procrastinators. These are people who don't pay their bills on time, who miss opportunities for buying tickets to concerts, who leave Christmas shopping until Christmas Eve. Let's not even talk about income taxes!

College seems to bring out the procrastination in people. In the college setting, up to 70 percent of students identify themselves as procrastinators.

Of course, it won't help you get things done any faster to know that procrastination isn't good for your health. But putting things off creates higher levels of stress and sends all those stress hormones coursing through your body, wearing it out faster. And it puts you

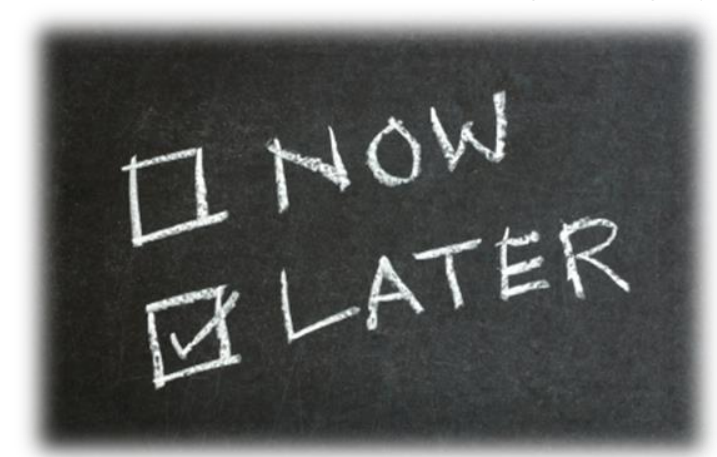
at risk for poor health because you're just as likely to delay seeking treatment for medical problems as you are to delay everything else. Procrastination actually weakens your immune system. It keeps you awake at night. And it doesn't do a thing for your relationships either. It makes loved ones resentful, because it shifts the burden of responsibilities onto them.

Procrastinators are made and not born. That's both the good news and the bad news. Good because it's a learned response, and what's learned can be unlearned. The bad news is that while it's possible to change, it takes a lot of psychic energy and you don't necessarily feel transformed internally. 
You should know that some people who think of themselves as procrastinators really aren't. In a world of unending deadlines, they just put too many things on their "To Do" list. They're not avoiding tasks, the mark of a bona fide procrastinator; they're getting things done, just not as many as they would like.

It's easy to tell whether you're a real procrastinator. According to Joseph Ferrari, Ph.D., associate professor of psychology at De Paul University in Chicago, real procrastinators tell themselves five lies:

- They overestimate the time they have left to perform tasks.

- They underestimate the time it takes to complete tasks.

- They overestimate how motivated they will feel the next day, the next week, the next month -- whenever they are putting things off to.

- They mistakenly think that succeeding at a task requires that they feel like doing it.

- They mistakenly believe that working when not in the mood is suboptimal.

Procrastinators also actively look for distractions, especially ones that don't take heavyduty commitment on their part. Checking e-mail is just about tailor-made for this purpose. The dirty little secret is that procrastinators distract themselves as a way of regulating their own emotions, such as fear of failure.

So face it. Some tasks are never going to be thigh-slappers no matter how long they marinate on your desk. You've got to do them now.

How to tackle procrastination? Dr. Ferrari recommends these strategies for reducing procrastination:

1. Make a list of everything you have to do.

2. Write a statement of intention.

3. Set realistic goals.

4. Break it down into specific tasks.

5. Make your task meaningful.

6. Promise yourself a reward.

7. Eliminate tasks you never plan to do. Be honest! 
8. Estimate the amount of time you think it will take you to complete a task. Then increase the amount by $100 \%$.

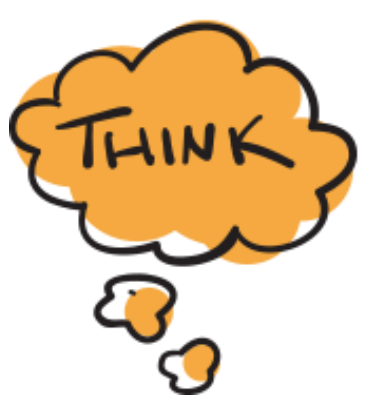

health EXCEPT

1. Procrastinating is:

A. working under pressure

B. working when you are in the mood

C. working when you are at your best

D. working when you can't put things off any longer

2. These are the harmful effects procrastination has on your
A. Creating higher levels of stress
B. Making your body tired
C. Delaying your seeking medical treatment
D. Weakening your immune system

\section{Real procrastinators are those who:}
A. Underestimate their motivation in the coming time
B. Put too many things on their "To do" list
C. Overestimate the time left to them
D. Believe that working when they feel like is not productive enough

\section{How many strategies to tackle procrastination can you remember?}

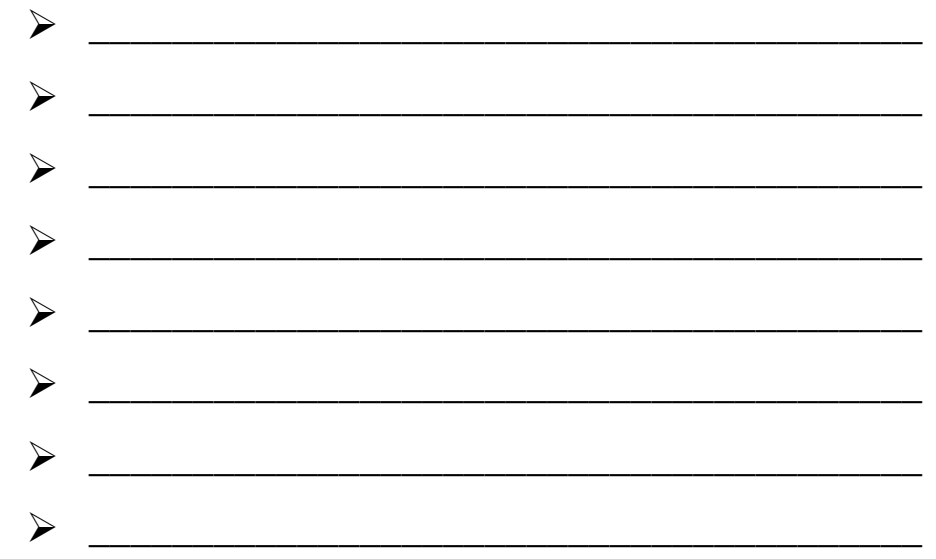




\section{$\underline{\text { Reading } 3}$}

\section{Five tips to improve your critical thinking}

WATCH: http://ed.ted.com/lessons/5-tips-to-improve-your-critical-thinkingsamantha-agoos\#review

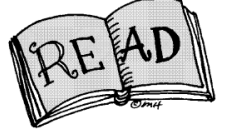

Everyday a sea of decisions stretches before us. Some are small and unimportant, but others have a larger impact on our lives. For example, which politician should I vote for? Should I try the latest diet craze? Or will email make me a millionaire? We're bombarded with so many decisions that it's impossible to make a perfect choice every time. But there are many ways to improve our chances, and one particularly effective technique is critical thinking. This is a way of approaching a question that allows us to carefully deconstruct a situation, reveal its hidden issues, such as bias and manipulation, and make the best decision. If the critical part sounds negative that's because in a way it is. Rather than choosing an answer because it feels right, a person who uses critical thinking subjects all available options to scrutiny and skepticism. Using the tools at their disposal, they will eliminate everything but the most useful and reliable information.

There are many different ways of approaching critical thinking, but here's one five-step process that may help you solve any number of problems.

\section{One: formulate your question.}

In other words, know what you're looking for. This isn't always as straightforward as it sounds. For example, if you are deciding whether to try out the newest diet craze, your reasons for doing so may be obscured by other factors, like claims that you'll see results in just two weeks. But if you approach the situation with a clear view of what you're actually trying to accomplish by dieting, whether that's weight loss, better nutrition, or having more energy, that'll equip you to sift through this information critically, find what you're looking for, and decide whether the new fad really suits your needs.

\section{Two: gather your information.}


There's lots of it out there, so having a clear idea of your question will help you determine what's relevant. If you're trying to decide on a diet to improve your nutrition, you may ask an expert for advice, or seek other people's testimonies. Information gathering helps you weigh different options, moving you closer to a decision that meets your goal.

\section{Three: apply the information, something you do by asking critical question.}

Facing a decision, ask yourself, "What concepts are at work?", "What assumptions exist?, "Is my interpretation of the information logically sound?" For example, in an email that promises you millions, you should consider, "What is shaping my approach to this situation?", "Do I assume the sender is telling the truth?", "Based on the evidence, is it logical to assume I'll win any money?"

\section{Four: consider the implications.}

Imagine it's election time, and you've selected a political candidate based on their promise to make it cheaper for drivers to fill up on gas. At first glance, that seems great. But what about the long-term environmental effects? If gasoline use is less restricted by cost, this could also cause a huge surge in air pollution, an unintended consequence that's important to think about.

\section{Five: explore other points of view.}

Ask yourself why so many people are drawn to the policies of the opposing political candidate. Even if you disagree with everything that candidate says, exploring the full spectrum of viewpoints might explain why some policies that don't seem valid to you appeal to others. This will allow you to explore alternatives, evaluate your own choices, and ultimately help you make more informed decisions.

This five-step process is just one tool, and it certainly won't eradicate difficult decisions from our lives. But it can help us increase the number of positive choices we make. Critical thinking can give us the tools to sift through a sea of information and find what we're looking for. And if enough of us use it, it has the power to make the world a more reasonable place. 


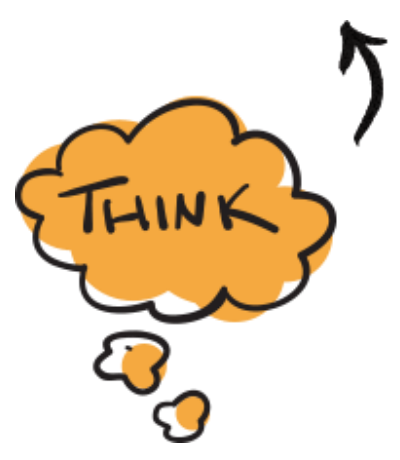

2. What is one advantage of critical thinking?

F. It's a process that helps us make only large, important decisions

G. It's a process that helps us make only small, unimportant decisions

H. It's a process that helps us create hidden issues, bias and manipulation

I. It's a process that helps us reveal hidden issues, bias and manipulation

2. When making a decision, what is the main purpose of gathering facts and information?

C. To make sure your assumptions are illogical

D. To weigh out various options

E. To ignore the implications of your choices

F. To explore your own perspective and point of view

3. Considering the implications of a decision means:

C. Examining its potential outcomes and effects

D. Asking questions to determine your goal

E. Gathering information to weigh out options

F. Determining whether information is logical

4. How can critical thinking improve your chances of making better choices?

E. Critical thinking helps you pick the correct and best choice for all situations

F. Critical thinking helps you explore only your own perspective and no others

G. Critical thinking helps you examine information and make unreasonable choices

H. Critical thinking provides you the tools to sift through complex information logically 


\section{Do Opposites Really Attract?}

BY JENNIFER VERDOLIN PH.D.

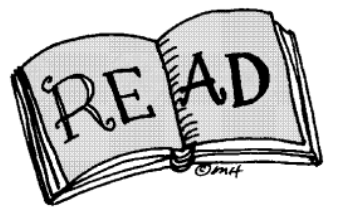

\section{Recent research sheds light on this familiar adage.}

Birds of a feather flock together.

\section{Opposites attract.}

These are two proverbs we are all familiar with. When it comes to friendship, we are keen on the former, but when it comes to love, it is the latter we hold dear. This got me thinking: Do animals make a similar distinction depending on whether they are looking for a best friend or for that special someone?

The answers tell us a lot about how we make these judgments as well.

First, let's establish that animals do form friendships with each other. Like humans, sometimes these friendships are fleeting, and other times they are stable over many years. Although there are many benefits to having friends, it takes time and energy to maintain these relationships. If you are human, that may involve latenight phone calls comforting a friend after a breakup. If you are a chimpanzee, you may spend time digging bugs and dirt out of your pal's hair.

But, human or chimp, how does one

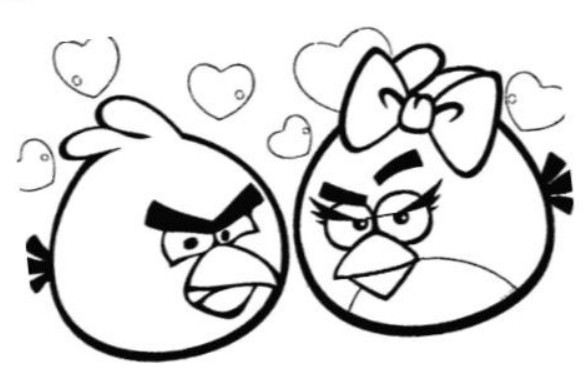
actually decide who to be friends with? How alike you are may be the key, whether it is age, gender, social status (high school, anyone?), or even personality. A recent study looking at what factors predicted friendships between pairs of chimpanzees revealed that individuals with similar personalities were more likely to be friends. Massen and colleagues report (in Evolution and Human Behaviour) that outgoing chimpanzees were buddies with each other, while shyer types also stuck together. For chacma baboons, touchy-feely types tended to pair up while the more aloof become friends - without all the touching and feeling, of course. 
Regardless of whether you are a human, chimpanzee, baboon, or even a meerkat, one thing is for certain: We become friends with others similar to ourselves.

Surely, then, when it comes to love opposites attract, right?

Wrong.

Barnacle geese prefer to mate with individuals that are similar in size, while in great tit birds, having a similar personality makes all the difference. But this trend toward finding someone like you isn't just for the birds - it's for us, too. Despite the common belief that opposites attract, the data prove otherwise and show that married couples are tend to be similar to each other on a variety of traits.

Until recently though, scientist weren't sure if couples start out that way or simply become more alike as time goes on; however, a study published last month in the Journal of Evolutionary Biology is shedding new light on this chicken-and-egg question. In it, researchers found that people in a rural Senegalese village choose to marry someone who is as cooperative and helpful to others as they themselves are.

Maybe, as in the animal world, you can't go wrong pairing up with people more like yourself, whether it's in size, shape, personality, or some other trait that matters to you, such as being thrifty, patient, or funny.

When Plato wrote, "Similarity begets friendship," did he forget about love? I don't think so. Perhaps that explains why friendship often is the best place to start when looking for a romantic partner.

(Verdolin, J. (2014, March 14). Do opposites really attract? Psychology Today. Retrieved from https://www.psychologytoday.com)

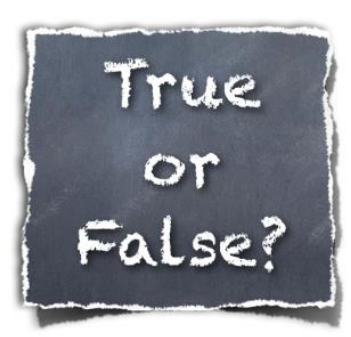

1. It's a common belief that people of opposite traits tend to love each other.

2. ___ Friendships between animals often last long.

3. ___ Both human beings and animals need to invest time and energy to keep up their relationships.

4. ___ Unlike chimpanzees, baboons normally make friends with those of different personalities.

5. ___ Birds habitually choose to mate with individuals of similar sizes, not with those of alike traits. 
6. ___ According to this article, looking for a romantic partner among your friends is a good idea. 


\section{$\underline{\text { Reading } 5}$}

\section{Why is it so fun to be scared?}

WATCH: $\quad$ http://ed.ted.com/lessons/why-do-we-like-to-scare-ourselvesmargee-kerr

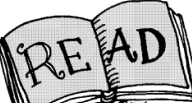

Somewhere right now, people are lining up to scare themselves, maybe with a thrill ride or horror movie. In fact, in October of 2015 alone, about 28 million people visited a haunted house in the U.S. But many consider this behaviour perplexing, asking the question, "What could possibly be fun about being scared?"

Fear has a bad rap, but it's not all bad. For starters, fear can actually feel pretty good. When a threat triggers our fight or flight response, our bodies prepare for danger by releasing chemicals that change how our brains and bodies function. This automatic response jumpstarts systems that can aid in survival. They do this by making sure we have enough energy and are protected from feeling pain, while shutting down nonessential systems, like critical thought. Feeling pain-free and energized, while not getting caught up in worrisome thoughts that normally occupy our brains, that all sounds great, and it can be because this response is similar, though not exactly the same, to what we experience in positive, high-arousal states, like excitement, happiness, and even during sex.

The difference lays in the context. If we're in real danger, we're focused on survival, not fun. But when we trigger this high arousal response in a safe place, we can switch over to enjoying the natural high of being scared. It's why people on roller

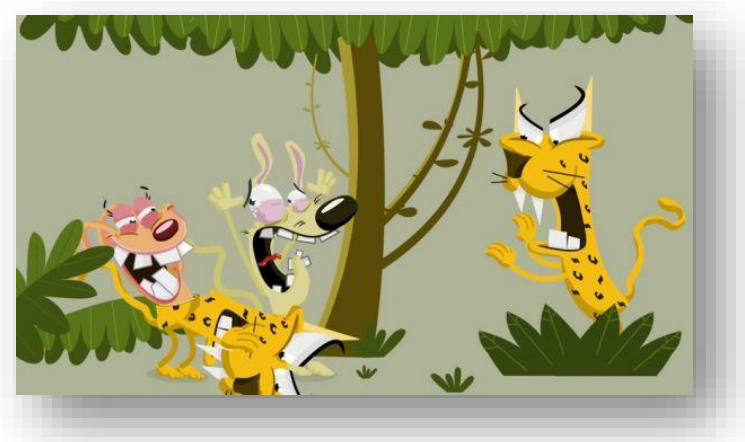
coasters can go from screaming to laughing within moments. Your body is already in a euphoric state. You're just 
relabeling the experience. And though the threat response is universal, research shows differences between individuals in how the chemicals associated with the threat response work. This explains why some are more prone to thrill-seeking than others. Other normal physical differences explain why some may love the dizziness associated with a loop-de-loop, while loathing the stomach-drop sensation of a steep roller coaster, or why some squeal with delight inside a haunted house, but retreat in terror if taken to an actual cemetery.

Fear brings more than just fun, natural high. Doing things that we're afraid of can give us a nice boost of self-esteem. Like any personal challenge, whether it's running a race or finishing a long book, when we make it through to the end, we feel a sense of accomplishment. This is true even if we know we're not really in any danger. Our thinking brains may know the zombies aren't real, but our bodies tell us otherwise. The fear feels real, so when we make it through alive, the satisfaction and sense of accomplishment also feel real. This is a great evolutionary adaptation. Those who had the right balance of bravery and wit to know when to push through the fear and when to retreat were rewarded with survival, new food, and new lands.

Finally, fear can bring people together. Emotions can be contagious, and when you see your friend scream and laugh, you feel compelled to do the same. This is because we make sense of what our friends are experiencing by recreating the experience ourselves. In fact, the parts of the brain that are active when our friend screams are active in us when we watch them. This not only intensifies our own emotional experience, but makes us feel closer to those we're with. The feeling of closeness during times of fear is aided by the hormone oxytocin released during fight or flight. Fear is powerful emotional experience, and anything that triggers a strong reaction is going to be stored in our memory really well. You don't want to forget what can hurt you. So if your memory of watching a horror film with your friends is positive and left you with a sense of satisfaction, then you'll want to do it over and over again. 
* 1. True $\square$ False $\square$ Our automatic nervous system is responsible for activating the fight or flight response.

2. During fight or flight, our body prioritizes ALL the following types of brain and body functioning except for:

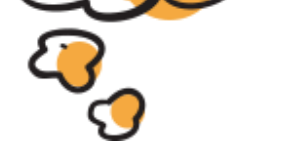
A. Metabolism to produce energy
B. Endorphins to keep us pain-free
C. Critical or cognitive functioning
D. None of the above

3. The fight or flight response is similar to what other arousal states (select all that apply):
A. Excitement
B. Surprise
C. Sexual arousal
D. All of the above

4. The threat response (fight or flight) is universal, but how individuals experience and interpret the response can vary from person to person.
A. True
B. False

5. What are the psychological benefits of voluntarily engaging with scary situations?
A. Boosting self esteem
B. Sense of accomplishment
C. Feelings of bravery and courageousness
D. All of the above

6. True $\square$ False $\square$ We tend to easily forget scary experiences. 


\section{$\underline{\text { Reading } 6}$}

\section{In Politics, a Closed Mouth Gathers No Foot—or Free Press}

\section{BY WENDY L. PATRICK PH.D.}

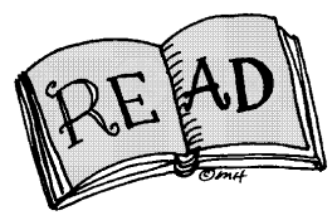

Trump's accessibility to the media is both free advertising and bad press

Where other politicians spend millions of dollars on television advertising, Trump is a walking

advertisement. Sometimes positive, often negative. He is not spending money on television advertisements because he gets the press for free. Yet he is no doubt learning that there is, in fact, such a thing as bad press.

Trump's campaign is constantly in the spotlight. Where other candidates speak in sound bites, Donald Trump speaks in headlines - although not always the type of headlines his supporters want to see. The more Trump puts his foot in his mouth, the more media coverage he gets, often completely overshadowing significant opportunities to discuss the missteps of his rival Hillary Clinton.

The question for his campaign team, is whether there is a way to take advantage of Trump's willingness to make himself accessible to the media, without consistently accumulating bad press.

\section{When It Comes to Political Coverage, Less is Not More}

A candidate running for President is expected to be accessible to the media. Hillary has been attracting negative press by avoiding the press. She is reported to be one of the least accessible candidates to the media, accused of being "allergic" to open press conferences. And no wonder. When she does hold them, they often go very badly and sometimes turn into adversarial inquisitions. Regardless of her motivation, her reluctance to engage with the press has an enormous impact on the viewing public, because viewers are voters.

Research indicates the media is a very effective tool that politicians can use to their advantage - if they use the media in the right way. 


\section{Maximizing Media Coverage Because Viewers are Voters}

Newscasters are considered to be trustworthy communicators. Political candidates are not. It therefore stands to reason that politicians play nice with the media in order to benefit from positive coverage, because research also shows that people like the candidates that their favorite newscaster appears to like. In fact, studies have demonstrated that even a newscaster smiling when discussing a particular political candidate can boost the candidate's electability.

Donald Trump often loses the opportunity to benefit from the public's trust of the media because his antics often reach the viewing public without a filter-both literally and figuratively. In other words, his comments and behavior are not reported by a voter's favorite anchor, but broadcast live, delivered to living rooms across America raw and uncensored, analyzed by the media only after the fact - by which time it often involves harshly negative analysis.

(Patrick, W. J. (2016, August 13). In Politics, a Closed Mouth Gathers No Foot - or Fee Press. Psychology Today. Retrieved from https://www.psychologytoday.com) 


\section{Reading 7}

\section{How playing sports benefits your body and your brain}

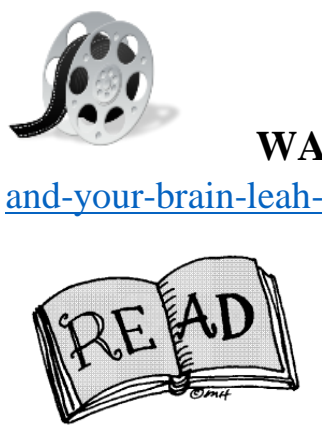

WATCH: http://ed.ted.com/lessons/how-playing-sports-benefits-your-bodyand-your-brain-leah-lagos-and-jaspal-ricky-singh

The victory of the underdog over the favoured team. The last minute penalty shot that wins the tournament. The high-energy training montages. Many people love to glorify victory on the playing field, cheer for favourite teams, and play sports. But here's a question: Should we be so obsessed with sports? Is playing sports actually as good for us as we make it out to be, or just a fun and entertaining pastime? What does science have to say?

First of all, it's well accepted that exercise is good for our bodies and minds, and that's definitely true. Exercising, especially when we're young, has all sorts of health benefits, like strengthening our bones, clearing out bad cholesterol from our arteries, and decreasing the risk of stroke, high blood pressure, and diabetes. Our brains also release a number of chemicals when we work out, including endorphins. These natural hormones, which control pain and pleasure responses in the central nervous system, can lead to feelings of euphoria, or, what's often called, a runner's high. Increased endorphins and consistent physical activity in general can sharpen your focus and improve your mood and memory. So does that mean we get just as much benefit going to the gym five days a week as we would be joining and competing?

Well, here's where it gets interesting: because it turns out that if you can find a sport and a team you like, studies show that there are all sorts of benefits that go beyond the physical and mental benefits of exercise alone. Some of the most significant are psychological benefits, both in the short and long term. Some of those come from the communal experience of being on a team, for instance, learning to trust and depend on others, to accept help, to give help, and to work together towards a common goal. In addition, commitment to a team and doing something fun can also make it easier to establish a regular habit of exercise. School sport participation has also been shown to reduce the 
risk of suffering from depression for up to four years. Meanwhile, your self-esteem and confidence can get a big boost.

There are a few reasons for that. One is found in training. Just by working and working at skills, especially with a good coach, you reinforce a growth mindset within yourself. That's when you say, “Even if I can't do something today, I can improve myself through practice and achieve it eventually." That mindset is useful in all walks of life. And then there's learning through failure, one of the most transformative, long-term benefits of playing sports. The experience of coming to terms with defeat can build the resilience and self-awareness necessary to manage academic, social, and physical hurdles.

So even if your team isn't winning all the time, or at all, there's a real benefit to your experience. Now, not everyone will enjoy every sport. Perhaps one team is too competitive, or not competitive enough. It can also take time to find a sport that plays to your strengths. That's completely okay. But if you spend some time looking, you'll be able to find a sport that fits your individual needs, and if you do, there are so many benefits. You'll be a part of a supportive community, you'll be building your confidence, you'll be exercising your body, not to mention having fun.

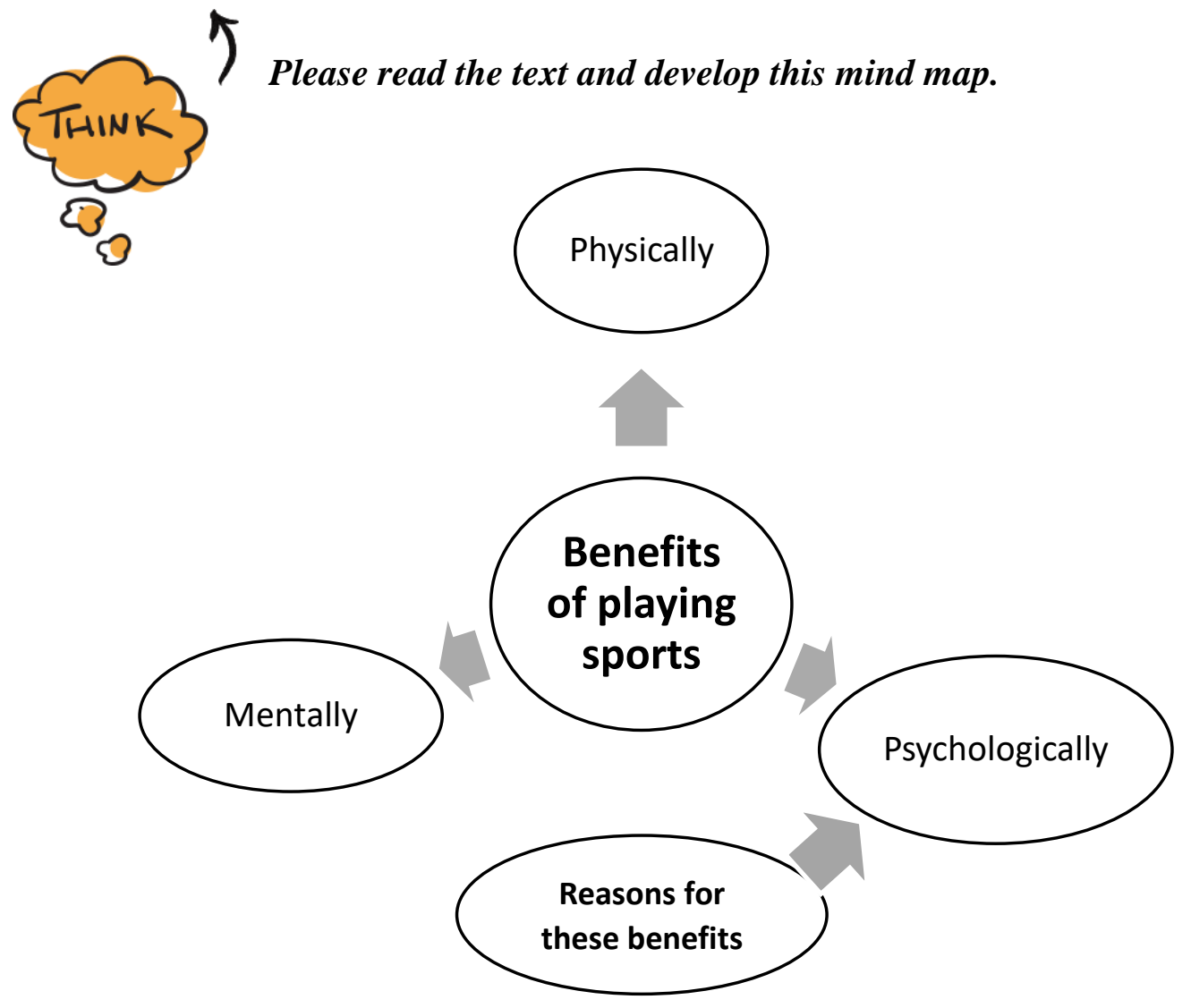

Page 244 of 276 


\section{$\underline{\text { Reading } 8}$}

\section{Routines: Comforting or Confining?}

\section{BY MEG SELIG}

These sentences have been picked up from the text. Please read the text and identify their previous positions in the numbered spaces.

a. Or you could update the old routine and polish it up until it shines again.

b. If a ritual like this is part of your routine, you've taken a giant step toward good self-care.

c. Good routines can provide structure to your day, and they also can save lives and sanity.

d. A routine is a series of habits.

e. So routines are great! Until they're not.

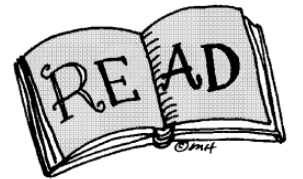

An artist friend recently told me that she was taking part of September off to travel, rest her brain, and "get out of my routines." Her comment made me think about the value of routines--and when they wear out

their welcome.

(1) If you've got a good routine set up--say a morning routine of breakfast-exerciseshower-dress-commute, you've freed yourself from a lot of small decisions that could slow you down or capture valuable brain-space that you'd prefer to use for something else. You can now go on autopilot and still accomplish your goals. In this way, paradoxically, a good routine can be freeing. No need for constant decision-making about what's coming next or what you should do. You're gonna brush your

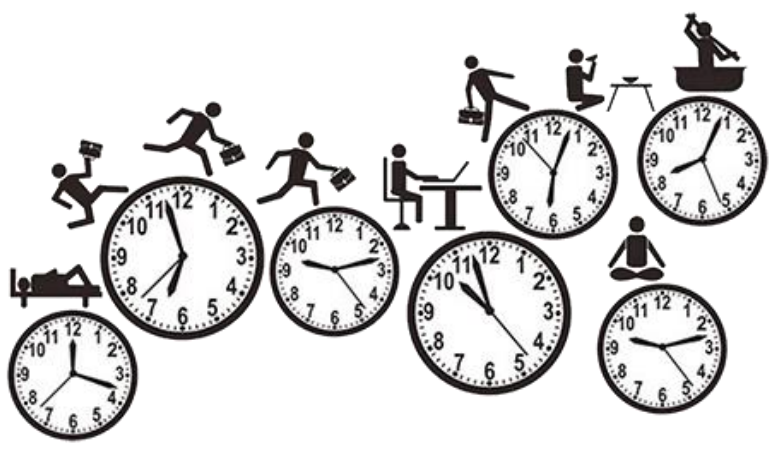
teeth before you leave the house, and that's that!

Along with your routines, maybe you have a ritual--a routine to which you've attached some meaning. Many people, for example, might meditate, exercise, or pray as a daily 
ritual to remind them to be present, be grateful, or for simple restoration after a stressful day. (2)

Of course, an unhealthy routine--stay up too late, press snooze button 5 times, think about what to wear, shower, think some more about what to wear, get dressed, skip breakfast because you must get going--slows you down, is hazardous to your health, and wears you out before you can even begin. Many addicts have negative rituals surrounding their drug use or cutting; they find false comfort in a series of familiar acts that disguise the treacherous nature of their habits.

(3) In 2010, 33 trapped miners in Chile could manage months underground waiting to be rescued thanks to their setup of working and eating routines. Though your life is probably not at stake, you, too, can benefit from a set of daily routines. Do you have a disciplined and humane routine that can:

- Free your creativity by putting some daily tasks on autopilot?

- Protect you from your more self-destructive impulses?

- Bring order and predictability to your life?

- Promote your health?

- Give you a few daily doses of R \& R?

If not, you could choose to break the old routine and consciously create a new one. (4). Maybe you could insert more "unwind" times into the daily grind, for example, so you can periodically jump off the treadmill of routine and get a fresh take on things.

(5). The disadvantages of an unhealthy routine are obvious. But even good, healthy routines can drag us down if we don't break them and re-form them from time to time. Is your routine so pleasant and comforting that you:

- Don't get creative ideas anymore?

- Forget the values and goals behind your routine?

- Feel your mind closing down?

- Realize you've lost your balance between work, relationships, and play?

What's helpful about the ritual of New Year's resolutions is that we have a specific time of year to reconsider our habits and routines and make a conscious change. Still, any time is a good time to re-evaluate your routines when they begin to smell a bit stale. 
So, whether a good routine is comforting or constricting may depend on what you need in your life right now--a firm scaffolding to hold you up and nourish your creativity or a renewed sense of self from opening up to new experiences. For me, daily routines help sustain me and make me more productive; but every now and then it's fun to jog my mind with a creative disruption. Routines are like the old song--know when to hold 'em, know when to fold 'em.

(Selig, M. (2010, September 14). Routines: Comforting or Confinining? Psychology Today. Retrieved from https://www.psychologytoday.com) 


\section{$\underline{\text { Reading } 9}$}

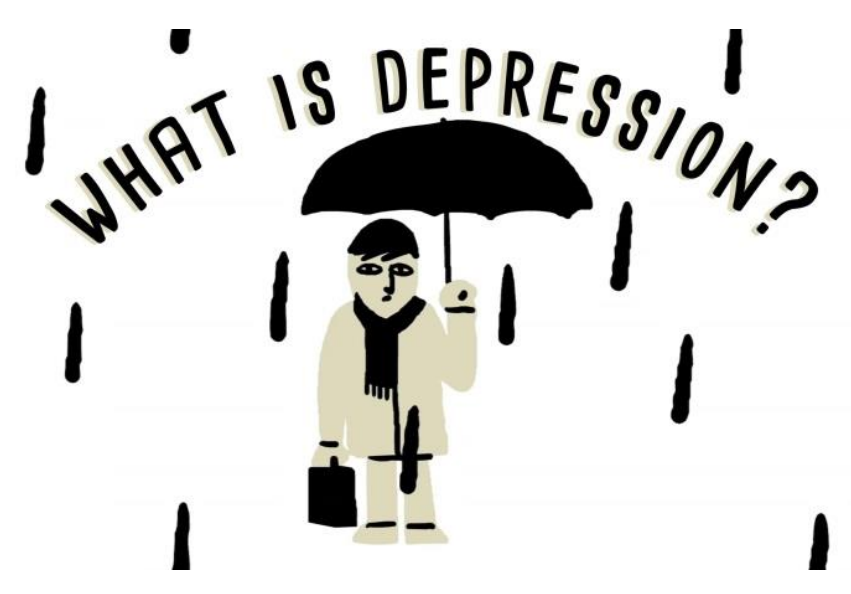

BY HELEN M. FARRELL

WATCH: http://ed.ted.com/lessons/what-is-depression-helen-m-farrell

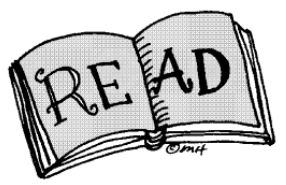

Depression is the leading cause of disability in the world. In the United States, close to $10 \%$ of adults struggle with depression. But because it's a mental illness, it can be a lot harder to understand than, say, high cholesterol. One major source of confusion is the difference between having depression and just feeling depressed. Almost everyone feels down from time to time. Getting a bad grade, losing a job, having an argument, even a rainy day can bring on feelings of sadness. Sometimes there's no trigger at all. It just pops up out of the blue. Then circumstances change, and those sad feelings disappear. Clinical depression is different. It's a medical disorder, and it won't go away just because you want it to. It lingers for at least two consecutive weeks, and significantly interferes with one's ability to work, play, or love.

Depression can have a lot of different symptoms: a low mood, loss of interest in things you normally enjoy, changes in appetite, feeling worthless or excessively guilty, sleeping either too much or too little, poor concentration, restlessness or slowness, loss of energy, or recurrent thoughts of suicide. If you have at least five of those symptoms, according to psychiatric guidelines, you qualify for a diagnosis of depression. 
And it's not just behavioural symptoms. Depression has physical manifestations inside the brain. First of all, there are changes that could be seen with the naked eye and X-ray vision. These include smaller frontal lobes and hippocampal volumes. On a more microscale, depression is associated with a few things: the abnormal transmission or depletion of certain neurotransmitters, especially serotonin, norepinephrine, or dopamine, blunted circadian rhythms, or specific changes in the REM and slow-wave parts of your sleep cycle, and hormone abnormalities, such as high cortisol and deregulation of thyroid hormones. But neuroscientists still don't have a complete picture of what causes depression. It seems to have to do with a complex interaction between genes and environment, but we don't have a diagnostic tool that can accurately predict where or when it will show up. And because depression symptoms are intangible, it's hard to know who might look fine and is actually struggling. According to the National Institute of Mental Health, it takes the average person suffering with a mental illness over ten years to ask for help.

But there are very effective treatments. Medication and therapy complement each other to boost brain chemicals. In extreme cases, electroconvulsive therapy, which is like a controlled seizure in the patient's brain, is also very helpful. Other promising treatments, like transcranial magnetic stimulation are being investigated, too. So, if you know someone struggling with depression, encourage them, gently, to seek out some of these options. You might even offer to help with specific tasks, like looking up therapists in the area, or making a list of questions to ask a doctor. To someone with depression, these first steps can seem insurmountable. If they feel guilty or ashamed, point out that depression is a medical condition, just like asthma or diabetes. It's not a weakness or a personality trait, and they shouldn't expect themselves to just get over it any more than they could will themselves to get over a broken arm. If you haven't experienced depression yourself, avoid comparing it to times you've felt down. Comparing what they're experiencing to normal, temporary feelings of sadness can make them feel guilty for struggling. Even just talking about depression openly can help. For example, research shows that asking someone about suicidal thoughts actually reduces their suicide risk. Open conversations about mental illness help erode stigma and make it easier for people to ask for help. And the more patients seek treatment, the more scientists will learn about depression, and the better the treatments will get. 


\section{$\underline{\text { Reading } 10}$}

\section{A Recipe For School Success}

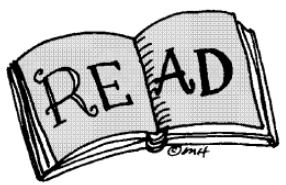

The poor nutritional quality of school meals has become an important issue and the government has set up a School Meals Review Panel to make recommendations. Recommendations made so far include the banning of junk food from school canteens and fizzy drinks from vending machines.

However, at a national conference on healthy eating in schools this week two major problems were highlighted: a lack of money to implement change and a need for more research.

There was a positive note. Research evidence suggests that if we crack the problem of poor nutrition amongst children, we may solve many of the problems of anti-social behaviour and poor learning.

That might seem a big claim but it came from an authoritative scientific source. Bernard Gesch, a researcher at Oxford University, made a presentation linking food to behaviour. His evidence is based on research he carried out, not in schools, but in prisons. This involved giving prisoners food supplements containing vitamins, minerals and essential fatty acids. The results were quite dramatic: the anti-social behaviours of those on the food supplements fell by over $35 \%$. The most serious violent acts fell by even more.

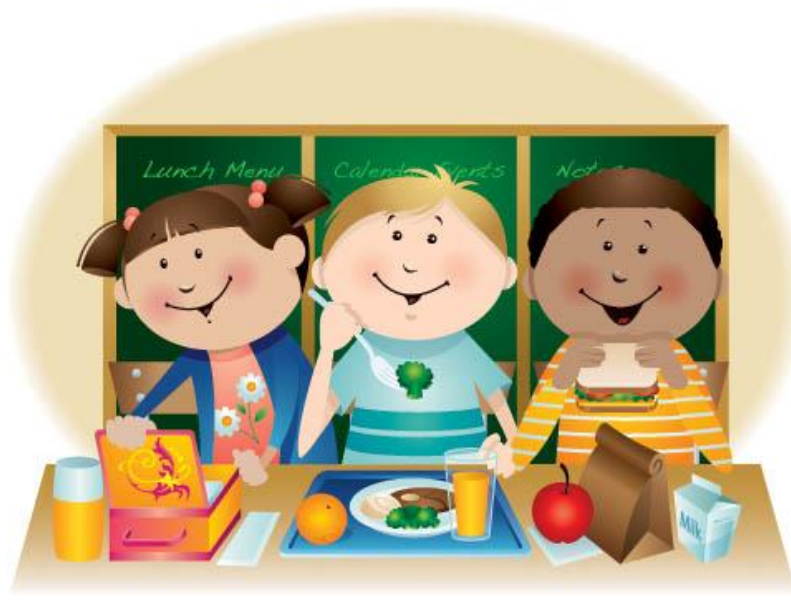

Another experiment, conducted by Dr Alex Richardson of Oxford University, involved young children, aged from six to 11 . All these children had learning difficulties and were more than two years behind in reading and spelling. The experiment provided the children with supplements containing Omega-3 and Omega-6 fatty acids and vitamin E. Again, the results were very clear. The children improved their reading ability at more than three times the normal rate, and more than twice the rate in spelling, over three months of treatment. These are significant improvements. 
So, the government would do good to channel more funds into school children's diets. This brings us to the problem of money. The chair of the School Meals Review Panel, Suzi Leather, told the conference that the cost of implementing nutrition standards in schools in England would amount to around $£ 500 \mathrm{~m}$ over three years. So far, the government has given only $£ 220 \mathrm{~m}$ for that period.

While the ban on junk food and fizzy drinks got plenty of media attention, less notice was given to the timetable for introducing nutrition standards. The School Meals Review Panel, recognising the obstacles to be overcome, set this at 2015 for primary schools and 2016 for secondary schools. This means that many school dinners may continue for several years to lack the nutritional content required for healthy living. This is serious, as we have not yet seen the full impact of poor diet on children's health. By 2020 it is estimated that one in five boys, and one in three girls, will be obese. That is not just overweight, but clinically obese. 
Please rearrange these keywords from the text in the order of their appearance.

\section{Introducing nutrition standards}

Poor learning

Violent acts

Junk food

Learning difficulties

Young children

prisoners

$£ 500 \mathrm{~m}$

Fizzy drinks

funds

Anti-social behaviour

Make a presentation

Reading ability

Vitamins

Poor learning 


\section{Appendix 2 - COCA guidelines}

\section{COCA - A QUICK GUIDE}

The Corpus of Contemporary American English (COCA) is the largest freely-available corpus of English, and the only large and balanced corpus of American English. COCA is probably the most widely-used corpus of English, and it is related to many other corpora of English that we have created, which offer unparalleled insight into variation in English.

The corpus contains more than 520 million words of text (20 million words each year 1990-2015) and it is equally divided among spoken, fiction, popular magazines, newspapers, and academic texts.

Here are some basic things you should know to initially exploit COCA.

\section{THE 'LIST' TAB}

\section{To find out how often a word/phrase occurs in this corpus}

- Type the word/ phrase in the blank box

- Click FIND MATCHING STRINGS

- Look at the FREQ (frequency) to see how often it occurs. Click on each line under CONTEXT if you want to see more of the texts.

These tips will be helpful to you:

- Capitalize all nouns and/ or verbs in the searched strings to receive the results of all forms of those nouns/ verbs (i.e. plural/ singular forms or different tenses). E.g.: BRING out, SHIFT the BURDEN.

- If the string consists of 's, treat it as a separate word with space on both sides. E.g.: that 's a great idea. The same rule applies to other punctuations.

\section{To find out how often a structure/ frame occurs in this corpus}

Use one $*$ symbol with space on both sides to stand for a word in the frame.

E.g.: as far as ** concerned

\section{To find out words that often come with a certain word (e.g. as collocations)}

Type the searched word with the part of speech you want (please see the table at the end of this guide for abbreviation of different parts of speech)

E.g. pretty NOUN (the results will show nouns that often go after 'pretty')

VERB money (for the most frequent verbs preceding 'money')

pretty-NOUN (for words that go after 'pretty' except nouns)

Note that $E N D \_v$ will give the results of all forms of END as a verb.

\section{To find out synonyms of a word (like in a thesaurus)}

Use the equal symbol '=' (no space after it).

E.g. =thick, = CLEAN_v

\section{THE 'COLLOCATES' TAB}

Another way of playing with collocations is using the COLLOCATES tab 
- Type the word/ phrase in the WORD/PHRASE box

- Change the number of words that go before or after the searched word/ phrase, if necessary

- Leave the COLLOCATES box blank, or assign the part of speech you want

- $\quad$ Click FIND COLLOCATES

Note: The results will display the MI (Mutual information) score which shows how strong the partnership of those words is. The higher the MI score, the higher chance those words co-occur.

\section{THE 'KWIC' TAB (for Keyword in Context)}

Use this to see the display of different contexts with the searched word in the middle. This will help you compare contexts and possibly infer how a word is used.

\section{LIST display: part of speech}

You can use parts of speech as part of your query. For example, ADJ eyes would find a two word string, composed of an adjective followed by the word eyes. Some other examples are rough NOUN, NAME Smith, VERB * money, TALK ADV,NUM people, LET PRON VERB.

\section{List of tags for parts of speech}

\begin{tabular}{|c|c|c|c|c|}
\hline $\begin{array}{l}\text { New } \\
\text { (word) }\end{array}$ & $\begin{array}{l}\text { New } \\
\text { (abbrev) }\end{array}$ & $\begin{array}{l}\text { CQP- } \\
\text { like }\end{array}$ & Explanation & Example \\
\hline NOUN & $\mathrm{N}$ & nn & Common nouns & sun, love \\
\hline NAME & NP & _np & Proper nouns & John, Chicago \\
\hline NOUN+ & $\mathrm{N}+$ & n & $\begin{array}{l}\text { Common and proper } \\
\text { nouns }\end{array}$ & sun, Sonny \\
\hline VERB & V & - VV & $\begin{array}{l}\text { Lexical verb (no } d o, b e \text {, } \\
\text { have) }\end{array}$ & decide, jumped \\
\hline VERB+ & $\mathrm{V}+$ & - v & $\begin{array}{l}\text { All verbs (incl do, be, } \\
\text { have) }\end{array}$ & decide, has, is \\
\hline ADJ & $\mathbf{J}$ & $\mathrm{j}$ & Adjectives & nice, clean \\
\hline $\mathrm{ADV}$ & $\mathrm{R}$ & -r & Adverbs & soon, quickly \\
\hline PRON & & $\_\mathrm{p}$ & Pronouns & she, everyone \\
\hline PREP & & _i & Prepositions & from, on \\
\hline ART & & _a & Articles & the, his \\
\hline DET & & _d & Determiners & these, all \\
\hline CONJ & & _c & Conjunctions & that, and, or \\
\hline NEG & & - $\mathrm{x}$ & Negation & not, n't \\
\hline NUM & & _m & Numbers & five, 5 \\
\hline
\end{tabular}




\section{Appendix 3 - Human Ethics}

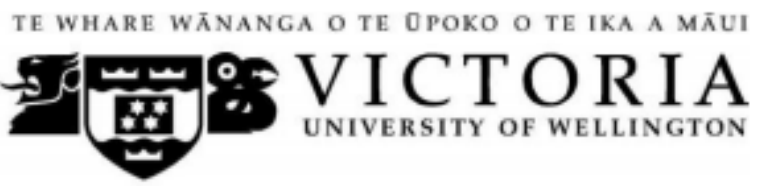

MEMORANDUM

Phone 0-4-4635205

Email stephen.marshall@vuw.ac.nz

\begin{tabular}{l|l}
\hline TO & Thuy Bui \\
\hline COPY TO & \\
\hline FROM & Dr Stephen Marshall, Acting Convener, Human Ethics Committee \\
\hline
\end{tabular}

\begin{tabular}{l|l}
\hline DATE & 27 June 2016 \\
\hline PAGES & 1 \\
\hline
\end{tabular}

SUBJECT

Ethics Approval: 23099

Intermediate EFL learners' uptake of multi-word units through awareness-raising approaches

Thank you for your application for ethical approval, which has now been considered by the Standing Committee of the Human Ethics Committee.

Your application has been approved from the above date and this approval continues until 1 November 2018. If your data collection is not completed by this date you should apply to the Human Ethics Committee for an extension to this approval.

Best wishes with the research.

Stephen Marshall,

Acting Convener, Victoria University Human Ethics Committee 
Appendix 4 - Information Sheet

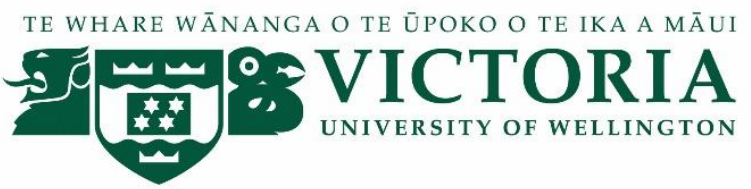

\section{Project Title}

\section{Promoting discovery learning of formulaic language with the aid of online resources: \\ A classroom-based study with intermediate EFL learners}

\section{INFORMATION SHEET FOR PARTICIPANTS}

Thank you for your interest in this project. Please read this information before deciding whether or not to take part. If you decide to participate, thank you. If you decide not to take part, thank you for considering my request.

\section{Who am I?}

My name is Thuy Thi Bich Bui and I am a Doctoral student in Linguistics and Applied Languages at Victoria University of Wellington. This research project is work towards my thesis.

\section{What is the aim of the project?}

This project aims to investigate the effectiveness of two teaching approaches in helping students broaden their vocabulary of English fixed and semi-fixed phrases. This research has been approved by the Victoria University of Wellington Human Ethics Committee [Approval No.: 23099].

\section{How can you help?}

If you agree to take part you will be attending an extra 50-minute English reading lesson each week over the 13 weeks' time. These lessons will take place outside your regular timetable in the semester. The lessons will fundamentally involve reading comprehension activities, together with post-reading tasks such as discussions, vocabulary learning tasks, etc. Two groups of third-year students at the English faculty will perform as two groups of participants in my research.

Your pair-work discussions with your peers when you are doing different tasks in the lessons will possibly be recorded every other week. I will listen to and summarize them later. I will possibly interview you about your class activities as well. Each interview will take around 10 minutes. I will record the interview and write it up later. You can stop the interview at any time, without giving a reason. 
In addition, I will track how much you benefit from these extra lessons by means of the occasional test. Don't worry - your performance will in no way influence the grades in your regular English courses. You will also receive a questionnaire about your perception of the activities we did during the reading lessons.

You can withdraw from the study up to four weeks after the first lesson. If you withdraw, the information you provided will be destroyed.

\section{Why should you participate in this project?}

Your participation in this project will bring you additional hours of EFL tuition over the 13 weeks of the project. You will have more time practising English reading and speaking skills with your peers and the opportunity to further develop self-study skills for your own vocabulary development. Besides, you will receive feedback from the researcher on your writing. You will also be given items of stationery as a token of the researcher's appreciation for your time and effort in the project.

\section{What will happen to the information you give?}

This research is confidential. I will not use your name in any reports, and I will not include any information that would identify you. Only my supervisors and I will read the notes or transcript of the interviews and recordings. The interview transcripts, summaries and recordings will be kept securely and destroyed 3 years after my Doctoral thesis has been finished, approximately in November 2018.

Neither your decision to participate in this project not your performance during this project will affect any of your course grades in any way.

\section{What will the project produce?}

The information from my research will be used in my $\mathrm{PhD}$ dissertation. You will not be identified in my report. I may also use the results of my research for conference presentations, and academic reports. I will take care not to identify you in any presentation or report.

\section{If you accept this invitation, what are your rights as a research participant?}

You do not have to accept this invitation if you don't want to. If you do decide to participate, you have the right to:

- choose not to answer any question;

- $\quad$ ask for the recorder to be turned off at any time during the interview;

- withdraw from the study up until four weeks after the first lesson;

- $\quad$ ask any questions about the study at any time;

- receive a copy of your interview recording (if it is recorded);

- read over and comment on a written summary of your interview;

- be able to read any reports of this research by emailing the researcher to request a copy. 
If you have any questions or problems, who can you contact?

If you have any questions, either now or in the future, please feel free to contact either:

Student:

Name: $\quad$ Thuy Thi Bich Bui

Email address:

Thuy.Bui@vuw.ac.nz

\section{Supervisor:}

\begin{tabular}{|c|c|}
\hline Name: & Frank Boers \\
\hline Role: & Associate Professor \\
\hline School: & $\begin{array}{l}\text { Linguistics and Applied } \\
\text { Language Studies }\end{array}$ \\
\hline Phone: & $0644463 \mathbf{6 0 1 4}$ \\
\hline
\end{tabular}

Frank.Boers@ @uw.ac.nz

\section{Human Ethics Committee information}

If you have any concerns about the ethical conduct of the research you may contact the Victoria University HEC Convener: Associate Professor Susan Corbett. Email susan.corbett@vuw.ac.nz or telephone +64-4-463 5480. 


\section{Appendix 5 - Consent Form}

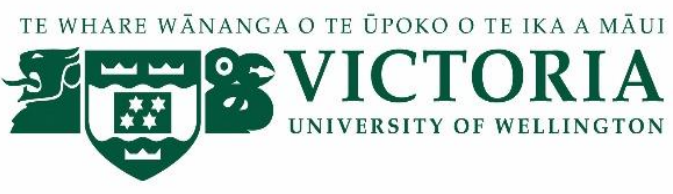

\section{Project Title \\ Promoting discovery learning of formulaic language with the aid of online resources: \\ A classroom-based study with intermediate EFL learners}

This consent form will be held for 3 years.

Researcher: $\quad$ Thuy Thi Bich Bui

School of Linguistics and Applied Language Studies

Victoria University of Wellington

- I have read the Information Sheet and the project has been explained to me. My questions have been answered to my satisfaction. I understand that I can ask further questions at any time.

- I agree to take part in weekly English lessons during the 13 weeks' time of the project.

- I agree to take part in audio recorded interviews.

I understand that:

- I may withdraw from this study up to four weeks after the first lesson and any information that I have provided will be returned to me or destroyed.

- The information I have provided will be destroyed 3 years after the researcher's Doctoral thesis is finished, approximately in November 2018.

- Any information I provide will be kept confidential to the researcher and the supervisor. I understand that the results will be used for a PhD report and a summary of the results may be used in academic reports and/or presented at conferences.

- My name will not be used in reports, nor will any information that would identify me.

- I would like a summary of my interview (if I am interviewed)

Yes $\square \quad$ No

- I would like to receive a summary of the research findings

Yes

No $\square$ and have added my email address below.

Signature of participant:

Name of participant:

Date:

Contact details: 
Appendix 6 - Template of pair work MWE lists and samples of students' work

\section{MY LIST OF PHRASES}

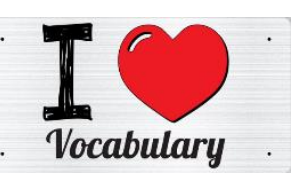

WEEK:

GROUP MEMBERS:

\begin{tabular}{|c|c|c|c|c|}
\hline & The phrases I highlighted & In a dictionary? Which? & $\begin{array}{l}\text { Dictionary definition/ My guess of } \\
\text { its meaning }\end{array}$ & Frequency on COCA \\
\hline 1. & & & & \\
\hline 2. & & & & \\
\hline 3. & & & & \\
\hline 4. & & & & \\
\hline 5. & & & & \\
\hline 6. & & & & \\
\hline 7. & & & & \\
\hline 8. & & & & \\
\hline 9. & & & & \\
\hline 10. & & & & \\
\hline 11. & & & & \\
\hline
\end{tabular}




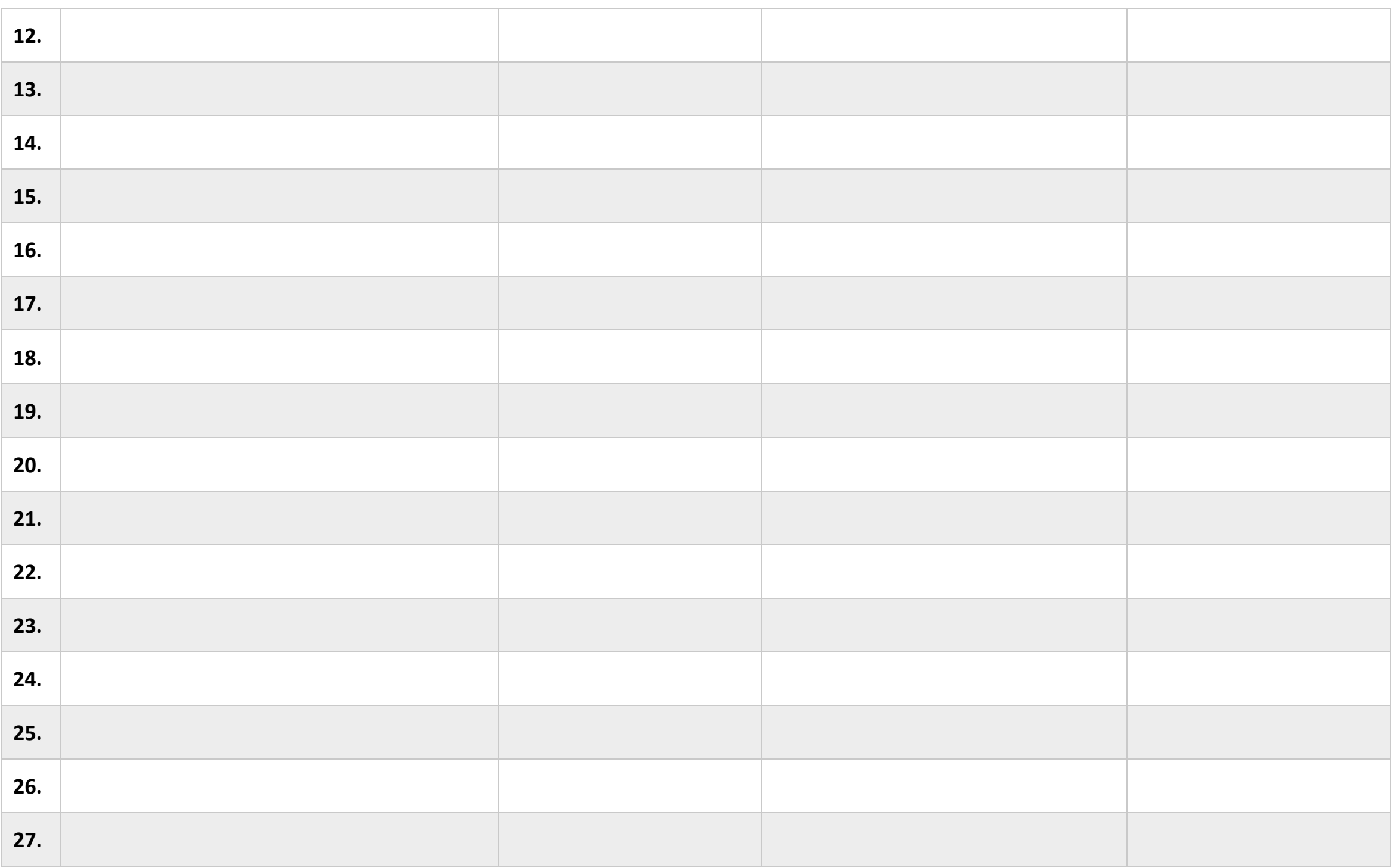

Page $\mathbf{2 6 1}$ of $\mathbf{2 7 6}$ 


\section{MY LIST OF PHRASES}

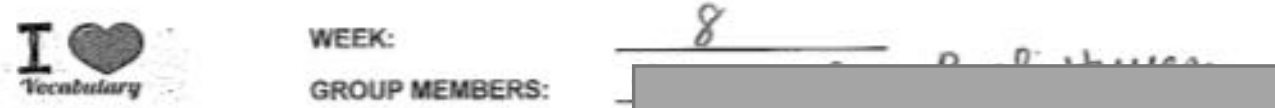

\begin{tabular}{|c|c|c|c|c|}
\hline No. & The phrases ifilighilightied & Ihe dictionan? Which? & $\begin{array}{l}\text { Dictionary definition/My guess of } \\
\text { its meaning }\end{array}$ & Frequenty on $C O C A$ \\
\hline 1. & to line up. & Oxjord learner & ostand in a line or row & 8138 \\
\hline 2. & a bad rap. & The Free Dictionary & unjustijied criticism. & 309 \\
\hline 3. & to aid in & Ox jord Leainer. & to help, to assist & 1959 \\
\hline 4. & be protected from & Ox jord Learnen & to be kept jrom baing & 710 \\
\hline 5. & get caught up in sh & Cambridge & $\begin{array}{l}\text { to becume iniolved in a } \\
\text { situation }\end{array}$ & 997 \\
\hline 6. & switch over & Cambridge & $\begin{array}{l}\text { to change from doung one } \\
\text { thing to ano her }\end{array}$ & 339 \\
\hline 7. & associate with & Macmillan & relate to & 37640 \\
\hline 8. & be prone to & MacMillom & $\begin{array}{l}\text { to ogten do sth or suyger } \\
\text { pon sth (esp bad ) }\end{array}$ & 1284 \\
\hline 9. & ntevery & & & \\
\hline 10. & make it through & & get over, succerd in & 1874 \\
\hline 11. & a sense of Noun & & a jeeling of & 7714 \\
\hline 12. & push through & The Eree Dictionay & to force sth & 2048 \\
\hline
\end{tabular}




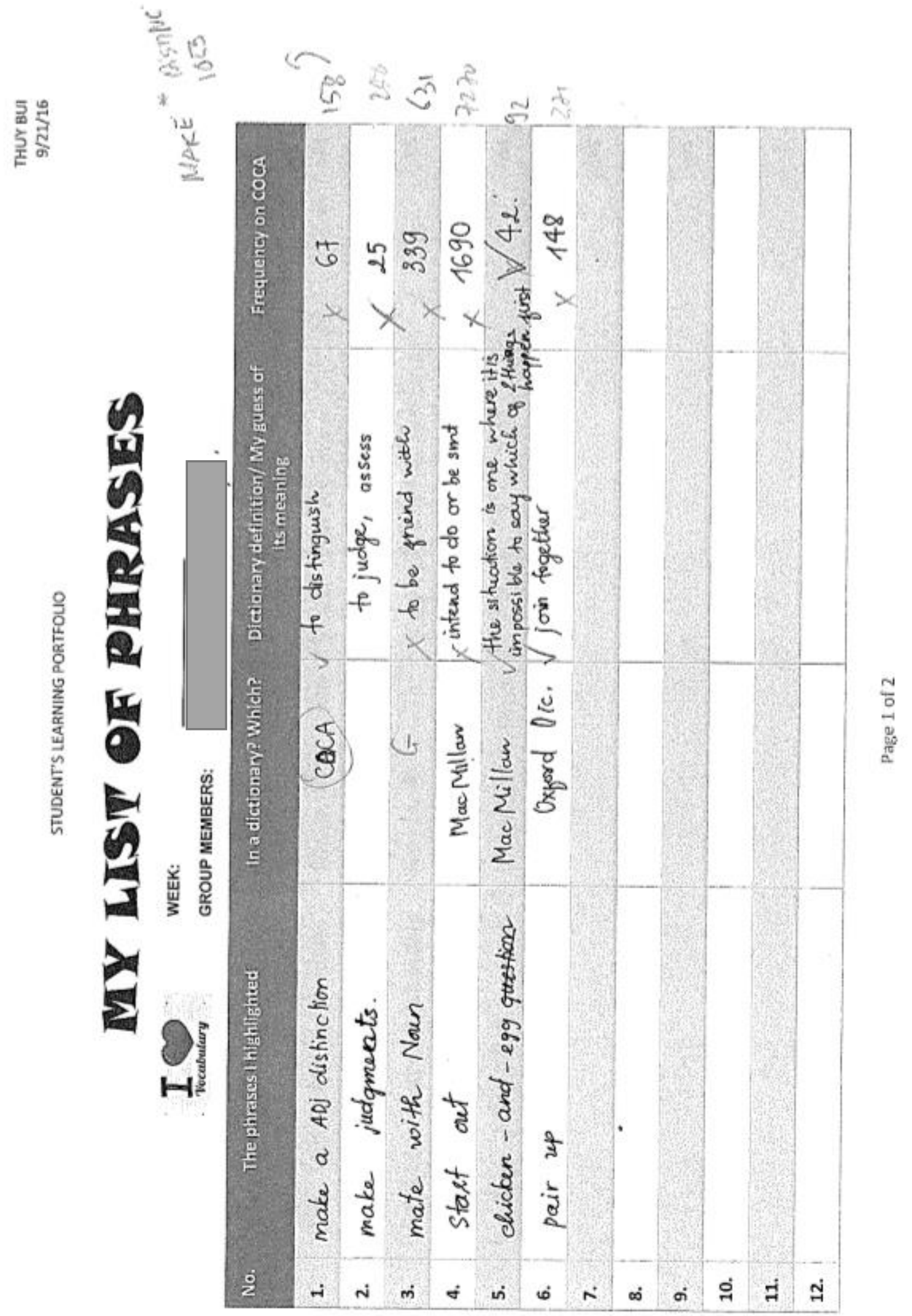




\section{Appendix 7 - Vocabulary test}

Please complete the following sentences with suitable words for the blanks. Each blank stands for one word, with its first letter given. Hints are given at the end of the sentences.

1. I still think of him $\mathrm{f}$ $\mathrm{t}$ $\mathrm{t}$ . (sometimes, but not often) (Answer: from time to time)

2. $\mathrm{O}$ a , women live between five and seven years longer than men. (used for talking about what is usually true) (Answer: On average)

3. The $\mathrm{v}$ $\mathrm{m}$ in the office dispenses really tasteless coffee. $(a$ machine that you can buy things from, for example cigarettes, sweets, or drinks) (Answer: vending machine)

4. A f drink is a sweet drink without alcohol that has bubbles. (Answer: fizzy)

5. People from a W o use the public library. (with diverse backgrounds or diverse jobs or positions in society) (Answer: all walks of life)

6. Everyone knows they're growing old, but to c $\mathrm{t}$ $\mathrm{t}$ $\mathrm{w}$ the situation is something else. (learn to accept and deal with an unpleasant situation) (Answer: come to terms with)

7. It pays to be proactive $\mathrm{w}$ i_ c your health (when the specified matter is under consideration) (Answer: when it comes to)

8. Police chiefs called a $\mathrm{p}$ to appeal for help from the public (an interview given to journalists by a prominent person in order to make an announcement or answer questions) (Answer: press conference)

9. Professors often find it difficult to encourage $\mathrm{c}$ among their students. (The objective analysis and evaluation of an issue in order to form a judgement) (Answer: critical thinking)

10. $\mathrm{E}$ $\mathrm{n}$ a $\mathrm{t}$ , you'll have bad apples and we try to weed them out. (sometimes, but not regularly or often) (Answer: Every now and then) 
11. She became o $\mathrm{W}$ the idea that there was something wrong with the baby. (always thinking about it, in a way that seems extreme to other people) (Answer: obsessed with)

12. Many schools don't t full a o the Internet. (use a situation or opportunity to get what you want) (Answer: take (full) advantage of)

13. A g hers is not the face of fifty-year-old woman. (at the moment when you first see something or find out about something) (Answer: At first glance)

14. I ended up in a $\mathrm{h}$ $\mathrm{h}$ in England, where I saw the ghosts but my companion didn't. (a place frequented by a ghost) (Answer: haunted house)

15. She thought she was pregnant, but it $t$ o to be a false alarm. (to be discovered finally and surprisingly) (Answer: turned out)

16. Fame is often a $\mathrm{W}$ wealth and success. (connected with something else in one's mind) (Answer: associated with)

17. I'm t Monday o to go to London. (to have Monday away from work) (Answer: taking (Monday) off)

18. Indeed, the $\mathrm{c}$ b is that the teacher who knows more about the student teaches more. (what most people think) (Answer: common belief)

19. I couldn't m i $\mathrm{t}$ those times without the support of my supervisor. (to manage to deal with a difficult experience) (Answer: make it through)

20. It is believed that unemployment is the 1 c_ of poverty in this area. (the most important reason) (Answer: leading cause)

21. When you're a parent, you use whatever tools you have a $\mathrm{y}$ d___ to protect your kid. (available for you to use at any time) (Answer: at your disposal)

22. $\mathrm{O}$ o $\mathrm{t}$ $\mathrm{b}$ she said, 'Your name's John, isn't it?' (in a way that is sudden and unexpected) (Answer: Out of the blue) 
23. Cutting jobs could be more expensive i $\mathrm{t}$ 1 $\mathrm{r}$ if we have to hire freelancers. (not immediately but at some time in the future) (Answer: in the long run)

24. It's not the right time for us to buy a house now. F $\mathrm{s}$ , it's too expensive. (the first point in a series, especially in an argument) (Answer: For starters)

25. He spent hours $s$ all the documents relating to the case. (examining information, documents, etc. in order to find what you are looking for) (Answer: sifting through)

26. By the second week of the election campaign, she was making all her speeches o a . (automatically, without thinking about what she was doing) (Answer: on autopilot)

27. My family was really cautious about keeping the media away and keeping my life private, because there's so much that could go wrong with being $\mathrm{i}$ $\mathrm{t} \_\mathrm{s} \_$. (a situation in which you get a lot of public attention) (Answer: in the spotlight)

28. With so many lives a a process of testing new medication that normally takes years is being compressed into months. (at risk) (Answer: at stake)

29. The $\mathrm{f}$ o__ response is a body reaction that occurs in response to a perceived harmful event, attack, or threat to survival. (Answer: fight or flight)

30. How do you maintain that joy in your marriage despite the $\mathrm{d}$ g__ ? (everyday routine of work or activity) (Answer: daily grind)

31. The boss gave the staff a $\mathrm{p}$ $\mathrm{t}$ this morning to boost sales. (a talk intended to make someone feel more courageous or enthusiastic) (Answer: pep talk)

32. I saw the boy who stole my bag with that gang of trouble makers last night - well, $b$ o_ a f $\mathrm{f}$ $\mathrm{t}$ they say. ( $a$ 
saying which means people who have similar characters or similar interests will often choose to spend time together) (Answer: birds of a feather flock together)

33. I had hoped that he would be able to $\mathrm{s}$ some 1 on the problem. (to provide new information that helps you understand something) (Answer: shed (some) light)

34. Strasburg, 23, and Gonzalez, 26, get along not despite their differences, but because of them. "o a , right?" Gonzalez said. (a saying meaning that people who are very different are attracted to each other for that reason) (Answer: opposites attract)

35. I really $\mathrm{p}$ $\mathrm{m}$ $\mathrm{f}$ m $\mathrm{m}$ - I asked her if Jane was her mother, but she said Jane is her sister. (accidentally saying something that is embarrassing or that upsets or annoys someone) (Answer: put my foot in my mouth)

36. If they don't like you, it s $\mathrm{t}$ $\mathrm{r}$ that they won't give you the job. (it is obvious because it is what most sensible people would expect) (Answer: stands to reason)

37. $\mathrm{S}$ a dramatic $\mathrm{p}$ Antonia announced that she was leaving. (Holding one's body in a particular position to create an impression) (Answer: Striking (a dramatic) pose)

38. Some people may be a $\mathrm{t}$ nuts. This means they may become sick or have red marks in their skin when they eat, breathe or touch nuts. (Answer: allergic to)

39. I am not really $\mathrm{i}$ $\mathrm{m}$ for shopping now. (feel like doing or having something) (Answer: in the mood)

40. I'm amazed you find the time, $\mathrm{n}$ $\mathrm{t}$ $\mathrm{m}$ the energy, to do any work at all given how busy you are with your kids. (used for adding a comment that emphasizes the main idea of what you have already said) (Answer: not to mention)

41. I will keep w the $\mathrm{o}$ until we're settled on a plan. (considering the possibilities) (Answer: weigh (the) options) 
42. $\mathrm{S}$ S consistent exposure to sounds above 100 decibels can leave you with some hearing problems. (the phrase to introduce a new scientific finding) (Answer: Studies show that)

43. We don't always $m$ $\mathrm{t}$ g we set in our professions or our private lives. (achieve something that you are trying to achieve) (Answer: meet the goals)

44. The children love those shoes so much. I'm sure they'll use them every day until they $\mathrm{W}$ them o (used them a lot so that they can no longer be used) (wear (them) out)

45. The assignment requires students to think critically, reason, analyse and $\mathrm{m}$ $\mathrm{r}$ (suggest or advise on how to solve a problem, deal with a situation, etc.) (Answer: make recommendations)

46. In fact, 7 million Americans a year $\mathrm{s}$ for sports-related injuries, more than 1 million of which involve the head or neck region. (ask for or try to get cured) (Answer: seek treatment)

47. Let's $\mathrm{f}$ this problem $\mathrm{h}$ o and try to solve it quickly and painlessly. (deal with it in a very direct way) (Answer: face (this problem) head-on)

48. Passive smoking affects non-smokers and makes them more $p$ respiratory diseases. (likely to be affected by) (Answer: prone to)

49. The actress looked down and saw a s of smiling faces. (a large amount of) (Answer: sea)

50. The report will probably $t$ a fierce $r$ from the governor. (to cause someone to do or say something) (Answer: trigger (a fierce) reaction)

51. Two dates in nine years hardly a an active social life. (to be the same as) (Answer: amounts to)

52. They finally won the race $i$ $\mathrm{t}$ $\mathrm{f}$ $\mathrm{o}$ stiff competition from all over the country. (in a situation where you have to deal with something unpleasant or difficult) (Answer: in the face of) 


\section{Appendix 8 - Sample of students' worksheets}

\section{$\underline{\text { Reading } 3}$ \\ 5 tips to improve your critical thinking \\ $\int \because$

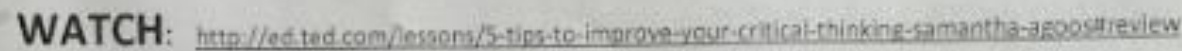

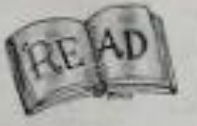

Everyday a sea of decisions stretches before us. Some are small and unimportant. but others have a larger impact on our lives. For example, which politician should I vote for? Should I try the latest diet craze? Or will email make me a millionaire? We re bombarded with so many decisions that it's impossible to make a perfect choice every time. But there are many ways to improve our chances, and one particularly effective technique is critica: thinking. This is a way of approaching a question that allows us to carefully deconstruct a situation, reveal its hidden issues, such as bias and manipulation, and make the best decision. If the critical part sounds negative that's because in a way it is. Rather than choosing an answer because it feels right. a person who uses critical thinking subjects all available options to scrutiny and sikepticism. Using the tools at their disposal, they will eliminate everything but the most useful and reliable information.

There are many different ways of approaching critical thinking, but here's one five-step process that may help you solve any number of problems

One: formulate your question

In other words, know what you're looking for. This isn't always as straightforward as it sounds. For example, if you are deciding whether to try out the newest diet craze, your reasons for doing so may be obscured by other factors, like claims that youll see results in just two weeks. But if you approach the stuation with a clear view of what you're actually trying to accomplish by dieting, whether that's weight loss, better nutsition, or having more energy. that'll equip you to sft through this information critically, find what you're looking for, and decide whether the new fad really suts your needs

Two: gather your information.

There's lots of t out there, so having a clear idea of your question will help you determine what's relevant. If you're trying to decide on a diet to improve your nutrition, you may ask an expert for advice, or seek other people's testimonies. Information gathering helps you weigh different cptions, moving you closer to a decision that meets your goal.

Three: apply the information, something you do by asking critical question.

Facing a decision, ask yourself. "What concepts are at Work?". What assumptions exist?, "Is my interpretation of the information logically sound?' For example, in an email that promises you millions. you should consider, What is shaping my approach to this stuation?; "Do I assume the sender is telling the truthr", "Based on the evidence, is it logcal to assume I'll win any money?'

Four: consider the implications 


\section{READING FOR PARTICIPANTS}

Imagine irs election time, and you've selected a political candidate based on their promise to make it cheaper for drivers to fill up on gas. At first glance, that seems great. But what about the long-term environmental effects? If gasoline use is less restricted by cost, this could also cause a huge surge in air polution, an unintended consequence that's important to think about

\section{Five: explore other points of view.}

Ask yourself why so many people are drawn to the policies of the opposing poitical candidate. Even if you disagree whit everything that candidate says, exploring the full spectrum of viewpoints might explain why some policies that don't seem valid to you appeal to others. This will allow you to explore alternatives, evaluate your own choices, and uitimately help you make more informed decisions.

This five-step process is just one tool, and it certainly wont eradicate difficult decisions from our fives. But $t$ can help us increase the number of positive choices we make. Critical thinking can give us the tools to sift through la sea of information and find what we're looking for. And if enough of us use it, it has the power to make the world a more reasonable place.

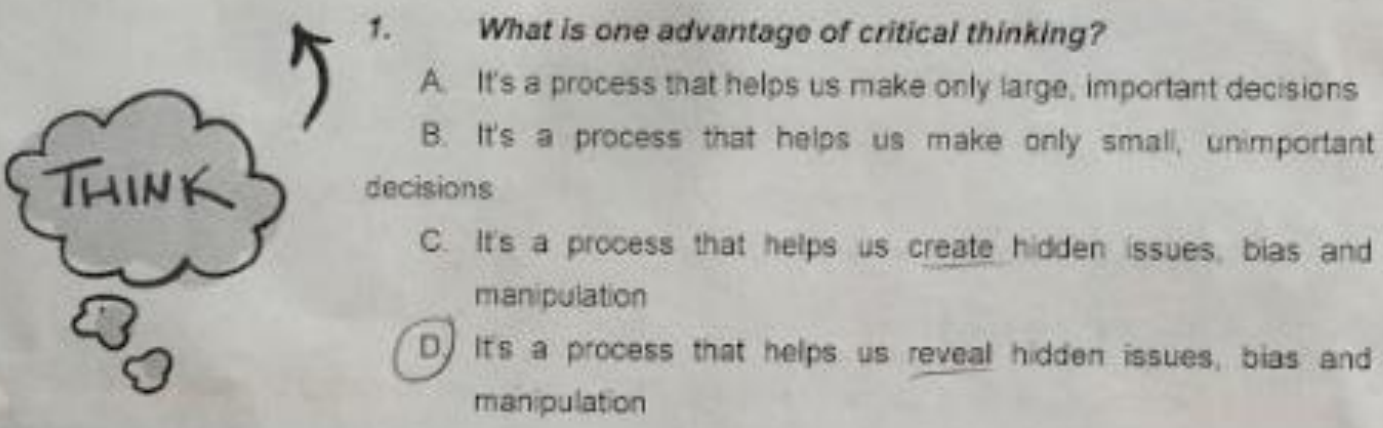

2. When making a docision, what is the main purpose of gathering facts and information?
A. To make sure your assumptions are illogical
B. To weigh out various options
C. To ignore the implications of your choices
D. To explore your own perspective and point of view

3. Considering the implications of a decision moans:
A. Examining its potental outcomes and effects
B. Asking questions to determine your goal
C. Gathering information to weigh out optons
D. Determining whether intormation is logical

4. How can critical thinking improvo your chances of making better choices?
A. Critical thinking helps you pick the correct and best choice for all stuations
B. Critical thinking helps you explote only your own perspective and no others
C. Critical thinking heips you examine information and make unreasonable choices (D.) Critical thinking provides you the tools to sift through complex information logically 


\section{Appendix 9 - Questionnaires \\ QUESTIONNAIRE}

Dear participants,

Thank you for agreeing to take part in my research project in the last few months. As you have been informed, this project is the crucial part of my PhD course at Victoria University of Wellington, New Zealand.

This questionnaire deals with your learning of English multiword expressions, i.e. a common combination of some vocabulary items such as phrasal verbs, collocations, idioms, and so on. It is being conducted so that I can gain a better insight into the impact the project has made on your study if any.

The questionnaire consists of two sections and will take you up to 30 minutes to finish.

Before answering the questionnaire, please keep in mind these instructions.

- This is not a test so there are no "right" or "wrong" answers.

- You do not have to write your name on it if you do not want to.

- Choose what you really do, not what you think as useful to be used.

- I am interested in your personal opinion. Please give your answers sincerely and carefully, as only this will guarantee the success of the project.

If you have any questions regarding this survey, please feel free to contact me, Ms. Thuy Thi Bich Thuy, at 084-912-759357 or Thuy.Bui@vuw.ac.nz.

\section{Thank you very much for your cooperation.}




\section{SECTION 1}

Below is a list of statements voicing your possible thoughts on your own learning of multiword expressions.

The BEFORE THE COURSE column is for the thoughts and behaviours that you had before the course, and the AFTER THE COURSE column is for your reflection now that you have taken part in the course.

Please put a mark from 1 to 4 under each column next to the statements to show to what extent each of them describes you.

$$
\begin{aligned}
& 1=\text { This does not describe me at all. } \\
& 2=\text { This does not really describe me. } \\
& 3=\text { This describes me quite right. } \\
& 4=\text { This describes me perfectly. }
\end{aligned}
$$

Here is an example.

\begin{tabular}{|l|l|l|}
\hline & $\begin{array}{l}\text { BEFORE } \\
\text { THE } \\
\text { COURSE }\end{array}$ & $\begin{array}{l}\text { AFTER } \\
\text { THE } \\
\text { COURSE }\end{array}$ \\
\hline $\begin{array}{l}\text { I pay more attention to single words rather than } \\
\text { combinations of words. }\end{array}$ & 4 & 3 \\
\hline
\end{tabular}

Please write one (and only one) whole number in each column next to the statements and don't leave out any of them. Thanks.

\section{No. STATEMENTS \\ BEFORE AFTER \\ THE THE \\ COURSE COURSE}

\section{A. MY AWARENESS OF MULTIWORD EXPRESSIONS}

1.1 I think a large proportion of English language is phrasal.

1.2 I think single words are more important to learn than combinations of words.

1.3 I have been notified by my teachers of the importance of multiword expressions (MWEs).

1.4 I think MWEs are very important for my reading comprehension.

1.5 I think MWEs are very important for my listening comprehension.

1.6 I think MWEs are very important for my speaking fluency.

1.7 I think MWEs are very important for my writing fluency.

1.8 I think using more MWEs can improve my scores in English proficiency tests. 
1.9 I think demonstrating accuracy in using MWEs is more important than demonstrating a large vocabulary.

\section{B. MY MULTIWORD EXPRESSION LEARNING STRATEGIES}

When I find a new MWE,...

1.10 I pay attention to new combinations of words when I listen to something in English.

1.11 When reading a text, I am attracted to the underlined or highlighted vocabulary items in the text if any.

1.12 I have the habit of scanning an English text for possible MWEs after answering the comprehension questions in class.

1.13 I have the habit of scanning the text for possible MWEs after reading an English text that I find interesting outside classroom.

1.14 I am interested in a new combination of familiar words.

1.15 I am interested in a combination of unknown words.

1.16 I am interested in a combination of words if I can see that combination from the second time.

1.17 I am interested in combinations of words that have similar structures to MWEs that I have known.

1.18 I try to guess the meaning of word combinations before I look them up.

1.19 I check MWEs that I find interesting on Google to see its number of hits.

1.20 I always look up MWEs that I find interesting in a general English dictionary.

(Please choose your preferred type of dictionary)

$\square$ A paper-based dictionary

An electronic dictionary

Please name 2-3 favourite dictionaries of yours in the order of preference:

a. b. c.

1.21 I look up MWEs that I find interesting in a collocation dictionary.

(Please choose your preferred type of dictionary)

$\square$ A paper-based dictionary

An electronic dictionary

Please name 2-3 favourite dictionaries of yours in the order of preference:

a. b. c.

1.22 I check MWEs that I find interesting in a corpus, e.g. COCA, to see if they are commonly used.

When I would like to learn a new MWE,... 
1.23 I would like to learn a MWE that appears in a dictionary.

1.24 I would like to learn a MWE which has a high frequency in a corpus.

Please specify your preferred range of frequency:

$\square 10-100$

$\square 100-1000$

$\square>=1000$

$\square$ Other ideas:

1.25 I would like to learn a MWE that I think I may need in the future.

1.26 I would like to learn a MWE that I think I can use for many topics.

1.27 I underline/ highlight MWEs that I would like to learn in a text.

1.28 I note down new MWEs in a vocabulary notebook.

1.29 I look at my vocabulary notebook regularly until I can memorise new MWEs.

1.30 I discuss new MWEs with my friends.

1.31 I make an effort to associate a new MWE with other MWEs that I have known (e.g. similar meaning, opposite meaning, same structures, etc.).

1.32 I make an effort to associate a new MWE with an equivalent Vietnamese MWE. (e.g. idioms, proverbs, collocations, etc.)

1.33 I make an effort to use newly learnt MWEs when I use English.

1.34 I try to use more MWEs when speaking in English.

1.35 I try to use more MWEs when writing in English.

For the following statements, please put a mark from 1 to 5 next to the statements to show to what extent you agree with each statement.

$1=$ Strongly disagree $2=$ Disagree $3=$ Neutral $4=$ Agree $\quad 5=$ Stronglyagree

\section{STATEMENTS}

\section{OPINION}

\section{MY SELF-EVALUATION OF THE LEARNING EFFECTS}

1.36 I think trying to identify possible MWEs in a text ("chunking" activity) is a very useful activity.

1.37 When chunking, I may become aware of MWEs that I may not otherwise.

1.38 I can better memorize the MWEs I have underlined/ highlighted in a text.

1.39 I can better memorize the MWEs I have looked up in a dictionary. 


\begin{tabular}{|c|c|}
\hline 1.40 & $\begin{array}{l}\text { I can better memorize the MWEs I have looked up in a } \\
\text { corpus. }\end{array}$ \\
\hline 1.41 & $\begin{array}{l}\text { I can better identify possible MWEs through discussions } \\
\text { with my friends. }\end{array}$ \\
\hline 1.42 & $\begin{array}{l}\text { I can better memorise an MWE of which I can find an } \\
\text { equivalent MWE in Vietnamese. }\end{array}$ \\
\hline 1.43 & $\begin{array}{l}\text { It is easier for me to memorise the meaning of an MWE } \\
\text { than its structure and grammatical functions. }\end{array}$ \\
\hline 1.44 & $\begin{array}{l}\text { I manage to think of more MWEs to use when I practise } \\
\text { English. }\end{array}$ \\
\hline 1.45 & $\begin{array}{l}\text { I manage to use some MWEs I learnt in the course in the } \\
\text { end-of-term tests. }\end{array}$ \\
\hline 1.46 & $\begin{array}{l}\text { I feel that I am better at identifying MWEs in reading } \\
\text { texts than I was before. }\end{array}$ \\
\hline 1.47 & $\begin{array}{l}\text { The use of online dictionaries has been helpful in my } \\
\text { vocabulary learning. }\end{array}$ \\
\hline 1.48 & $\begin{array}{l}\text { The use of corpora has been helpful in my vocabulary } \\
\text { learning. }\end{array}$ \\
\hline 1.49 & $\begin{array}{l}\text { A corpus is a reliable resource for me to check if my use } \\
\text { of English sounds native. }\end{array}$ \\
\hline \multirow[t]{2}{*}{1.50} & $\begin{array}{l}\text { When I have problems finding the right words for my } \\
\text { writing, I seek help in a corpus. }\end{array}$ \\
\hline & If not, please specify your ways to seek help: \\
\hline
\end{tabular}

\section{SECTION 2}

In this section, please write your answers to the questions in the space provided. Feel free to write in Vietnamese if it is more comfortable for you. Thank you.

2.1 Which resources (paper dictionaries, electronic dictionaries, corpora, etc.) do you find the most useful in looking up new items of vocabulary? Why?

2.2 Are there any difficulties you encounter when using a corpus (e.g. COCA)?

2.3 What are your ways of acquiring more multiword expressions that have been mentioned in Section 1?

Thank you again for taking part in this project. If you would like to receive the results of this survey, please leave your email address below.

Your email: @ 